\title{
Removal of various contaminants from water by renewable lignocellulose -derived biosorbents: A comprehensive and critical review
}

Hai Nguyen Tran ${ }^{1 *}$, Hoang Chinh Nguyen ${ }^{2}$, Seung Han $\mathrm{Woo}^{3}$, Tien Vinh Nguyen ${ }^{4}$, Saravanamuth Vigneswaran $^{4}$, Ahmad Hosseini-Bandegharaei ${ }^{5,6}$, Jörg Rinklebe ${ }^{7,8}$, Ajit Kumar Sarmah ${ }^{9}$, Andrei Ivanets $^{10}$, Guilherme Luiz Dotto ${ }^{11}$, Tho Truong Bui ${ }^{12}$, Ruey-Shin Juang ${ }^{13,14 *}$, Huan-Ping Chao ${ }^{15 *}$

${ }^{1}$ Institute of Fundamental and Applied Sciences, Duy Tan University, Ho Chi Minh city 700000, Vietnam

${ }^{2}$ Faculty of Applied Sciences, Ton Duc Thang University, Ho Chi Minh city 700000, Vietnam

${ }^{3}$ Department of Chemical and Biological Engineering, Hanbat National University, 125 Dongseodaero, Yuseong-Gu, Daejeon 305-719, Republic of Korea

${ }^{4}$ Faculty of Engineering and IT, University of Technology, Sydney (UTS), Sydney, Australia

${ }^{5}$ Wastewater Division, Faculty of Health, Sabzevar University of Medical Sciences, PO Box 319, Sabzevar, Iran

${ }^{6}$ Department of Engineering, Kashmar Branch, Islamic Azad University, PO Box 161, Kashmar, Iran ${ }^{7}$ University of Wuppertal, School of Architecture and Civil Engineering, Institute of Foundation Engineering, Water- and Waste-Management, Laboratory of Soil- and Groundwater-Management, Pauluskirchstraße 7, 42285 Wuppertal, Germany

${ }^{8}$ Department of Environment and Energy, Sejong University, 98 Gunja-Dong, Guangjin-Gu, Seoul, Republic of Korea

${ }^{9}$ Department of Civil \& Environmental Engineering, Faculty of Engineering, The University of Auckland, Private Bag 92019, Auckland 1142, New Zealand

${ }^{10}$ Institute of General and Inorganic Chemistry of National Academy of Sciences of Belarus, 220072 Minsk, Belarus

${ }^{11}$ Chemical Engineering Department, Federal University of Santa Maria-UFSM, 1000, Roraima Avenue, 97105-900 Santa Maria, RS, Brazil

${ }^{12}$ The Centre of Hi-tech Application in Agriculture, Chau Thanh district, Ben Tre province, Vietnam

${ }^{13}$ Department of Chemical and Materials Engineering, Chang Gung University, Guishan, Taoyuan 33302, Taiwan

${ }^{14}$ Division of Nephrology, Department of Internal Medicine, Chang Gung Memorial Hospital, Linkou, Taiwan

${ }^{15}$ Department of Environmental Engineering, Chung Yuan Christian University, Chung Li District, Taoyuan City 32023, Taiwan

\section{Corresponding authors:}

H.N. Tran (trannguyenhai@duytan.edu.vn); R.-S. Juang (rsjuang@,mail.cgu.edu.tw); and H.-P. Chao (hpchao@cycu.edu.tw) 


\begin{abstract}
Contaminants in water bodies cause potential health risks for humans and great environmental threats. Therefore, the development and exploration of low-cost, promising adsorbents to remove contaminants from water resources as a sustainable option is one focus of the scientific community. Here, we conducted a critical review regarding the application of pristine and modified/treated biosorbents derived from leaves for the removal of various contaminants. These include potentially toxic cationic and oxyanionic metal ions, radioactive metal ions, rare earth elements, organic cationic and anionic dyes, phosphate, ammonium, and fluoride from water media. Similar to lignocellulosebased biosorbents, leaf-based biosorbents exhibit a low specific surface area and total pore volume but have abundant surface functional groups, high concentrations of light metals, and a high net surface charge density. The maximum adsorption capacity of biosorbents strongly depends on the operation conditions, experiment types, and adsorbate nature. The absorption mechanism of contaminants onto biosorbents is complex; therefore, typical experiments used to identify the primary mechanism of the adsorption of contaminants onto biosorbents were thoroughly discussed. It was concluded that byproduct leaves are renewable, biodegradable, and promising biosorbents which have the potential to be used as a low-cost green alternative to commercial activated carbon for effective removal of various contaminants from the water environment in the real-scale plants.
\end{abstract}

Keywords: Leaf; biosorbent; biosorption; adsorption mechanism; water treatment; critical review. 


\section{Contents}

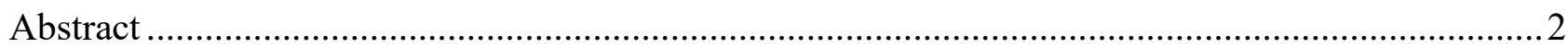

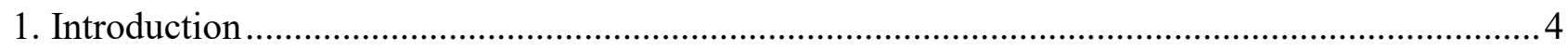

2. Preparation and characterization of leaf-derived biosorbents .................................................. 6

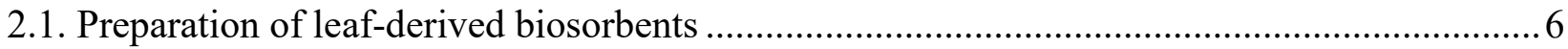

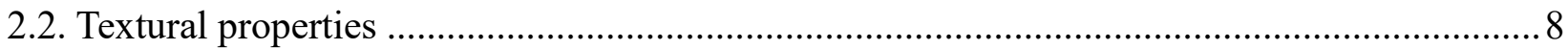

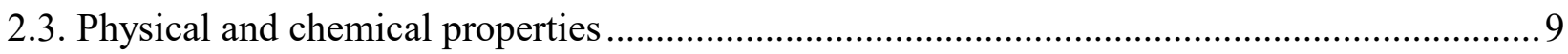

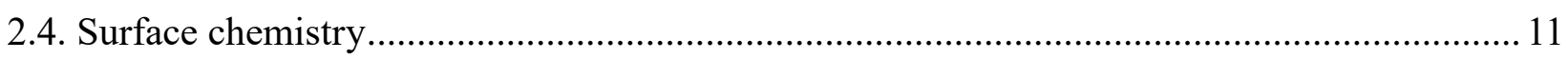

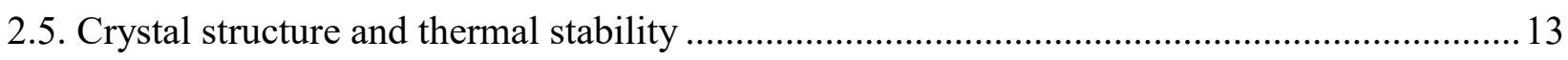

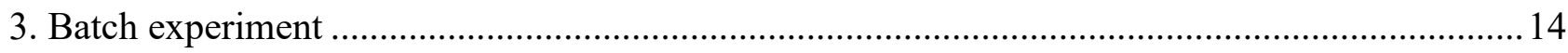

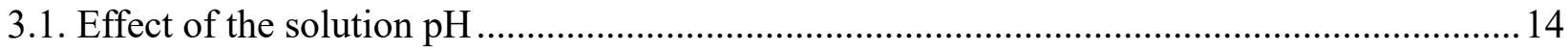

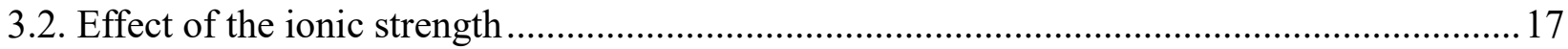

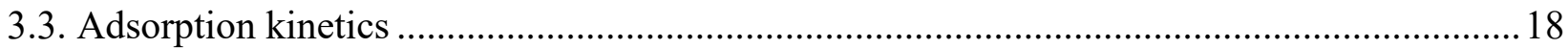

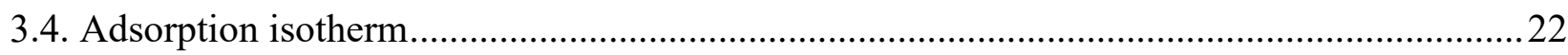

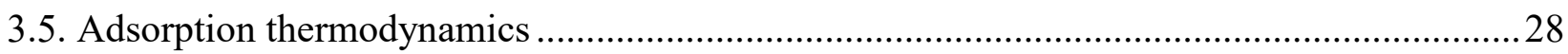

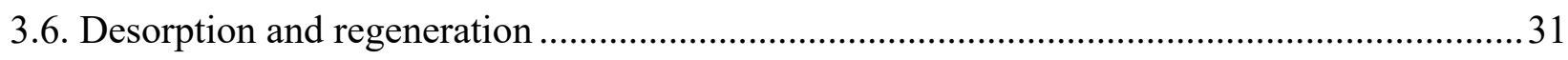

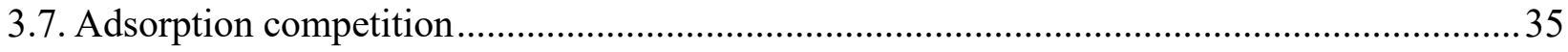

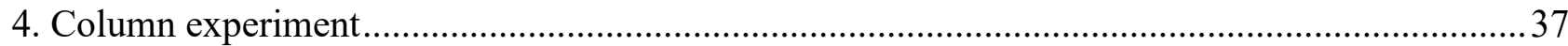

5. Application of biosorption technology to real samples............................................................. 41

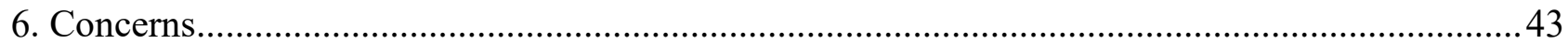

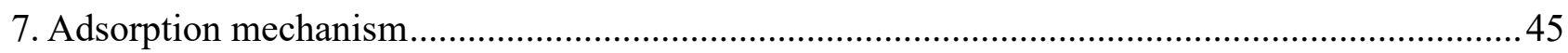

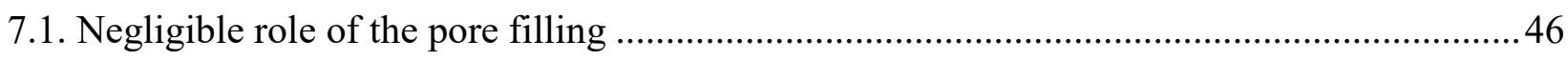

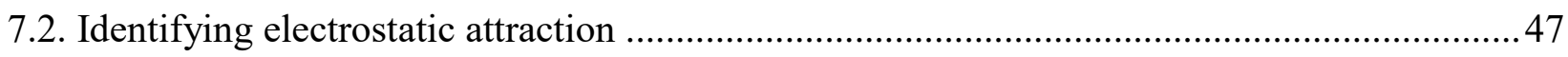

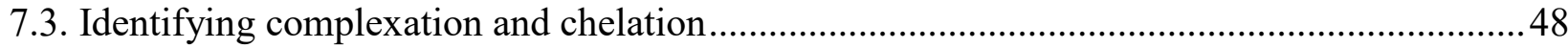

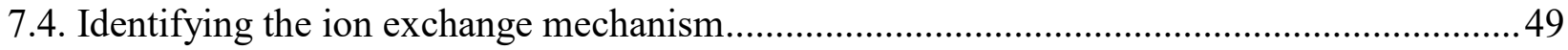

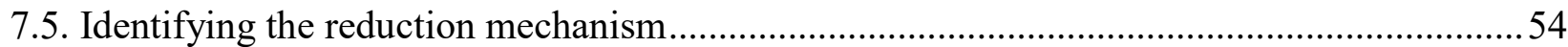

7.6. Identification of functional groups relevant for the adsorption mechanism .........................58

7.6.1. Adsorption of potentially toxic metals, fluoride, uranium, and ammonium ...................59

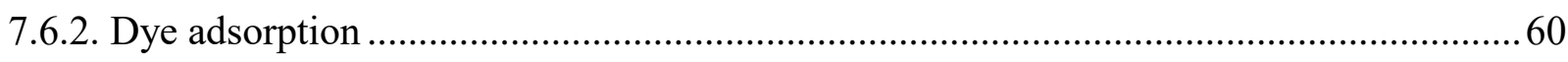

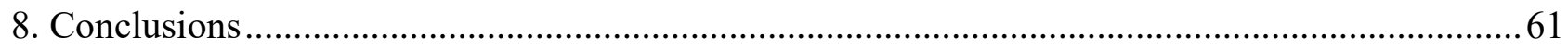

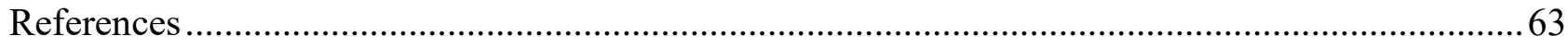




\section{Introduction}

The increasingly uncontrolled discharge of contaminated effluents from various industrial activities has adversely affected the quality of water resources. Numerous alternative water treatment techniques, such as membrane filtration, chemical oxidation, precipitation, coagulation, and biological treatments, have been applied to remove hazardous chemicals from wastewater (Tchobanoglous and Angelakis, 1996). Although these methods could be applied to remove contaminants in the water bodies or wastewater, the operation cost and removal efficiency are the crucial factors to determine the selected method. Precipitation is a low-cost method, but it is only used for high concentrations of contaminants. Ion exchange resins and membrane filtration with high removal of contaminants are the expensive technologies. They are seldom used in wastewater treatment. The biological treatment often focuses on the biodegradable contaminants. Among current advanced technologies, adsorption is considered to be the most favorable alternative method for the removal of a variety of contaminants from polluted water resources (Abdolali et al., 2014; $\underline{\text { De Gisi et }}$ al., 2016). The advantages for the removal of contaminants from water bodies or wastewater by renewable leaf-derived biosorbents include a high removal efficiency for the contaminants at low concentrations, simplicity of design, cost effectiveness, and minimal generation of secondary byproducts such as sludge (Ali and Gupta, 2007; Fomina and Gadd, 2014).

In water purification, activated carbon $(\mathrm{AC})$ has been proven to be an excellent adsorbent that can remove a great variety of toxins from contaminated water due to its highly developed porosity, large surface area, and high total pore volume (Giannakoudakis et al., 2016; Wong et al., 2018; Yagub et al., 2012). However, expensive production and regeneration costs restrict the application of AC in larger-scale industries and developing countries (Vu et al., 2018). The total adsorbent preparation cost of aluminate-treated Casuarina equisetifolia leaves is US\$48/t (Khan Rao and Khatoon, 2017), which is remarkably lower than that of available commercial AC (US\$400-1500/t). Unlike carbonaceous materials (i.e., AC and biochar), biosorbents are low energy-consuming materials (Section 2.1) because they do not require a further pyrolysis process at high temperature (often $>700{ }^{\circ} \mathrm{C}$ for $\mathrm{AC}$ or 
$>300^{\circ} \mathrm{C}$ for biochar). Furthermore, $\mathrm{AC}$ is highly carbonaceous porous material and has few functional groups on its surface; consequently, it has a very low ability to absorb charged chemicals such as heavy metals (Huang et al., 2014). Notably, several researchers found that biosorbents exhibit a higher adsorption capacity than AC under the same operation conditions (Amarasinghe and Williams, 2007; Aoyama et al., 2000a). In fact, Aoyama et al. (2000a) compared the removal efficiency of harmful metal cations from dilute solution by biosorbents obtained from the leaves of 34 conifer species with that of three different types of commercial ACs. They reported a removal efficiency of $\mathrm{Cr}$ (III) by leaves ranging from to $60 \%$ to $97 \%$, while the corresponding values for commercial ACs are between $24 \%$ and $52 \%$.

The literature survey indicates that many authors reviewed the use of various adsorbents derived from various feedstock resources for the removal of diverse contaminants from water media. Such alternative adsorbents include agricultural byproducts (i.e., banana, coffee, eggshell, and coconut wastes), industrial wastes (i.e., fly ash, sludge and slag, red mud, black liquor lignin, and waste slurry), activated carbon, biochar, bentonite, montmorillonite, zeolites, layered double hydroxides, iron oxide nanomaterials, and geopolymers (Abdolali et al., 2014; De Gisi et al., 2016; Neris et al., 2019; Siyal et al., 2018; Wong et al., 2018). Among the existing lignocellulosic materialsderived biosorbent, the plant-derived biomass has been acknowledged as a promising biosorbent to remove various contaminants from water environment. Notably, some researchers found that in the same experimental operation conditions, the biosorbent prepared from tree's leaves often exhibited a higher adsorption capacity than the biosorbent originated from its barks (Arshad et al., 2008), branches (Al-Masri et al., 2010), stems (Liu et al., 2010a; $\underline{\text { Prasad and Freitas, 2000), and roofs (Prasad }}$ and Freitas, 2000). The leaves are selected as target adsorbents in this study because (1) most abundant research data among them are present in literature, (2) other plant parts have significantly different characteristics from leaves-elemental composition, surface area, and adsorption performance — which may cause diverse results and intensify the confusion, and (3) the leaf biomass can be easily collected, consequently used, and economically advanced. 
Here, we collected information from previous scientific papers (approximately 295 relevant original papers and review articles, mainly published from 1994 to 2018) on applying leaves (approximately 240 types of leaves) as green biosorbents for the removal of diverse pollutants from water environments (Figure S1). The biosorbent properties play a paramount role in estimating the adsorption capacity of these contaminants and proposing the primary adsorption mechanism. Thus, in Section 2, we summarize principal and relevant properties of leaves, such as textural, physicochemical, thermal, and crystal properties, especially the surface chemistry. We also clarify the effects of prevailing operational conditions on adsorption processes in batch and column experiments (see Figure 1; Sections 3 and 4). The potential application of biosorbents in wastewater is discussed in Section 5. Several problems regarding the direct use of biosorbents for water treatment are mentioned in Section 6. Importantly, the adsorption mechanism plays an integral role in elucidating the corresponding interactions between contaminant and biosorbent. Therefore, we focus on summarizing common techniques/experiments in Section 7 to identify adsorption mechanism pathways. Lastly, we provide a critical analysis and discussion, which are integral to this study.

\section{Preparation and characterization of leaf-derived biosorbents}

\subsection{Preparation of leaf-derived biosorbents}

Leaf-derived biosorbents are composed mainly of molecules of organic origin, such as, cellulose, lignin, hemicellulose, pectin and extractive compounds (Liu et al., 2010c). From one side, this is an interesting characteristic, since these organic compounds contain a series of functional groups which can act as active sites for biosorption. On the other side, the structure and functionality of these organic molecules can be easily damaged by the temperature, $\mathrm{pH}$, air humidity, oxygen, and others (Escudero et al., 2018). Because of this, a detailed preparation of the leaf-derived biosorbents is fundamental. Figure 1 indicates the leaf can be synthesized adsorbents through various processes. In recent studies, the leaf-derived biosorbents were widely applied in the batch and column experiments of adsorption. Furthermore, the important parameters, which have a strong effect on the 
adsorption process, are also represented in Figure 1.

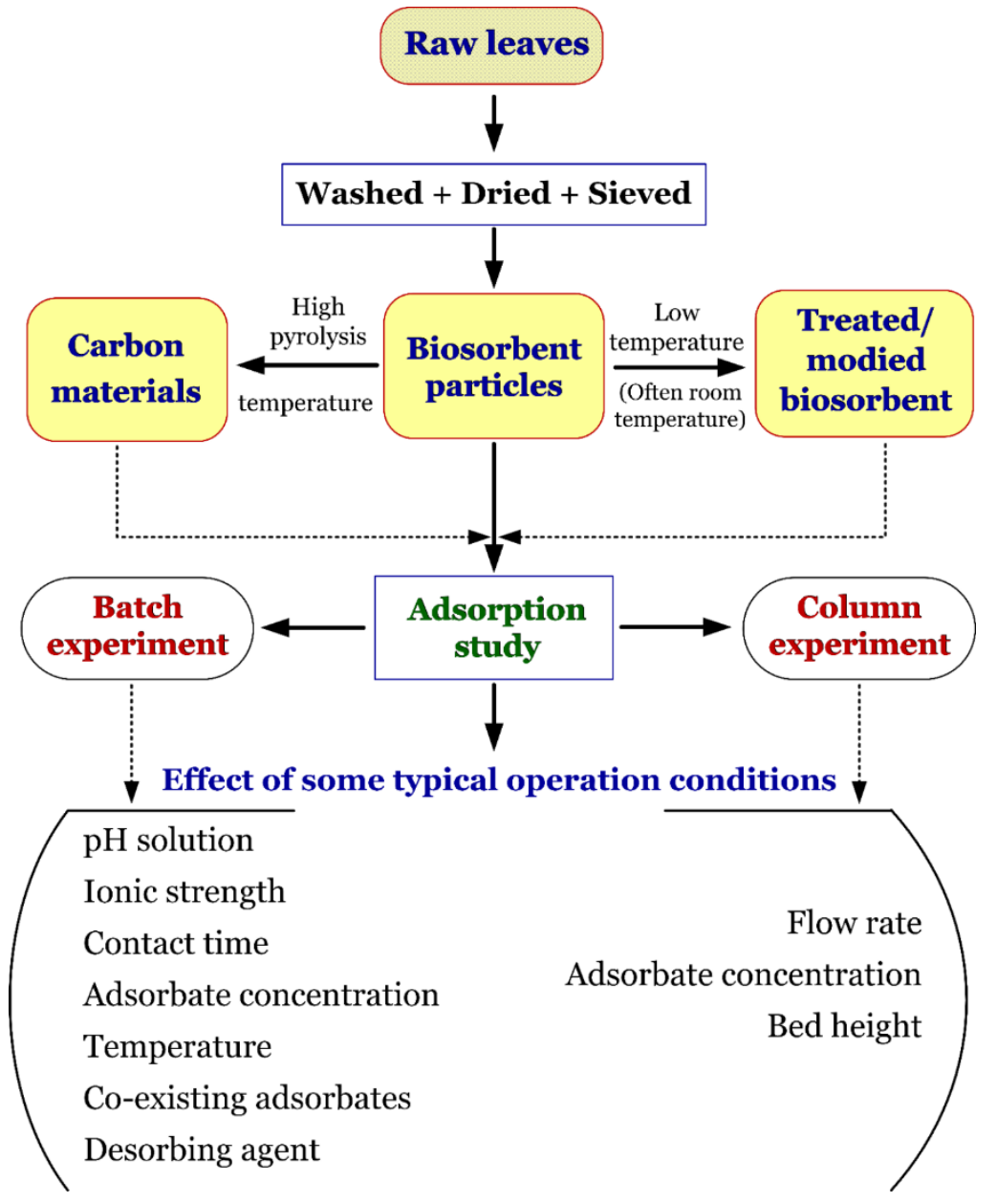

Figure 1. Preparation of the biosorbent for several typical adsorption batch and column experiments In general, the leaf-derived biosorbents are prepared by consecutive steps as follows (Dotto et al., 2017; Dotto et al., 2015): (1) firstly, the raw material is thoroughly washed with deionized or distilled water to remove any adhering dirt and water-soluble impurities; (2) the material is then dried under controlled temperature and time. Drying operation should guarantee that the moisture content remains below to the monolayer, in order to avoid the physicochemical or microbiological degradation of the material. Normally the air-drying temperature is around $40-60{ }^{\circ} \mathrm{C}$ to avoid thermal degradation; and (3) finally the material is ground to attain a specific particle size. In cases where the biosorbent is composed by extractive molecules, the material is extracted with solvents, such as $n$ hexane and ethanol (Chao et al., 2014; $\underline{\text { Chao and Chen, 2012), chloroform and methanol (Chao et al., }}$ 2014; Chao and Chen, 2012), and hexane (Immich et al., 2009). This operation aims the removal of the extractive compound from the solid matrix, to avoid its released during the biosorption operation 
(Georgin et al., 2018). After these preparation steps, the biosorbent material can be stored in tightly closed bottles or plastic bags for several months, or even years, and their physicochemical characteristics are unchanged.

\subsection{Textural properties}

Several methods to determine the specific surface area of solid materials are described in literature. The specific surface area of spent tea leaves was determined in Agarry et al. (2013) using the methylene blue adsorption method. They reported that the surface area of tea leaves is approximately $175 \mathrm{~m}^{2} / \mathrm{g}$. The sample method was applied in Kahina and Nasser (2017) and Baruah et al. (2017) to determine the specific surface areas of globe artichoke and bael leaves; surface areas of 723 and $110 \mathrm{~m}^{2} / \mathrm{g}$, respectively, were reported. Clearly, the specific surface areas of tea, globe artichoke, and bael leaves determined by the methylene blue adsorption method are much higher than that of other leaf-derived biosorbents obtained by using the nitrogen adsorption/desorption isotherm.

Table S1 indicates the specific surface area $\left(S_{\mathrm{BET}}\right)$ ranged from 0.08 to $67.0 \mathrm{~m}^{2} / \mathrm{g}$ for agriculture products or wastes in literatures. The different synthesis processes and the unique properties of leaves might lead to a high diversity in the $S_{\mathrm{BET}}$ value.

In a recent study, Tran (2017) suggested that the specific surface area of an adsorbent can be determined by the nitrogen adsorption/desorption isotherm but that it is impractical to analyze it using methylene blue or iodine adsorption methods. A typical nitrogen adsorption/desorption isotherm of arborvitae leave-developed biosorbent is presented in Figure S2. Based on Tran et al. (2017a), the $S_{\mathrm{BET}}$ of a solid material can be calculated with the Brunauer-Emmett-Teller method (Section S1).

Essentially, $S_{\mathrm{BET}}$ is one of the characteristics that affect the maximum adsorption capacity of an adsorbent toward certain contaminants. Generally, any adsorbent with a large specific surface area is supposed to exhibit a superb adsorption capacity. Similar to other types of biosorbents, leaf-derived biosorbents can be classified as nonporous materials because of their poor textural properties. In fact, the $S_{\mathrm{BET}}$ and $V_{\text {total }}$ of leave-originated biosorbents range from 0.08 to $67 \mathrm{~m}^{2} / \mathrm{g}$ and 0.001 to $0.11 \mathrm{~cm}^{3} / \mathrm{g}$, 
respectively (see Table S1). Meanwhile, other types of biosorbents, such as peanut shell $\left(1.8 \mathrm{~m}^{2} / \mathrm{g}\right.$ and $\left.0.003 \mathrm{~cm}^{3} / \mathrm{g}\right)$, sawdust $\left(1.6 \mathrm{~m}^{2} / \mathrm{g}\right.$ and $\left.0.004 \mathrm{~cm}^{3} / \mathrm{g}\right)$ (Ahmad et al., 2017), golden shower pod (5.7 $\mathrm{m}^{2} / \mathrm{g}$ and $\left.0.0099 \mathrm{~cm}^{3} / \mathrm{g}\right)$, coconut shell $\left(3.2 \mathrm{~m}^{2} / \mathrm{g}\right.$ and $\left.0.0041 \mathrm{~cm}^{3} / \mathrm{g}\right)$, orange peel $\left(2.1 \mathrm{~m}^{2} / \mathrm{g}\right.$ and 0.0042 $\left.\mathrm{cm}^{3} / \mathrm{g}\right)$ (Tran et al., 2017c) , cantaloupe peel $\left(5.2 \mathrm{~m}^{2} / \mathrm{g}\right.$ and $\left.0.0049 \mathrm{~cm}^{3} / \mathrm{g}\right)$, pine cone $\left(4.6 \mathrm{~m}^{2} / \mathrm{g}\right.$ and $\left.0.0042 \mathrm{~cm}^{3} / \mathrm{g}\right)$, litchi fruit peel $\left(5.2 \mathrm{~m}^{2} / \mathrm{g}\right.$ and $\left.0.0041 \mathrm{~cm}^{3} / \mathrm{g}\right)$, annona squamosal peel $\left(4.3 \mathrm{~m}^{2} / \mathrm{g}\right.$ and

$\left.0.0032 \mathrm{~cm}^{3} / \mathrm{g}\right)$, sugarcane bagasse $\left(7.9 \mathrm{~m}^{2} / \mathrm{g}\right.$ and $\left.0.0056 \mathrm{~cm}^{3} / \mathrm{g}\right)$, and bamboo shoot $\left(2.6 \mathrm{~m}^{2} / \mathrm{g}\right.$ and $\left.0.0019 \mathrm{~cm}^{3} / \mathrm{g}\right)(\underline{\text { Tran and Chao, 2018b }})$, have lower $S_{\mathrm{BET}}$ and $V_{\text {total }}$ values. Moreover, Figure S3a shows the morphology of a typical leaves-based biosorbent before adsorption. The SEM image also indicated the non-porous structure of the biosorbent.

Furthermore, Pandey et al. (2015) reported that the porosity of Kush grass and bamboo leaves only accounts for $0.11 \%$ and $0.15 \%$, respectively. Therefore, the role of the pore filling mechanism in the biosorption process of contaminants in aqueous media is negligible. In this case, the available presence of active functional groups (hydroxyl, carboxylic, and amino), alkaline earth metals (Ca and $\mathrm{Mg}$ ), and alkali metals ( $\mathrm{K}$ and $\mathrm{Na}$ ) on the biosorbent surface will play a major role in adsorbing adsorbate ions in solution.

\subsection{Physical and chemical properties}

Table 1 summarizes the major polysaccharide constituents including cellulose hemicellulose and lignin of leaf-based materials. Clearly, polymer carbohydrates (cellulose and hemicellulose) and lignin are the most abundant components of such materials. These constituents possibly contain polar surface functional groups, for instance alcohols, aldehydes, ketones, carboxyl, phenol, and ether (Liu et al., 2010c). Notably, the percentage of such constituents varies depending on the unique properties of each leaf type (Table 1).

Table 1. Polysaccharide components (\%) of leaf-based materials

\begin{tabular}{|c|c|c|c|c|}
\hline Leaves & Cellulose & Hemicellulose & Lignin & Reference \\
\hline
\end{tabular}




\begin{tabular}{|c|c|c|c|c|}
\hline Southern cattail & 34.1 & 31.2 & 4.16 & Abdel-Ghani et al., 2009 \\
\hline Roxburgh fig & 35.6 & 18.8 & 9.96 & $\begin{array}{l}\text { Rangabhashiyam et al., } \\
\underline{2015}\end{array}$ \\
\hline Pineapple & 66.2 & 19.5 & 4.20 & Daud et al., 2014 \\
\hline Oriental plane & 32.5 & 19.7 & 30.1 & Li et al., 2017 \\
\hline Pineapple & 36.3 & 22.9 & 27.5 & $\underline{\text { Santos et al., } 2013}$ \\
\hline Oil palm & 44.5 & 3.17 & - & $\underline{\text { Setiabudi et al., } 2016}$ \\
\hline Bamboo & 18.6 & 16.5 & 12.3 & Peng et al., 2013 \\
\hline Tea & 37.0 & - & 14.7 & Bajpai and Jain, 2012 \\
\hline Sakura & 16.6 & 10.4 & 18.3 & $\underline{\text { Wenfang et al., } 2015}$ \\
\hline Maguey & 80 & 5 & 15 & $\underline{\text { Hamissa et al., } 2010}$ \\
\hline Esparto grass & 45.3 & 23.7 & 23.9 & $\underline{\text { Lafi et al., } 2015}$ \\
\hline Average & 40.6 & 17.1 & 16.0 & - \\
\hline Standard deviation & 18.6 & 8.67 & 9.01 & - \\
\hline Minimum & 16.6 & 3.17 & 4.16 & - \\
\hline Maximum & 80.0 & 31.2 & 30.1 & - \\
\hline Median & 36.3 & 19.2 & 14.9 & - \\
\hline
\end{tabular}

The element composites of leaf-derived adsorbents can be analyzed by energy-dispersive Xray spectroscopy (EDS; Figure S3b) or other instruments. The contents of carbon (C) and oxygen (O) can affect the functional groups on the surface of adsorbent. Alkaline earth $(\mathrm{Ca}$ and $\mathrm{Mg})$ and alkali ( $\mathrm{K}$ and $\mathrm{Na}$ ) metals on the biosorption surface play an essential role in adsorbing potentially toxic metals through ion exchange mechanisms (Figures S3b-c) (Wan Ngah and Hanafiah, 2008).

Figure 2 and Table S2 demonstrate that carbon and oxygen are the primary elements of leaf composites. The leaf-generated biosorbent exhibits high oxygen content (31.4-64.1\%), suggesting 
that the biosorbent has many oxygen-containing functional groups on its surface (i.e., carboxylic and phenolic groups). Furthermore, the leaf-produced biosorbent has higher atomic oxygen/carbon (0.41.81) and hydrogen/carbon (1.2-2.8) ratios because of the presence of organic plant residues (i.e., main hemicellulose, cellulose, and lignin).

The proximate analysis (Figure 2 and Table S2) shows that leaf-derived biosorbent (average $\pm \mathrm{SD})$ has low moisture $(5.9 \pm 2.7 \%)$, total ash $(11.5 \pm 6.8 \%$; water-soluble substances), and fixed carbon $(20.3 \pm 20.3 \%)$ contents but a high volatile content $(60.4 \pm 20.6 \%)$. A low moisture contents is because the biosorbent has been dried during the preparation process (see Section 2.1). In contrast, high volatility is evident because cellulose, hemicellulose, and lignin are present in large amounts. Moreover, the average $\mathrm{pH}$ value and density of the leaf-based absorbent are $6.12 \pm 0.87(n=16)$ and $0.33 \pm 0.17 \mathrm{~g} / \mathrm{cm}^{3}(n=9)$, respectively (Table S4). Accordioning to Figure 2, it can be concluded that proximate analysis and ultimate analysis possess the high bias. Moreover, surface chemistry becomes the important factors to determine the adsorption capacities of contaminants.

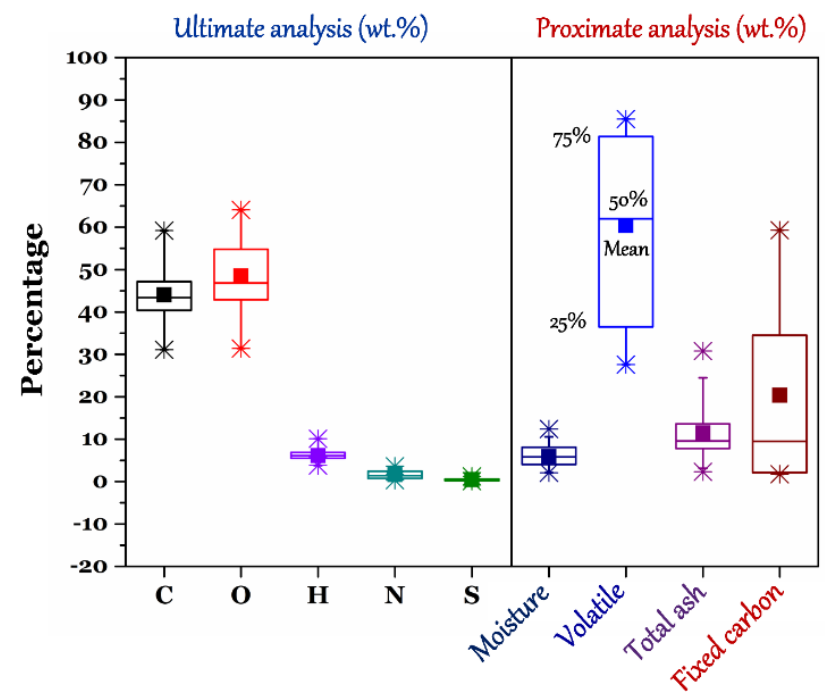

Figure 2. Ultimate and proximate analyses (wt.\%) of leaf-based biosorbents (Data taken from Tables S2-S3)

\subsection{Surface chemistry}

The presence of the main functional groups on the external surface of the biosorbent can be 
qualitatively evaluated by Fourier transform infrared spectroscopy (FTIR) or X-ray photoelectron spectroscopy (XPS). As mentioned above, leaves are considered to be lignocellulosic biomassrich material (Table 1). Consequently, they exhibit surface functional properties that resemble that of other waste substances (i.e., coconut shell, pistachio nut shell, and orange peel). A typical FTIR spectrum of a leaf-based biosorbent is shown in Figure S4a and the spectroscopic assignment of the functional groups is provided in Figure S4b. Similarly, the surface chemistry properties of leaf-based biosorbent can be analyzed by XPS (Figures S4c-d). The leaf-derived biosorbent exhibits abundant oxygen functional groups on its surface, similar to other biosorbents (i.e., orange peel, golden shower pod, coconut shell) (Tran et al., 2017c).

Unlike the FTIR and XPS techniques, conductometric (Boehm) or potentiometric titration can be used to obtain quantitative information on the oxygen-containing functionality (acid and basic groups) of the biosorbent surface. The standardization of the Boehm titration has been investigated by Goertzen et al. (2010). Several researchers found that the results obtained by the two methods differ insignificantly (Fourest and Volesky, 1995; Komy et al., 2006). Although acidic groups (i.e., carboxylic and phenolic) attached to the biosorbent surface have been acknowledged as active groups when adsorbing various contaminants in solution onto biosorbent, quantitative information on such functionality is scarce in the literature. Table S5 shows pristine biosorbent derived from leaves exhibits a concentration of total acid groups $(1.5-6.2 \mathrm{mmol} / \mathrm{g})$ similar to that from agricultural wastederived biosorbents (e.g., $8.7 \mathrm{mmol} / \mathrm{g}$ for golden shower pod, $6.9 \mathrm{mmol} / \mathrm{g}$ for orange peel, and 4.21 $\mathrm{mmol} / \mathrm{g}$ for coconut shell) (Tran et al., 2017c). The relatively higher acid groups facilitate the adsorption of cationic contaminants.

The surface electrostatic state of any adsorbent in aqueous phase is typically characterized by the point of zero charge (PZC) or the isoelectric point (IEP). The difference between them has been discussed by many scholars and summarized in the recent review work (Tran et al., 2017b). Figure S5 shows the point of zero charge of leaf-based biomaterials. The $\mathrm{pH}_{\mathrm{PZC}}$ is defined as the $\mathrm{pH}$ value at which the net surface charge density (external and internal) of the adsorbent equals zero (Figures 
S5a-b). In contrast, the $\mathrm{pH}$ value at which the electrokinetic $(\zeta)$ potential at the shear plane equals zero is defined as $\mathrm{pH}_{\mathrm{IEP}}$ (Figures S5c-d). The surface charge of adsorbent is negative when the solution $\mathrm{pH}$ approximates 7.0. The result favors cationic ion adsorption in solution. Table S6 summarizes the $\mathrm{pH}_{\mathrm{PZC}}$ and $\mathrm{pH}_{\mathrm{IEP}}$ of leaf-based biosorbents, and Table $\mathbf{S} 7$ lists the $\zeta$ potential of several

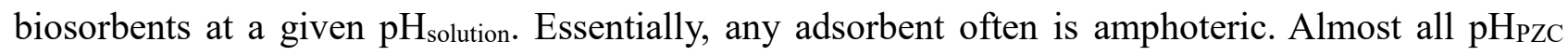
values of the observed biosorbents are lower than 7.0, suggesting that the total amount of acidic groups on the biosorbent surface will dominate.

\subsection{Crystal structure and thermal stability}

The crystallinities of leaf biomass can be determined by X-ray diffraction (XRD). As represented in Figure S6, two reflections at approximately $15^{\circ}$ and $22^{\circ}$ are characteristic for crystalline cellulose material (Khan Rao and Khatoon, 2017; Wang et al., 2016). Cellulose in the leaf biomass has a parallel alignment and crystalline structure, which is the consequence of hydrogen bonds and van der Waals interactions between adjacent molecules, while lignin and hemicellulose are amorphous (Percival and Lynd, 2004; Tran et al., 2018).

The thermal stability of the adsorbent was evaluated by thermogravimetric analysis (TGA). Figure S7b shows thermal decomposition peaks at approximately $330{ }^{\circ} \mathrm{C}$ and $450{ }^{\circ} \mathrm{C}$ that can be assigned to the thermal degradation of cellulose and lignin, which is in good agreement with observations of some researchers (Tran et al., 2017c; Tongpoothorn et al., 2011; Lafi et al., 2015). Notably, lignin component is more difficult to decompose because it contains the full of aromatic rings with various branches. Therefore, the degradation of lignin often occurs within a wide temperature range (between $160{ }^{\circ} \mathrm{C}$ and $900{ }^{\circ} \mathrm{C}$ ) (Yang et al., 2007). The endpoint temperature of the leaf-based biosorbent is approximately $500{ }^{\circ} \mathrm{C}$ (Figure S7), suggesting that complete carbonization of the biosorbent requires a minimum temperature of $500{ }^{\circ} \mathrm{C}$. 


\section{Batch experiment}

\subsection{Effect of the solution pH}

The $\mathrm{pH}$ of a certain solution is the most important parameter in adsorption analysis because it has a strong effect on the charge of the adsorbent surface (Figure S5) and speciation of the adsorbate (Figure S8). Figure 3 shows that the biosorption process strongly depends on the solution pH value. Generally, the adsorption capacity of the biosorbent with respect to cationic adsorbates usually increases when the $\mathrm{pH}_{\text {solution }}$ value increases. The surface charge of the biosorbent becomes more negative when the $\mathrm{pH}_{\text {solution }}$ value increases (Figure S5). Therefore, the electrostatic attraction between the negatively charged surface of the biosorbent and adsorbate cations in solution is also simulated. Another possible reason is a decrease in the adsorption competition between adsorbates (i.e., $\mathrm{Cd}^{2+}$ ) and $\mathrm{H}^{+}$ions for active adsorption sites (i.e., $-\mathrm{COO}^{-}$) on the surface of the biosorbent. This can be confirmed by the experimental conditions of the adsorption isotherm (Tables S8-S9). 

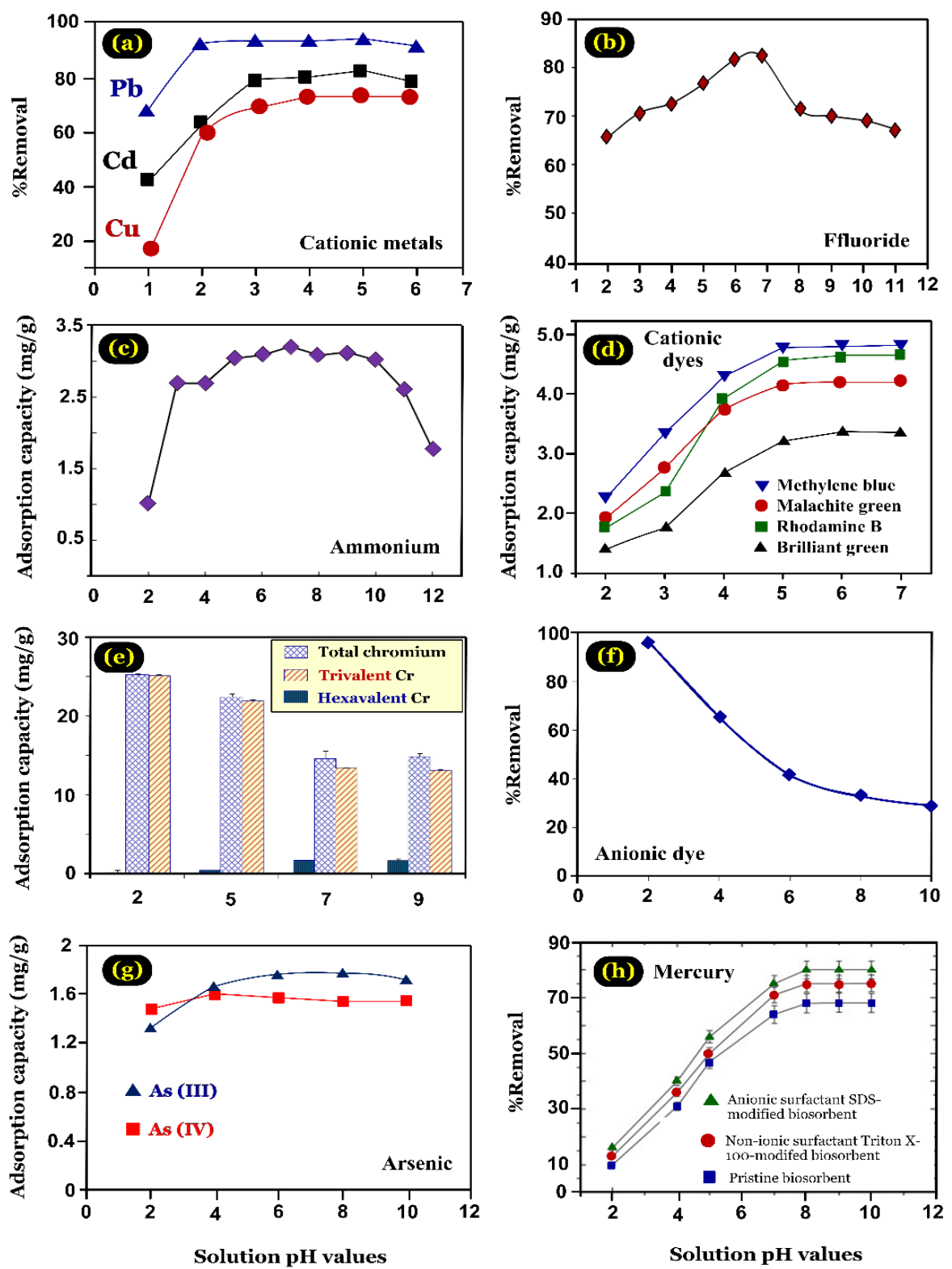

Figure 3. Effect of the $\mathrm{pH}$ solution on the adsorption process on (a) potentially toxic metal cations onto Fraxinus excelsior tree leaf-biosorbent (Sangi et al., 2008) [License number: 4435910682650],(b) fluoride onto Azadirachta $\underline{\text { indica }}$ tree leaf-biosorbent (Bharali and Bhattacharyya, 2015; Sangi et al., 2008) [License number: 4440010650238], (c) ammonium onto Parthenocissus tricuspidata tree leaf-biosorbent (Liu et al., 2010b) [License number: 4435910810287], (d) cationic dyes onto Saraca asoca tree leaf-biosorbent (Gupta et al., 2012) [License number: 4435910987708], (e) hexavalent chromium onto Melaleuca diosmifolia tree leaf-biosorbent (Kuppusamy et al., 2016) [License number: 4435911095229], (f) acid violet 17 dye onto activated Ficus racemosa tree leaf-adsorbent (Jain and Gogate, 2017b), [License number: 4435911196015] (g) arsenic onto Psidium guajava leaf tree leafbiosorbent (Kamsonlian et al., 2012) [License number: 4435940299690], and (h) mercury onto pristine and modified bamboo leaf tree leaf-biosorbents (Mondal et al., 2013) [License number: 4435920032442] 
In contrast, the biosorbent adequately adsorbs adsorbate anions such as chromate or

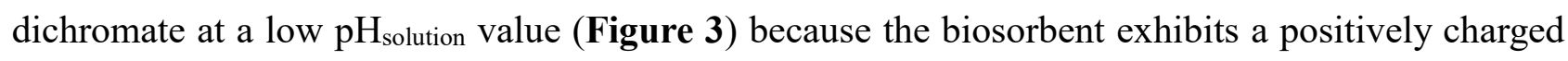
surface at a low $\mathrm{pH}_{\text {solution }}$ value, which results in the protonation of hydroxyl groups (i.e., $-\mathrm{COOH}_{2}^{+}$ or $-\mathrm{OH}_{2}^{+}$). The biosorbent has a high affinity to contaminant anions in the solution during electrostatic attraction. This hypothesis is consistent with the literature. Some authors emphasized that the adsorption of hexavalent chromium onto leaf-based biosorbents reaches the optimal adsorption efficiency at a $\mathrm{pH}_{\text {solution }}$ of 2.0 (Ahmad et al., 2017; Babu and Gupta, 2008; Nag et al., 2016; Nakkeeran et al., 2016; Rangabhashiyam et al., 2015; Saha and Saha, 2014; Wenfang et al., 2015). A similar optimal $\mathrm{pH}_{\text {solution }}$ was found for the adsorption of acid violet 17 dye onto activated cluster fig tree leaves ( Jain and Gogate, 2017b), acid blue 25 dye onto $\mathrm{NaOH}$-treated cluster fig leaves

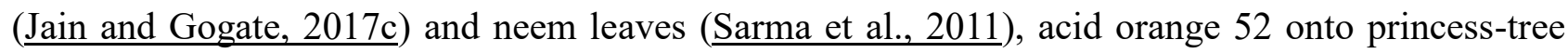
leaves (Deniz and Saygideger, 2010), acid green 25 onto NaOH-treated almond leaves (Jain and Gogate, 2018), two anionic dyes (Sumfixe Supra red and Alpacelle Lumiere brown) onto maguey leaves ( and Niazi, 2013), Rhodamine B onto neem leaves (arma et al., 2008), methyl orange onto pristine

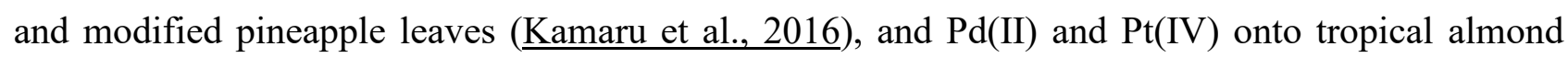
leaves (

However, other investigators emphasized the negligible effect of the $\mathrm{pH}_{\text {solution }}$ on the

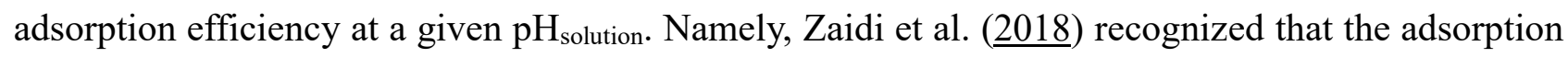
of cationic methyl violet $2 \mathrm{~B}$ dye onto pristine and $\mathrm{NaOH}$-treated terap leaves is insignificantly

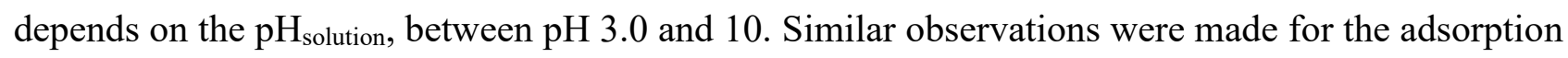
of hexavalent chromium onto $\mathrm{NaOH}$-treated false ashoka leaves (Anwar et al., 2011); As(III) and As(V) onto guava leaves (Kamsonlian et al., 2012); cationic methyl violet 2B dye onto pristine and treated terap leaves (Lim et al., 2016); malachite green dye onto Glossogyne tenuifolia leaves (Yang

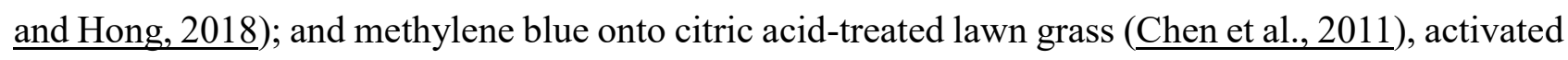
carbon prepared from Neptune grass (Dural et al., 2011), and pineapple leaves (Kamaru et al., 2016). 


\subsection{Effect of the ionic strength}

Similar to the solution $\mathrm{pH}$, the adsorption capacity of biosorbents is adversely affected by the addition of a salt (Table S10) such as $\mathrm{NaNO}_{3}, \mathrm{NaClO}_{4}, \mathrm{CaCl}_{2}, \mathrm{NaCl}, \mathrm{Na}_{2} \mathrm{SO}_{4}, \mathrm{KNO}_{3},\left(\mathrm{NH}_{4}\right)_{2} \mathrm{SO}_{4}$, $\mathrm{NaHCO}_{3}$, and $\mathrm{Ca}\left(\mathrm{NO}_{3}\right)_{2}$. Among these, $\mathrm{NaCl}$ is the most common salt used for the investigation of the effect of the ionic strength on biosorption. Generally, the presence of salt causes a profound decline in the removal efficiency of both anionic and cationic contaminants from aqueous solutions. Figure S9 shows a typical example of the impact of the ionic strength on the biosorption of various potentially toxic metals onto Ulmus carpinifolia leaves (Sangi et al., 2008). Many scholars also documented a similar decrease in the adsorption capacity of leaf-based biosorbents towards potentially toxic metals, which is caused by the presence of inorganic salts (Al-Haidary et al., 2011; Ngah and Hanafiah, 2008; Rao et al., 2011a;2010b; Srinivasa Rao et al., 2010; Weng and Wu, 2012; Zhang et al., 2015). However, the ion strength is difficultly controlled in the realistic wastewater treatment. The ion strength is only regarded as a reference.

Furthermore, the adsorption process of cationic and anionic dyes is also examined due to the presence of a specific salt. In fact, many researchers concluded that the addition of salt results in a significant decrease of the adsorption efficiency of leaf-based biosorbents toward methylene green (Han et al., 2014; Kushwaha et al., 2014), malachite green (Han et al., 2014), methylene blue (Ansari et al., 2016; Han et al., 2007; Han et al., 2011; Kushwaha et al., 2014; Yagub et al., 2012), basic red

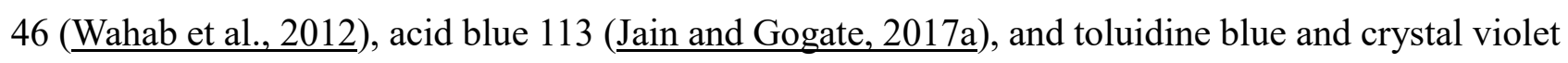
(Lafi et al., 2015).

The deceased adsorption ability of adsorbent due to an increase in the inorganic salt concentration is possibly attributed to a screening effect (known as electrostatic screening) between the positively charged biosorbent surface and cationic pollutants. When the adsorbent is added to the adsorbate solution, the latter will be surrounded by an electrical double layer (EDL; Section S2). Nevertheless, the EDL can be significantly expanded by the presence of a certain electrolyte agent 
(Krishnan and Anirudhan, 2003; Ngah and Hanafiah, 2008; Wang et al., 2007; Weng et al., 2009).

This expansion prevents adsorbent particles and adsorbate ions from being very close to each other, which causes a remarkable electrostatic attraction. As a consequence, the adsorption capacity of the adsorbent to adsorbate will decrease. For example, Weng et al. (2009) pointed out that an increase in the $\mathrm{NaNO}_{3}$ concentration causes a remarkable decrease in the EDL thickness (Figure S10) and an increase in the amount of indifferent ions approaching the surface of the biosorbent. This outcome demonstrates the increasing competition between cationic methylene blue dye molecules and $\mathrm{Na}^{+}$ ions for available adsorbing sites on the biosorbent surface when the salt concentration increases.

However, some authors suggested that the biosorption phenomenon is insignificantly impacted by the addition of salt (hen et al., 2010; Lim et al., 2016). For example, Chen et al. (2010) used camphor leaves to remove $\mathrm{Cu}$ (II) from aqueous media. They concluded that the adsorption efficiency of leaves only slightly decreases (by 7\%) in the presence of external electrolytes, even at high salt concentrations up to $0.5 \mathrm{M} \mathrm{NaCl}$.

\subsection{Adsorption kinetics}

Generally, the effect of contact time plays an important role in determining the (1) true equilibrium, (2) adsorption rate, and (3) activation energy of the adsorption process. The equilibrium time and adsorption rate strongly depend on the biosorbent properties, adsorbate nature, and especially in the operation conditions - the initial adsorbate concentration, solution temperature, solution $\mathrm{pH}$, particle size of biosorbent, coexisting ions, ionic strength, and shaking speed.

Unlike porous adsorbents (i.e., spherical and non-spherical activated carbon and biochar, zeolite, and macroreticular resin), the adsorption of contaminants onto nonporous biosorbents often takes less time to reach true equilibrium because the adsorption phenomenon mainly occurs on the biosorbent surface. For example, King et al. $(\underline{2007} ; \underline{2008})$ reported that the biosorption of $\mathrm{Pb}^{2+}$ and $\mathrm{Zn}^{2+}$ ions on jambolan leaves reaches an equilibrium within 10 min of contact, which agrees with the conclusions of other scholars (Tables S9-S10). Moreover, Amarasinghe and Williams (2007) 
compared the adsorption rate of potentially toxic metals onto tea leave waste and granular activated carbon. They concluded that the rate constant $\left(k_{2} ; \mathrm{g} / \mathrm{mg} \times \min \right)$ of the pseudo-second-order equation of tea leaves $(0.0091$ and 0.0133$)$ to $\mathrm{Pb}(\mathrm{II})$ and $\mathrm{Cu}$ (II) is significantly higher than that of granular $\mathrm{AC}$ (0.0064 and 0.0020 , respectively). This means that, under the same operation conditions, the metal ion removal by leaf-based biosorbents occurs faster than that by AC.

When the adsorption process reaches a real equilibrium, specific adsorption kinetic models can possibly be applied to determine relative adsorption parameters. Common models that are extensively used in adsorption studies are the pseudo-first-order, pseudo-second-order, Elovich, and intraparticle diffusion equations. The true derivation and accurate application of such models in the field of adsorption science and technology have been discussed by Tran et al. (2017b). Generally, most studies revealed that the pseudo-second-order model (Equation 9) can adequately describe all experimental kinetics data in an adsorption batch experiment. In this case, the adsorption rate constant $\left(k_{2} ; \mathrm{g} / \mathrm{mg} \times \mathrm{min}\right)$ is useful to describe the adsorption process. A higher $k_{2}$ value corresponds to an adsorption process that reaches saturation faster. The effects of typical operation conditions on the adsorption rate constant are presented in Figure 4; the values in parentheses represent the amount of adsorbate adsorbed onto biosorbents in equilibrium $\left(q_{\mathrm{e}} ; \mathrm{mg} / \mathrm{g}\right)$, which was calculated using the pseudo-second-order equation (Section S3). As showed in Figure 4, the adsorption rate constants are proportional to solid/liquid ratio and stirring speed, and inversely proportional to initial adsorbate concentration, ionic strength, and adsorbent's particle size. Especially in temperature, whether or not the adsorption rate constant increases with the increasing temperature. The adsorption mechanism is an important factor to determine it. 

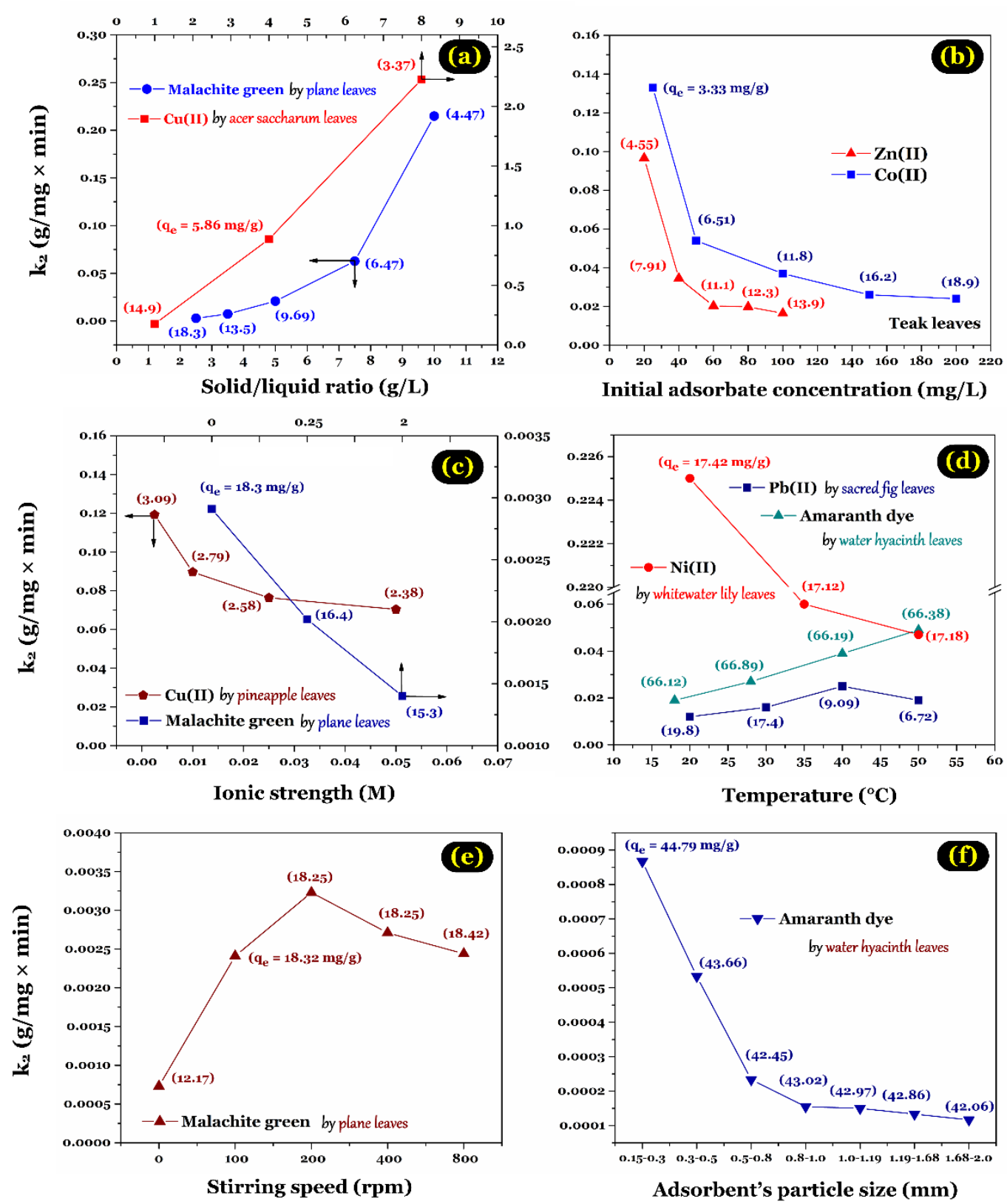

Figure 4. Effect of typical operation conditions on the rate constant $\left(\mathrm{k}_{2}\right)$ of the pseudo-second-order equation, such as (a) solid/liquid ratio [( (Amirnia et al., 2016) for $\mathrm{Cu}(\mathrm{II})$ adsorption]; (b) initial adsorbate metal concentration [( Kumar et al., 2006) for Zn(II) adsorption and (Vilvanathan and Shanthakumar, 2016) for Co(II) adsorption]; (c) ionic strength [(Weng and Wu, 2012) for $\mathrm{Cu}(\mathrm{II})$ adsorption and (Hamdaoui et al., 2008) for malachite green adsorption]; (d) temperature [(Zahedi et al., 2015) for $\mathrm{Ni(II)}$ adsorption, (Qaiser et al., 2009) for $\mathrm{Pb}(\mathrm{II})$ adsorption, and (Guerrero-Coronilla et al., 2015) for amaranth dye adsorption]; (e) shaking speed (Hamdaoui et al., 2008); and (f) adsorbent particle size (Guerrero-Coronilla et al., 2015) 
In most cases, the $k_{2}$ constant is applied to determine the activation energy (Ea). The $E \mathrm{a}$ of the adsorption process (in $\mathrm{kJ} / \mathrm{mol}$ ) is defined as the minimum energy that must be overcome by the adsorbate molecules and can be computed through the Arrhenius equation (Section S3). For example, Weng and $\mathrm{Wu}(\underline{2012})$ applied pineapple leaf powder to absorb $\mathrm{Cu}(\mathrm{II})$ ions in a water solution. They reported a magnitude of $E$ a of the biosorption of $7.0 \mathrm{~kJ} / \mathrm{mol}$ (Figure S11), which is similar to the $E_{\mathrm{a}}$ value $(5.2 \mathrm{~kJ} / \mathrm{mol})$ of $\mathrm{Cu}(\mathrm{II})$ biosorption onto peanut hull (Ali et al., 2016). The low $E_{\mathrm{a}}$ magnitude (typically $<40 \mathrm{~kJ} / \mathrm{mol}$ ) suggests that the biosorption process was primarily physical adsorption. Conversely, Lin et al. (2011) examined the removal behavior of $\mathrm{Cu}^{2+}$ ions by humic acid-immobilized surfactant-modified zeolite, concluding that the adsorption process was chemisorption $\left(E_{\mathrm{a}}=63.1\right.$ $\mathrm{kJ} / \mathrm{mol}$ ). In addition, Boparai et al. (2011) claimed that the $E_{\mathrm{a}}$ value of chemisorption of Cd(II) cations onto nano-zero-valent iron particles is approximately $55 \mathrm{~kJ} / \mathrm{mol}$.

Some activation energy highlights are of concern here. Firstly, the value of the activation energy is strongly dependent on the operation conditions, especially the initial adsorbate concentration $\left(C_{0} ; \mathrm{mg} / \mathrm{L}\right)$. For example, Ren et al. (2015) investigated crystal violet dye biosorption from aqueous solution using the leaves of the phoenix tree at three solution temperatures $(20,30$, and $40^{\circ} \mathrm{C}$ ). They discovered that the $E_{\mathrm{a}}$ value of the biosorption process is $25.3 \mathrm{~kJ} / \mathrm{mol}$ at $100 \mathrm{mg} / \mathrm{L}, 45.8$ $\mathrm{kJ} / \mathrm{mol}$ at $300 \mathrm{mg} / \mathrm{L}$, and $37.7 \mathrm{~kJ} / \mathrm{mol}$ at $400 \mathrm{mg} / \mathrm{L}$. Similarly, Guerrero-Coronilla et al. (2015) highlighted that the $E_{\mathrm{a}}$ value of the biosorption process of amaranth dye onto water hyacinth leaves at different solution temperatures $\left(18,28,40\right.$, and $\left.50{ }^{\circ} \mathrm{C}\right)$ increases if the $C_{\mathrm{o}}$ value increases. They reported that the $E_{\mathrm{a}}$ values increases in the following order: $19.8 \mathrm{~kJ} / \mathrm{mol}$ at $C_{\mathrm{o}}$ of $50 \mathrm{mg} / \mathrm{L}<23.5$ $\mathrm{kJ} / \mathrm{mol}$ at $100 \mathrm{mg} / \mathrm{L}<34.8 \mathrm{~kJ} / \mathrm{mol}$ at $200 \mathrm{mg} / \mathrm{L}$.

Secondly, the activation energy strongly depends on the derivation of the rate constant. For example, Agarry et al. (2013) applied the rate constants of the pseudo-first-order $\left(k_{1}\right)$ and pseudosecond-order $\left(k_{2}\right)$ equations to calculate the activation energy of naphthalene adsorption onto spent tea. An $E_{\mathrm{a}}$ value of $15.9 \mathrm{~kJ} / \mathrm{mol}$ and $28.9 \mathrm{~kJ} / \mathrm{mol}$ was obtained when applying the $k_{1}$ and $k_{2}$ constants, respectively. Furthermore, in some cases, an accurate activation energy was not obtained because of 
the low $R^{2}$ value of the Arrhenius equation such as $R^{2}=0.1671$ ( $k_{1}$ value) and $R^{2}=0.5671$ ( $k_{2}$ value) (Wahab et al., 2012).

Table 2 indicates the estimated $E_{\mathrm{a}}$ values in the literature. A calculation mistake has been found in previous publications (Chakraborty et al., 2012; Chowdhury et al., 2011). According to the reported $k_{2}$ values, the correct $E_{\mathrm{a}}$ values of the biosorption process of basic green 4 and crystal violet onto pineapple leaves should be $-58.9 \mathrm{~kJ} / \mathrm{mol}$ and $-46.1 \mathrm{~kJ} / \mathrm{mol}$, while the $E_{\mathrm{a}}$ values reported in the original papers are 58.9 and 45.8, respectively. Thirdly and lastly, because the rate constant is important for the accurate calculation of $E_{\mathrm{a}}$, the adsorption rate constant at different solution temperatures should be reported in adsorption kinetic studies. Unfortunately, some authors ignored the presentation of the rate constant and readers therefore cannot verify the accuracy of the $E_{\mathrm{a}}$ values (see Table 2).

Table 2. Activation energy ( $E \mathrm{a} ; \mathrm{kJ} / \mathrm{mol})$ of the biosorption process

\begin{tabular}{|c|c|c|c|c|}
\hline Leaves & $\begin{array}{c}\text { Adsor- } \\
\text { bate }\end{array}$ & $\mathbf{E a}$ & Remark & Ref. \\
\hline Bael & $\mathrm{Pb}(\mathrm{II})$ & $22.2 *$ & Corrected & Chakravarty et al., 2010 \\
\hline Treated Australian pine & $\mathrm{Pb}(\mathrm{II})$ & 6.38 & Re-calculated & Khan Rao and Khatoon, 2017 \\
\hline Pineapple & $\mathrm{Cu}(\mathrm{II})$ & $6.99 *$ & Corrected & Weng and $\mathrm{Wu}, 2012$ \\
\hline $\mathrm{NaOH}$-treated tea & $\mathrm{Cu}(\mathrm{II})$ & $4.12 *$ & Corrected & Weng et al., 2014 \\
\hline Treated Australian pine & $\mathrm{Cu}(\mathrm{II})$ & 12.53 & Re-calculated & Khan Rao and Khatoon, 2017 \\
\hline Treated Australian pine & $\mathrm{Ni}(\mathrm{II})$ & 11.98 & Re-calculated & Khan Rao and Khatoon, 2017 \\
\hline Black tea & $\mathrm{Cr}(\mathrm{VI})$ & 16.2 & Corrected & Hossain et al., 2005 \\
\hline London plane & MB & $14.26^{*}$ & $\begin{array}{l}\text { Re-calculated } \\
(11.67)\end{array}$ & Kong et al., 2015 \\
\hline Pine & MB & 3.081 & Re-calculated & Yagub et al., 2012b \\
\hline
\end{tabular}




\begin{tabular}{|c|c|c|c|c|}
\hline Oriental plane & MG & $7.13 *$ & Corrected & Hamdaoui et al., 2008 \\
\hline Treated maize husk & MG & $21.5^{*}$ & Unreported $k_{2}$ & $\underline{\text { Jalil et al., } 2012}$ \\
\hline Pineapple & BG4 & $45.79 *$ & $\begin{array}{l}\text { Re-calculated (- } \\
46.1)\end{array}$ & $\underline{\text { Chowdhury et al., } 2011}$ \\
\hline Princess-tree & $\mathrm{AO52}$ & $9.64 *$ & Corrected & $\underline{\text { Deniz and Saygidege, } \mathrm{r} 2010}$ \\
\hline Pineapple & $\mathrm{CV}$ & $58.9 *$ & $\begin{array}{l}\text { Re-calculated (- } \\
59.06)\end{array}$ & Chakraborty et al., 2012 \\
\hline Jackfruit & $\mathrm{CV}$ & -45.99 & Re-calculated & $\underline{\text { Saha et al., } 2012}$ \\
\hline Phoenix & $\mathrm{CV}$ & $\begin{array}{l}25.3- \\
45.8\end{array}$ & Re-calculated & $\underline{\text { Ren et al., } 2015}$ \\
\hline Pine & BR46 & $38.39 *$ & Unreported $k_{2}$ & $\underline{\text { Deniz and Karaman, } 2011}$ \\
\hline Water hyacinth & AR27 & $\begin{array}{l}19.8- \\
34.8^{*}\end{array}$ & Corrected & Guerrero-Coronilla et al., 2015 \\
\hline Treated cluster fig & AV17 & 7.07 & Unreported $k_{2}$ & $\underline{\text { Jain and Gogate } 2017 \mathrm{~b}}$ \\
\hline Treated almond & AG25 & 6.22 & Corrected & Jain and Gogate, 2018 \\
\hline Spent tea & $\mathrm{C}_{10} \mathrm{H}_{8}$ & 15.89 & $\begin{array}{l}\text { Re-calculated } \\
(28.9)\end{array}$ & Agarry et al., 2013 \\
\hline Treated almond & $\mathrm{AB} 113$ & $6.54 *$ & Unreported $k_{2}$ & $\underline{\text { Jain and Gogate, } 2017 \mathrm{a}}$ \\
\hline
\end{tabular}

Note: The $E_{\mathrm{a}}$ values were calculated from the Arrhenius equation at different $k_{2}$ constant rates of the pseudosecond-order equation. *the data were reported in the original data. "Re-calculated" means that the $E_{\text {a }}$ value was re-calculated from the $k_{2}$ value of the original paper; "Corrected" means that the $E_{\text {a }}$ values recalculated and reported are the same; "Unreported $k_{2}$ means that the $k_{2}$ valuwas not reported in the original paper. Adsorbate: MB (methylene blue), CV (crystal violet), MG (malachite green), AO52 (acid orange 52), BG4 (basic green 4), BR46 (basic red 46), AB113 (acid blue 113), AR27 (acid red 27), AG25 (acid green 25), $\mathrm{AV} 17$ (acid violet 17), and $\mathrm{C}_{10} \mathrm{H}_{8}$ (naphthalene). 


\subsection{Adsorption isotherm}

In batch adsorption studies, the adsorption isotherm (Figure 5) plays a key role in recognizing the regions (e.g., Henry, Freundlich, Langmuir, and BET) containing the actual experimental data corresponding to the adsorption equilibrium. In particular, two methods used to obtain an adsorption isotherm have been reported in the literature. Firstly, the adsorption isotherm (Figure 5a) is most commonly determined at different initial adsorbate concentrations under fixed experimental conditions (i.e., temperature, solution $\mathrm{pH}$, solid/liquid ratio, ionic strength, adsorbent particle size, and contact time) (시도 et al., 2009). Secondly, the adsorption isotherm (Figure 5b) can be examined at different solid/liquid ratios under constant experimental conditions including the temperature, solution $\mathrm{pH}$, initial adsorbate concentration, ionic strength, adsorbent particle size, and reaction time (Chen et al., 2010).
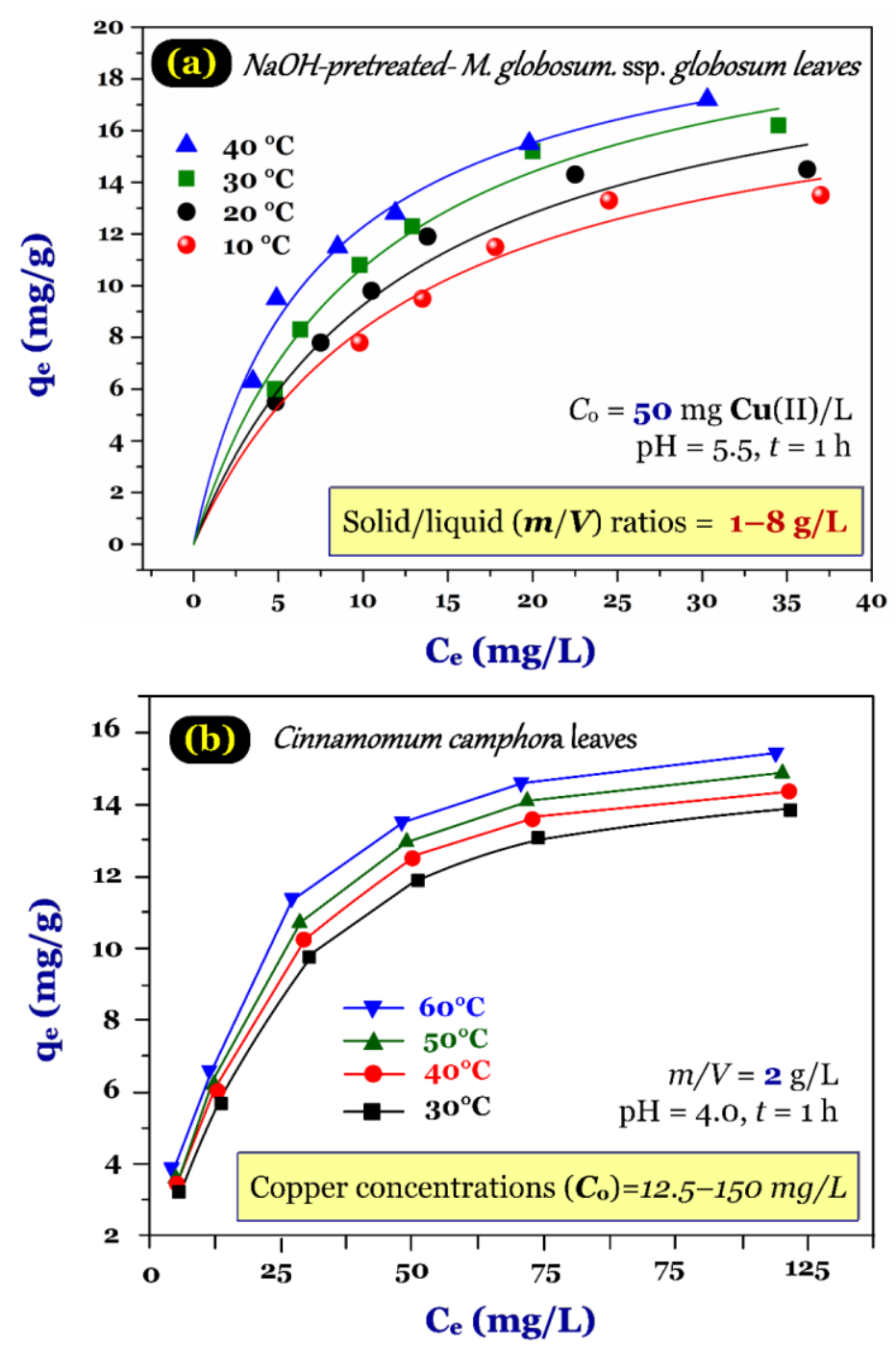
Figure 5. Typical adsorption isotherm determined by two different methods, that is by changing (a) solid/liquid ratio (K1lıç et al., 2009) [License number: 501431317], and (b) initial adsorbate

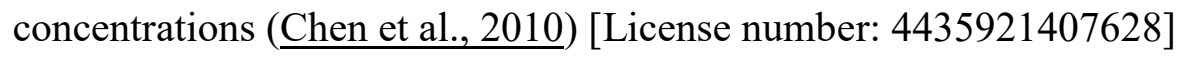

Several adsorption isothermal models have been used in the scientific literature such as the Langmuir, Freundlich, Dubinin-Radushkevich, and Redlich-Peterson models. Among these, the Langmuir model (Section S4) is the most commonly used one because the maximum adsorption capacity of a certain adsorbent can be calculated under given experimental conditions. When the adsorption process reaches a true equilibrium under optimal conditions, the $Q^{\circ}$ max parameter is helpful to (1) compare the adsorption efficiency among adsorbents and (2) design the adsorption study in a fixed-bed column. Tables S8-S9 summarize the Langmuir maximum adsorption capacities $\left(Q^{\mathrm{o}}{ }_{\max }\right)$ of various pristine and treated biosorbents derived from leaves from previous literature. Based on the data in Tables S8-S9, basic statistical analyses were performed, and the results are listed in Figure 6. Figure 6 indicates $Q^{\circ}{ }_{\text {max }}$ of modified/treated leaves are quite higher those of pristine leaves. Furthermore, the of modified/treated leaves also exhibit the relatively higher bias in the estimated $Q^{\mathrm{o}}{ }_{\max }$ values. 


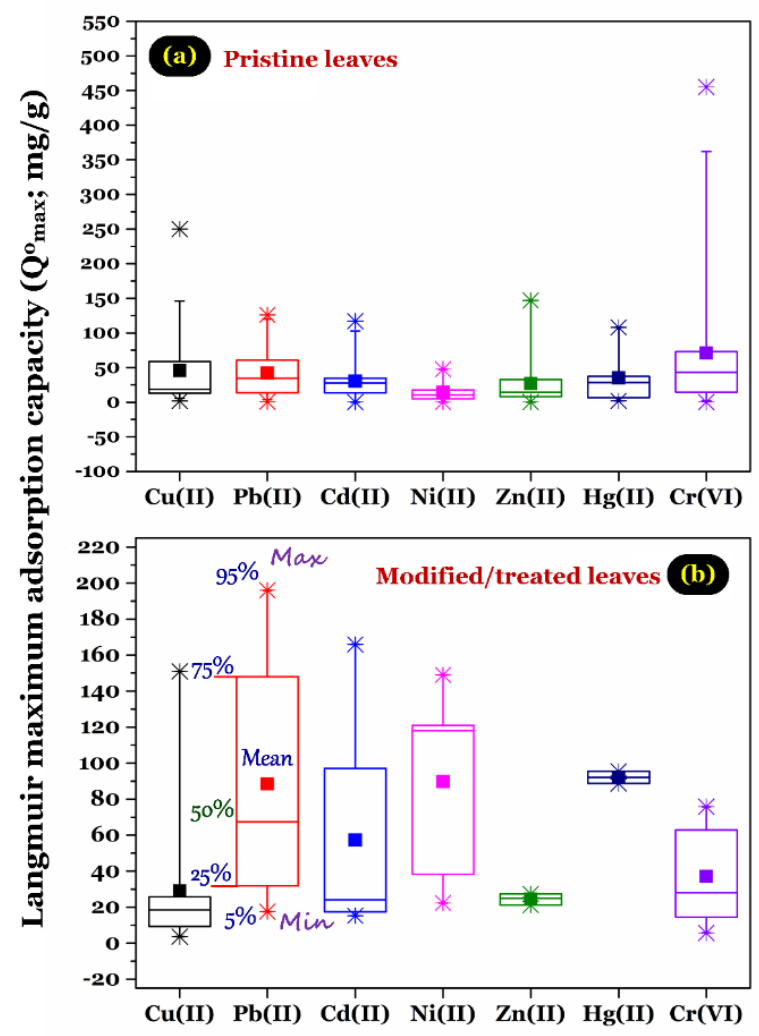

Figure 6. The Langmuir maximum adsorption capacity $\left(Q^{\circ}{ }_{\max }, \mathrm{mg} / \mathrm{g}\right)$ of leaf-based biosorbent (batch experiment) to some typical toxic metal ions (Data were analyzed based on summarizing data reported in the literature; see Tables S8-S9)

Notably, although the $Q^{\mathrm{o}}{ }_{\max }$ value plays an important role in adsorption studies, the maximum adsorption capacity of an adsorbent to a certain adsorbate strongly depends on the properties of the adsorbent (mainly its particle size) and operation conditions. The $Q^{\circ}$ max value is often inversely proportional to the particle size of the adsorbent. For example, Hanafiah and Ngah (2009) reported that the $Q^{\circ}$ max value of protonated rubber leaf biosorbent deceases in the following order when its particle size increases from less than $180 \mu \mathrm{m}$ to $180-355 \mu \mathrm{m}$ and to $355-500 \mu \mathrm{m}: 8.4 \mathrm{mg} / \mathrm{g}>6.9$ $\mathrm{mg} / \mathrm{g}>5.8 \mathrm{mg} / \mathrm{g}$. An analogous conclusion was drawn by Ngo et al. (2014).

In addition, the effects of the operation conditions on the $Q^{\circ}$ max value often comprise the solid/liquid ratio, solution $\mathrm{pH}$, and temperature. First, Bhattacharyya et al. (2009) applied neem leaves to remove $\mathrm{Ni}(\mathrm{II})$ from an aqueous medium. They reported that the $Q^{\circ}{ }_{\text {max }}$ values $(\mathrm{mg} / \mathrm{g})$ decrease when the solid/liquid ratios $(\mathrm{g} / \mathrm{L})$ increase, as follows: $9.1 \mathrm{mg} / \mathrm{g}($ at $0.5 \mathrm{~g} / \mathrm{L})>6.3 \mathrm{mg} / \mathrm{g}(1.0 \mathrm{~g} / \mathrm{L})>5.0 \mathrm{mg} / \mathrm{g}$ 
$(1.5 \mathrm{~g} / \mathrm{L})>4.2(2.0 \mathrm{~g} / \mathrm{L})>3.0 \mathrm{mg} / \mathrm{L}(3.0 \mathrm{~g} / \mathrm{L})>2.4 \mathrm{mg} / \mathrm{g}(4.0 \mathrm{~g} / \mathrm{L})$. Similar reports were found in the literature (Baruah et al., 2017; Bhattacharyya and Sarma, 2003; Bhattacharyya et al., 2010; Bhattacharyya and Sharma, 2004; Gowda et al., 2012; Sharma and Bhattacharyya, 2005). However, there is a potential problem regarding true equilibrium adsorption, which should be carefully considered. For example, Baruah et al. (2017) applied bael leaves to remove methylene blue dye from synthetic water. They determined the adsorption isotherm at very low initial dye concentrations (from $10 \mathrm{mg} / \mathrm{L}$ to $50 \mathrm{mg} / \mathrm{L})$. The $Q^{\circ}{ }^{m}$ ax values $(\mathrm{mg} / \mathrm{L})$ at different solid/liquid ratios $(\mathrm{g} / \mathrm{L})$ were $500 \mathrm{mg} / \mathrm{L}$ (at $0.2 \mathrm{~g} / \mathrm{L}), 167 \mathrm{mg} / \mathrm{L}(0.4 \mathrm{~g} / \mathrm{L}), 100 \mathrm{mg} / \mathrm{L}(0.6 \mathrm{~g} / \mathrm{L}), 91 \mathrm{mg} / \mathrm{L}(0.8 \mathrm{~g} / \mathrm{L})$, and $52 \mathrm{mg} / \mathrm{L}(1.0 \mathrm{~g} / \mathrm{L})$. Unfortunately, they did not include the adsorption isotherm in the published paper. A similar problem has been found in reference (Bhattacharyya and Sharma, 2004), with the $Q^{\circ}{ }_{\text {max }}$ value for $\mathrm{Pb}$ (II) biosorption onto neem leaves at a $C_{\mathrm{o}}$ range $(50-150 \mathrm{mg} / \mathrm{L})$ being $833 \mathrm{mg} / \mathrm{g}$ (at a solid/liquid ratio $=$ $0.2 \mathrm{~g} / \mathrm{L}), 270 \mathrm{mg} / \mathrm{g}(0.4 \mathrm{~g} / \mathrm{L}), 196 \mathrm{mg} / \mathrm{g}(0.6 \mathrm{~g} / \mathrm{L}), 119 \mathrm{mg} / \mathrm{g}(0.9 \mathrm{~g} / \mathrm{L})$, and $82 \mathrm{mg} / \mathrm{L}(1.2 \mathrm{~g} / \mathrm{L})$. Therefore, the critical question is whether the adsorption process can reach a true equilibrium at low initial adsorbate concentrations (i.e., $10-50 \mathrm{mg} / \mathrm{L}$ ) and high solid/liquid ratio (i.e., $1.0 \mathrm{~g} / \mathrm{L}$ ). If the adsorption process cannot reach a true equilibrium in the adsorption isotherm, the calculated $Q^{\mathrm{o}}{ }_{\max }$ values are invalid. This mistake has been discussed by many scholars (Hai, 2017; Kumar, 2006; Tran et al., 2017b; Vasanth Kumar and Sivanesan, 2006).

Second, Sharma and Forster (1994) reported the $Q^{\text {o }}$ max values of leaf mould with respect to chromium adsorption at different initial $\mathrm{pH}_{\text {solution values }}(1.5,2.0,2.5,3.0,4.0,6.0$, and 10), that is, 27.6, 43.1, 23.4, 8.9, 7.1, 3.9, and $2.5 \mathrm{mg} / \mathrm{g}$, respectively. In another study, it was also reported that

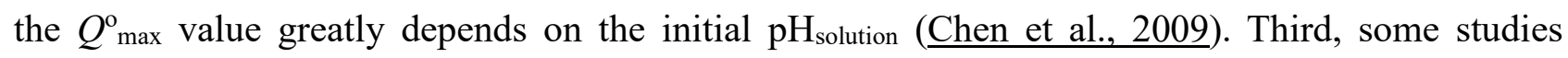
demonstrated that the $Q^{\mathrm{o}}$ max values increase when the temperatures increase, while others indicated the opposite trend. For example, Yuvaraja et al. (2014) hightlighted that the $Q^{\mathrm{o}} \max$ values of Solanum melongena leaf biosorbent toward $\mathrm{Pb}(\mathrm{II})$ decrease in the following order: $71.4 \mathrm{mg} / \mathrm{g}\left(\right.$ at $\left.50{ }^{\circ} \mathrm{C}\right)>62.5$ $\mathrm{mg} / \mathrm{g}\left(40{ }^{\circ} \mathrm{C}\right)>55.6 \mathrm{mg} / \mathrm{g}\left(30^{\circ} \mathrm{C}\right)$. In constrast, K1lıç et al. $(\underline{2009})$ reported that the $Q^{\mathrm{o}}{ }_{\max }$ values of 
$\mathrm{NaOH}$-pretreated Marrubium globosum ssp. globosum leaves to copper ions decrease in the following order: $21.1 \mathrm{mg} / \mathrm{g}\left(\right.$ at $\left.20^{\circ} \mathrm{C}\right)>20.3 \mathrm{mg} / \mathrm{g}\left(30^{\circ} \mathrm{C}\right)>19.7 \mathrm{mg} / \mathrm{g}\left(40{ }^{\circ} \mathrm{C}\right)>18.5 \mathrm{mg} / \mathrm{g}\left(45^{\circ} \mathrm{C}\right)$.

\subsection{Adsorption thermodynamics}

The study of adsorption thermodynamics is an indispensable part for the estimation of the adsorption mechanism (i.e., physical or chemical). Taking the adsorption of heavy metals as a typical example, physical adsorption involves relatively weak interactions (i.e., van der Waals force), while chemical adsorption is generated from stronger chemical interactions (i.e., coordination) with associated transfer of electrons between the adsorbent and adsorbate.

The thermodynamic parameters of a reaction, including the changes in Gibbs energy $(\Delta G)$, entropy $(\Delta S)$, and enthalpy $(\Delta H)$, can be obtained from calorimetric measurements (Ferreira et al., 2017) or based on the van't Hoff approach (Tran et al., 2017b). However, we found that the van't Hoff approach was used in almost all publications relevant for this work (Section S5). Tables S11-S15 compile the thermodynamic parameters for the biosorption process of various contaminants onto pristine and treated biosorbents derived from leaves. The signs and magnitudes of the parameters strongly depend on the properties of both the biosorbent and adsorbate. In addition, the effects of temperature on the amount of adsorbate adsorbed on the biosorbent are reflected by the sign of the enthalpy change. The biosorption capacity of the biosorbent is enhanced when the temperature rises, suggesting that the biosorption is an endothermic process $(\Delta H>0)$. On the other hand, the negative $\Delta H$ reflects the exothermic nature of the biosorption process, which is demonstrated by a decreased biosorption capacity at higher temperatures. For example, $\mathrm{NaOH}$-treated dead leaves of Ficus racemose were applied to remove anionic dyes from synthetic water. Based on the results, the $\Delta H$ value of the adsorption of acid green 25 is $+7.0 \mathrm{~kJ} / \mathrm{mol}$ ( Jain and Gogate, 2018), that of acid blue $25 \mathrm{is}+29.9 \mathrm{~kJ} / \mathrm{mol}$ (Jain and Gogate, 2017c), and that of acid blue 113 is $-31.3 \mathrm{~kJ} / \mathrm{mol}$ (Jain and Gogate, 2017a). This means that the adsorption process of acid green 25 and acid blue 25 is endothermic, but that of acid blue 113 is exothermic. These results were very consistent with the equilibrium study (i.e., the 
adsorption isotherms at different temperatures and the Langmuir maximum adsorption capacity; $Q^{\mathrm{o}}{ }_{\max }$ ). The $Q^{\mathrm{o}}{ }_{\max }$ value for acid green 25 adsorption increases in the following order: $44.3 \mathrm{mg} / \mathrm{g}$ (at $\left.20{ }^{\circ} \mathrm{C}\right)<46.6 \mathrm{mg} / \mathrm{g}\left(30{ }^{\circ} \mathrm{C}\right)<48.9 \mathrm{mg} / \mathrm{g}\left(40^{\circ} \mathrm{C}\right)<50.8 \mathrm{C}\left(50{ }^{\circ} \mathrm{C}\right)$; thus, $\Delta H$ is positive. In contrast, the $Q^{\circ}{ }_{\text {max }}$ value for acid blue 113 adsorption decreases in the following order: $97.1 \mathrm{mg} / \mathrm{g}\left(\right.$ at $\left.20{ }^{\circ} \mathrm{C}\right)>$ $93.5 \mathrm{mg} / \mathrm{g}\left(\right.$ at $\left.\left.30^{\circ} \mathrm{C}\right)>90.1 \mathrm{mg} / \mathrm{g} 40^{\circ} \mathrm{C}\right)>87.0 \mathrm{mg} / \mathrm{g}\left(50^{\circ} \mathrm{C}\right)$; thus, $\Delta H$ is negative. Based on Tables S11-S15, it can be concluded that most biosorbent processes are endothermic in nature (accounting for approximately $70 \%$ of the processes, $n=65 / 93$ ).

Generally, the removal process of contaminants from aqueous solutions (adsorption onto the biosorbent) occurs spontaneously or naturally (accounting for approximately 90\%, $n=84 / 93$ ), which is supported by the negative $\Delta G$ values (Tables S11-S15). Furthermore, the sign of the entropy change reflects whether the organization of the adsorbate at the solid/solution interface during the biosorption becomes less random $(\Delta S<0)$. As shown in Tables S11-S15, raw and modified biosorbents exhibit a positive $\Delta S$ value in most cases $(\sim 71 \%, n=66 / 93)$, suggesting that the organization of the adsorbate ions at the solid/solution interface becomes more random during the biosorption process.

Figure 7 illustrates the relationship between $\Delta H$ and $\Delta S$ for the adsorption of heavy metal ions and organic dyes on the biosorbents. However, the results indicated that the enthalpy-entropy compensation (plot of $\Delta H$ versus $\Delta S$ ) shows a relative strong linear relationship (exclusion of some unlogic points). This phenomenon seems strange and is difficult to explain because the results are based on different studies with different experimental conditions. One possible explanation is that both $\Delta H$ and $\Delta S$ are calculated using the same equation.

Other significant concerns are that the sign and magnitude of $\Delta S$ and $\Delta H$ demonstrate a confused representation because the thermodynamic parameters given in Tables S11-S15 were calculated based on the equilibrium constant $K_{\mathrm{c}}$, which is assumed from different alternatives (i.e., $K_{\mathrm{L}}, K_{p}^{o}$, and $K_{\mathrm{d}}$ ) and units (i.e., $\mathrm{L} / \mathrm{mol}, \mathrm{L} / \mathrm{mg}, \mathrm{L} / \mathrm{g}$, and dimensionless). Moreover, the operating conditions of biosorption 
experiments are dissimilar. For example, $\underline{\text { Shah et al. (2015) }}$ applied the distribution coefficient $\left(K_{\mathrm{d}}=\right.$ $q_{\mathrm{e}} / C_{\mathrm{e}} ; \mathrm{L} / \mathrm{g}$ ) at an initial $\mathrm{Ni}(\mathrm{II})$ concentration of $5 \mathrm{mg} / \mathrm{L}$, but Kushwaha et al. (2014) applied the distribution coefficient $\left[K_{\mathrm{d}}=\left(q_{\mathrm{e}} / C_{\mathrm{e}}\right) \times(\mathrm{m} / \mathrm{V})\right.$; dimensionless $]$ at an initial dye concentration of $10 \mathrm{mg} / \mathrm{L}$ to compute the thermodynamic parameters. Meanwhile, Jalil et al. (2012) calculated the thermodynamic parameters from the partition coefficient $\left(K_{\mathrm{p}}=C_{\mathrm{s}} / C_{\mathrm{e}}\right.$; dimensionless) at an initial dye concentration of $200 \mathrm{mg} / \mathrm{L}$ and different temperatures $(313-363 \mathrm{~K})$. In contrast, Yuvaraja et al. (2014) applied the Langmuir constant $\left(K_{\mathrm{L}} ; \mathrm{L} / \mathrm{mg}\right)$ at different initial $\mathrm{Pb}(\mathrm{II})$ concentrations $(30-90 \mathrm{mg} / \mathrm{L})$, and Jain and Gogate (2018) applied the Langmuir constant $\left(K_{\mathrm{L}}\right.$; dimensionless) at different initial dye concentrations $(50-300 \mathrm{mg} / \mathrm{L})$ to calculate the thermodynamic parameters.

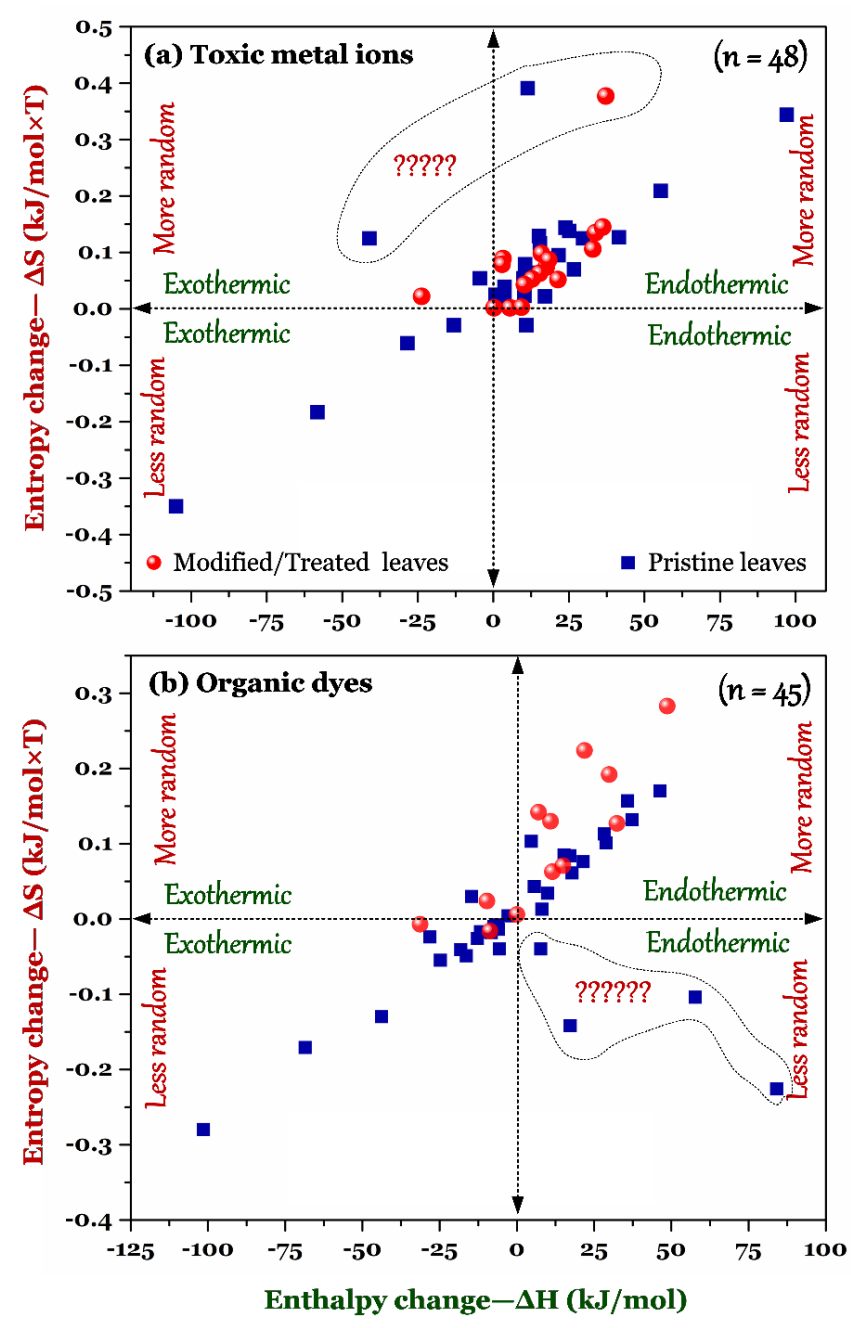

Figure 7. Enthalpy-entropy compensation plot for the biosorption of (a) potential toxic metals and (b) organic dyes onto the raw and modified biosorbents derived from leaves (data collected from Tables S11-S15) 
It is accepted that the following two steps consecutively occur during adsorption in aqueous solution: (1) release of pre-adsorbed water molecules from adsorption sites $\left(\Delta H_{1}>0, \Delta S_{1}>0\right)$ and (2) adsorption of the adsorbate on the solid surface in a more ordered manner than that in bulk liquid phase $\left(\Delta H_{2}<0, \Delta S_{2}<0\right)$. In this regard, a highly positive $\Delta H$ and/or highly positive/negative $\Delta S$ of the adsorption appears abnormal, unless sufficient experimental evidence is provided. Therefore, to obtain an appropriate conclusion or remark at this stage, several requirements need to be met in the existing studies. First, the alternative of the equilibrium constant $K_{\mathrm{c}}$ must be dimensionless. Second, the linear regression coefficient $\left(R^{2}\right)$ of the van't Hoff equation must be high. Third, the initial concentration of the adsorbate utilized in adsorption studies must be low or high. If the initial concentrations of the adsorbate are very high, the distribution and partition coefficients might not be appropriate for the calculation of thermodynamic adsorption parameters (Chang et al., 2016; Tran et al., 2016; Tran et al., $\underline{2017 b)}$.

\subsection{Desorption and regeneration}

The adsorption reversibility is often determined by desorption studies. To some extent, the desorption study can help to understand the uppermost reaction between adsorbent and adsorbate in solution. Because leaf-based biosorbents are nonporous carbonaceous materials, surface interaction (i.e., electrostatic attraction) greatly contribute to the adsorption mechanism. In general, if electrostatic attraction is mainly responsible for the adsorption of cationic adsorbates (i.e., $\mathrm{Cu}^{2+}$ ), the adsorption process is highly reversible when pure water at a low $\mathrm{pH}$ value (often $\mathrm{pH} 2.0$ ) is used as the desorbing agent. For example, Chakravarty et al. (2010) speculated about $\mathrm{Pb}(\mathrm{II})$ biosorption by bael leaves, concluding that the desorption efficiency of $\mathrm{Pb}(\mathrm{II})$ from bael leaves has the following other: $85 \%($ at $\mathrm{pH} 2.0)>35 \%(\mathrm{pH} 3.0)>10 \%(\mathrm{pH} 4.0-7.0)$.

In contrast, highly alkaline conditions (often $\mathrm{pH} 12$ ) simulate the desorption efficiency of anionic adsorbates (i.e., $\mathrm{Cr}_{2} \mathrm{O}_{7}{ }^{2-}$ ) from the surface of the adsorbent if the adsorption process primarily involves electrostatic attraction. Figure 8 collects the plots regarding to the research of desorption 
from biosorbents in the literature. A typical example was described in Hamissa et al. (2007) for the biosorption of two anionic dyes (Sumfixe Supra Red and Alpacelle Lumiere Brown) onto maguey leaves (Figures 8a-b), which agrees with the findings of other authors (Guerrero-Coronilla et al., 2015; Jain and Gogate, 2018; Namasivayam et al., 1996; Singh et al., 2009). Similarly, GuerreroCoronilla et al. $(\underline{2015})$ concluded that the decline in the acid red 27 desorption efficiency has the following order: strongly alkaline $(0.01 \mathrm{M} \mathrm{NaOH}$ and $\mathrm{KOH} ; \mathrm{pH} \approx 12)>$ weakly alkaline $(0.1 \mathrm{M}$ $\left.\mathrm{Na}_{2} \mathrm{CO}_{3} ; \mathrm{pH} \approx 11.5\right)>$ neutral salt $\left(0.1 \mathrm{M} \mathrm{NaCl}, \mathrm{NaNO}_{3}\right.$, and $\left.\mathrm{Na}_{2} \mathrm{SO}_{4} ; \mathrm{pH} \approx 7.0\right)>$ weak acid $(0.1 \mathrm{M}$ $\left.\mathrm{NH}_{4} \mathrm{Cl} ; \mathrm{pH} \approx 5.1\right)>$ strong acid $\left(0.1 \mathrm{M} \mathrm{HCl}, \mathrm{H}_{2} \mathrm{SO}_{4}\right.$, and $\left.\mathrm{HNO}_{3} ; \mathrm{pH} \approx 1.0\right)$ solutions.
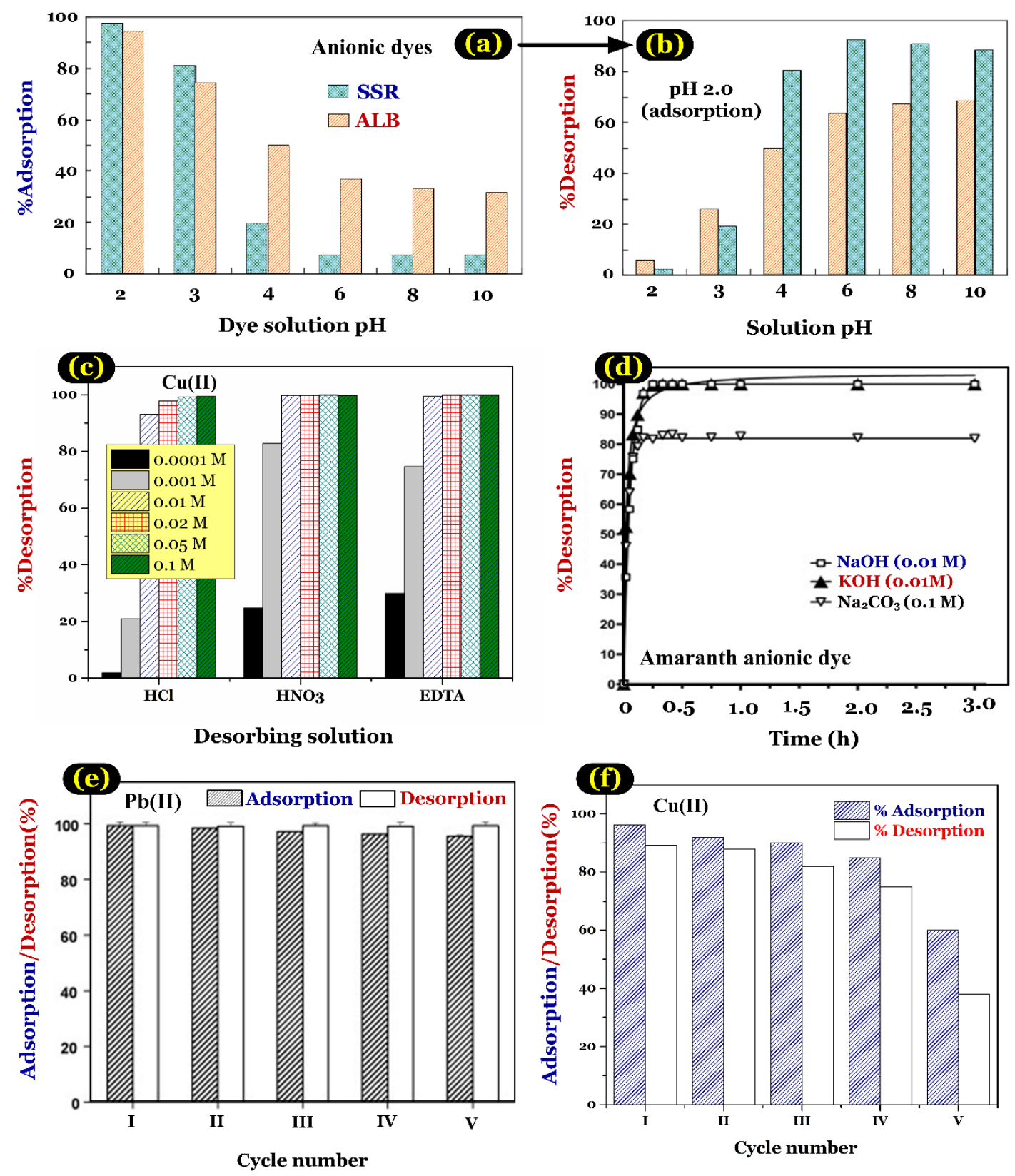
Figure 8. (a) Effect of solution $\mathrm{pH}$ on the adsorption of two anionic dyes ([Sumfixe Supra red (SSR) and Alpacelle Lumiere brown (ALB)] onto Agave americana leaves, and (b) effect of $\mathrm{pH}$ on the dye desorption (Hamissa et al., 2007) [Creative Commons CC-BY by SAGE]; (c) Effect of different eluents on copper desorption from treated rubber leaves (Ngah and Hanafiah, 2008) [License number: 4443540449114]; (d) Desorption kinetics of anionic Amaranth dye from water hyacinth leaves (Guerrero-Coronilla et al., 2015) [License number: 4435930384912]; (e) Five cycles of $\mathrm{Pb}(\mathrm{II})$ adsorption-desorption with $0.4 \mathrm{M} \mathrm{HCl}$ (Reddy et al., 2010) [License number: 4435930464723]; (f) Biosorption-desorption cycles for regenerating SATCEL with 0.1 N $\mathrm{HCl}$ (Khan Rao and Khatoon, 2017) [License number: 4435930646149]

Generally, the desorption efficiency of potential toxic metals is enhanced when the solution concentration of used desorbing agent increases. For example, Chen et al. (2011) found that the desorption efficiency of $\mathrm{Cu}(\mathrm{II})$ ions from $\mathrm{NaOH}$-treated rubber leaves increases from $1.9 \%$ to $99.4 \%$, $24.7 \%$ to $99.9 \%$, and $29.9 \%$ to $99.9 \%$ when the concentrations of $\mathrm{HCl}, \mathrm{HNO}_{3}$, and EDTA increase from $0.0001 \mathrm{M}$ to $0.1 \mathrm{M}$, respectively (Figure 8c). They suggested that ion exchange is the primary desorption mechanism. The exact performance was reported by other scholars (A1 Rmalli et al., 2008; Chen et al., 2011; Chojnacka et al., 2005; Mambo et al., 2016; Ngah and Hanafiah, 2009; Qi and Aldrich, 2008; Reddy et al., 2012; Saha et al., 2017; Serencam et al., 2008; Yuvaraja et al., 2012).

Similar to the adsorption process, the desorption process of adsorbate from the laden biosorbent derived from leaves reaches a fast equilibrium (Cengiz and Cavas, 2010; GuerreroCoronilla et al., 2015; Hossain et al., 2012; Jain and Gogate, 2017b; Rao et al., 2011b). In fact, Guerrero-Coronilla et al. (2015) reported that the desorption process of amaranth anionic dye from laden water hyacinth leaves reaches a desorption equilibrium at approximately 15 min within all assayed alkaline eluents (i.e., $\mathrm{NaOH}, \mathrm{KOH}$, and $\mathrm{Na}_{2} \mathrm{CO}_{3}$; Figure 8d). In addition, Rao et al. (2011b) reported very fast desorption kinetics fast, where approximately $95.6 \% \mathrm{Cd}(\mathrm{II})$ in the jambolana leafbased biosorbent were desorbed within a short period of time, that is, $5 \mathrm{~min}$. However, Qi and Aldrich (2008) found that the desorption process of potentially toxic metals (i.e., $\mathrm{Ni}, \mathrm{Zn}, \mathrm{Cd}, \mathrm{Cu}$, and $\mathrm{Pb}$ ) 
from tobacco leaves reaches an equilibrium after $8 \mathrm{~h}$.

When the adsorption is highly reversible, an adsorption-desorption cycle is performed to explore the possibility of spent biosorbent regeneration and adsorbate recovery. Generally, the adsorption-desorption efficiency progressively decreases with increasing regeneration cycle number (Abedi et al., 2016; Amirnia et al., 2016; Cheraghi et al., 2015; Jain and Gogate, 2017a;2018; Kong et al., 2015; Khan Rao and Khatoon, 2017; Nag et al., 2016; Peydayesh and Rahbar-Kelishami, 2015; Qaiser et al., 2009; Serencam et al., 2008; Setiabudi et al., 2016; Xiao et al., 2016). For example, Khan Rao and Khatoon (2017) asserted that the percentage of $\mathrm{Cu}(\mathrm{II})$ adsorbed onto Australian pine leaves decreased from $96.3 \%$ to $60 \%$ after five consecutive cycles using $0.1 \mathrm{~N} \mathrm{HCl}$ as a desorbing solution and the percentage of $\mathrm{Cu}(\mathrm{II})$ desorbed from laden biosorbent decreased from $89.2 \%$ to $37.9 \%$ (Figure 8f).

In contrast, many researchers postulated that the reusability percentages insignificantly

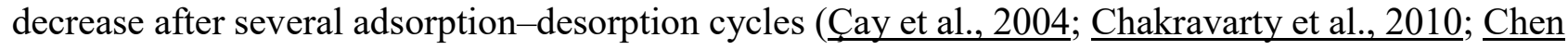
et al., 2010; Gupta et al., 2012; Han et al., 2014; Hossain et al., 2014a; Jain and Gogate, 2017b; Jain and Gogate, 2017c; Khorshidi et al., 2015; Lim et al., 2016; Ngah and Hanafiah, 2009; Reddy et al.,

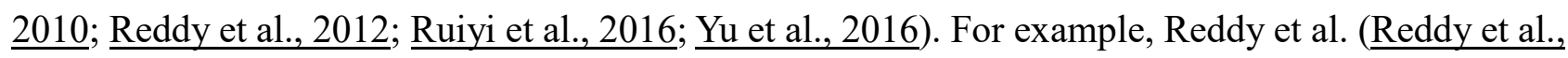
2010) assessed that the desorption of $\mathrm{Pb}(\mathrm{II})$ from chemically modified drumstick leaves in all four cycles remained at very high efficiency, with more than $98 \%$ recovery of $\mathrm{Pb}(\mathrm{II})$ in each cycle (Figure 8e). In conclusion for Figure 8, the desorption/regeneration processes of heavy metals or dyes form the biosorbents are easily carried out. The adsorption efficiency often decreases with the increasing cycles in regeneration.

However, other authors claimed that the adsorption affinity of biosorbents to adsorbate is

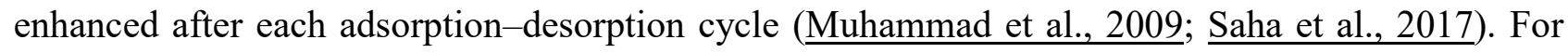
example, Saha et al. (2017) found that the adsorption and desorption efficiency noticeably increased after the first cycle. They concluded that the $\mathrm{HNO}_{3}$ solution (used as desorbing agent) could dissolve the organic portion of the leaves, activating the binding site and consequently enhancing the 
adsorption efficiency. A similar phenomenon was found for the desorption of $\mathrm{Cu}$ (II) from laden banana peel using a $\mathrm{H}_{2} \mathrm{SO}_{4}$ desorbing agent (Hossain et al., 2012), $\mathrm{Pb}$ (II) and $\mathrm{Cd}(\mathrm{II})$ from laden mango peel using $\mathrm{HCl}$ (Iqbal et al., 2009), and $\mathrm{Zn}$ (II) and $\mathrm{Ni}$ (II) from grapefruit peel using $\mathrm{HCl}$ (Muhammad et al., 2009). Similarly, Yazic1 et al. (2008) also discovered that the adsorption capacity of Cu(II) onto lamiaceae leaves was improved when the leaves were pretreated with $\mathrm{H}_{2} \mathrm{SO}_{4}$ and $\mathrm{HNO}_{3}$ because the pretreatment with such acids possibly causes the protonation of the biomass surface and consequently an increased ion exchange capacity. In addition, Hanafiah and Ngah (2009) found that the pretreatment of rubber leaves with $\mathrm{HCl}$ contributes to increasing protonation of silanol, carboxyl, amino, and hydroxyl groups on the leaf surface. This presumably results in an increased adsorption capacity of copper cations in the bulk solution.

The adsorption of anionic contaminants is a process that often occurs adequately at a low solution $\mathrm{pH}$ because of the large contribution of electrostatic attraction. Therefore, desorption will be favored at a higher $\mathrm{pH}$ (alkaline condition). For example, Jain and Gogate $(\underline{2017 \mathrm{c}})$ reported that the process of acid blue 25 adsorption onto $\mathrm{NaOH}$-treated cluster fig leaves reaches the highest adsorption efficiency at $\mathrm{pH}$ 2.0. The results of a desorption-adsorption study using distilled water at $\mathrm{pH} 12$ as a desorbing agent signify that the adsorption capacity of the biosorbent slightly declines, from $24.6 \pm 0.34 \mathrm{mg} / \mathrm{g}$ in the first cycle to $24.4 \pm 0.42 \mathrm{mg} / \mathrm{g}$ in the seventh cycle at $C_{\mathrm{o}}=100 \mathrm{mg} / \mathrm{L}$.

With respect to desorption competition, Çay et al. (2004) found that the desorption efficiency of toxic metals from laden tea waste in single and binary systems is similar. An amount of $0.1 \mathrm{M} \mathrm{HCl}$ can desorb $97.2 \% \mathrm{Cu}(\mathrm{II})$ and $98.1 \% \mathrm{~Pb}(\mathrm{II})$ in the single system and approximately $97 \% \mathrm{Cu}(\mathrm{II})$ and $\mathrm{Pb}(\mathrm{II})$ in the binary system.

\subsection{Adsorption competition}

Adsorption competition occurs in a multi-adsorbate system. In fact, the adsorption capacity of the adsorbent is strongly impacted by the presence of multi-adsorbates because of (1) the competitive adsorption phenomenon of adsorbates in the mixed system for adsorption sites on the 
adsorbent surface and (2) their antagonistic effect.

For example, Shi et al. (2016) reported that the Langmuir maximum adsorption capacity $\left(Q^{\mathrm{o}}{ }_{\max }\right)$ of arborvitae leaves toward potentially toxic metals in non-competitive adsorption $(35.8 \mathrm{mg} / \mathrm{g}$ for $\mathrm{Pb}, 7.9 \mathrm{mg} / \mathrm{g}$ for $\mathrm{Cu}$, and $6.8 \mathrm{mg} / \mathrm{g}$ for $\mathrm{Co})$ is much higher than in competitive adsorption $(9.3$ $\mathrm{mg} / \mathrm{g}$ for $\mathrm{Pb}, 3.1 \mathrm{mg} / \mathrm{g}$ for $\mathrm{Cu}$, and $1.54 \mathrm{mg} / \mathrm{g}$ for $\mathrm{Co}$ ). Similarly, Kamar Firas et al. (2017) stated that the $Q^{\mathrm{o}}{ }_{\text {max }}$ values of cabbage leaves with respect to $\mathrm{Pb}(\mathrm{II}), \mathrm{Cu}(\mathrm{II})$, and $\mathrm{Cd}(\mathrm{II})$ in a single system $(6.3$, 5.8 , and $5.1 \mathrm{mg} / \mathrm{g})$ are higher than the corresponding values in a ternary system $(4.54,3.35$, and 2.48 $\mathrm{mg} / \mathrm{g})$. In addition, Khan Rao and Khatoon (2017) reported $Q^{\mathrm{o}}$ max values of $\mathrm{Cu}(44.5$ and $13.0 \mathrm{mg} / \mathrm{g})$, $\mathrm{Pb}(28.6$ and $21.7 \mathrm{mg} / \mathrm{g})$, and $\mathrm{Ni}(39.9$ and $7.79 \mathrm{mg} / \mathrm{g})$ adsorption onto aluminate-treated Australian pine leaves in single and multi-metal systems, respectively. A similar tendency was discussed

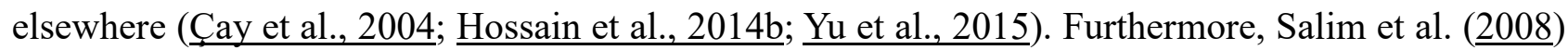
explored the $\mathrm{Cd}(\mathrm{II})$ removal efficiency from aquatic environments of 20 species of plant leaves. They concluded that the existence of foreign ions $(\mathrm{Zn}, \mathrm{Pb}$, and $\mathrm{Cu})$ or complexing agents (EDTA) causes a significant decrease in the biosorption efficiency of cadmium onto the plant leaves.

With respect to adsorption selectivity, the $Q^{\mathrm{o}} \max$ value $(\mathrm{mmol} / \mathrm{g})$ of leaf-based biosorbent decreases in the following order: $\mathrm{Cu}(\mathrm{II})>\mathrm{Pb}(\mathrm{II})>\mathrm{Co}$ (II) (Shi et al., 2016) $\mathrm{Cu}(\mathrm{II})>\mathrm{Cd}(\mathrm{II})>\mathrm{Pb}(\mathrm{II})$ (Kamar Firas et al., 2017) $) \mathrm{Cu}(\mathrm{II})>\mathrm{Ni}(\mathrm{II})>\mathrm{Pb}(\mathrm{II})$ (Khan Rao and Khatoon, 2017)$) ; \mathrm{Cu}(\mathrm{II})>\mathrm{Cd}(\mathrm{II})$ (Cay et al., 2004); $\mathrm{Cu}(\mathrm{II})>\mathrm{Cd}(\mathrm{II})>\mathrm{Pb}(\mathrm{II}), \mathrm{Zn}(\mathrm{II})>\mathrm{Cd}(\mathrm{II})>\mathrm{Pb}(\mathrm{II}), \mathrm{Zn}(\mathrm{II})>\mathrm{Cu}(\mathrm{II})>\mathrm{Cd}(\mathrm{II})$, and $\mathrm{Cu}(\mathrm{II})>\mathrm{Cd}(\mathrm{II})>\mathrm{Zn}(\mathrm{II})(\underline{\text { Hossain et al., 2014b }}) ; \mathrm{Cu}(\mathrm{II})>\mathrm{Cd}(\mathrm{II})(\underline{\text { Nag et al., 2016}}) ; \mathrm{Cu}(\mathrm{II})>\mathrm{Zn}(\mathrm{II})>$ $\mathrm{Cd}(\mathrm{II})(\underline{\text { Yu et al., 2015)}}$; and $\mathrm{Cu}(\mathrm{II})>\mathrm{Pb}(\mathrm{II})>\mathrm{Zn}(\mathrm{II})>\mathrm{Cd}(\mathrm{II})>\mathrm{Ni}(\mathrm{II})$ (Qi and Aldrich, 2008).

Furthermore, Zolgharnein et al. (2017) used XPS to identify the biosorption affinity of modified Buxus sempervirens tree leaves to a ternary mixture of metal ions. The surface composition (atomic percentage) was ranked as $\mathrm{Cu}(0.3 \%)>\mathrm{Cd}(0.3 \%) \sim \mathrm{Ni}(0.3 \%)$. Clearly, the leaf-developed biosorbent favors the adsorption of $\mathrm{Cu}(\mathrm{II})$ and not the mixture containing the metal ion solution.

Because the limitation of adsorption competition study in multi-adsorbate system using leaves 
as biosorbent in the literature, we compared the $Q^{\circ}{ }_{\text {max }}$ values of biosorbents to potentially toxic metals in the single system. The $Q^{\mathrm{o}}{ }_{\max }$ values $(\mathrm{mmol} / \mathrm{g})$ exhibit a decreasing order: $\mathrm{Cu}(\mathrm{II})>\mathrm{Ni}(\mathrm{II})>\mathrm{Cd}(\mathrm{II})$ ( $\underline{\text { Reddy et al., 2012) }}, \mathrm{Cu}(\mathrm{II})>\mathrm{Cd}(\mathrm{II})>\mathrm{Pb}(\mathrm{II})$ ( $\underline{\text { Kamar Firas et al., 2017; }}$ Wan et al., 2014) $\mathrm{Hg}(\mathrm{II})>$ $\mathrm{Cu}(\mathrm{II})>\mathrm{Pb}(\mathrm{II})$ ( $\underline{\text { Zhang et al., 2015) }}), \mathrm{Cr}(\mathrm{III})>\mathrm{Cr}(\mathrm{VI})>\mathrm{Pb}(\mathrm{II})$ (Copello et al., 2011), $\mathrm{Cr}(\mathrm{III})>\mathrm{Cd}(\mathrm{II})$ $>$ Cr(VI) (Sawalha et al., 2006), $\mathrm{Co}(\mathrm{II})>\mathrm{Ni}(\mathrm{II})$ (Vilvanathan and Shanthakumar, 2016), $\mathrm{Cu}(\mathrm{II})>$ $\mathrm{Ni}(\mathrm{II})>\mathrm{Pb}(\mathrm{II})(\underline{\text { Khan Rao and Khatoon, 2017) }}, \mathrm{Cr}(\mathrm{III})>\mathrm{Cu}(\mathrm{II})>\mathrm{Pb}(\mathrm{II})>\mathrm{Zn}(\mathrm{II})$ ( Abedi et al., 2016) , $\mathrm{Cr}(\mathrm{III})>\mathrm{Cu}(\mathrm{II})>\mathrm{Zn}$ (II) (awat et al., 2014), $\mathrm{Pb}(\mathrm{II})>\mathrm{Cd}(\mathrm{II})$ ( $\underline{\text { Hossain et al., 2014c }}), \mathrm{Cu}(\mathrm{II})>\mathrm{Pb}(\mathrm{II})$

$>\mathrm{Cd}(\mathrm{II})(\underline{\text { Sangi et al., 2008) }}), \mathrm{Cr}(\mathrm{III})>\mathrm{Cu}(\mathrm{II})>\mathrm{Cd}(\mathrm{II})(\underline{\text { Chojnacka et al., 2005) }}, \mathrm{Cu}(\mathrm{II})>\mathrm{Zn}(\mathrm{II})>$ $\mathrm{Cd}(\mathrm{II})(\underline{\text { Yu et al., 2015) }}, \mathrm{Cu}(\mathrm{II})>\mathrm{Ni}(\mathrm{II})>\mathrm{Pb}(\mathrm{II})(\underline{\text { Salehi et al., 2008) }}, \mathrm{Cu}(\mathrm{II})>\mathrm{Zn}(\mathrm{II})>\mathrm{Pb}(\mathrm{II})>\mathrm{Cd}(\mathrm{II})$ ( $\underline{\text { Abdolali et al., 2016) }}$, and $\mathrm{Cu}(\mathrm{II})>\mathrm{Co}(\mathrm{II})>\mathrm{Ni}(\mathrm{II})>\mathrm{Cr}(\mathrm{III})>\mathrm{Zn}(\mathrm{II})>\mathrm{Cd}(\mathrm{II})>\mathrm{Pb}(\mathrm{II})$ ( Batool et al., 2017).

\section{Column experiment}

Continuous fixed-bed analysis is often performed to comprehend the effects of various process parameters, such as the bed height, flow rate, and initial adsorbate concentrations, on the dynamic adsorption process. To analyze the breakthrough profiles in the fixed-bed adsorption process, various mathematical models have been applied to describe the dynamic adsorption behavior of adsorbates in the fixed-bed column including the Thomas, Adams-Bohart, and Yoon-Nelson models. Similar to the Langmuir model, the Thomas model (Section S6) is commonly applied to estimate the maximum adsorption capacity of the adsorbent $\left(q_{\mathrm{o}} ; \mathrm{mg} / \mathrm{g}\right)$ under given experimental conditions.

Generally, breakthrough and exhaustion times significantly decrease when the flow rate and initial adsorbate concertation increase, while they increase with increasing bed height (used adsorbent mass). For example, Tamez Uddin et al. (2009) conducted a fixed-bed column study of methylene blue removal from water media using jackfruit leaf powders (Figure S12). With respect to the effect of the flow rate $(Q ; \mathrm{mL} / \mathrm{min})$, the breakthrough and exhaustion times exhibited the following order: 3350 and $530 \mathrm{~min}($ at $30 \mathrm{~mL} / \mathrm{min})>250$ and $390 \mathrm{~min}($ at $40 \mathrm{~mL} / \mathrm{min})>190$ and $300 \mathrm{~min}($ at 50 
$\mathrm{mL} / \mathrm{min})$, respectively. Meanwhile, the breakthrough time $\left(\mathrm{t}_{b} ; \min \right)$ and exhaustion time $\left(t_{s} ; \min \right)$ decreased from 490 and $780 \mathrm{~min}$ to 250 and $390 \mathrm{~min}$ and then to 170 and $270 \mathrm{~min}$ when the initial dye concentration $\left(C_{0} ; \mathrm{mg} / \mathrm{L}\right)$ increased from $100 \mathrm{mg} / \mathrm{L}$ to $200 \mathrm{mg} / \mathrm{L}$ and then to $300 \mathrm{mg} / \mathrm{L}$, respectively. In contrast, the $t_{\mathrm{b}}$ and $t_{s}$ values increased when the bed height $(Z ; \mathrm{cm})$ rose as follows: 170 and $270 \mathrm{~min}$ (at $5 \mathrm{~cm}$ ), 275 and $390 \mathrm{~min}$ (at $7.5 \mathrm{~cm}$ ), and 400 and $490 \mathrm{~min}$ (at $10 \mathrm{~cm}$ ), respectively. Notably, although the breakthrough and exhaustion times strongly depend on the operation conditions (i.e., $Z, Q$, and $\left.C_{\mathrm{o}}\right)$, the Thomas maximum adsorption capacity $\left(q_{\mathrm{o}} ; \mathrm{mg} / \mathrm{g}\right)$ of jackfruit leaves is almost the same under different operation conditions. The $q_{\mathrm{o}}$ values ranged from 245 to $251 \mathrm{mg} / \mathrm{g}$ (for the flow rate study), from 256 to $266 \mathrm{mg} / \mathrm{g}$ (bed height), and from 245 to $256 \mathrm{mg} / \mathrm{g}$ (initial dye concentration). Similar results were reported elsewhere (Amirnia et al., 2016; Das et al., 2016; Han et al., 2009; Rao et al., 2011b; Yu et al., 2015), but contrary findings were also documented (․min et al., 2017; Jain and Gogate, 2018; Nag et al., 2016; Saha et al., 2012). Table 3 summarizes the maximum equilibrium adsorption capacity in the column of the Thomas model of various pollutants onto leaf-based biosorbents. In Table 3, the adsorption capacities significantly vary with the operation conditions.

Table 3. Thomas maximum adsorption capacity $\left(q_{\mathrm{o}} ; \mathrm{mg} / \mathrm{g}\right)$ of leaf-based bisorbents (column experiment) at different operation conditions including flow rate $(Q ; \mathrm{mL} / \mathrm{min})$, bed height $(Z ; \mathrm{cm})$, and initial adsorbate concentration $\left(C_{0} ; \mathrm{mg} / \mathrm{L}\right)$

\begin{tabular}{|c|c|c|c|c|c|c|}
\hline \multirow[t]{2}{*}{ Leaves } & \multirow{2}{*}{$\begin{array}{l}\text { Adsor- } \\
\text { bate }\end{array}$} & & $\begin{array}{l}\text { Opera } \\
\text { ondit }\end{array}$ & & $\mathbf{q}_{\mathbf{o}}$ & \multirow[t]{2}{*}{ Reference } \\
\hline & & $\mathbf{Q}$ & $\mathbf{Z}$ & $\mathrm{C}_{\mathbf{o}}$ & & \\
\hline Sacred fig & $\mathrm{Pb}(\mathrm{II})$ & 5 & 50 & 100 & 16.42 & Qaiser et al., 2009 \\
\hline Tea waste & $\mathrm{Pb}(\mathrm{II})$ & 20 & $15^{\mathrm{a}}$ & 100 & 46.0 & $\begin{array}{l}\text { Amarasinghe and Williams } \\
\underline{2007}\end{array}$ \\
\hline MSG-treated rubber & $\mathrm{Pb}(\mathrm{II})$ & NA & 1.0 & 20 & 75.8 & Fadzil et al., 2016 \\
\hline
\end{tabular}




\begin{tabular}{|c|c|c|c|c|c|c|}
\hline $\mathrm{HNO}_{3}$-treated rubber & $\mathrm{Pb}(\mathrm{II})$ & NA & 1.0 & 20 & 48.7 & $\underline{\text { Fadzil et al., } 2016}$ \\
\hline Jambolan & $\mathrm{Cd}(\mathrm{II})$ & 20 & 5.0 & 100 & 25.2 & $\underline{\text { Rao et al., } 2011 \mathrm{~b}}$ \\
\hline Tea waste & $\mathrm{Cu}(\mathrm{II})$ & 20 & $15^{\mathrm{a}}$ & 100 & 13.0 & $\begin{array}{l}\text { Amarasinghe and Williams } \\
\underline{2007}\end{array}$ \\
\hline Date palm & $\mathrm{Cu}(\mathrm{II})$ & 3 & 5 & 150 & 5.19 & Amin et al., 2017 \\
\hline MA-treated date palm & $\mathrm{Cu}(\mathrm{II})$ & 2 & 5 & 100 & 9.64 & Amin et al., 2017 \\
\hline Rubber & $\mathrm{Cr}(\mathrm{VI})$ & 15 & 3 & 10 & 19.2 & Nag et al., 2016 \\
\hline Castor & $\mathrm{Hg}(\mathrm{II})$ & 2 & $1.0^{\mathrm{a}}$ & 100 & 35.5 & Al Rmalli et al., 2008 \\
\hline Neptune grass & $\mathrm{MB}$ & 7.3 & 9.0 & 100 & 482 & Cavas et al., 2011 \\
\hline Jackfruit & MB & 40 & 7.5 & 300 & 266 & $\underline{\text { Tamez Uddin et al., } 2009}$ \\
\hline Phoenix & MB & 8 & 15 & 100 & 149 & $\underline{\text { Han et al., } 2009}$ \\
\hline Pineapple & MG & 10 & 5 & 200 & 85.2 & $\underline{\text { Das et al., } 2016}$ \\
\hline $\mathrm{NaOH}$-treated almond & AG25 & 8 & 4 & 200 & 38.1 & $\underline{\text { Jain and Gogate } 2018}$ \\
\hline Jackfruit & $\mathrm{CV}$ & 5 & 12 & 50 & 66.7 & $\underline{\text { Saha et al., } 2012}$ \\
\hline Treated cluster fig & AV 17 & 8 & 4 & 200 & 70.9 & Jain and Gogate, $2017 b$ \\
\hline
\end{tabular}

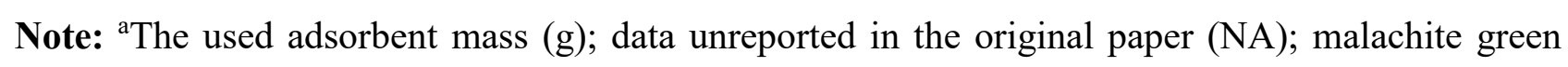
(MG); methylene blue (MB); crystal violet (CV); acid violet 17 (AV17); acid green 25 (AG25); monosodium glutamate (MSG); and mercaptoacetic acid (MA).

Furthermore, the maximum adsorption capacity of an adsorbent in batch experiments $\left(Q^{\mathrm{o}}{ }_{\max }\right.$; $\mathrm{mg} / \mathrm{g})$ is often higher than that in column experiments $\left(q_{\mathrm{o}} ; \mathrm{mg} / \mathrm{g}\right)$. For example, Jain and Gogate (2017b) reported that the $Q^{\circ}{ }_{\max }$ value of treated cluster fig leaves toward acid violet 17 dye $(111 \mathrm{mg} / \mathrm{g})$ is significantly higher than the $q_{\mathrm{o}}$ value $(35.8-70.9 \mathrm{mg} / \mathrm{g})$. Similarly, Fadzil et al. (2016) found that 
the $Q^{\mathrm{o}}{ }_{\max }$ values of citric acid-modified rubber leaves and monosodium glutamate-modified rubber leaves toward $\mathrm{Pb}(\mathrm{II})$ are 97.2 and $110 \mathrm{mg} / \mathrm{g}$, respectively, that is, significantly higher than the $q_{\mathrm{o}}$ values $(37.7-48.7 \mathrm{mg} / \mathrm{g}$ and $51.3-75.8 \mathrm{mg} / \mathrm{g}$, respectively). In addition, Amarasinghe and Williams (2007) reported that the maximum adsorption capacity of tea waste to $\mathrm{Cu}(\mathrm{II})$ and $\mathrm{Pb}$ (II) exhibits the following order: $Q^{\mathrm{o}}{ }_{\max }(48$ and $65 \mathrm{mg} / \mathrm{g})>q_{\mathrm{o}}(13$ and $46 \mathrm{mg} / \mathrm{g})$, respectively. A higher $Q^{\mathrm{o}}{ }_{\max }$ value (46.6 mg/g) compared with $q_{\mathrm{o}}(20.5-38.1 \mathrm{mg} / \mathrm{g})$ was also reported by Jain and Gogate (2018) for acid green 25 adsorption onto $\mathrm{NaOH}$-treated almonds.

Moreover, Amarasinghe and Williams (2007) highlighted that the column adsorption capacity of tea waste $[13 \mathrm{mg} / \mathrm{g}$ for $\mathrm{Cu}(\mathrm{II})$ adsorption and $46 \mathrm{mg} / \mathrm{g}$ for $\mathrm{Pb}$ adsorption] is remarkably higher than that of coconut shell-based granular activated carbon $(8$ and $19 \mathrm{mg} / \mathrm{g}$, respectively). A comparable result was observed for $\mathrm{Cr}(\mathrm{VI})$ adsorption onto rubber leaves, $Q^{\mathrm{o}}{ }_{\max }=23.0 \mathrm{mg} / \mathrm{g}>q_{\mathrm{o}}(8.2-18.8 \mathrm{mg} / \mathrm{g})$ (Nag et al., 2016), and $\mathrm{Pb}(\mathrm{II})$ adsorption onto sacred fig leaves, $Q^{\mathrm{o}}{ }_{\max }=37.5 \mathrm{mg} / \mathrm{g}>q_{\mathrm{o}}(13.4-16.4$ mg/g) (Qaiser et al., 2009).

However, Al Rmalli et al (2008) found that the $Q^{\mathrm{o}}{ }_{\max }(35.5 \mathrm{mg} / \mathrm{g})$ and $q_{\mathrm{o}}(37.2 \mathrm{mg} / \mathrm{g})$ values of $\mathrm{Hg}(\mathrm{II})$ adsorption onto castor leaves are similar. In contrast, Saha et al. (2012) proposed that jackfruit leaves have a higher $q_{\mathrm{o}}$ value $(57.3-66.7 \mathrm{mg} / \mathrm{g})$ than $Q^{\mathrm{o}}$ max $(41.1 \mathrm{mg} / \mathrm{g})$ based on an

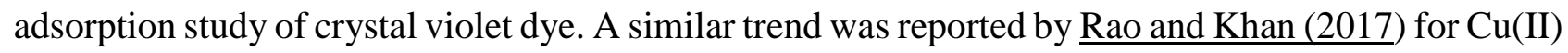
adsorption onto Boston fern leaves: $q_{\mathrm{o}}(37.5 \mathrm{mg} / \mathrm{g})>Q^{\mathrm{o}}{ }_{\max }(27.0 \mathrm{mg} / \mathrm{g})$.

The column adsorption could be assumed as a plug flow reactor. In the realistic operation, the adsorption difficultly reaches equilibrium. On the other hand, the adsorption equilibrium can be regarded as a batch reaction. The maximum adsorption capacity can be estimated through Langmuir equation. Thus, the adsorption capacities in the batch adsorption equilibrium frequently are higher than those in the column adsorption. The adsorption capacity in the column adsorption varies with the operation conditions such as bed height, flowrate and initial concentration. The adsorption capacity in the adsorption equilibrium only varies with the properties of solution such as $\mathrm{pH}$ and temperature. In addition, the column adsorption is frequently used in the realistic wastewater 
treatment operation. However, the particle sizes of biosorbents might affect the adsorption efficiencies toward heavy metal ions or dyes. When the biosorbents are applied to treat the realistic wastewater using column, the particle size is regarded as a crucial factor. The produced biosorbents possess the relatively lower particle size, which wastewater needs to take a long period to pass the column.

\section{Application of biosorption technology to real samples}

To explore the feasibility of the application in realistic wastewater, it is necessary to examine the adsorption efficiency of the leaf-based biosorbent in a real-life scenario. For example, Ruiyi et al. (2016) applied $\mathrm{NaOH}$-treated biosorbent derived from fallen persimmon leaves to treat industrial wastewater from the GEM High-Tech Co., Ltd., China. The results indicated that the treated biosorbent can effectively remove approximately $96 \% \mathrm{Zn}(\mathrm{II}), 88 \% \mathrm{Ni}(\mathrm{II})$, and $82 \% \mathrm{~Pb}$ (II) from industrial wastewater. Similarly, Tewari (2013) reported that approximately $99 \% \mathrm{Cr}(\mathrm{VI}), 95 \% \mathrm{Cu}(\mathrm{II})$, and $93 \% \mathrm{Zn}(\mathrm{II})$ were removed from brass and electroplating industry effluent by pine leaves. Meanwhile, diethylenetriamine functionalized sago palm leaves were applied to remove uranium from nuclear industry wastewater at different U(VI) concentrations. The removal efficiency decreased in the following order: 87.7\% (at $\left.C_{\mathrm{o}}=200 \mu \mathrm{g} / \mathrm{L}\right)>84.3 \%$ (at $\left.10 \mu \mathrm{g} / \mathrm{L}\right)>82.8 \%($ at $5 \mu \mathrm{g} / \mathrm{L})(\underline{\text { Xiao et }}$ al., 2016). For the removal efficiency of various potentially toxic metals from different wastewater samples, refer to Table 4. It can be found in Table 4 that removal efficiencies of contaminants are highly affected by the initial concentration, solid/liquid ratio and solution $\mathrm{pH}$.

Table 4. Removal efficiency (R\%) of toxic metal by leaf-based biosorbents at different real water samples

\begin{tabular}{llllllll}
\hline & Chemical & & $\mathrm{Co}_{0}$ & $\mathrm{~m} / \mathrm{V}$ & & \\
Site Leaves & & Adsorbate & & pH & R\% & Ref. \\
& & & $(\mathrm{mg} / \mathrm{L})$ & $(\mathrm{g} / \mathrm{L})$ & & & \\
\hline
\end{tabular}




\begin{tabular}{|c|c|c|c|c|c|c|c|c|}
\hline 1. & Poplar & - & $\mathrm{Pb}(\mathrm{II})$ & 0.17 & - & - & 99.8 & (1) \\
\hline 2. & Poplar & - & $\mathrm{Cd}(\mathrm{II})$ & 1.65 & - & - & 95.0 & (1) \\
\hline 3. & potato & $\mathrm{NaOH}$ & $\mathrm{Cu}(\mathrm{II})$ & 15.5 & 50 & 5.2 & 95.8 & (2) \\
\hline 4. & Persimmon & $\mathrm{NaOH}$ & $\mathrm{Pb}(\mathrm{II})$ & 4.73 & 10 & 5.0 & 81.6 & (3) \\
\hline 4. & Persimmon & $\mathrm{NaOH}$ & $\mathrm{Zn}(\mathrm{II})$ & 16.6 & 10 & 5.0 & 95.9 & (3) \\
\hline 4. & Persimmon & $\mathrm{NaOH}$ & $\mathrm{Ni}(\mathrm{II})$ & 8.23 & 10 & 5.0 & 87.9 & (3) \\
\hline 5. & Chinaberry & $\mathrm{NaOH}+\mathrm{HCl}$ & $\mathrm{Pb}(\mathrm{II})$ & 5.86 & - & - & 75.1 & (4) \\
\hline 6. & Taro & - & $\mathrm{Pb}(\mathrm{II})$ & 10 & 1 & 6.0 & 99.8 & (5) \\
\hline 7. & Waste tea & Formaldehyde & $\mathrm{Ni}(\mathrm{II})$ & 0.5 & 25 & 7.0 & 99.8 & (6) \\
\hline 8. & Waste tea & Formaldehyde & $\mathrm{Ni}(\mathrm{II})$ & 0.5 & 25 & 7.0 & 99.7 & (6) \\
\hline 9. & Waste tea & Formaldehyde & $\mathrm{Ni}(\mathrm{II})$ & 0.5 & 25 & 7.0 & 99.8 & (6) \\
\hline 10. & Gum arabic & - & $\mathrm{Cr}(\mathrm{VI})$ & - & - & $\begin{array}{r}2.0- \\
8.0\end{array}$ & 65.0 & (7) \\
\hline 11. & Bael & - & $\mathrm{Pb}(\mathrm{II})$ & 55.4 & 1 & 6.2 & 88.1 & (8) \\
\hline 12. & Pine & - & $\mathrm{Cr}(\mathrm{VI})$ & 2.74 & 40 & 4 & 99.8 & (9) \\
\hline 12. & Pine & - & $\mathrm{Cu}(\mathrm{II})$ & 4.55 & 40 & 4 & 94.5 & (9) \\
\hline 12. & Pine & - & $\mathrm{Zn}(\mathrm{II})$ & 5.53 & 40 & 4 & 93.1 & (9) \\
\hline 13. & Sotetsu & DETA & $\mathrm{U}(\mathrm{VI})$ & 0.2 & 0.2 & - & 87.7 & (10) \\
\hline
\end{tabular}

Sites: ${ }^{1} \mathrm{~Pb}$-battery factory disposal site; ${ }^{2}$ Disposal sites of Phosphogypsum piles; ${ }^{3}$ Copper plating effluent; ${ }^{4}$ Industrial wastewater from GEM high-tech Co. Ltd., China; ${ }^{5}$ Industrial sample; ${ }^{6}$ River water; ${ }^{7}$ Tap water; ${ }^{8}$ River Badabaira, Peshawar; ${ }^{9}$ River Swat, Charsadda; ${ }^{10}$ Real industrial wastewater collected from a metal finishing industry in Tirupur near to Coimbatore; ${ }^{11}$ Battery waste effluent; 
${ }^{12}$ Industrial effluent obtained from brass and electroplating industry; and ${ }^{13}$ Nuclear industry wastewater. DETA means diethylenetriamine.

Reference: (1) (Al-Masri et al., 2010), (2) (Mambo et al., 2016), (3) (uiyi et al., 2016), (4)

(Khokhar et al., 2015), (5) (aha et al., 2017), (6) (Shah et al., 2015), (7) (Prasad and

Thirumalisamy, 2013), (8) (Chakravarty et al., 2010), (9) (Tewari, 2013), (10) (Xiao et al., 2016).

Interestingly, Prasad and Thirumalisamy (2013) applied gum arabic leaves to remove hazardous $\mathrm{Cr}(\mathrm{VI})$ from industrial and synthetic wastewater. They found that the removal process is independent of the $\mathrm{pH}_{\text {solution }}$ ranging from 2.0 to 8.0. However, their finding is dissimilar to that of Chakravarty et al. (2010) for the removal of $\mathrm{Pb}(\mathrm{II})$ ions from battery waste effluent using bael leaves.

\section{Concerns}

Similar to other lignocellulose materials-derived biomass, the leaf-based biosorbent can release solute organic compounds (i.e., lignin, pectin, and tannin) during the adsorption process, which results in a high chemical oxygen demand (COD) of the water. This organics release may lead to a second form of pollution, which can turn the color of treated water into light yellow or brown. For example, Çekim et al. (2015) reported that, although pristine tobacco leaf-derived biosorbent exhibits an excellent adsorption capacity to $\mathrm{Cu}(\mathrm{II})$ with its high removal efficiency $(90.7 \%)$, it results in organic-originated pollution of the biosorption system. They reported that the COD levels in water after adsorption varied between $208-235 \mathrm{mg} / \mathrm{L}$ at varying temperatures.

However, many researchers found that the leaching problem of organic solutes can be overcome if the biosorbent is pretreated. For example, Ngah and Hanafiah (2009) reported that formaldehyde rubber leaves can minimize the COD concentration in treated water. The results showed that the COD level rose from 7 to $37 \mathrm{mg} / \mathrm{L}$ when the solid/liquid ratio rose from 2 to $10 \mathrm{~g} / \mathrm{L}$, respectively. Similarly, Šćiban et al. (2006) reported that the leaching of organic matter during Zn(II) biosorption from modified wood sawdust-derived biosorbent is significantly lower than that of pristine wood sawdust. The COD level exhibited the following order: pristine fir sawdust (82 $\mathrm{mg} / \mathrm{L}$ ) 
$>\mathrm{NaOH}$-treated fir sawdust $(63 \mathrm{mg} / \mathrm{L})$ and pristine poplar sawdust $(31.5 \mathrm{mg} / \mathrm{L})>\mathrm{NaOH}$-treated poplar sawdust $(29 \mathrm{mg} / \mathrm{L})$.

Another problem is the disposal of metal ion-adsorbed adsorbent that can create another serious environmental issue because acid rain can wash out adsorbed metal ions of the adsorbent surface into the environment (Cay et al., 2004). A number of investigators have studied the desorption of heavy metal ions from the biosorbents (see Section 3.6). When the metal ions release from the ionadsorbed adsorbent through the extraction process, the adsorbents can be used repeatedly. The extractive solution needs to be treated or recycled according to the characteristics of the solution. The metal-load adsorbents might be regarded as hazardous waste if the adsorbent cannot be used continuously. The safe disposal of hazardous waste needs to be evaluated carefully. For example, Nag et al. (2016) were interested in the safe disposal of $\mathrm{Cr}(\mathrm{VI})$-loaded rubber leaf powder. The laden leaves were first incinerated at $700{ }^{\circ} \mathrm{C}$ and then mixed in deionized water. Surprisingly, they reported that $\mathrm{Cr}(\mathrm{VI})$ was not found in the ash sample; therefore, the ash can be disposed in a landfill. This mistake might result from their analysis method of chromium (VI) ions that is the colorimetric method.

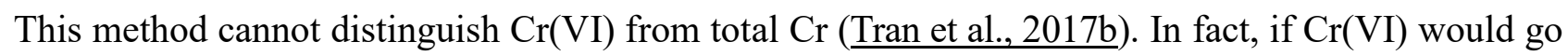
into the air during incineration, it would be serious problem. The question is whether the reduction mechanism plays a primary role in removing $\mathrm{Cr}(\mathrm{VI})$ from the aqueous phase (see Section 7.5). This means that most $\mathrm{Cr}(\mathrm{VI})$ anions are reduced to $\mathrm{Cr}(\mathrm{III})$ cations into solution without adsorbing onto the surface of the biosorbent. Furthermore, Ruiyi et al. (2016) observed the thermogravimetry (TG) and differential thermogravimetry (DTG) curves of $\mathrm{NaOH}$-treated persimmon leaves before and after adsorption of $\mathrm{Pb}(\mathrm{II})$. They concluded that the ash contains abundant $\mathrm{Pb}(\mathrm{II})$ metals after incineration, which can be recycled as secondary lead resource or disposed of properly. A similar outcome was reported by Saha et al. (2017).

It is essential to separate the contaminants before disposing the exhausted adsorbents. At their end of life, the exhausted leaf biosorbents can be regenerated, dried, and burned. Although the final products can be disposed in landfills, some researchers have suggested exploiting them in preferable 
ways, like in the preparation of hybrid inorganic-organic composites. The prepared composites are often used for padding in the stone blocks (Visa, 2012) and incorporating in brick, cement, and road construction (De Gisi et al., 2016). As mentioned in Section 3.6, various reagents and chemicals can be used for desorption of contaminants and their separation from the exhausted biosorbents.

Overall, from real-life application point of view, the usage of untreated leaves has an obvious drawback related to considerable amounts of potentially hazardous contaminants leached into the environment and increase of COD levels of the treated water bodies. In this regard, the pretreatment of leaves with some certain chemical regents can serve as a superior option to lessen the leaching problems. On the other hand, although by-product leaves are promising alternatives that can be potentially utilized in full-scale plants, almost all of the reported studies are referred to using the biosorbents for the removal of various contaminants from synthetic solutions in lab-scale systems. Also, the studies related to regeneration of adsorbents and, specially, safe disposal or using the exhausted biosorbents for other purposes are not very high. To overcome the practical limitations in using by-product leaves as an alternative to commercial activated carbon, in the future studies, more focus should be placed on finding suitable low-cost strategies for eliminating of leaching contaminants from the leave bodies. Further studies should also focus on the biosorbent performances with real water and wastewater samples. Regeneration and reuse of the adsorbents for several adsorption-desorption cycles, and environmentally safe disposal of the biosorbents should be looked at.

\section{Adsorption mechanism}

As previously discussed, the adsorption capacity and mechanism of an adsorbent essentially depend on the adsorbent properties and its adsorbate nature. For example, in adsorption studies of cadmium, Salim et al. (2008) utilized 20 species of plant leaves and concluded that the most efficient types of leaves for cadmium biosorption are that of styrax, walnut, pomegranate, and plum plants. A

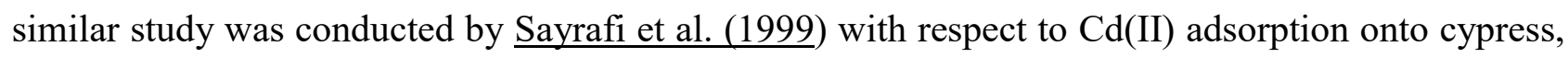


pine, and oak leaves. Whilst these followed important adsorption mechanisms, others have been discussed and reported in the literature.

\subsection{Negligible role of the pore filling}

Generally, the adsorption capacity of the adsorbent is directly proportional to its specific surface area. However, as aforementioned in Section 2.1, leaf-based biosorbent is nonporous material due to its lack of porosity properties (i.e., low surface area and pore volume). Consequently, the contribution of the pore filling mechanism to the adsorption process of contaminants (i.e., potentially toxic cationic and anionic metal ions, cationic and anionic dyes, and others) is less important. In addition, Setiabudi et al. (2016) reported that the $S_{\mathrm{BET}}$ and $V_{\text {total }}$ of oil palm leaves before adsorption $\left(2.6 \mathrm{~m}^{2} / \mathrm{g}\right.$ and $0.0020 \mathrm{~cm}^{3} / \mathrm{g}$, respectively) are similar to those of methylene after blue dye adsorption $\left(2.3 \mathrm{~m}^{2} / \mathrm{g}\right.$ and $0.0008 \mathrm{~cm}^{3} / \mathrm{g}$, respectively). This result further proved the insignificant role of the pore filling. Similarly, Nag et al. (2016) found that the $S_{\mathrm{BET}}$ of rubber leaves slightly decreases after $\mathrm{Cr}(\mathrm{VI})$ adsorption, from 29.2 to $13.1 \mathrm{~m}^{2} / \mathrm{g}$. While studying $\mathrm{Ni}(\mathrm{II}), \mathrm{Zn}(\mathrm{II})$, and $\mathrm{Co}(\mathrm{II})$ adsorption onto industrial waste-derived biosorbent, Ramrakhiani et al. (2017) noted the $S_{\mathrm{BET}}$ values of pristine and laden biosorbents of 23.6 and $18.7 \mathrm{~m}^{2} / \mathrm{g}$, respectively.

Although the leaves are nonporous biosorbents, they exhibit abundant surface functional groups (i.e., carboxylic and amine groups) and high concentrations of light metal ions (i.e., $\mathrm{Ca}, \mathrm{Mg}$, $\mathrm{K}$, and $\mathrm{Na}$ ) on their surface. Such functionalities and inorganic salts will play a decisive role in the adsorption mechanism. This means that the adsorption process will occur on the external surface of the biosorbent, which is visible when subjected to scanning electron microscope (SEM; Figure S13) and atomic force microscopy (AFM; Figure S14) analyses. For example, Khan Rao and Khatoon (2017) compared the AFM data before and after adsorption of $\mathrm{Cu}(\mathrm{II})$ and concluded that the average roughness of Australian pine leaves increases from 8.41 to $18.46 \mathrm{~nm}$ (Figure S14). This outcome confirmed that the biosorption process mainly took place on the leaf surface. An identical result was reported by Deng et al. (2003) for adsorption of $\mathrm{Pb}(\mathrm{II})$ and $\mathrm{Cu}(\mathrm{II})$ onto aminated polyacrylonitrile 
fibers (APANF). The surface roughness of APANF increased from $1.174 \mathrm{~nm}$ to $1.616 \mathrm{~nm}$ and 1.555 $\mathrm{nm}$ after the adsorption of $\mathrm{Pb}(\mathrm{II})$ and $\mathrm{Cu}(\mathrm{II})$ ions, respectively.

\subsection{Identifying electrostatic attraction}

Similar to other adsorbents, leaf-based biosorbents typically coexist with both acidic and basic solutions (amphoteric nature). Hence, the biosorbents can adsorb both cationic and anionic contaminants through electrostatic attraction. Several common experiments have been used to identify the presence of electrostatic attraction such as the effect of the solution $\mathrm{pH}$ (see Section 3.1) and ionic strength (Section 3.2) and desorption studies (Section 3.6).

With respect to the adsorption of potentially toxic metals, electrostatic attraction is known as outer-sphere complexation, while non-electrostatic attraction is known as inner-sphere complexation (Goldberg, 2013). The hydroxyl and carboxylic groups play a predominant role in the adsorption process. The outer-sphere (electrostatic: weakly bonded ions) interaction results from a dipole-ion attraction between the metallic cation and the dipole of the oxygen from the $-\mathrm{OH}$ or $-\mathrm{COOH}$ groups. In contrast, the inner-sphere (surface coordination or surface complexation: strongly bonded ions) interaction is caused by covalent bonding between one pair of electrons of the oxygen (donor) from the $-\mathrm{OH}$ or $-\mathrm{COOH}$ groups and the metallic cation (acceptor) (Davis and Kent, 1990). To identify the existence of electrostatic attraction between tobacco leaves and a toxic metal, Qi and Aldrich (2008) compared the leaves' zeta potential before and after adsorption. They found that the magnitude of the zeta potential value significantly decreased after adsorption, by approximately $40 \%$.

Notably, a new classification of the metal biosorption mechanism has been proposed by

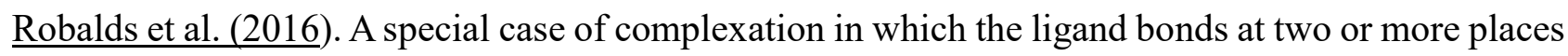
to a metal ion is usually regarded as chelation (chemisorption) (Manahan, 2000). Figure S15 presents several active binding functional groups for adsorption (Volesky, 2007) and the binding mechanism of a metal ion $\left(\mathrm{M}^{2+}\right)$ by oxygen-containing functional groups (Manahan, 2000). For biosorption, the elements of oxygen, nitrogen and sulfur might generate complexation reaction with the metal ions. 


\subsection{Identifying complexation and chelation}

Among the current advanced techniques, FTIR is widely used to identify the main functional groups present on the adsorbent surface. However, with respect to the adsorption of potentially toxic metals, FTIR cannot distinguish between outer- and inner-sphere complexes. In contrast, XPS can help to identify the inner-sphere complexes (complexation) between toxic metal ions and the functional groups on the adsorbent surface.

For example, Ruiyi et al. (2016) applied the XPS technique to investigate the $\mathrm{Pb}(\mathrm{II})$ adsorption mechanism onto $\mathrm{NaOH}$-treated persimmon fallen leaves and suggested that there is an interaction between $\mathrm{Pb}(\mathrm{II})$ in the solution and $\mathrm{O}$ elements in the functional groups of the leaves. This outcome after $\mathrm{Pb}(\mathrm{II})$ adsorption, the peak of $\mathrm{Pb} 4 \mathrm{f}$ at $138.85 \mathrm{eV}$ demonstrated that: firstly, bonding occurred between $\mathrm{Pb}(\mathrm{II})$ ions and the carboxyl group of the biosorbent; and secondly, the peak at $143.65 \mathrm{eV}$ further confirmed the fixation of $\mathrm{Pb}$ onto the biosorbent. The $\mathrm{O} 1 \mathrm{~s}$ peak at $530.70 \mathrm{eV}$ confirmed the presence of $\mathrm{PbO}$ after $\mathrm{Pb}(\mathrm{II})$ adsorption. Therefore, the authors concluded that there is chelation between the carboxylate ligand and hydroxyl group on the biosorbent and $\mathrm{Pb}(\mathrm{II})$ in the solution, forming the $\mathrm{Pb}(\mathrm{II})$ complex.

In their study, Chen and Yang (2006) applied pristine and formaldehyde-modified Sargassum $s p$. biosorbent to remove heavy metals from water media. Based on the XPS data before and after adsorption, they concluded that the $-\mathrm{COO}^{-}$group is the uppermost functional group in the formation of the metal complexes. During the formation of carboxyl-metal complexes, the oxygen atom donated electrons to the metal ions. Therefore, the electron density at the adjacent carbon atom in $\mathrm{C}=\mathrm{O}$ and C-O significantly decreased.

In addition, Ramrakhiani et al. (2017) studied the adsorption process of Ni(II), Co(II), Zn(II), and $\mathrm{Cd}(\mathrm{II})$ onto industrial waste-derived biosorbent. They reported that the deconvolution of $\mathrm{N} 1 \mathrm{~s}$ and C 1s XPS spectra produced two and one additional peaks, respectively, suggesting the formation of amino-metal complexes. The $\mathrm{N}$ atom derived from the $\mathrm{R}-\mathrm{NH}_{2}$ and $\mathrm{R}-\mathrm{NH}_{3}{ }^{+}$groups is mainly in 
nitrogen form and interacts with toxic metal ions. A lone pair of electrons in the $\mathrm{N}$ atom is donated to the covalent bond between nitrogen and metal ions. The formation of amino-metal complexes comprises $\mathrm{R}-\mathrm{NH}_{2} \mathrm{Ni}^{2+}, \mathrm{R}-\mathrm{NH}_{2} \mathrm{Co}^{2+}, \mathrm{R}-\mathrm{NH}_{2} \mathrm{Zn}^{2+}$, and $\mathrm{R}-\mathrm{NH}_{2} \mathrm{Cd}^{2+}$. Correspondingly, the electron cloud density of the $\mathrm{N}$ atom decreases, and a higher binding energy peak is observed. An increase in the atomic concentration of total oxygen and a decrease in the atomic concentration of total carbon on the surface of metal-loaded biosorbent further explain the formation of different metal complexes on the biosorbent surface.

The change of $\mathrm{pH}$ PZC before and after adsorption of potentially toxic metals might confirm that the adsorption process is chemisorption. For example, Rao et al. (2010a) found that the pHPZC of guava leaves $(\mathrm{pH}$ PZC $=6.54)$ increased by 0.74 units after $\mathrm{Cd}(\mathrm{II})$ adsorption $(\mathrm{pH} P \mathrm{PC}=7.01)$. They concluded that the positive shift is indicative of $\mathrm{Cd}(\mathrm{II})$ ion adsorption involved in chemisorption. In another study, they reported that the $\mathrm{pH}_{\mathrm{PZC}}$ value of teak leaves shifted 0.83 units after $\mathrm{Cd}(\mathrm{II})$ adsorption; the $\mathrm{pH}$ PZC of pristine and laden biosorbents was 7.85 and 7.02, respectively (Srinivasa

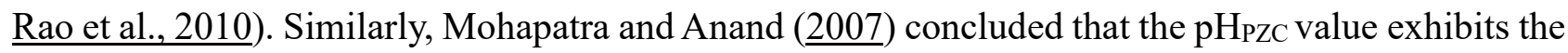
following order: 6.48 (pristine adsorbent) $<7.8$ (Cd-loaded adsorbent). In contrast, Babić et al. (1999) reported that the $\mathrm{pH}$ PZC of activated carbon cloth decreased after toxic metals adsorption from 7.0 to 6.0 (for $\mathrm{Zn}$ adsorption) and to 6.5 (for $\mathrm{Cd}$ adsorption). They explained that the decrease in the $\mathrm{pH}$ PZC of $\mathrm{AC}$ occurs due to the specific adsorption of $\mathrm{Zn}^{2+}$ and $\mathrm{Cd}^{2+}$ ions. However, it should be noted that the term "specific adsorption" is too general.

\subsection{Identifying the ion exchange mechanism}

As previously discussed in Section 2.2, the leaf-based biosorbent contains a high concentration of light metal ions (i.e., $\mathrm{Ca}, \mathrm{Mg}, \mathrm{K}$, and $\mathrm{Na}$ ). Thus, ion exchange is expected to be the primary adsorption mechanism between potentially toxic metals and the biosorbent. Based on the literature, many methods have been applied to identify the presence of ion exchange during the adsorption process. Here, we summarize and analyze several common and useful methods. 
The first method is a comparison between the amount of adsorbed toxic metal ions and the amount of exchanged metal ions. The ion exchange mechanism during adsorption of potentially toxic metals onto adsorbent can be quantitatively investigated by following the release of alkali metal ions $\left(\mathrm{Na}^{+}\right.$and $\left.\mathrm{K}^{+}\right)$, alkaline earth metal ions $\left(\mathrm{Ca}^{2+}\right.$ and $\left.\mathrm{Mg}^{2+}\right)$, and proton binding $\mathrm{H}^{+}$ions from the adsorbent after the adsorption process reached an equilibrium. However, the release of light metal ions from the adsorbent is often divided into two types: "dissolved" and "released" ions (Shin et al., 2007). The light metal ions can be transferred to the solution (control or blank sample only consisting of adsorbent and double-distilled water) by simple dissolution without ion exchange with toxic metals (i.e., $\mathrm{Cd}^{2+}$ ), which is referred to as "dissolved." Meanwhile, the metal ions released in the presence of $\mathrm{Cd}^{2+}$ are called "released." The net release amount of metal ions from the adsorption process ("exchanged") is defined as the difference between the amount of "released" and "dissolved" metals (Figure S3). In addition, the displacement of $\mathrm{H}^{+}$ions (effect of protons in the exchange mechanism) can be determined by the corresponding values of the solution $\mathrm{pH}$ before and after adsorption (Fiol

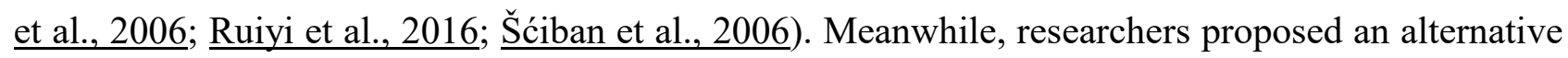
method to calculate the amount of released protons during the adsorption process based on the amount of $\mathrm{NaOH}$ added to maintain the $\mathrm{pH}$ at 5.0 until reaching the adsorption equilibrium (Iqbal et al., 2009; Zolgharnein et al., 2013).

According to the stoichiometric ratio of cations, the release of one divalent ion would be equivalent to releasing two monovalent ions. Therefore, the sum of exchanged cations $[E]$ can be calculated as $\mathrm{Ca}^{2+}+\mathrm{Mg}^{2+}+\mathrm{Na}^{+} / 2+\mathrm{K}^{+} / 2+\mathrm{H}^{+} / 2$. The ion exchange mechanism is given by the $R_{[\mathrm{A}] /[\mathrm{E}]}$ ratio, which has been acknowledged by researchers working in adsorption science and with the relevant technology (Fiol et al., 2006; Hanafiah et al., 2009; Iqbal et al., 2009; Ngah and Hanafiah, 2009; Šćiban et al., 2006; Villaescusa et al., 2004; Zolgharnein et al., 2013; Zolgharnein et al., 2015):

$$
R_{[A] /[E]}=\frac{[A]}{[E]}=\frac{\left[\text { i.e., } C d^{2+}\right]}{\left[\mathrm{Ca}^{2+}\right]+\left[\mathrm{Mg}^{2+}\right]+1 / 2\left[\mathrm{~K}^{+}\right]+1 / 2\left[\mathrm{Na}^{+}\right]+1 / 2\left[\mathrm{H}^{+}\right]}
$$


where the concentration of all cations is commonly expressed as $\mathrm{mmol} / \mathrm{L}$ or $\mathrm{meq} / \mathrm{g}$ and $[\mathrm{A}]$ is the amount of toxic metal ions (i.e., $\mathrm{Cd}^{2+}$ ) adsorbed onto the adsorbent in equilibrium. If the coefficient $R_{[\mathrm{A}] /[\mathrm{E}]}$ is equal to 1 , the adsorption process involves a pure ion exchange mechanism.

For example, Ngah and Hanafiah (2009) investigated the $\mathrm{Cu}(\mathrm{II})$ adsorption onto surfacemodified rubber leaves. They noted that the calculated $R_{[\mathrm{A}] /[\mathrm{E}]}$ ratio is 1.42 . A $R_{[\mathrm{A}] /[\mathrm{E}]}$ value greater than unity corresponds to the amount of $\mathrm{Cu}$ (II) ions adsorbed on the biosorbent; it is greater than the sum of cations released into the solution during the adsorption. This result suggests that ion exchange and complexation primarily involve the removal of copper ions, which is in line with Ngah and Hanafiah's EDS analysis, that is, the peaks corresponding to $\mathrm{Mg}$ and $\mathrm{Ca}$ ions disappeared after copper adsorption. Similarly, Fiol et al. (2006) reported that the $R_{[\mathrm{A}] /[\mathrm{E}]}$ value of the adsorption of $\mathrm{Pb}(\mathrm{II}), \mathrm{Ni}(\mathrm{II}), \mathrm{Cu}(\mathrm{II})$, and $\mathrm{Cd}(\mathrm{II})$ cations onto olive stone waste is $1.7,0.9,1.4$, and 2.3 , respectively. They asserted that another mechanism (surface complexation), in addition to ion exchange, must be involved in the adsorption process of such metals. A comparable result was reported by other scholars (Table 5). Furthermore, for the multi-adsorbate system $\left(\mathrm{Pb}^{2+}, \mathrm{Cd}^{2+}, \mathrm{Ni}^{2+}\right.$, and $\left.\mathrm{Cu}^{2+}\right)$, Abdolali et al. (2016) reported that the total amounts of adsorbed heavy metal ions $(1.43 \mathrm{mmol} / \mathrm{L})$ and exchanged alkali ions $(1.51 \mathrm{mmol} / \mathrm{L})$ were approximately equal. The ion exchange can be regarded as one of primary adsorption mechanisms but being the unique adsorption mechanism.

Table 5. The $\mathrm{R}[\mathrm{A}] /[\mathrm{E}]$ ratio between the net amount of adsorbed toxic metals $[\mathrm{A}]$ and exchanged cations [E]

\begin{tabular}{|c|c|c|c|c|c|c|c|c|c|c|}
\hline \multirow{2}{*}{ Adsorbent } & \multirow{2}{*}{$\begin{array}{l}\text { Toxic } \\
\text { Metal }\end{array}$} & \multicolumn{9}{|c|}{ Concentration of cations (exchanged)* } \\
\hline & & {$[\mathbf{A}]$} & {$[\mathrm{E}]$} & $\mathbf{C a}^{2+}$ & $\mathbf{M g}^{2+}$ & $\mathrm{Na}^{+} / 2$ & $\mathbf{K}^{+} / \mathbf{2}$ & $\mathbf{H}^{+} / \mathbf{2}$ & $\mathbf{R}_{[\mathrm{A}] /[\mathrm{E}]}$ & Ref \\
\hline \multicolumn{11}{|c|}{ Leaves-biosorbent } \\
\hline Treated weed & $\mathrm{Cu}$ & 0.132 & 0.159 & 0.043 & 0.031 & 0.069 & 0.011 & 0.0045 & 0.83 & (1) \\
\hline Treated rubber & $\mathrm{Cu}$ & 0.136 & 0.146 & 0.045 & 0.079 & 0.069 & - & -0.048 & 0.93 & $(2)$ \\
\hline
\end{tabular}




\begin{tabular}{|c|c|c|c|c|c|c|c|c|c|}
\hline Modified rubber & $\mathrm{Cu}$ & 0.103 & 0.073 & 0.011 & 0.004 & 0.017 & - & 0.041 & 1.42 \\
\hline Judas $^{\mathrm{b}}$ & $\mathrm{Ag}$ & 0.093 & 0.029 & - & - & - & - & - & 3.21 \\
\hline Hardy catalpa ${ }^{\mathrm{b}}$ & $\mathrm{Pb}$ & 0.163 & 0.128 & - & - & - & - & - & 1.27 \\
\hline \multicolumn{10}{|c|}{ Other kinds of biosorbent } \\
\hline Juniper bark ${ }^{\mathrm{a}}$ & $\mathrm{Cd}$ & 91.6 & 95.4 & - & - & - & - & - & 1.04 \\
\hline Juniper wood ${ }^{\mathrm{a}}$ & $\mathrm{Cd}$ & 24.8 & 19.5 & - & - & - & - & - & 0.78 \\
\hline Grape stalk & $\mathrm{Cu}$ & 0.234 & 0.247 & 0.131 & 0.031 & - & 0.063 & 0.022 & 0.95 \\
\hline Grape stalk & $\mathrm{Ni}$ & 0.186 & 0.206 & 0.119 & 0.030 & - & 0.049 & 0.008 & 0.90 \\
\hline Oil palm bunche & $\mathrm{Pb}$ & 0.038 & 0.042 & 0.017 & 0.005 & 0.055 & 0.007 & -0.041 & 0.91 \\
\hline Mango peel ${ }^{\mathrm{b}}$ & $\mathrm{Cd}$ & 0.914 & 1.197 & 0.513 & 0.118 & 0.007 & 0.142 & 0.135 & 1.32 \\
\hline Mango peel ${ }^{\mathrm{b}}$ & $\mathrm{Pb}$ & 0.783 & 0.937 & 0.506 & 0.123 & 0.006 & 0.119 & 0.030 & 1.20 \\
\hline Grapefruit peel $^{b}$ & $\mathrm{Ni}$ & 1.331 & 1.166 & 0.718 & 0.293 & 0.020 & 0.049 & 0.085 & 1.14 \\
\hline Grapefruit peel $^{\mathrm{b}}$ & $\mathrm{Zn}$ & 1.512 & 1.285 & 0.749 & 0.323 & 0.018 & 0.051 & 0.145 & 1.18 \\
\hline
\end{tabular}

Note: The unit of ${ }^{\mathrm{a}}(\mu \mathrm{mol} / \mathrm{g})$ and ${ }^{\mathrm{b}}(\mathrm{meq} / \mathrm{g}) ;[\mathrm{A}]$ is total metal adsorbed $(\mathrm{mmol} / \mathrm{L}) ;[\mathrm{E}]$ is total metal exchanged $(\mathrm{mmol} / \mathrm{L})=\left[\mathrm{Ca}^{2+}\right]+\left[\mathrm{Mg}^{2+}\right]+\left[\mathrm{Na}^{+} / 2\right]+\left[\mathrm{K}^{+} / 2\right]+\left[\mathrm{H}^{+} / 2\right] ;$ * concentration of cations $($ exchanged $)=$ concentration of cations (released) - concentration of cations (dissolved).

References: (1) (Hanafiah et al., 2009), (2) (Ngah and Hanafiah, 2008), (3) (Ngah and Hanafiah, 2009), (4) (Zolgharnein et al., 2013b), (5) (Zolgharnein et al., 2015), (6) (Shin et al., 2007), (7) (Shin et al., 2007), (8) (Villaescusa et al., 2004), (9) (Villaescusa et al., 2004), (10) (Ibrahim et al., 2010), (11) (Iqbal et al., 2009), (12) (Iqbal et al., 2009), (13) (Muhammad et al., 2009), (14) (Muhammad et al., 2009).

Another method is the comparison of the Langmuir adsorption capacity of the adsorbent $\left(Q^{\circ}{ }_{\text {max }} ; \mathrm{mmol} / \mathrm{g}\right)$ and target toxic cationic metal with the cation exchange capacity $(\mathrm{CEC} ; \mathrm{mmol} / \mathrm{g})$ of the adsorbent. Because the $\mathrm{CEC}$ of the adsorbent plays a key role in estimating the maximum adsorption capacity of potentially toxic metal onto the adsorbent and primary adsorption mechanism, 
Chao and Chen (2012) defined a parameter $\alpha$ as the ratio of $Q^{\circ}{ }_{\text {max }}$ to CEC. If the adsorption process only involves ion exchange, the $\alpha$ value is unity (Chao and Chang, 2012; Tran and Chao, 2018b). In contrast, the external cation exchange capacity (ECEC) plays a vital role in estimating the maximum adsorption capacity of adsorbent to toxic anionic metal and parameter $\beta$ is defined as the ratio of $Q^{\circ} \max$ to ECEC (Chao and Chen, 2012). Although the CEC and ECEC values of leaf-based biosorbents play a deciding role in estimating the maximum adsorption capacity of potentially toxic metals onto adsorbents and primary adsorption mechanism, these important properties were not reported in the literature. Therefore, we summarized the $\alpha$ and $\beta$ values of other adsorbents with similar ion exchange characteristics such as zeolite and agricultural waste-based biosorbents (Table S16).

Thirdly, many researchers applied the EDS technique (Figure S3b-c) to quantitatively analyze the presence of ion exchange by comparing the EDS spectra of the adsorbent before and after

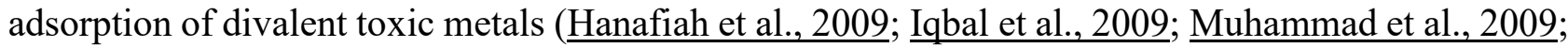

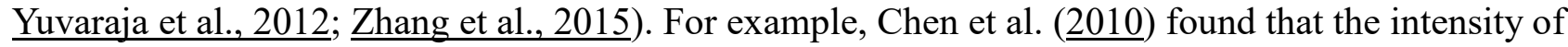
the $\mathrm{Ca}, \mathrm{Na}, \mathrm{K}$, and $\mathrm{S}$ peaks in the EDS spectrum decreased after copper adsorption and copper peaks are visible in the spectrum. They suggested that ion exchange is an integral part of the adsorption process. Similarly, Yuvaraja et al. $(\underline{2012})$ concluded that several light metal cations $\left(\mathrm{Ca}^{2+}, \mathrm{Mg}^{2+}\right.$, and $\mathrm{Na}^{+}$) disappeared from the EDX spectrum of $\mathrm{Cu}(\mathrm{II})$-laden biosorbent, suggesting the involvement of an ion exchange mechanism in the adsorption process.

Similar to the EDS technique, the advanced instrumental analyses of XRF are also used to quantitatively identify ion exchange (Dabbagh et al., 2016; Zahedi et al., 2015). For example, Dabbagh et al. $(\underline{2016})$ concluded that the changed $\mathrm{Mg}^{2+}$ and $\mathrm{Ca}^{2+}$ ions possibly resulted from ion exchange or replacing cobalt ions with such ions. They found that the composition of $\mathrm{CaO}$ and $\mathrm{MgO}$ (42.3\% and $4.9 \%$, respectively) significantly decreased after adsorption $(16.1 \%$ and $0.97 \%$, respectively).

Lastly, some authors used the magnitude of the mean adsorption energy ( $E$; calculated from the Dubinin-Radushkevich equation) to propose whether the adsorption process primarily involved 
ion exchange. More relevant information on such equations has been discussed in our recent work (Tran et al., 2016; Tran et al., 2017b). As acknowledged by many researchers, the adsorption energy of physical adsorption often ranges from 1-8 kJ/mol, while an ion exchange process usually involves a higher adsorption energy $(8-16 \mathrm{~kJ} / \mathrm{mol})$. For example, Hanafiah and Ngah (2009) investigated the $\mathrm{Cu}$ (II) removal process by $\mathrm{HCl}$-treated rubber leaves. Based on the EDS data (no Ca peak detected in the EDS spectrum after adsorption) and $E$ value (12.7-14.4 kJ/mol at different leaf particle sizes), they concluded that the main adsorption mechanism is ion exchange. In addition, Ngah and Hanafiah (2008) proposed that ion exchange is primarily responsible for $\mathrm{Cu}(\mathrm{II})$ biosorption onto $\mathrm{NaOH}$-treated rubber leaves because (1) the $E$ value was $8.8 \mathrm{~kJ} / \mathrm{mol}$ and (2) the ratio of adsorbed cations $\left(\mathrm{Cu}^{2+}\right)$ to cations $\left(\mathrm{H}^{+}, \mathrm{Na}^{+}, \mathrm{Ca}^{2+}\right.$, and $\left.\mathrm{Mg}^{2+}\right)$ released from the leaves was almost unity. Similarly, Chen et al. (2010) pointed out that the $E$ values at different temperatures $(302-332 \mathrm{~K})$ range from 10.0 to 11.6 $\mathrm{kJ} / \mathrm{mol}$. Based on a combination of the analysis of EDS and FTIR data, they also concluded that ion exchange is the primary $\mathrm{Cu}(\mathrm{II})$ biosorption mechanism of camphor leaves. Similar results were

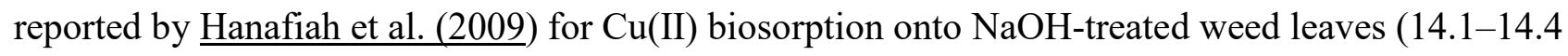
$\mathrm{kJ} / \mathrm{mol}$ at $300-310 \mathrm{~K}$ ); by Brahman et al. (2016) for biosorption of inorganic arsenic species onto rohida leaves [15.8 kJ/mol for As(III) and $12.9 \mathrm{~kJ} / \mathrm{mol}$ for As(V)]; by Hymavathi and Prabhakar (2017) for Co(II) biosorption onto banyan leaves (12.9 kJ/mol); and by Sawalha et al. (2006) for $\operatorname{Cr}(\mathrm{III})$, $\mathrm{Cr}(\mathrm{VI})$, and $\mathrm{Cd}(\mathrm{II})$ adsorption onto saltbush leaves $(10.8,9.5$, and $9.1 \mathrm{~kJ} / \mathrm{mol}$, respectively).

\subsection{Identifying the reduction mechanism}

The reduction mechanism during adsorption mainly involves certain redox active elements such as chromium. This type of mechanism is also known as "adsorption-coupled reduction". Figure 9 shows the potential adsorption mechanisms of $\mathrm{Cr}(\mathrm{VI})$ on the biosorbents presented in the literature. The adsorption-reduction mechanism can be summarized as follows: (1) Cr(VI) anions are electrostatically attracted by the positively charged adsorbent surface (i.e., $-\mathrm{NH}_{3}{ }^{+}$or $-\mathrm{OH}_{2}{ }^{+}$) when $\mathrm{pH}_{\text {solution }}<\mathrm{pH}$ PZC or $\mathrm{pH}_{\mathrm{IEP}}$; and (2) $\mathrm{Cr}(\mathrm{VI})$ anions are directly reduced to $\mathrm{Cr}$ (III) cations when they are in contact with electron donor groups of the adsorbent (i.e., amino and carboxylic groups) under 
strongly acidic conditions. Notably, the converted $\mathrm{Cr}$ (III) cations were neither retained in the functional groups on the adsorbent surface through the complexation of converted $\mathrm{Cr}$ (III) with the adjacent functional groups capable of Cr-binding nor released (desorbed) to the solution due to electrostatic repulsion between the positively charged groups and $\mathrm{Cr}$ (III) cations (Gagrai et al., 2013; Gardea-Torresdey et al., 2000; Mohan and Pittman, 2006; Park et al., 2006;2005; Qi et al., 2016; Zhou et al., 2016).

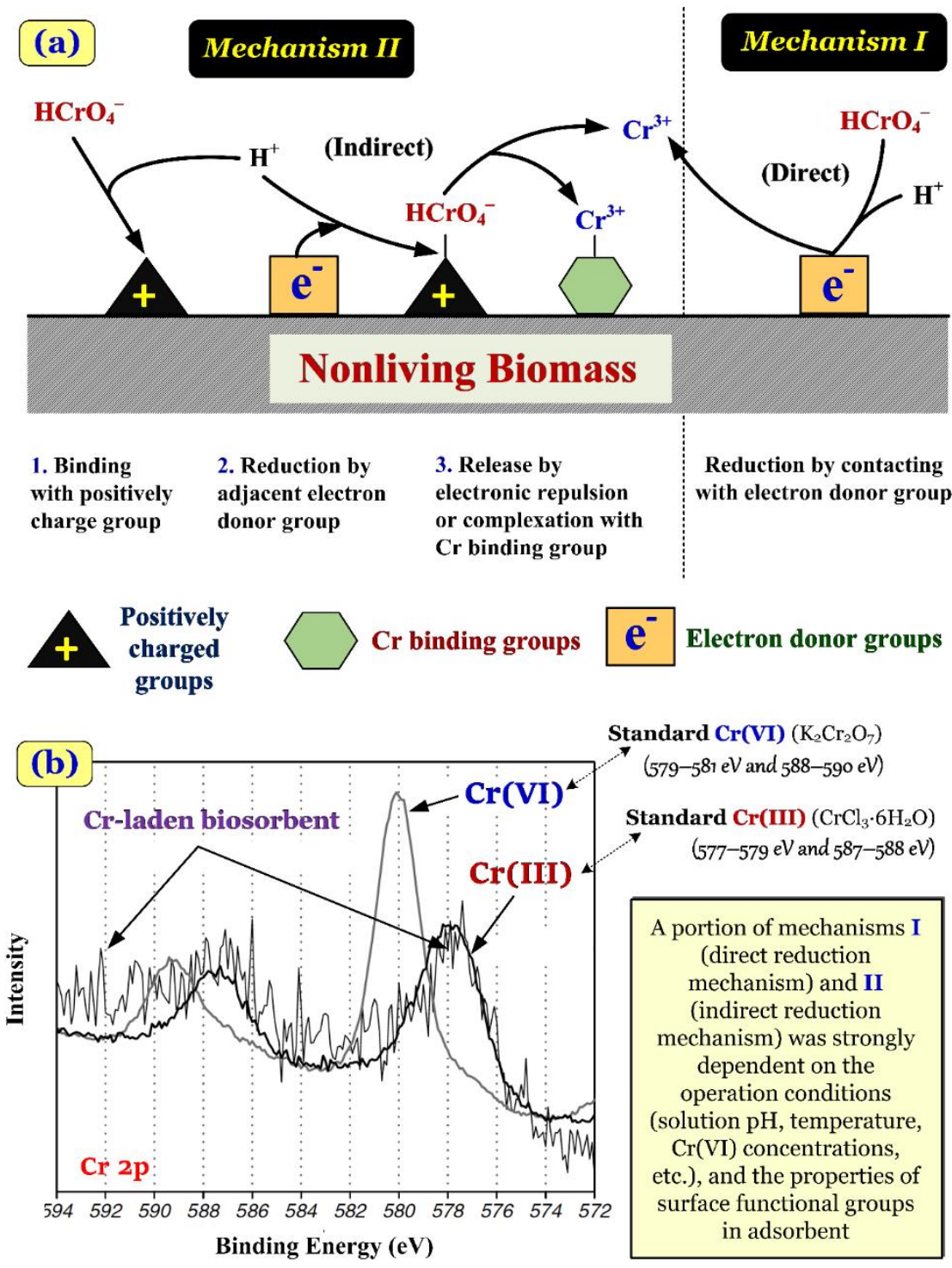

Figure 9. (a) Mechanisms proposed for Cr(VI) biosorption by nonliving biomass (Park et al. 2005) [License number: 4440510789887]; and (b) high-resolution spectra collected from the $\mathrm{Cr} 2 \mathrm{p}$ core regions of the Cr-laden biosorbent derived from Korean red pine tree leaves as well as standard Cr(III) and Cr(VI) chemicals (Park et al., 2011) [License number: 4435931207985] 
In the aqueous phase, $\mathrm{Cr}(\mathrm{III})$ and $\mathrm{Cr}(\mathrm{VI})$ are the prevalent species. Meanwhile, hexavalent $\left(\mathrm{HCrO}_{4}^{-}\right.$and $\left.\mathrm{Cr}_{2} \mathrm{O}_{7}^{2-}\right)$ and trivalent $\left(\mathrm{Cr}^{3+}\right.$ and $\left.\mathrm{CrOH}^{2+}\right)$ chromium species are dominant in industrial wastewater (Park et al., 2005). In addition, Aoyama and Tsuda (2001) reported that the hydrogen chromate ion $\left(\mathrm{HCrO}_{4}^{-}\right)$is the dominant anionic chromium species in the solution when the initial $\mathrm{pH}$ of $\mathrm{K}_{2} \mathrm{Cr}_{2} \mathrm{O}_{7}$ solution ranges from 1.0 to 5.0 [see $\mathrm{Cr}(\mathrm{VI})$ speciation diagram as a function of the $\mathrm{pH}$ in Figure S16]. This is similar to the assumption of other scholars (Abdolali et al., 2014; Aoyama, 2003b; Park et al., 2004;2005; Weng et al., 2006). Previous studies demonstrated that biomass-derived biosorbent can reduce toxic $\mathrm{Cr}(\mathrm{VI})$ to less toxic $\mathrm{Cr}(\mathrm{III})$. Aqueous $\mathrm{Cr}(\mathrm{VI})$ commonly exists as five species: $\mathrm{H}_{2} \mathrm{CrO}_{4}, \mathrm{HCrO}_{4}^{-}, \mathrm{CrO}_{4}{ }^{2-}, \mathrm{Cr}_{2} \mathrm{O}_{7}{ }^{2-}$, and $\mathrm{HCr}_{2} \mathrm{O}_{7}^{-}$(Abdolali et al., 2014; Mukherjee et al., 2016; Park et al., 2004). It has been noted that protons and electrons are consumed during the reduction of $\mathrm{Cr}(\mathrm{VI})$, as presented in Equations 2-5. Therefore, the reduction of $\mathrm{Cr}(\mathrm{VI})$ to Cr(III) occurs in a strongly acidic environment.

$$
\begin{array}{lr}
\mathrm{Cr}_{2} \mathrm{O}_{7}^{2-}+14 \mathrm{H}^{+}+6 e^{-} \leftrightarrow 2 \mathrm{Cr}^{3+}+7 \mathrm{H}_{2} \mathrm{O} & E^{\circ}=+1.33 \mathrm{~V} \\
\mathrm{CrO}_{4}^{2-}+8 \mathrm{H}^{+}+3 e^{-} \leftrightarrow \mathrm{Cr}^{3+}+4 \mathrm{H}_{2} \mathrm{O} & E^{\circ}=+1.48 \mathrm{~V} \\
\mathrm{HCrO}_{4}^{-}+7 \mathrm{H}^{+}+3 e^{-} \leftrightarrow \mathrm{Cr}^{3+}+4 \mathrm{H}_{2} \mathrm{O} & E^{\circ}=+1.35 \mathrm{~V} \\
\mathrm{H}_{2} \mathrm{CrO}_{4}+6 \mathrm{H}^{+}+3 e^{-} \leftrightarrow \mathrm{Cr}^{3+}+4 \mathrm{H}_{2} \mathrm{O} & E^{\circ}=+1.33 \mathrm{~V}
\end{array}
$$

Generally, when $\mathrm{Cr}(\mathrm{VI})$ oxyanions in solution are in contact with organic substances or reducing agents (especially in an acidic medium), the $\mathrm{Cr}(\mathrm{VI})$ species are easily reduced to $\mathrm{Cr}$ (III) species because of the redox reaction (Á (oxidation/reduction) potential (often higher than $+1.3 \mathrm{~V}$ ) under standard conditions (Park et al., 2005). As reported in the literature, when $\mathrm{Cr}(\mathrm{VI})$ oxyanions are in contact with electron donor groups of the biosorbent (i.e., amino and carboxylic groups), $\mathrm{Cr}$ (VI) spontaneously reduces to $\mathrm{Cr}$ (III). The electron-donor groups must have a reduction potential lower than $1.3 \mathrm{~V}$. This mechanism is called direct reduction (Figure 9a).

Interestingly, the $\mathrm{Cr}(\mathrm{IV})$ concentration is often determined with the colorimetric method. The 
pink-colored complex, which was formed from 1,5-diphenylcarbazide and chromium ions in an acidified solution, can be spectrophotometrically analyzed at $540 \mathrm{~nm}$. Meanwhile, the total $\mathrm{Cr}$ concentration can be determined as follows: $\mathrm{Cr}(\mathrm{III})$ is converted to $\mathrm{Cr}(\mathrm{VI})$ at high temperature (130 $-140{ }^{\circ} \mathrm{C}$ ) and an oxidation treatment with $\mathrm{KMnO}_{4}$ is performed before the 1,5-diphenylcarbazide reaction. The $\mathrm{Cr}(\mathrm{III})$ concentration can be calculated from the difference between the total $\mathrm{Cr}$ and Cr(VI) concentrations (Park et al., 2008; $\underline{\text { Singh et al., 2009). }}$.

Generally, some organic carbons of the adsorbent are completely oxidized into inorganic carbon (i.e., $\mathrm{HCO}_{3}{ }^{-}$and $\mathrm{CO}_{2}$ ) during $\mathrm{Cr}(\mathrm{IV})$ reduction. The reduction rate of $\mathrm{Cr}(\mathrm{VI})$ to $\mathrm{Cr}(\mathrm{III})$ strongly depends on the $\mathrm{pH}_{\text {solution. }}$ The reduction rate of $\mathrm{Cr}(\mathrm{VI})$ decreases with increasing $\mathrm{pH}_{\text {solution }}$ because the proton consumption decreases during $\mathrm{Cr}(\mathrm{VI})$ reduction (Table S17). For example, Aoyama et al. (1999) found that approximately $33 \% \mathrm{Cr}(\mathrm{VI})$ are reduced to $\mathrm{Cr}(\mathrm{III})$ at $\mathrm{pH} 2.0$ during the adsorption process by coniferous leaves because of increased proton consumption in the acidic solution. However, the reduction rate of $\mathrm{Cr}(\mathrm{VI})$ seems negligible when the $\mathrm{pH}_{\text {solution }}$ is higher than 3.0, which agrees with the findings of other studies (Abdolali et al., 2014; Aoyama, 2003a; Aoyama and Tsuda, 2001). Notably, Abdolali et al. (2014) concluded that a reduction of $\mathrm{Cr}(\mathrm{VI})$ to $\mathrm{Cr}(\mathrm{III})$ did not occur in the absence of the biosorbent.

Furthermore, XPS, X-ray absorption spectroscopy (XAS), and extended X-ray absorption fine structure (EXAFS) analysis are three useful advanced techniques to ascertain the oxidation state of the chromium bound on the biomass-derived adsorbent. For example, Gardea-Torresdey et al. (2000) studied the $\mathrm{Cr}(\mathrm{VI})$ binding and reduction to $\mathrm{Cr}$ (III) by oat biomass (containing different ligands). Their XAS analysis indicated that the biomass catalyzes the reduction of the much more toxic (VI) state of chromium to the less toxic (III) state. The EXAFS study indicated that the reduced $\mathrm{Cr}$ (III) is bound to the oxygen-containing functional group (possibly carboxyl groups) on the biomass surface. Meanwhile, based on the XPS data, Zhou et al. (2016) concluded that the binding energies at 577.2 and $579.2 \mathrm{eV}$ (in the $\mathrm{Cr} 2 \mathrm{p}_{3 / 2}$ orbitals) correspond to $\mathrm{Cr}$ (III) and $\mathrm{Cr}(\mathrm{VI})$ after $\mathrm{Cr}(\mathrm{VI})$ adsorption. The results indicated that the $\mathrm{Cr}(\mathrm{III})$ and $\mathrm{Cr}(\mathrm{VI})$ ions coexist on the surface of the adsorbent, with the 
former and the latter accounting for $93.33 \%$ and $6.67 \%$, respectively. This result agrees with that of other investigators (Dambies et al., 2001; Park et al., 2011; Qi et al., 2016). Notably, the Cr 2p3/2 and $\mathrm{Cr} 2 \mathrm{p} 1 / 2$ binding energies of $\mathrm{Cr}(\mathrm{VI})$ and $\mathrm{Cr}(\mathrm{III})$ chemicals were thoroughly reviewed by (Tran (2019) to avoid the undesirable mistakes and the propagation of incorrect information in the scientific literature.

Notably, Park et al. (2007) applied sixteen natural biomaterials (i.e., pine needle, pine cone, rice husk, pine bark, sawdust, fungal biomass of Rhizopus, walnut shell, green tea waste, peanut shell, banana skin, orange peel, oak leaf, rice straw, seaweed biomasses of Sargassum, Ecklonia, and Enteromorpha) to thoroughly investigate the adsorption-coupled reduction mechanism of $\mathrm{Cr}(\mathrm{VI})$ removal from aqueous solution. Based on the XPS data before and after adsorption, they concluded that the spectra of the Cr-adsorbed biomaterials are consistent with that of the standard $\mathrm{Cr}$ (III) compound $\left(\mathrm{CrCl}_{3} \bullet 6 \mathrm{H}_{2} \mathrm{O}\right)$. This suggests that the chromium bound to the surface of the selected sixteen biosorbents was mainly or totally in $\mathrm{Cr}$ (III) form. Therefore, the evidence indicates that the removal mechanism of $\mathrm{Cr}(\mathrm{VI})$ by natural biosorbents is an adsorption-coupled reduction.

Similarly, Park et al. (2011) applied the emerging XPS technique to propose the adsorptioncoupled reduction mechanism for the removal of $\mathrm{Cr}(\mathrm{VI})$ or total $\mathrm{Cr}$ by the leaves of Pinus densiflora. They compared the XPS spectrum of Cr-loaded biosorbents and standard Cr(III) compounds $\left(\mathrm{CrCl}_{3} \bullet 6 \mathrm{H}_{2} \mathrm{O}\right)$ and standard $\mathrm{Cr}(\mathrm{VI})$ compounds $\left(\mathrm{K}_{2} \mathrm{Cr}_{2} \mathrm{O}_{7}\right)$ in the $\mathrm{Cr} 2 \mathrm{p}$ core regions. The direct comparison demonstrated that the spectrum of the Cr-loaded biosorbent matches that of the standard Cr(III) compound (Figure 9b). An analogous conclusion was proposed by Qi et al. (2016).

\subsection{Identification of functional groups relevant for the adsorption mechanism}

Similar to lignocellulose-derived biosorbent, leaf-based biosorbents exhibit abundant functional groups on their surface, which have been regarded as active groups important for the adsorption of various adsorbates (i.e., potentially toxic metals and dyes). However, the functional 
properties of each biosorbent are unique and the functionality, which is part of the adsorption process, is generally dissimilar. Compared with the XPS technique, the FTIR technique is widely used for the identification of the main functional groups of certain adsorbents. The main functionality corresponding to the adsorption process can be identified by comparing the FTIR spectra of pristine and laden adsorbents.

\subsubsection{Adsorption of potentially toxic metals, fluoride, uranium, and ammonium}

The potential adsorption mechanisms between toxic metals and biosorbents are illustrated in Figure 10. The electrostatic attraction, complexation and ion exchange were regarded as the main adsorption mechanisms. These mechanisms highly correlated with the functional groups and element composites on the surface of biosorbents.

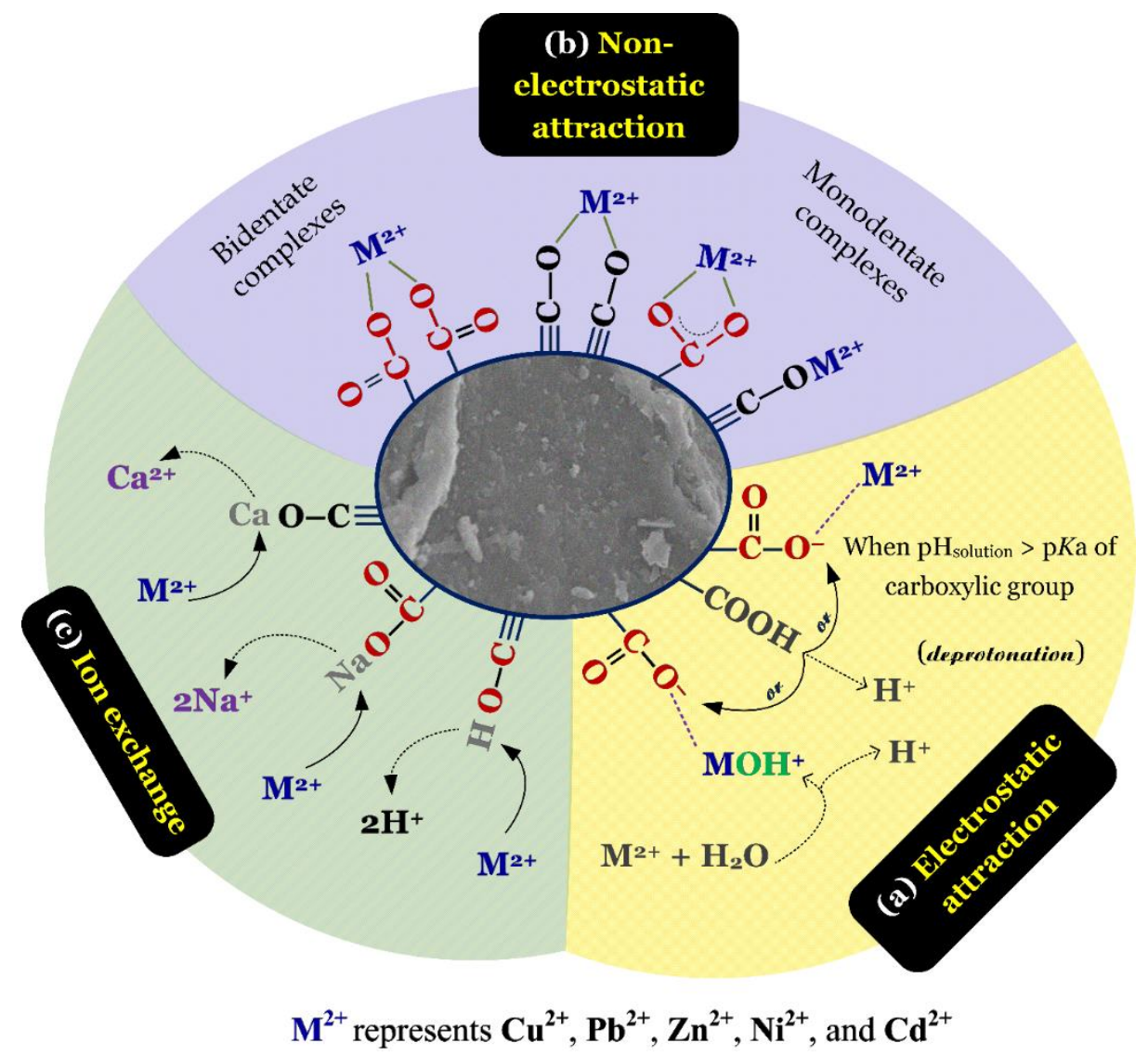

Figure 10. The potential adsorption mechanisms between toxic metals and biosorbents (Tran and Chao, 2018a) [License number: 4525340872276]

Because of the length limitation required by the journal, more information on adsorption of 
potentially toxic metals, fluoride, uranium, and ammonium is summarized in Section S7. For example, Rao and Khan (2017) compared the FTIR spectrum of Boston fern leaves before and after $\mathrm{Cu}(\mathrm{II})$ adsorption, concluding that the peak shifts from 3391 to $3397 \mathrm{~cm}^{-1}(-\mathrm{OH}), 1244$ to $1246 \mathrm{~cm}^{-1}(\mathrm{C}=\mathrm{O})$, and 534 to $537 \mathrm{~cm}^{-1}(\mathrm{C}-\mathrm{H})$ are due to the binding of $\mathrm{Cu}(\mathrm{II})$ ions with carboxyl and hydroxyl groups. Similarly, some authors proposed that the hydroxyl, carbonyl, and carboxyl groups greatly contribute to binding $\mathrm{Cu}(\mathrm{II})$ ions onto grey nicker leaves (Yuvaraja et al., 2012), $\mathrm{Cr}(\mathrm{VI})$ onto mango leaves ( $\underline{\text { Saha }}$ and Saha, 2014), $\mathrm{Cd}(\mathrm{II})$ and $\mathrm{Pb}(\mathrm{II})$ onto mango peel (Iqbal et al., 2009), $\mathrm{Ni}(\mathrm{II})$ and $\mathrm{Zn}(\mathrm{II})$ onto grapefruit peel (Muhammad et al., 2009), and Cd(II) onto guava leaves (․ㅡo et al., 2010a) and teak leaves ( $\underline{\text { Srinivasa Rao et al., 2010)}}$.

A comprehensive study on the application of FTIR and electron paramagnetic resonance (EPR) to identify the main functional groups participating in $\mathrm{Cu}(\mathrm{II})$ biosorption onto dried leaves was

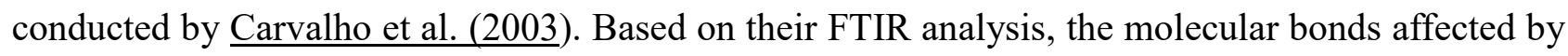
the existence of the copper ions are $\mathrm{C}=\mathrm{C}, \mathrm{C}-\mathrm{H}$, and $\mathrm{O}-\mathrm{H}$ bonds; these are all present in the carbon rings of the biosorbent. The EPR analysis indicated that $\mathrm{Cu}(\mathrm{II})$ ions are incorporated into the biosorbent, at sites with strong axial symmetry (Figure S17).

\subsubsection{Dye adsorption}

Figure 11 indicates the typical interactions contributing to the adsorption of cationic methylene green 5 dye onto biosorbent. Similarly, the functional groups can determine the adsorption capacities of dyes on the biosorbent. Dissimilar to the adsorption of potentially toxic metals, the adsorption mechanism of organic compounds onto the adsorbent can be determined by comparing the FTIR spectra of the adsorbent before and after adsorption. For example, Tran et al. (2017c) studied the adsorption mechanism of cationic methylene green 5 onto various biosorbents. Based on adsorption (effect of $\mathrm{pH}, \mathrm{NaCl}$ salt, temperature, and initial dye concentration) and desorption studies and FTIR analysis, they proposed that the primary involved adsorption mechanisms are electrostatic attraction, dipole-dipole and Yoshida hydrogen bonding formations, and $n-\pi$ interaction. Their FTIR spectra verified that the $-\mathrm{OH}, \mathrm{C}=\mathrm{O}$, and $\mathrm{C}-\mathrm{O}$ peaks shift and decrease in intensity after dye adsorption. 
(c) Yoshida H-bonding interaction

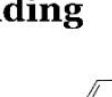

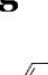

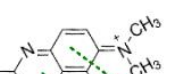
(a)

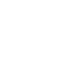

-

(b) Dipole-dipole H-bonding interaction

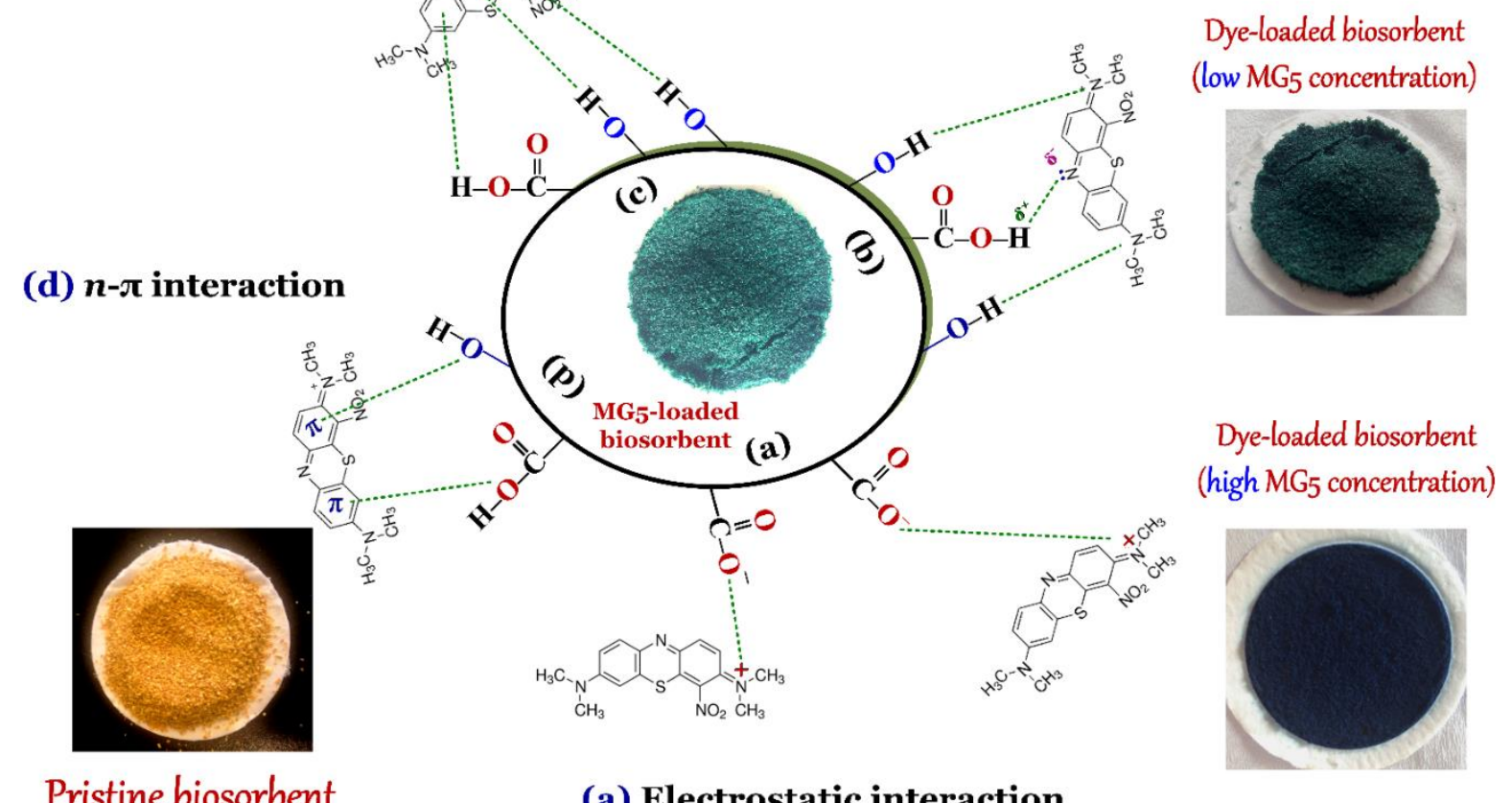

(a) Electrostatic interaction

Figure 11. Typical interactions contributing to the adsorption of cationic methylene green 5 dye onto biosorbent (Tran et al., 2017c) License number: 4435940108341]

Based on FTIR spectral analysis, Saha et al. (2012) suggested the major role of the $\mathrm{C}=\mathrm{O}, \mathrm{O}-$ $\mathrm{H}$, and $\mathrm{C}-\mathrm{O}$ groups in the biosorption of crystal violet dye onto jackfruit leaves. Similarly, Setiabudi et al. $(\underline{2016})$ concluded that the $\mathrm{C}=\mathrm{O}, \mathrm{C}-\mathrm{O}, \mathrm{O}-\mathrm{H}$, and $\mathrm{C}-\mathrm{H}$ groups play a vital role in removing cationic methylene blue using oil palm leaves. Its performance has been documented by other scholars (Han et al., 2011; Han et al., 2014; Jain and Gogate, 2017c; Lafi et al., 2015; Lim et al., 2016; Tamez Uddin et al., 2009; Zhu et al., 2016).

\section{Conclusions}

Based on the viewpoints discussed in the literature and this study, it can be concluded that:

- The leaves by-products can be made ready for sorption usages by several consecutive simple steps, i.e., thoroughly washing of raw material with water, drying under controlled temperature and time, grounding the material to attain a specific particle size and, if needed, pre-treating of 
the material for lessening the leaching problems.

- Leaf-based biosorbents are nonporous materials with average $S_{\mathrm{BET}}$ and $V_{\text {total }}$ values of $9.9 \pm 13.4 \mathrm{~m}^{2} / \mathrm{g}(n=60)$ and $0.019 \pm 0.027 \mathrm{~cm}^{3} / \mathrm{g}(n=25)$, respectively. Therefore, the pore filling mechanism was ruled out in the adsorption study of contaminants.

- Depending on the unique surface chemistry properties of the biosorbent, the adsorption affinity and mechanism of each biosorbent are dissimilar. Among the existing functional groups on the biosorbent surface, the carboxylic group $(-\mathrm{COOH})$ plays a more important role in interacting with various contaminants than the amino $\left(-\mathrm{NH}_{2}\right)$, sulfhydryl $(-\mathrm{SH})$, and phenolic $(-\mathrm{OH})$ groups.

- Leaf-based biosorbents (pristine and modified/treated) have been used as promising adsorbents to remove potentially toxic cationic metal and oxyanionic metal ions, organic cationic and anionic dyes, radioactive metal ions, rare earth elements, phosphate, ammonium, and fluoride.

- The adsorption process rapidly reaches an equilibrium (approximately 60-180 min for almost all contaminants). The optimal $\mathrm{pH}$ value strongly depends on the target adsorbate; acidic conditions are favorable for anionic adsorbate biosorption, while neutral or alkaline conditions are favorable for cationic adsorbate biosorption. The presence of specific salts (i.e., $\mathrm{NaCl}$ and $\mathrm{NaNO}_{3}$ ) causes a significant decrease in the adsorption capacity of the biosorbent to most adsorbates.

- The characteristic thermodynamic parameters for the biosorption process using pristine and modified leaves are $\Delta G<0(96 \%, n=46 / 48), \Delta H>0(83 \%, n=40 / 48)$, and $\Delta S>0(88 \%, n=$ $42 / 48)$ for toxic metal ions and $\Delta G<0(84 \%, n=38 / 45), \Delta H>0(55 \%, n=25 / 45)$, and $\Delta S>0$ $(53 \%, n=24 / 45)$ for organic dyes.

- Among toxic metals, copper is adsorbed most by the biosorbent in both single and multicomponent adsorption studies. 
- Desorption studies indicate that the adsorption process of contaminants onto the biosorbent is normally reversible when the primary adsorption mechanism is electrostatic attraction and/or ion exchange.

- The removal efficiency of potentially toxic metals from the water samples collected from different industrial effluents by leaves ranges from $65 \%$ to $99.8 \%$, depending on the operation conditions.

- Electrostatic attraction plays an important role in the adsorption of most adsorbates. Ion exchange mainly involves the adsorption process of potentially toxic cationic metals and ammonium. The adsorption mechanism of $\mathrm{Cr}(\mathrm{VI})$ is regarded to be adsorption-coupled reduction. Meanwhile, the hydrogen bond formation and $n-\pi$ interaction are primarily responsible for the adsorption of most organic dyes.

Nontoxic leaf-derived biosorbents are promising dual-electronic adsorbents for the removal of various anionic and cationic adsorbates from water media. However, in order to take advantages of these sorbents in real treatment plants, future studies should address the limitations which confront their full-scale usages. For example, such studies should consider the strategies by which the leaching of organic chemicals can be satisfactorily lessened, the reusability of biosorbents after regeneration via suitable cheap manners, and their performances towards real waters and wastewaters, as well as exploring adequate safe methods for their end-of-life disposal or exploiting the possibility of using the exhausted sorbents for other purposes.

\section{References}

Abdel-Ghani, N.T., Hegazy, A.K. and El-Chaghaby, G.A., 2009. Typha domingensis leaf powder for decontamination of aluminium, iron, zinc and lead: Biosorption kinetics and equilibrium modeling. International Journal of Environmental Science \& Technology, 6, 243-248.

Abdolali, A., Guo, W.S., Ngo, H.H., Chen, S.S., Nguyen, N.C. and Tung, K.L., 2014. Typical lignocellulosic wastes and by-products for biosorption process in water and wastewater 
treatment: A critical review. Bioresource Technology, 160, 57-66.

Abdolali, A., Ngo, H.H., Guo, W., Lu, S., Chen, S.-S., Nguyen, N.C., Zhang, X., Wang, J. and Wu, Y., 2016. A breakthrough biosorbent in removing heavy metals: Equilibrium, kinetic, thermodynamic and mechanism analyses in a lab-scale study. Science of The Total Environment, 542, 603-611.

Abedi, S., Zavvar Mousavi, H. and Asghari, A., 2016. Investigation of heavy metal ions adsorption by magnetically modified aloe vera leaves ash based on equilibrium, kinetic and thermodynamic studies. Desalination and Water Treatment, 57, 13747-13759.

Agarry, S.E., Ogunleye, O.O. and Aworanti, O.A., 2013. Biosorption equilibrium, kinetic and thermodynamic modelling of naphthalene removal from aqueous solution onto modified spent tea leaves. Environmental Technology, 34, 825-839.

Ahmad, A., Ghazi, Z.A., Saeed, M., Ilyas, M., Ahmad, R., Muqsit Khattak, A. and Iqbal, A., 2017. A comparative study of the removal of $\mathrm{Cr}(\mathrm{VI})$ from synthetic solution using natural biosorbents. New Journal of Chemistry, 41, 10799-10807.

Al-Haidary, A.M.A., Zanganah, F.H.H., Al-Azawi, S.R.F., Khalili, F.I. and Al-Dujaili, A.H., 2011. A study on using date palmfibers and leaf base of palm as adsorbents for $\mathrm{Pb}(\mathrm{II})$ ions from its aqueous solution. Water, Air, \& Soil Pollution, 214, 73-82.

Al-Masri, M.S., Amin, Y., Al-Akel, B. and Al-Naama, T., 2010. . Biosorption of cadmium, lead, and uranium by powder of poplar leaves and branches. Applied Biochemistry and Biotechnology, 160, 976-987.

Al Rmalli, S.W., Dahmani, A.A., Abuein, M.M. and Gleza, A.A., 2008. Biosorption of mercury from aqueous solutions by powdered leaves of castor tree (Ricinus communis L.). Journal of Hazardous Materials, 152, 955-959.

Ali, I. and Gupta, V.K., 2007. Advances in water treatment by adsorption technology. Nature protocols, 1, 2661.

Ali, R.M., Hamad, H.A., Hussein, M.M. and Malash, G.F., 2016. Potential of using green adsorbent of heavy metal removal from aqueous solutions: Adsorption kinetics, isotherm, thermodynamic, mechanism and economic analysis. Ecological Engineering, 91, 317-332.

Amarasinghe, B.M.W.P.K. and Williams, R.A., 2007. Tea waste as a low cost adsorbent for the 
removal of $\mathrm{Cu}$ and $\mathrm{Pb}$ from wastewater. Chemical Engineering Journal, 132, 299-309.

Amin, M., Alazba, A. and Shafiq, M., 2017. Batch and fixed-bed column studies for the biosorption of $\mathrm{Cu}(\mathrm{II})$ and $\mathrm{Pb}(\mathrm{II})$ by raw and treated date palm leaves and orange peel. Global Nest Journal, $19,464-478$.

Amirnia, S., Ray, M.B. and Margaritis, A., 2016. Copper ion removal by Acer saccharum leaves in a regenerable continuous-flow column. Chemical Engineering Journal, 287, 755-764.

Ansari, S.A., Khan, F. and Ahmad, A., 2016. Cauliflower leave, an agricultural waste biomass adsorbent, and its application for the removal of $\mathrm{MB}$ dye from aqueous solution: Equilibrium, kinetics, and thermodynamic studies. International Journal of Analytical Chemistry, 2016, 10.

Anwar, J., Shafique, U., Waheed uz, Z., un Nisa, Z., Munawar, M.A., Jamil, N., Salman, M., Dar, A., Rehman, R., Saif, J., Gul, H. and Iqbal, T., 2011. Removal of chromium on Polyalthia longifolia leaves biomass. International Journal of Phytoremediation, 13, 410-420.

Aoyama, M., 2003a. Comment on "Biosorption of chromium(VI) from aqueous solution by cone biomass of Pinus sylvestris". Bioresource Technology, 89, 317-318.

Aoyama, M., 2003b. Removal of Cr(VI) from aqueous solution by London plane leaves. Journal of Chemical Technology \& Biotechnology, 78, 601-604.

Aoyama, M., Sugiyama, T., Doi, S., Cho, N.S. and Kim, H.E., 1999. Removal of hexavalent chromium from dilute aqueous solution by coniferous leaves. Holzforschung, 365.

Aoyama, M. and Tsuda, M., 2001. Removal of Cr(VI) from aqueous solutions by larch bark. Wood Science and Technology, 35, 425-434.

Aoyama, M., Tsuda, M., Cho, N.-S. and Doi, S., 2000a. Adsorption of trivalent chromium from dilute solution by conifer leaves. Wood Science and Technology, 34, 55-63.

Aoyama, M., Tsuda, M., Seki, K., Doi, S., Kurimoto, Y. and Tamura, Y., 2000b. Adsorption of Cr(VI) from Dichromate Solutions onto Black Locust Leaves. Holzforschung, 340.

Arshad, M., Zafar, M.N., Younis, S. and Nadeem, R., 2008. The use of Neem biomass for the biosorption of zinc from aqueous solutions. Journal of Hazardous Materials, 157, 534-540.

Babić, B.M., Milonjić, S.K., Polovina, M.J. and Kaludierović, B.V., 1999. Point of zero charge and intrinsic equilibrium constants of activated carbon cloth. Carbon, 37, 477-481. 
Babu, B.V. and Gupta, S., 2008. Adsorption of Cr(VI) using activated neem leaves: kinetic studies. Adsorption, 14, 85-92.

Bajpai, S.K. and Jain, A., 2012. Equilibrium and thermodynamic studies for adsorption of crystal violet onto spent tea leaves (STL). Water, 4, 52-71.

Baruah, S., Devi, A., Bhattacharyya, K.G. and Sarma, A., 2017. Developing a biosorbent from Aegle Marmelos leaves for removal of methylene blue from water. International Journal of Environmental Science and Technology, 14, 341-352.

Batool, F., Iqbal, S. and Akbar, J., 2017. Impact of metal ionic characteristics on adsorption potential of Ficus carica leaves using QSPR modeling. Journal of Environmental Science and Health, Part B, 1-6.

Bharali, R.K. and Bhattacharyya, K.G., 2015. Biosorption of fluoride on Neem (Azadirachta indica) leaf powder. Journal of Environmental Chemical Engineering, 3, 662-669.

Bhattacharyya, K.G. and Sarma, A., 2003. Adsorption characteristics of the dye, Brilliant Green, on Neem leaf powder. Dyes and Pigments, 57, 211-222.

Bhattacharyya, K.G., Sarma, A. and Sarma, J., 2010. Adsorption of Cu(II) ions onto a cellulosic biosorbent, Azadirachta Indica leaf powder: Application in water treatment. Adsorption Science \& Technology, 28, 869-883.

Bhattacharyya, K.G., Sarma, J. and Sarma, A., 2009. Azadirachta indica leaf powder as a biosorbent for Ni(II) in aqueous medium. Journal of Hazardous Materials, 165, 271-278.

Bhattacharyya, K.G. and Sharma, A., 2004. Adsorption of $\mathrm{Pb}(\mathrm{II})$ from aqueous solution by Azadirachta indica (Neem) leaf powder. Journal of Hazardous Materials, 113, 97-109.

Boparai, H.K., Joseph, M. and O'Carroll, D.M., 2011. Kinetics and thermodynamics of cadmium ion removal by adsorption onto nano zerovalent iron particles. Journal of Hazardous Materials, $186,458-465$.

Brahman, K.D., Kazi, T.G., Afridi, H.I., Baig, J.A., Abro, M.I., Arain, S.S., Ali, J. and Khan, S., 2016. Simultaneously removal of inorganic arsenic species from stored rainwater in arsenic endemic area by leaves of Tecomella undulata: A multivariate study. Environmental Science and Pollution Research, 23, 15149-15163. 
Carvalho, d.R.P., Freitas, J.R., de Sousa, A.M.G., Moreira, R.L., Pinheiro, M.V.B. and Krambrock, K., 2003. Biosorption of copper ions by dried leaves: chemical bonds and site symmetry. Hydrometallurgy, 71, 277-283.

Cavas, L., Karabay, Z., Alyuruk, H., Doğan, H. and Demir, G.K., 2011. Thomas and artificial neural network models for the fixed-bed adsorption of methylene blue by a beach waste Posidonia oceanica (L.) dead leaves. Chemical Engineering Journal, 171, 557-562.

Çay, S., Uyanık, A. and Özaşık, A., 2004. Single and binary component adsorption of copper(II) and cadmium(II) from aqueous solutions using tea-industry waste. Separation and Purification Technology, 38, 273-280.

Çekim, M., Yildiz, S. and Dere, T., 2015. Biosorption of copper from synthetic waters by using tobacco leaf: Equilibrium, inetic and thermodynamic tests. Journal of Environmental Engineering and Landscape Management, 23, 172-182.

Cengiz, S. and Cavas, L., 2010. A promising evaluation method for dead leaves of Posidonia oceanica (L.) in the adsorption of methyl violet. Marine Biotechnology, 12, 728-736.

Copello, G.J., Garibotti, R.E., Varela, F., Tuttolomondo, M.V. and Diaz, L.E., 2011. Exhausted yerba mate leaves (Ilex Paraguariensis) as biosorbent for the removal of metals from aqueous solutions. Journal of the Brazilian Chemical Society, 22, 790-795.

Chakraborty, S., Chowdhury, S. and Saha, P.D., 2012. Insight into biosorption equilibrium, kinetics and thermodynamics of crystal violet onto Ananas comosus (pineapple) leaf powder. Applied Water Science, 2, 135-141.

Chakravarty, S., Mohanty, A., Sudha, T.N., Upadhyay, A.K., Konar, J., Sircar, J.K., Madhukar, A. and Gupta, K.K., 2010. Removal of $\mathrm{Pb}(\mathrm{II})$ ions from aqueous solution by adsorption using bael leaves (Aegle marmelos). Journal of Hazardous Materials, 173, 502-509.

Chang, Y., Lai, J.-Y. and Lee, D.-J., 2016. Thermodynamic parameters for adsorption equilibrium of heavy metals and dyes from wastewaters: Research updated. Bioresource Technology, 222, 513-516.

Chao, H.-P. and Chang, C.-C., 2012. Adsorption of copper(II), cadmium(II), nickel(II) and lead(II) from aqueous solution using biosorbents. Adsorption, 18, 395-401.

Chao, H.-P., Chang, C.-C. and Nieva, A., 2014. Biosorption of heavy metals on Citrus maxima peel, 
passion fruit shell, and sugarcane bagasse in a fixed-bed column. Journal of Industrial and Engineering Chemistry, 20, 3408-3414.

Chao, H.-P. and Chen, S.-H., 2012. Adsorption characteristics of both cationic and oxyanionic metal ions on hexadecyltrimethylammonium bromide-modified $\mathrm{NaY}$ zeolite. Chemical Engineering Journal, 193-194, 283-289.

Chen, H., Dai, G., Zhao, J., Zhong, A., Wu, J. and Yan, H., 2010. Removal of copper(II) ions by a biosorbent-Cinnamomum camphora leaves powder. Journal of Hazardous Materials, 177, 228-236.

Chen, J.P. and Yang, L., 2006. Study of a heavy metal biosorption onto raw and chemically modified Sargassum sp. via spectroscopic and modeling analysis. Langmuir, 22, 8906-8914.

Chen, L., Ramadan, A., Lü, L., Shao, W., Luo, F. and Chen, J., 2011. Biosorption of methylene blue from aqueous solution using lawny grass modified with citric acid. Journal of Chemical \& Engineering Data, 56, 3392-3399.

Chen, Y., Tang, G., Yu, Q.J., Zhang, T., Chen, Y. and Gu, T., 2009. Biosorption properties of hexavalent chromium on to biomass of tobacco-leaf residues. Environmental Technology, 30, 1003-1010.

Cheraghi, E., Ameri, E. and Moheb, A., 2015. Adsorption of cadmium ions from aqueous solutions using sesame as a low-cost biosorbent: kinetics and equilibrium studies. International Journal of Environmental Science and Technology, 12, 2579-2592.

Chojnacka, K., Chojnacki, A. and Górecka, H., 2005. Biosorption of $\mathrm{Cr}^{3+}, \mathrm{Cd}^{2+}$ and $\mathrm{Cu}^{2+}$ ions by blue-green algae Spirulina sp.: Kinetics, equilibrium and the mechanism of the process. Chemosphere, 59, 75-84.

Chowdhury, S., Chakraborty, S. and Saha, P., 2011. Biosorption of Basic Green 4 from aqueous solution by Ananas comosus (pineapple) leaf powder. Colloids and Surfaces B: Biointerfaces, $84,520-527$.

Dabbagh, R., Ashtiani Moghaddam, Z. and Ghafourian, H., 2016. Removal of cobalt(II) ion from water by adsorption using intact and modified Ficus carica leaves as low-cost natural sorbent. Desalination and Water Treatment, 57, 19890-19902.

Dambies, L., Guimon, C., Yiacoumi, S. and Guibal, E., 2001. Characterization of metal ion 
interactions with chitosan by X-ray photoelectron spectroscopy. Colloids and Surfaces A: Physicochemical and Engineering Aspects, 177, 203-214.

Das, P., Das, P. and Datta, S., 2016. Continuous biosorption of Malachite Green by Ananus comosus (pineapple) leaf powder in a fixed bed reactor: Experimental, breakthrough time and mathematical modeling. Desalination and Water Treatment, 57, 25842-25847.

Daud, Z., Awang, H., Kassim, M., Sari, A., Hatta, M., Zainuri, M. and Aripin, A.M., 2014. Comparison of pineapple leaf and Cassava peel by chemical properties and morphology characterization. Advanced Materials Research, 974.

Davis, J.A. and Kent, D., 1990. Surface complexation modeling in aqueous geochemistry. Reviews in Mineralogy and Geochemistry, 23, 177-260.

De Gisi, S., Lofrano, G., Grassi, M. and Notarnicola, M., 2016. Characteristics and adsorption capacities of low-cost sorbents for wastewater treatment: A review. Sustainable Materials and Technologies, 9, 10-40.

Deniz, F. and Karaman, S., 2011. Removal of Basic Red 46 dye from aqueous solution by pine tree leaves. Chemical Engineering Journal, 170, 67-74.

Deniz, F. and Saygideger, S.D., 2010. Equilibrium, kinetic and thermodynamic studies of Acid Orange 52 dye biosorption by Paulownia tomentosa Steud. leaf powder as a low-cost natural biosorbent. Bioresource Technology, 101, 5137-5143.

Deng, S., Bai and Chen, J.P., 2003. Aminated polyacrylonitrile fibers for lead and copper removal. Langmuir, 19, 5058-5064.

dos Santos, R.M., Neto, W.P.F., Silvério, H.A., Martins, D.F., Dantas, N.O. and Pasquini, D., 2013. Cellulose nanocrystals from pineapple leaf, a new approach for the reuse of this agro-waste. Industrial Crops and Products, 50, 707-714.

Dotto, G.L., Salau, N.P.G., Piccin, J.S., Cadaval, T.R.S.A. and de Pinto, L.A.A., 2017. . Adsorption kinetics in liquid phase: Modeling for discontinuous and continuous system. In A. BonillaPetriciolet et al. (eds.) Adsorption Processes for Water Treatment and Purification, 53-76). Cham: Springer International Publishing.

Dotto, G.L., Sharma, S.K. and Pinto, L.A., 2015. Biosorption of organic dyes: Research opportunities and challenges. Green Chemistry for Dyes Removal from Wastewater: Research Trends and 
Applications, 295-329.

Dural, M.U., Cavas, L., Papageorgiou, S.K. and Katsaros, F.K., 2011. Methylene blue adsorption on activated carbon prepared from Posidonia oceanica (L.) dead leaves: Kinetics and equilibrium studies. Chemical Engineering Journal, 168, 77-85.

Escudero, L.B., Quintas, P.Y., Wuilloud, R.G. and Dotto, G.L., 2018. Recent advances on elemental biosorption. Environmental Chemistry Letters.

Fadzil, F., Ibrahim, S. and Hanafiah, M.A.K.M., 2016. Adsorption of lead(II) onto organic acid modified rubber leaf powder: Batch and column studies. Process Safety and Environmental Protection, 100, 1-8.

Ferreira, G.M.D., Ferreira, G.M.D., Hespanhol, M.C., de Paula Rezende, J., dos Santos Pires, A.C., Gurgel, L.V.A. and da Silva, L.H.M., 2017. Adsorption of red azo dyes on multi-walled carbon nanotubes and activated carbon: A thermodynamic study. Colloids and Surfaces A: Physicochemical and Engineering Aspects, 529, 531-540.

Fiol, N., Villaescusa, I., Martínez, M., Miralles, N., Poch, J. and Serarols, J., 2006. Sorption of Pb(II), $\mathrm{Ni}(\mathrm{II}), \mathrm{Cu}(\mathrm{II})$ and $\mathrm{Cd}(\mathrm{II})$ from aqueous solution by olive stone waste. Separation and Purification Technology, 50, 132-140.

Fomina, M. and Gadd, G.M., 2014. Biosorption: current perspectives on concept, definition and application. Bioresource Technology, 160, 3-14.

Fourest, E. and Volesky, B., 1995. Contribution of sulfonate groups and alginate to heavy metal biosorption by the dry biomass of Sargassum fluitans. Environmental Science \& Technology, 30, 277-282.

Gagrai, M.K., Das, C. and Golder, A.K., 2013. Reduction of Cr(VI) into Cr(III) by Spirulina dead biomass in aqueous solution: Kinetic studies. Chemosphere, 93, 1366-1371.

Gardea-Torresdey, J.L., Tiemann, K.J., Armendariz, V., Bess-Oberto, L., Chianelli, R.R., Rios, J., Parsons, J.G. and Gamez, G., 2000. Characterization of Cr(VI) binding and reduction to Cr(III) by the agricultural byproducts of Avena monida (Oat) biomass. Journal of Hazardous Materials, 80, 175-188.

Georgin, J., da Silva Marques, B., da Silveira Salla, J., Foletto, E.L., Allasia, D. and Dotto, G.L., 2018. Removal of Procion Red dye from colored effluents using $\mathrm{H}_{2} \mathrm{SO} 4-/ \mathrm{HNO}_{3}$-treated avocado 
shells (Persea americana) as adsorbent. Environmental Science and Pollution Research, 25, 6429-6442.

Goertzen, S.L., Thériault, K.D., Oickle, A.M., Tarasuk, A.C. and Andreas, H.A., 2010. Standardization of the Boehm titration. Part I. $\mathrm{CO}_{2}$ expulsion and endpoint determination. Carbon, 48, 1252-1261.

Goldberg, S., 2013. Surface Complexation Modeling. Reference Module in Earth Systems and Environmental Sciences: Elsevier.

Gowda, R., Nataraj, A. and Rao, N.M., 2012. Coconut leaves as a low cost adsorbent for the removal of nickel from electroplating effluents. Int J Sci Eng Res, 2, 1-5.

Guerrero-Coronilla, I., Morales-Barrera, L. and Cristiani-Urbina, E., 2015. Kinetic, isotherm and thermodynamic studies of amaranth dye biosorption from aqueous solution onto water hyacinth leaves. Journal of Environmental Management, 152, 99-108.

Gupta, N., Kushwaha, A.K. and Chattopadhyaya, M.C., 2012. Adsorption studies of cationic dyes onto Ashoka (Saraca asoca) leaf powder. Journal of the Taiwan Institute of Chemical Engineers, 43, 604-613.

Giannakoudakis, D.A., Kyzas, G.Z., Avranas, A. and Lazaridis, N.K., 2016. Multi-parametric adsorption effects of the reactive dye removal with commercial activated carbons. Journal of Molecular Liquids, 213, 381-389.

Hai, T.N., 2017. Comments on "Effect of temperature on the adsorption of methylene blue dye onto sulfuric acid-treated orange peel”. Chemical Engineering Communications, 204, 134-139.

Hamdaoui, O., Saoudi, F., Chiha, M. and Naffrechoux, E., 2008. Sorption of malachite green by a novel sorbent, dead leaves of plane tree: Equilibrium and kinetic modeling. Chemical Engineering Journal, 143, 73-84.

Hamissa, A.M.B., Brouers, F., Mahjoub, B. and Seffen, M., 2007. Adsorption of textile dyes using Agave americana (L.) fibres: Equilibrium and kinetics modelling. Adsorption Science \& Technology, 25, 311-325.

Hamissa, A.M.B., Lodi, A., Seffen, M., Finocchio, E., Botter, R. and Converti, A., 2010. Sorption of $\mathrm{Cd}(\mathrm{II})$ and $\mathrm{Pb}$ (II) from aqueous solutions onto Agave americana fibers. Chemical Engineering Journal, 159, 67-74. 
Han, R., Wang, Y., Zhao, X., Wang, Y., Xie, F., Cheng, J. and Tang, M., 2009. Adsorption of methylene blue by phoenix tree leaf powder in a fixed-bed column: Experiments and prediction of breakthrough curves. Desalination, 245, 284-297.

Han, R., Zou, W., Yu, W., Cheng, S., Wang, Y. and Shi, J., 2007. Biosorption of methylene blue from aqueous solution by fallen phoenix tree's leaves. Journal of Hazardous Materials, 141, 156162.

Han, X., Wang, W. and Ma, X., 2011. Adsorption characteristics of methylene blue onto low cost biomass material lotus leaf. Chemical Engineering Journal, 171, 1-8.

Han, X., Yuan, J. and Ma, X., 2014. Adsorption of malachite green from aqueous solutions onto lotus leaf: Equilibrium, kinetic, and thermodynamic studies. Desalination and Water Treatment, 52, 5563-5574.

Hanafiah, M.A.K.M. and Ngah, W.S.W., 2009. Preparation, characterization and adsorption mechanism of $\mathrm{Cu}(\mathrm{II})$ onto protonated rubber leaf powder. CLEAN-Soil, Air, Water, 37, 696703.

Hanafiah, M.A.K.M., Zakaria, H. and Wan Ngah, W.S., 2009. Preparation, characterization, and adsorption behavior of $\mathrm{Cu}$ (II) Ions onto alkali-treated weed (Imperata cylindrica) leaf powde. Water, Air, and Soil Pollution, 201, 43-53.

Hossain, M.A., Kumita, M., Michigami, Y. and Mori, S., 2005. Optimization of parameters for Cr (VI) adsorption on used black tea leaves. Adsorption, 11, 561-568.

Hossain, M.A., Ngo, H.H., Guo, W., Zhang, J. and Liang, S., 2014a. A laboratory study using maple leaves as a biosorbent for lead removal from aqueous solutions. Water Quality Research Journal of Canada, 49, 195-209.

Hossain, M.A., Ngo, H.H., Guo, W.S., Nghiem, L.D., Hai, F.I., Vigneswaran, S. and Nguyen, T.V., 2014b. Competitive adsorption of metals on cabbage waste from multi-metal solutions. Bioresource Technology, 160, 79-88.

Hossain, M.A., Ngo, H.H., Guo, W.S. and Nguyen, T.V., 2012. Biosorption of $\mathrm{Cu}(\mathrm{II})$ from water by banana peel based biosorbent: Experiments and models of adsorption and desorption. Journal of Water Sustainability, 2, 87-104.

Hossain, M.A., Ngo, H.H., Guo, W.S., Nguyen, T.V. and Vigneswaran, S., 2014c. Performance of 
cabbage and cauliflower wastes for heavy metals removal. Desalination and Water Treatment, $52,844-860$.

Huang, F.-C., Lee, C.-K., Han, Y.-L., Chao, W.-C. and Chao, H.-P., 2014. Preparation of activated carbon using micro-nano carbon spheres through chemical activation. Journal of the Taiwan Institute of Chemical Engineers, 45, 2805-2812.

Hymavathi, D. and Prabhakar, G., 2017. Studies on the removal of Cobalt(II) from aqueous solutions by adsorption with Ficus benghalensis leaf powder through response surface methodology. Chemical Engineering Communications, 204, 1401-1411.

Ibrahim, M.N.M., Ngah, W.S.W., Norliyana, M.S., Daud, W.R.W., Rafatullah, M., Sulaiman, O. and Hashim, R., 2010. A novel agricultural waste adsorbent for the removal of lead (II) ions from aqueous solutions. Journal of Hazardous Materials, 182, 377-385.

Immich, A.P.S., Ulson de Souza, A.A. and Ulson de Souza, S.M.d.A.G., 2009. Removal of Remazol Blue RR dye from aqueous solutions with Neem leaves and evaluation of their acute toxicity with Daphnia magna. Journal of Hazardous Materials, 164, 1580-1585.

Iqbal, M., Saeed, A. and Zafar, S.I., 2009. FTIR spectrophotometry, kinetics and adsorption isotherms modeling, ion exchange, and EDX analysis for understanding the mechanism of $\mathrm{Cd}^{2+}$ and $\mathrm{Pb}^{2+}$ removal by mango peel waste. Journal of Hazardous Materials, 164, 161-171.

Jain, S.N. and Gogate, P.R., 2017a. Acid Blue 113 removal from aqueous solution using novel biosorbent based on $\mathrm{NaOH}$ treated and surfactant modified fallen leaves of Prunus Dulcis. Journal of Environmental Chemical Engineering, 5, 3384-3394.

Jain, S.N. and Gogate, P.R., 2017b. Adsorptive removal of acid violet 17 dye from wastewater using biosorbent obtained from $\mathrm{NaOH}$ and $\mathrm{H}_{2} \mathrm{SO}_{4}$ activation of fallen leaves of Ficus racemosa. Journal of Molecular Liquids, 243, 132-143.

Jain, S.N. and Gogate, P.R., 2018. Efficient removal of Acid Green 25 dye from wastewater using activated Prunus Dulcis as biosorbent: Batch and column studies. Journal of Environmental Management, 210, 226-238.

Jain, S.N. and Gogate, P.R., 2017c. NaOH-treated dead leaves of Ficus racemosa as an efficient biosorbent for Acid Blue 25 removal. International Journal of Environmental Science and Technology, 14, 531-542. 
Jalil, A.A., Triwahyono, S., Yaakob, M.R., Azmi, Z.Z.A., Sapawe, N., Kamarudin, N.H.N., Setiabudi, H.D., Jaafar, N.F., Sidik, S.M., Adam, S.H. and Hameed, B.H., 2012. Utilization of bivalve shell-treated Zea mays L. (maize) husk leaf as a low-cost biosorbent for enhanced adsorption of malachite green. Bioresource Technology, 120, 218-224.

Kahina, L. and Nasser, S.M., 2017. Adsorption of Auramine-O using activated Globe artichoke leaves: Kinetic and isotherm studies. Asian Journal of Chemistry, 29.

Kamar Firas, H., Nechifor Aurelia, C., Nechifor, G., Al-Musawi Tariq, J. and Mohammed Asem, H., 2017. Aqueous phase biosorption of $\mathrm{Pb}(\mathrm{II}), \mathrm{Cu}(\mathrm{II})$, and $\mathrm{Cd}(\mathrm{II})$ onto cabbage leaves powder International Journal of Chemical Reactor Engineering.

Kamaru, A.A., Sani, N.S. and Malek, N.A.N.N., 2016. Raw and surfactant-modified pineapple leaf as adsorbent for removal of methylene blue and methyl orange from aqueous solution. Desalination and Water Treatment, 57, 18836-18850.

Kamsonlian, S., Suresh, S., Majumder, C.B. and Chand, S., 2012. Biosorption of arsenic from contaminated water onto solid Psidium guajava leaf surface: Equilibrium, kinLetics, thermodynamics, and desorption study. Bioremediation Journal, 16, 97-112.

Kılıç, M., Yazıcı, H. and Solak, M., 2009. A comprehensive study on removal and recovery of copper(II) from aqueous solutions by $\mathrm{NaOH}$-pretreated Marrubium globosum ssp. globosum leaves powder: Potential for utilizing the copper(II) condensed desorption solutions in agricultural applications. Bioresource Technology, 100, 2130-2137.

King, P., Rakesh, N., Beenalahari, S., Prasanna Kumar, Y. and Prasad, V.S.R.K., 2007. Removal of lead from aqueous solution using Syzygium cumini L.: Equilibrium and kinetic studies. Journal of Hazardous Materials, 142, 340-347.

King, P., Rakesh, N., Lahari, S.B., Kumar, Y.P. and Prasad, V.S.R.K., 2008. Biosorption of zinc onto Syzygium cumini L.: Equilibrium and kinetic studies. Chemical Engineering Journal, 144, 181-187.

Komy, Z.R., Gabar, R.M., Shoriet, A.A. and Mohammed, R.M., 2006. Characterisation of acidic sites of Pseudomonas biomass capable of binding protons and cadmium and removal of cadmium via biosorption. World Journal of Microbiology and Biotechnology, 22, 975-982.

Kong, L., Gong, L. and Wang, J., 2015. Removal of methylene blue from wastewater using fallen leaves as an adsorbent. Desalination and Water Treatment, 53, 2489-2500. 
Krishnan, K.A. and Anirudhan, T., 2003. Removal of cadmium (II) from aqueous solutions by steamactivated sulphurised carbon prepared from sugar-cane bagasse pith: Kinetics and equilibrium studies. Water Sa, 29, 147-156.

Kumar, K.V., 2006. Comments on "Adsorption of acid dye onto organobentonite". Journal of Hazardous Materials, 137, 638-639.

Kumar, Y.P., King, P. and Prasad, V.S.R.K., 2006. Zinc biosorption on Tectona grandis L.f. leaves biomass: Equilibrium and kinetic studies. Chemical Engineering Journal, 124, 63-70.

Kuppusamy, S., Thavamani, P., Megharaj, M., Venkateswarlu, K., Lee, Y.B. and Naidu, R., 2016. Potential of Melaleuca diosmifolia leaf as a low-cost adsorbent for hexavalent chromium removal from contaminated water bodies. Process Safety and Environmental Protection, 100, 173-182.

Kushwaha, A.K., Gupta, N. and Chattopadhyaya, M.C., 2014. Removal of cationic methylene blue and malachite green dyes from aqueous solution by waste materials of Daucus carota. Journal of Saudi Chemical Society, 18, 200-207.

Khan Rao, R.A. and Khatoon, A., 2017. Aluminate treated Casuarina equisetifolia leaves as potential adsorbent for sequestering $\mathrm{Cu}(\mathrm{II}), \mathrm{Pb}(\mathrm{II})$ and $\mathrm{Ni}(\mathrm{II})$ from aqueous solution. Journal of Cleaner Production, 165, 1280-1295.

Khokhar, A., Siddique, Z. and Misbah, 2015. Removal of heavy metal ions by chemically treated Melia azedarach L. leaves. Journal of Environmental Chemical Engineering, 3, 944-952.

Khorshidi, N., Niazi, A. and Mohammad Nazari, B., 2015. Optimization of pyrocatechol violet biosorption by Robinia pseudoacacia leaf powder using response surface methodology: kinetic, isotherm and thermodynamic studies. Journal of Water Reuse and Desalination.

Lafi, R., Hamdi, N. and Hafiane, A., 2015. Study of the performance of Esparto grass fibers as adsorbent of dyes from aqueous solutions. Desalination and Water Treatment, 56, 722-735.

Li, Y., Zhang, Z., Jing, Y., Ge, X., Wang, Y., Lu, C., Zhou, X. and Zhang, Q., 2017. Statistical optimization of simultaneous saccharification fermentative hydrogen production from Platanus orientalis leaves by photosynthetic bacteria HAU-M1. International Journal of Hydrogen Energy, 42, 5804-5811.

Lim, L.B.L., Priyantha, N. and Mohamad Zaidi, N.A.H., 2016. A superb modified new adsorbent, 
Artocarpus odoratissimus leaves, for removal of cationic methyl violet 2B dye. Environmental Earth Sciences, 75, 1179.

Lin, J., Zhan, Y. and Zhu, Z., 2011. Adsorption characteristics of copper (II) ions from aqueous solution onto humic acid-immobilized surfactant-modified zeolite. Colloids and Surfaces A: Physicochemical and Engineering Aspects, 384, 9-16.

Liu, H., Dong, Y., Liu, Y. and Wang, H., 2010a. Screening of novel low-cost adsorbents from agricultural residues to remove ammonia nitrogen from aqueous solution. Journal of Hazardous Materials, 178, 1132-1136.

Liu, H., Dong, Y., Wang, H. and Liu, Y., 2010b. Adsorption behavior of ammonium by a bioadsorbent - Boston ivy leaf powder. Journal of Environmental Sciences, 22, 1513-1518.

Liu, H., Dong, Y., Wang, H. and Liu, Y., 2010c. Ammonium adsorption from aqueous solutions by strawberry leaf powder: Equilibrium, kinetics and effects of coexisting ions. Desalination, $263,70-75$.

Mambo, M., Admire, C. and Tichaona, N., 2016. Removal of Copper from Aqueous Solution Using Chemically Treated Potato (Solanum tuberosum) Leaf Powder. CLEAN-Soil, Air, Water, 44, 488-495.

Manahan, S., 2000. Chapter 3. Fundamentals of Aquatic Chemistry. Environmental chemistry: CRC press.

Mohan, D. and Pittman, C.U., 2006. Activated carbons and low cost adsorbents for remediation of tri- and hexavalent chromium from water. Journal of Hazardous Materials, 137, 762-811.

Mohapatra, M. and Anand, S., 2007. Studies on sorption of Cd(II) on Tata chromite mine overburden. Journal of Hazardous Materials, 148, 553-559.

Mondal, D.K., Nandi, B.K. and Purkait, M.K., 2013. Removal of mercury (II) from aqueous solution using bamboo leaf powder: Equilibrium, thermodynamic and kinetic studies. Journal of Environmental Chemical Engineering, 1, 891-898.

Muhammad, I., Silke, S. and Randall, C., 2009. Mechanistic elucidation and evaluation of biosorption of metal ions by grapefruit peel using FTIR spectroscopy, kinetics and isotherms modeling, cations displacement and EDX analysis. Journal of Chemical Technology \& Biotechnology, $84,1516-1526$. 
Mukherjee, K., Ghosh, D. and Saha, B., 2016. Reliable bioremediation of hexavalent chromium from wastewater using mango leaves as reductant in association with the neutral and anionic micellar aggregation as redox accelarators. Desalination and Water Treatment, 57, 1691916926.

Nag, S., Mondal, A., Mishra, U., Bar, N. and Das, S.K., 2016. Removal of chromium(VI) from aqueous solutions using rubber leaf powder: Batch and column studies. Desalination and Water Treatment, 57, 16927-16942.

Nakkeeran, E., Saranya, N., Giri Nandagopal, M.S., Santhiagu, A. and Selvaraju, N., 2016. Hexavalent chromium removal from aqueous solutions by a novel powder prepared from Colocasia esculenta leaves. International Journal of Phytoremediation, 18, 812-821.

Namasivayam, C., Muniasamy, N., Gayatri, K., Rani, M. and Ranganathan, K., 1996. Removal of dyes from aqueous solutions by cellulosic waste orange peel. Bioresource Technology, 57, 3743.

Neris, J.B., Luzardo, F.H.M., da Silva, E.G.P. and Velasco, F.G., 2019. Evaluation of adsorption processes of metal ions in multi-element aqueous systems by lignocellulosic adsorbents applying different isotherms: A critical review. Chemical Engineering Journal, 357, 404-420.

Ngah, W.S.W. and Hanafiah, M.A.K.M., 2008. Biosorption of copper ions from dilute aqueous solutions on base treatedrubber (Hevea brasiliensis) leaves powder: Kinetics, isotherm, and biosorption mechanisms. Journal of Environmental Sciences, 20, 1168-1176.

Ngah, W.S.W. and Hanafiah, M.A.K.M., 2009. Surface modification of rubber (Hevea brasiliensis) leaves for the adsorption of copper ions: kinetic, thermodynamic and binding mechanisms. Journal of Chemical Technology \& Biotechnology, 84, 192-201.

Ngo, H.H., Guo, W. and Liu, C., 2014. Biosorbent for heavy metal removal: Google Patents.

Pandey, R., Prasad, R.L., Ansari, N.G. and Murthy, R.C., 2015. Utilization of NaOH modified Desmostachya bipinnata (Kush grass) leaves and Bambusa arundinacea (bamboo) leaves for Cd(II) removal from aqueous solution. Journal of Environmental Chemical Engineering, 3, 593-602.

Park, D., Lim, S.-R., Yun, Y.-S. and Park, J.M., 2007. Reliable evidences that the removal mechanism of hexavalent chromium by natural biomaterials is adsorption-coupled reduction. Chemosphere, 70, 298-305. 
Park, D., Yun, Y.-S., Kim, J.Y. and Park, J.M., 2008. How to study Cr(VI) biosorption: Use of fermentation waste for detoxifying $\mathrm{Cr}(\mathrm{VI})$ in aqueous solution. Chemical Engineering Journal, 136, 173-179.

Park, D., Yun, Y.-S., Lee, D.S. and Park, J.M., 2011. Optimum condition for the removal of Cr(VI) or total Cr using dried leaves of Pinus densiflora. Desalination, 271, 309-314.

Park, D., Yun, Y.-S. and Park, J.M., 2006. Mechanisms of the removal of hexavalent chromium by biomaterials or biomaterial-based activated carbons. Journal of Hazardous Materials, 137, 1254-1257.

Park, D., Yun, Y.-S. and Park, J.M., 2004. Reduction of Hexavalent Chromium with the Brown Seaweed Ecklonia Biomass. Environmental Science \& Technology, 38, 4860-4864.

Park, D., Yun, Y.-S. and Park, J.M., 2005. Studies on hexavalent chromium biosorption by chemically-treated biomass of Ecklonia sp. Chemosphere, 60, 1356-1364.

Peng, H., Zhou, M., Yu, Z., Zhang, J., Ruan, R., Wan, Y. and Liu, Y., 2013. Fractionation and characterization of hemicelluloses from young bamboo (Phyllostachys pubescens Mazel) leaves. Carbohydrate polymers, 95, 262-271.

Percival, Z.Y.H. and Lynd, L.R., 2004. Toward an aggregated understanding of enzymatic hydrolysis of cellulose: Noncomplexed cellulase systems. Biotechnology and Bioengineering, 88, 797 824.

Peydayesh, M. and Rahbar-Kelishami, A., 2015. Adsorption of methylene blue onto Platanus orientalis leaf powder: Kinetic, equilibrium and thermodynamic studies. Journal of Industrial and Engineering Chemistry, 21, 1014-1019.

Prasad, A.L. and Thirumalisamy, S., 2013. Evaluation of the use of acacia nilotica leaf as an ecofriendly adsorbent for $\mathrm{Cr}(\mathrm{VI})$ and its suitability in real waste water: Study of residual errors. Journal of Chemistry, 2013, 7.

Prasad, M.N.V. and Freitas, H., 2000. Removal of toxic metals from solution by leaf, stem and root phytomass of Quercus ilex L. (holly oak). Environmental Pollution, 110, 277-283.

Qaiser, S., Saleemi, A.R. and Umar, M., 2009. Biosorption of lead from aqueous solution by Ficus religiosa leaves: Batch and column study. Journal of Hazardous Materials, 166, 998-1005. 
Qi, B.C. and Aldrich, C., 2008. Biosorption of heavy metals from aqueous solutions with tobacco dust. Bioresource Technology, 99, 5595-5601.

Qi, W., Zhao, Y., Zheng, X., Ji, M. and Zhang, Z., 2016. Adsorption behavior and mechanism of Cr(VI) using Sakura waste from aqueous solution. Applied Surface Science, 360, 470-476.

Ramakul, P., Yanachawakul, Y., Leepipatpiboon, N. and Sunsandee, N., 2012. Biosorption of palladium(II) and platinum(IV) from aqueous solution using tannin from Indian almond (Terminalia catappa L.) leaf biomass: Kinetic and equilibrium studies. Chemical Engineering Journal, 193-194, 102-111.

Ramrakhiani, L., Halder, A., Majumder, A., Mandal, A.K., Majumdar, S. and Ghosh, S., 2017. Industrial waste derived biosorbent for toxic metal remediation: Mechanism studies and spent biosorbent management. Chemical Engineering Journal, 308, 1048-1064.

Rangabhashiyam, S., Nakkeeran, E., Anu, N. and Selvaraju, N., 2015. Biosorption potential of a novel powder, prepared from Ficus auriculata leaves, for sequestration of hexavalent chromium from aqueous solutions. Research on Chemical Intermediates, 41, 8405-8424.

Rao, K., Anand, S. and Venkateswarlu, P., 2010a. Psidium guvajava L. leaf powder-a potential lowcost biosorbent for the removal of cadmium(II) Ions from wastewater. Adsorption Science \& Technology, 28, 163-178.

Rao, K.S., Anand, S. and Venkateswarlu, P., 2011a. Adsorption of cadmium from aqueous solution by Ficus religiosa leaf powder and characterization of loaded biosorbent. CLEAN - Soil, Air, Water, 39, 384-391.

Rao, K.S., Anand, S. and Venkateswarlu, P., 2010b. Cadmium removal from aqueous solutions using biosorbent Syzygium cumini leaf powder: Kinetic and equilibrium studies. Korean Journal of Chemical Engineering, 27, 1547-1554.

Rao, K.S., Anand, S. and Venkateswarlu, P., 2011b. Modeling the kinetics of Cd(II) adsorption on Syzygium cumini L. leaf powder in a fixed bed mini column. Journal of Industrial and Engineering Chemistry, 17, 174-181.

Rao, R.A.K. and Khan, U., 2017. Adsorption studies of $\mathrm{Cu}(\mathrm{II})$ on Boston fern (Nephrolepis exaltata Schott cv. Bostoniensis) leaves. Applied Water Science, 7, 2051-2061.

Rawat, A.P., Giri, K. and Rai, J.P.N., 2014. Biosorption kinetics of heavy metals by leaf biomass of 
Jatropha curcas in single and multi-metal system. Environmental Monitoring and Assessment, $186,1679-1687$.

Reddy, D.H.K., Harinath, Y., Seshaiah, K. and Reddy, A.V.R., 2010. Biosorption of Pb(II) from aqueous solutions using chemically modified Moringa oleifera tree leaves. Chemical Engineering Journal, 162, 626-634.

Reddy, D.H.K., Seshaiah, K., Reddy, A.V.R. and Lee, S.M., 2012. Optimization of Cd(II), Cu(II) and Ni(II) biosorption by chemically modified Moringa oleifera leaves powder. Carbohydrate Polymers, 88, 1077-1086.

Ren, X., Xiao, W., Zhang, R., Shang, Y. and Han, R., 2015. Adsorption of crystal violet from aqueous solution by chemically modified phoenix tree leaves in batch mode. Desalination and Water Treatment, 53, 1324-1334.

Robalds, A., Naja, G.M. and Klavins, M., 2016. Highlighting inconsistencies regarding metal biosorption. Journal of Hazardous Materials, 304, 553-556.

Rostami, B. and Niazi, A., 2013. Biosorption of a textile dye (Eosin) by eucalyptus tree leaves biomass: estimation of equilibrium, thermodynamic and kinetic parameters. Advanced Science Focus, 1, 50-56.

Ruiyi, F., Qingping, Y., Yucong, X., Feng, X., Qinglin, Z. and Zhengrong, L., 2016. Enhanced adsorption and recovery of $\mathrm{Pb}(\mathrm{II})$ from aqueous solution by alkali-treated persimmon fallen leaves. Journal of Applied Polymer Science, 133.

Saha, G.C., Hoque, M.I.U., Miah, M.A.M., Holze, R., Chowdhury, D.A., Khandaker, S. and Chowdhury, S., 2017. Biosorptive removal of lead from aqueous solutions onto Taro (Colocasiaesculenta(L.) Schott) as a low cost bioadsorbent: Characterization, equilibria, kinetics and biosorption-mechanism studies. Journal of Environmental Chemical Engineering, $5,2151-2162$.

Saha, P.D., Chakraborty, S. and Chowdhury, S., 2012. Batch and continuous (fixed-bed column) biosorption of crystal violet by Artocarpus heterophyllus (jackfruit) leaf powder. Colloids and Surfaces B: Biointerfaces, 92, 262-270.

Saha, R. and Saha, B., 2014. Removal of hexavalent chromium from contaminated water by adsorption using mango leaves (Mangifera indica). Desalination and Water Treatment, 52, 1928-1936. 
Salehi, P., Asghari, B. and Mohammadi, F., 2008. Removal of heavy metals from aqueous solutions by Cercis siliquastrum L. Journal of the Iranian Chemical Society, 5, S80-S86.

Salim, R., Al-Subu, M. and Dawod, E., 2008. Efficiency of removal of cadmium from aqueous solutions by plant leaves and the effects of interaction of combinations of leaves on their removal efficiency. Journal of Environmental Management, 87, 521-532.

Sangi, M.R., Shahmoradi, A., Zolgharnein, J., Azimi, G.H. and Ghorbandoost, M., 2008. Removal and recovery of heavy metals from aqueous solution using Ulmus carpinifolia and Fraxinus excelsior tree leaves. Journal of Hazardous Materials, 155, 513-522.

Sarma, J., Sarma, A. and Bhattacharyya, K.G., 2011. Biosorption of Acid Blue 25 on Azadirachta indica (NEEM) leaf powder World Environmental and Water Resources Congress 2011: Bearing Knowledge for Sustainability, 3927-3940).

Sarma, J., Sarma, A. and Bhattacharyya, K.G., 2008. Biosorption of commercial dyes on Azadirachta indica leaf powder: A case study with a basic dye Rhodamine B. Industrial \& Engineering Chemistry Research, 47, 5433-5440.

Sawalha, M.F., Peralta-Videa, J.R., Romero-González, J. and Gardea-Torresdey, J.L., 2006. Biosorption of $\mathrm{Cd}(\mathrm{II}), \mathrm{Cr}(\mathrm{III})$, and $\mathrm{Cr}(\mathrm{VI})$ by saltbush (Atriplex canescens) biomass: Thermodynamic and isotherm studies. Journal of Colloid and Interface Science, 300, 100104.

Sayrafi, O., Sayrafi, S.A. and Salim, R., 1999. Removal of cadmium from polluted water using decaying leaves - effect of acidity. Journal of Environmental Science and Health, Part A, 34, 835-851.

Šćiban, M., Klašnja, M. and Škrbić, B., 2006. Modified softwood sawdust as adsorbent of heavy metal ions from water. Journal of Hazardous Materials, 136, 266-271.

Serencam, H., Gundogdu, A., Uygur, Y., Kemer, B., Bulut, V.N., Duran, C., Soylak, M. and Tufekci, M., 2008. Removal of cadmium from aqueous solution by Nordmann fir (Abies nordmanniana (Stev.) Spach. Subsp. nordmanniana) leaves. Bioresource Technology, 99, 1992-2000.

Setiabudi, H.D., Jusoh, R., Suhaimi, S.F.R.M. and Masrur, S.F., 2016. Adsorption of methylene blue onto oil palm (Elaeis guineensis) leaves: Process optimization, isotherm, kinetics and thermodynamic studies. Journal of the Taiwan Institute of Chemical Engineers, 63, 363-370. 
Shah, J., Jan, M.R., Haq, A.u. and Zeeshan, M., 2015. Equilibrium, kinetic and thermodynamic studies for sorption of $\mathrm{Ni}$ (II) from aqueous solution using formaldehyde treated waste tea leaves. Journal of Saudi Chemical Society, 19, 301-310.

Sharma, A. and Bhattacharyya, K.G., 2005. Adsorption of Chromium (VI) on Azadirachta Indica (Neem) Leaf Powder. Adsorption, 10, 327-338.

Sharma, D.C. and Forster, C.F., 1994. The treatment of chromium wastewaters using the sorptive potential of leaf mould. Bioresource Technology, 49, 31-40.

Shi, J., Fang, Z., Zhao, Z., Sun, T. and Liang, Z., 2016. Comparative study on $\mathrm{Pb}(\mathrm{II}), \mathrm{Cu}(\mathrm{II})$, and Co(II) ions adsorption from aqueous solutions by arborvitae leaves. Desalination and Water Treatment, 57, 4732-4739.

Shin, E.W., Karthikeyan, K.G. and Tshabalala, M.A., 2007. Adsorption mechanism of cadmium on juniper bark and wood. Bioresource Technology, 98, 588-594.

Singh, K.K., Hasan, S.H., Talat, M., Singh, V.K. and Gangwar, S.K., 2009. Removal of Cr (VI) from aqueous solutions using wheat bran. Chemical Engineering Journal, 151, 113-121.

Siyal, A.A., Shamsuddin, M.R., Khan, M.I., Rabat, N.E., Zulfiqar, M., Man, Z., Siame, J. and Azizli, K.A., 2018. A review on geopolymers as emerging materials for the adsorption of heavy metals and dyes. Journal of Environmental Management, 224, 327-339.

Rao, K.S., Anand, S. and Venkateswarlu, P., 2010. Adsorption of cadmium (II) ions from aqueous solution by Tectona grandis LF (teak leaves powder). BioResources, 5, 438-454.

Tamez Uddin, M., Rukanuzzaman, M., Maksudur Rahman Khan, M. and Akhtarul Islam, M., 2009. Adsorption of methylene blue from aqueous solution by jackfruit (Artocarpus heteropyllus) leaf powder: A fixed-bed column study. Journal of Environmental Management, 90, 34433450 .

Tchobanoglous, G. and Angelakis, A.N., 1996. Technologies for wastewater treatment appropriate for reuse: Potential for applications in Greece. Water Science and Technology, 33, 15-24.

Tewari, H., 2013. Removal of heavy metals from industrial effluent using Pinus roxburghii leaves as biosorbent: equilibrium modelling. Water Science and Technology, 67, 1894-1900.

Tongpoothorn, W., Sriuttha, M., Homchan, P., Chanthai, S. and Ruangviriyachai, C., 2011. 
Preparation of activated carbon derived from Jatropha curcas fruit shell by simple thermochemical activation and characterization of their physico-chemical properties. Chemical Engineering Research and Design, 89, 335-340.

Tran, H.N., 2019. Comment on "simultaneous and efficient removal of $\mathrm{Cr}(\mathrm{VI})$ and methyl orange on LDHs decorated porous carbons". Chemical Engineering Journal, 359, 810-812.

Tran, H.N., 2017. Comments on "Characterization and adsorption capacity of raw pomegranate peel biosorbent for copper removal”. Journal of Cleaner Production, 144, 553-558.

Tran, H.N. and Chao, H.-P., 2018a. Adsorption and desorption of potentially toxic metals on modified biosorbents through new green grafting process. Environmental Science and Pollution Research, 25, 12808-12820.

Tran, H.N. and Chao, H.-P., 2018b. Adsorption and desorption of potentially toxic metals on modified biosorbents through new green grafting process. Environmental Science and Pollution Research.

Tran, H.N., Chao, H.-P. and You, S.-J., 2018. Activated carbons from golden shower upon different chemical activation methods: Synthesis and characterizations. Adsorption Science \& Technology, 36, 95-113.

Tran, H.N., Lee, C.-K., Nguyen, T.V. and Chao, H.-P., 2017a. Saccharide-derived microporous spherical biochar prepared from hydrothermal carbonization and different pyrolysis temperatures: synthesis, characterization, and application in water treatment. Environmental Technology, 1-14.

Tran, H.N., You, S.-J. and Chao, H.-P., 2016. Thermodynamic parameters of cadmium adsorption onto orange peel calculated from various methods: A comparison study. Journal of Environmental Chemical Engineering, 4, 2671-2682.

Tran, H.N., You, S.-J., Hosseini-Bandegharaei, A. and Chao, H.-P., 2017b. Mistakes and inconsistencies regarding adsorption of contaminants from aqueous solutions: A critical review. Water Research, 120, 88-116.

Tran, H.N., You, S.-J., Nguyen, T.V. and Chao, H.-P., 2017c. Insight into the adsorption mechanism of cationic dye onto biosorbents derived from agricultural wastes. Chemical Engineering Communications, 204, 1020-1036. 
Vasanth Kumar, K. and Sivanesan, S., 2006. Equilibrium data, isotherm parameters and process design for partial and complete isotherm of methylene blue onto activated carbon. Journal of Hazardous Materials, 134, 237-244.

Villaescusa, I., Fiol, N., Martínez, M.a., Miralles, N., Poch, J. and Serarols, J., 2004. Removal of copper and nickel ions from aqueous solutions by grape stalks wastes. Water Research, 38, 992-1002.

Vilvanathan, S. and Shanthakumar, S., 2016. Removal of Ni(II) and Co(II) ions from aqueous solution using teak (Tectona grandis) leaves powder: adsorption kinetics, equilibrium and thermodynamics study. Desalination and Water Treatment, 57, 3995-4007.

Visa, M., 2012. Tailoring fly ash activated with bentonite as adsorbent for complex wastewater treatment. Applied Surface Science, 263, 753-762.

Volesky, B., 2007. Biosorption and me. Water Research, 41, 4017-4029.

Vu, M.T., Chao, H.-P., Van Trinh, T., Le, T.T., Lin, C.-C. and Tran, H.N., 2018. Removal of ammonium from groundwater using $\mathrm{NaOH}$-treated activated carbon derived from corncob wastes: Batch and column experiments. Journal of Cleaner Production, 180, 560-570.

Wahab, M.A., Boubakri, H., Jellali, S. and Jedidi, N., 2012. Characterization of ammonium retention processes onto Cactus leaves fibers using FTIR, EDX and SEM analysis. Journal of Hazardous Materials, 241-242, 101-109.

Wan Ngah, W.S. and Hanafiah, M.A.K.M., 2008. Adsorption of copper on rubber (Hevea brasiliensis) leaf powder: Kinetic, equilibrium and thermodynamic studies. Biochemical Engineering Journal, 39, 521-530.

Wan, S., Ma, Z., Xue, Y., Ma, M., Xu, S., Qian, L. and Zhang, Q., 2014. Sorption of lead(II), cadmium(II), and copper(II) ions from aqueous solutions using tea waste. Industrial \& Engineering Chemistry Research, 53, 3629-3635.

Wang, C., Wang, H. and Liu, Y., 2016. Purification of $\mathrm{Pb}$ (II) ions from aqueous solution by camphor leaf modified with succinic anhydride. Colloids and Surfaces A: Physicochemical and Engineering Aspects, 509, 80-85.

Wang, X.-S., Huang, J., Hu, H.-Q., Wang, J. and Qin, Y., 2007. Determination of kinetic and equilibrium parameters of the batch adsorption of $\mathrm{Ni}$ (II) from aqueous solutions by $\mathrm{Na}-$ 
mordenite. Journal of Hazardous Materials, 142, 468-476.

Wenfang, Q., Yue, W., Min, J., Yingxin, Z. and Zhenya, Z., 2015. Highly efficient adsorption of Cr (VI) by Sakura leaves from aqueous solution. Chemistry Letters, 44, 697-699.

Weng, C.-H., Lin, T.Y., Chu, S.-H. and Yuan, C., 2006. Laboratory-scale evaluation of Cr (VI) removal from clay by electrokinetics incorporated with Fe $(\mathrm{O})$ barrier. Practice Periodical of Hazardous, Toxic, and Radioactive Waste Management, 10, 171-178.

Weng, C.-H., Lin, Y.-T., Hong, D.-Y., Sharma, Y.C., Chen, S.-C. and Tripathi, K., 2014. Effective removal of copper ions from aqueous solution using base treated black tea waste. Ecological Engineering, 67, 127-133.

Weng, C.-H., Lin, Y.-T. and Tzeng, T.-W., 2009. Removal of methylene blue from aqueous solution by adsorption onto pineapple leaf powder. Journal of Hazardous Materials, 170, 417-424.

Weng, C.-H. and Wu, Y.-C., 2012. Potential low-cost biosorbent for copper removal: Pineapple leaf powder. Journal of Environmental Engineering, 138, 286-292.

Wong, S., Ngadi, N., Inuwa, I.M. and Hassan, O., 2018. Recent advances in applications of activated carbon from biowaste for wastewater treatment: A short review. Journal of Cleaner Production, 175, 361-375.

Xiao, X., Xue, J., Ding, D., He, B., He, D., Tan, L. and Liao, L., 2016. Adsorption of low concentration of Uranium(VI) from aqueous solution by diethylenetriamine functionalized Cycas revoluta leaves. Journal of Radioanalytical and Nuclear Chemistry, 308, 1027-1037.

Yagub, M.T., Sen, T.K. and Ang, H.M., 2012. Equilibrium, kinetics, and thermodynamics of methylene blue adsorption by pine tree leaves. Water, Air, \& Soil Pollution, 223, 5267-5282.

Yang, H., Yan, R., Chen, H., Lee, D.H. and Zheng, C., 2007. Characteristics of hemicellulose, cellulose and lignin pyrolysis. Fuel, 86, 1781-1788.

Yang, J.-X. and Hong, G.-B., 2018. Adsorption behavior of modified Glossogyne tenuifolia leaves as a potential biosorbent for the removal of dyes. Journal of Molecular Liquids, 252, 289-295.

Yazıcı, H., Kılıç, M. and Solak, M., 2008. Biosorption of copper(II) by Marrubium globosum subsp. globosum leaves powder: Effect of chemical pretreatment. Journal of Hazardous Materials, $151,669-675$. 
Yu, H., Wang, T., Yu, L., Dai, W., Ma, N., Hu, X. and Wang, Y., 2016. Remarkable adsorption capacity of Ni-doped magnolia-leaf-derived bioadsorbent for congo red. Journal of the Taiwan Institute of Chemical Engineers, 64, 279-284.

Yu, J.-x., Feng, L.-y., Cai, X.-1., Wang, L.-y. and Chi, R.-a., 2015. Adsorption of $\mathrm{Cu}^{2+}, \mathrm{Cd}^{2+}$ and $\mathrm{Zn}^{2+}$ in a modified leaf fixed-bed column: competition and kinetics. Environmental Earth Sciences, 73, 1789-1798.

Yuvaraja, G., Krishnaiah, N., Subbaiah, M.V. and Krishnaiah, A., 2014. Biosorption of Pb(II) from aqueous solution by Solanum melongena leaf powder as a low-cost biosorbent prepared from agricultural waste. Colloids and Surfaces B: Biointerfaces, 114, 75-81.

Yuvaraja, G., Subbaiah, M.V. and Krishnaiah, A., 2012. Caesalpinia bonducella leaf powder as biosorbent for $\mathrm{Cu}(\mathrm{II})$ removal from aqueous environment: Kinetics and isotherms. Industrial \& Engineering Chemistry Research, 51, 11218-11225.

Zahedi, R., Dabbagh, R., Ghafourian, H. and Behbahanini, A., 2015. Nickel removal by Nymphaea alba leaves and effect of leaves treatment on the sorption capacity: A kinetic and thermodynamic study. Water Resources, 42, 690-698.

Zaidi, N.A.H.M., Lim, L.B.L. and Usman, A., 2018. Artocarpus odoratissimus leaf-based cellulose as adsorbent for removal of methyl violet and crystal violet dyes from aqueous solution. Cellulose.

Zhang, Y., Li, X. and Li, Y., 2015. Influence of solution chemistry on heavy metals removal by bioadsorbent tea waste modified by poly (vinyl alcohol). Desalination and Water Treatment, $53,2134-2143$.

Zhou, L., Liu, Y., Liu, S., Yin, Y., Zeng, G., Tan, X., Hu, X., Hu, X., Jiang, L., Ding, Y., Liu, S. and Huang, X., 2016. Investigation of the adsorption-reduction mechanisms of hexavalent chromium by ramie biochars of different pyrolytic temperatures. Bioresource Technology, 218, 351-359.

Zhu, L., Wang, Y., He, T., You, L. and Shen, X., 2016. Assessment of potential capability of water bamboo leaves on the adsorption removal efficiency of cationic dye from aqueous solutions. Journal of Polymers and the Environment, 24, 148-158.

Zolgharnein, J., Bagtash, M., Feshki, S., Zolgharnein, P. and Hammond, D., 2017. Crossed mixture process design optimization and adsorption characterization of multi-metal ( $\mathrm{Cu}(\mathrm{II}), \mathrm{Zn}$ (II) and 
$\mathrm{Ni}(\mathrm{II}))$ removal by modified Buxus sempervirens tree leaves. Journal of the Taiwan Institute of Chemical Engineers, 78, 104-117.

Zolgharnein, J., Shariatmanesh, T. and Asanjarani, N., 2013. Cercis siliquastrum tree leaves as an efficient adsorbent for removal of $\mathrm{Ag}(\mathrm{I})$ : Response surface optimization and characterization of biosorption. CLEAN - Soil, Air, Water, 41, 1183-1195.

Zolgharnein, J., Shariatmanesh, T., Asanjarani, N. and Zolanvari, A., 2015. Doehlert design as optimization approach for the removal of $\mathrm{Pb}$ (II) from aqueous solution by Catalpa Speciosa tree leaves: adsorption characterization. Desalination and Water Treatment, 53, 430-445. 
Supporting Information

Removal of various contaminants from water by renewable leafderived biosorbents: A comprehensive and critical review 


\section{Table of Contents}

\section{Supporting Section}

Section S1. Additional discussion on calculating textural properties ............................................ 5

Section S2. Additional discussion electrical double layer (EDL) ............................................... 5

Section S3. Additional discussion on adsorption kinetics ....................................................... 6

Section S4. Additional discussion on adsorption isotherm ..................................................... 7

Section S5. Additional discussion on adsorption thermodynamics............................................. 7

Section S6. Additional discussion on adsorption dynamics ....................................................... 9

Section S7. Additional discussion on identifying functional groups relevant for the adsorption

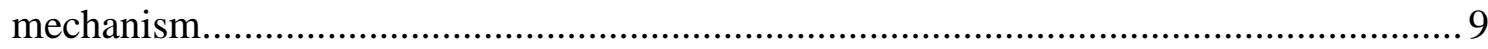

Adsorption of potentially toxic metals, fluoride, uranium, and ammonium ................................. 9

\section{Supporting Table}

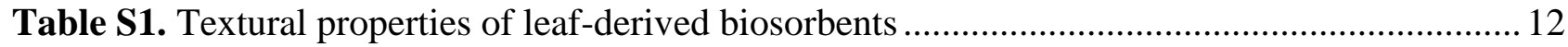

Table S2. Ultimate analysis (wt.\%) of leaf-based biosorbents...................................................... 13

Table S3. Proximate analysis (wt.\%) of leaf-based biosorbent.................................................... 14

Table S4. pH value and density of leaves-based biosorbent ....................................................... 15

Table S5. Quantitative information on oxygen-containing functional groups ( $\mathrm{mmol} / \mathrm{g}$ )................ 16

Table S6. $\mathrm{pH}$ at the point of zero charge ( $\mathrm{pH}_{\mathrm{PZC}}$ ) of leaf-based biosorbents ................................. 17

Table S7. Zeta potential of leaf-based biosorbent at a given solution $\mathrm{pH}$..................................... 18

Table S8. Comparison of maximum adsorption capacity $\left(Q^{\mathrm{o}}{ }_{\max }, \mathrm{mg} / \mathrm{g}\right)$ of pristine biosorbent calculated from the Langmuir model (single component)

Table S9. Comparison of maximum adsorption capacity $\left(Q^{\mathrm{o}}{ }_{\mathrm{max}}, \mathrm{mg} / \mathrm{g}\right)$ of modified/treated biosorbent calculated from the Langmuir model (single component) ........................................ 30

Table S10. Some common inorganic salt used for the effect study of ionic strength ..................... 34

Table S11. Thermodynamic parameters for the biosorption of toxic metal ions onto pristine leaves

Table S12. Thermodynamic parameters for the biosorption of toxic metal ions onto modified/treated leaves

Table S13. Thermodynamic parameters for the biosorption of organic dyes onto pristine leaves ... 40

Table S14. Thermodynamic parameters for the biosorption of organic dyes onto modified/treated leaves

Table S15. Thermodynamic parameters for the biosorption of other contaminants onto pristine and treated/modified leaves

Table S16. The $Q^{\mathrm{o}}{ }_{\text {max }}(\mathrm{mmol} / \mathrm{kg}), \mathrm{CEC}(\mathrm{mmol} / \mathrm{kg})$, ECEC $(\mathrm{mmol} / \mathrm{kg}), \alpha$ or $\beta$ ratio of bisorbent and zeolite to some cationic and oxyanionic metal ions

Table S17. Removal percentage of $\mathrm{Cr}(\mathrm{VI})$ from dichromate solutions by various biosorbents Aoyama, 2003a 


\section{Supporting Figure}

Figure S1. Number of articles published applying leaf-based biosorbent for removal of toxic pollutants from water bodies per year (only for the published original papers) and distribution of publisher relevant to the topic

Figure S2. Typical adsorption/desorption isotherm of biosorbent derived from Brazilian orchid tree (pata-de-vaca) leaves and its pore size distribution (Jorgetto et al., 2015)

Figure S3. (a) SEM image of rubber (Hevea brasiliensis) leaf powders, (b)-(c) EDS spectra, and (d) confirmation of the ion exchange mechanism (Wan Ngah and Hanafiah, 2008)

Figure S4. (a) FTIR spectra of pristine biosorbent derived from fallen Cinnamomum camphora leaves (Chen et al., 2010b) and (b) the spectroscopic assignment; and (c) XPS spectra of arborvitae leaves and (b) C 1s XPS spectra of arborvitae leaves (Shi et al., 2016b)......52

Figure S5. Point of zero charge (PZC) of (a) tea waste leaves determined by the acid-base titration method Uddin et al., 2009 [License number: 4435871145286] and (b) gulmohar leaves determined by the "drift method" Ponnusami et al., 2009b [License number: 4435871247208]; and isoelectric point (IEP) of (c) treated black tea waste leaves determined by a zeta meter Weng et al., 2014a [License number: 4435871464044] and (d) strawberry leaves determined by an electrokinetic analyzer Liu et al., 2010d [License Number: 4435880051225]

Figure S6. XRD spectra of (a) pristine (CLP) and succinic anhydride-modified camphor (SCLP) leaves (Wang et al., 2016), and (b) pristine (CEL) and aluminate-treated Casuarina equisetifolia (SATCEL) leaves (Khan Rao and Khatoon, 2017)

Figure S7. (a) TG and (b) DTG curves of alkali-treated persimmon fallen leaves (NPFL) (Ruiyi et al., 2016), (c) TG-DTG curves of raw phoenix tree leaves (Liang et al., 2016), and (d) TGA of pristine and $\mathrm{Pb}$-loaded Taro leaves (Saha et al., 2017)

Figure S8. (a) Distribution of various cadmium species as a function of the pH (Srivastava et al., 2006); (b) chemical structure of Congo Red dye and (c) UV-Vis spectra of Congo Red solutions at different solution pH values (Zhou et al., 2011)

Figure S9. Effect of the ionic strength on the adsorption process of (a-b) potentially toxic metals onto Ulmus carpinifolia tree leaves (Sangi et al., 2008), (c) cationic dyes onto Daucus carota stems and leaves (Kushwaha et al., 2014b), and (d) anionic dye onto surfactantmodified Prunus Dulcis leaves (Jain and Gogate, 2017b) 57

Figure S10. Linear relationship between the rate constant $k_{2}$ of pseudo-second-order model and the thickness of the electrical double layer Weng et al., 2009

Figure S11. (a) Effect of the contact time on the $\mathrm{Cu}(\mathrm{II})$ adsorption process onto pineapple leaf powders at different operation temperatures, and (b) plot of the Arrhenius equation (Weng and $\mathrm{Wu}, 2012)$

Figure S12. Typical breakthrough curve for methylene blue adsorption onto jackfruit leaves at different (a) flow rates, (b) feed concentrations, and (c) bed heights (Tamez Uddin et al., 2009)

Figure S13. (a) Scanning Electron Micrographs of Syzygium cumini L. leaves after Cd(II) adsorption (Rao et al., 2010c), (b) Element distributions of EDX analysis region of tobacco leaves after $\mathrm{Cu}$ (II) biosorption (Çekim et al., 2015), (c) Cr mapping of Sakura leaves after $\mathrm{Cr}$ 
(VI) adsorption (Wenfang et al., 2015), and (d) X-ray mapping of maple leaves after $\mathrm{Pb}$ (II) adsorption (Hossain et al., 2014b)

Figure S14. Atomic force microscopy (AFM) image of sodium aluminate-treated Casuarina equisetifolia leaves (a) before and (b) after $\mathrm{Cu}$ (II) biosorption (Khan Rao and Khatoon, 2017)

Figure S15. (a) Some major binding functional groups for adsorption (Volesky, 2007), and (b) binding of a metal ion $\left(\mathrm{M}^{2+}\right)$ by oxygen-containing functional groups (Manahan, 2000). 63

Figure S16. Cr(VI) speciation diagram as function of $\mathrm{pH}$ (Weng et al., 2006) 64

Figure S17. Model for the possible sorption site of a copper ion between two adjacent fibers of the biomass derived from Maitenus truncata leaves Carvalho et al., 2003 .65

Licenses 66

References.... 68 
Section S1. Additional discussion on calculating textural properties

Based on Tran et al., 2017a, the specific surface area $\left(S_{\mathrm{BET}}\right)$ of a solid material can be calculated with the Brunauer-Emmett-Teller method (Equation S1). The calculations of the total pore volume $\left(V_{\text {total }} ; \mathrm{cm}^{3} / \mathrm{g}\right)$ and mean pore diameter $\left(L_{\mathrm{o}} ; \mathrm{nm}\right)$ are shown in Equations $\mathrm{S} 4$ and S5, respectively.

$$
S_{B E T}=\frac{\left(0.1620 \mathrm{~nm}^{2}\right) \times\left(6.023 \times 10^{23}\right)}{\left(22414 \mathrm{~cm}^{3} \mathrm{STP}\right) \times\left(10^{18} \mathrm{~nm}^{2} / \mathrm{m}^{2}\right) \times\left(S_{1}+I_{1}\right)}
$$

where the constant of $0.162 \mathrm{~nm}^{2}$ is the molecular cross-sectional area of the analysis gas $\left(\mathrm{N}_{2}\right)$; $6.023 \times 10^{23}$ is the Avogadro number; $22414 \mathrm{~cm}^{3}$ is the volume of 1 mole gas at standard temperature and pressure (STP); $S_{1}\left(\mathrm{~g} / \mathrm{cm}^{3} \mathrm{STP}\right)$ and $I_{1}\left(\mathrm{~g} / \mathrm{cm}^{3} \mathrm{STP}\right)$ are the slope $\left(C-1 / Q_{\mathrm{BET}} \times C\right)$ and intercept $\left(1 / Q_{\mathrm{BET}} \times C\right)$ of a plot of $1 / Q(p \% p-1)$ versus $p / p^{\circ}$ (Equation $\left.\mathrm{S} 2\right)$, respectively; and the parameter $C$ of the BET equation is obtained using Equation S3.

$$
\begin{aligned}
& \frac{1}{Q\left(p^{o} / p-1\right)}=\frac{C-1}{Q_{B E T} \times C} p / p^{o}+\frac{1}{Q_{B E T} \times C} \\
& C=\frac{S_{1}+I_{1}}{I_{1}}=\frac{1}{Q_{B E T} \times I_{1}} \\
& V_{\text {total }}=\frac{Q_{0.99}}{647} \\
& L_{o}=\frac{4 \times V_{\text {total }}}{S_{B E T}} \times 1000
\end{aligned}
$$

where $Q$ is the adsorbed quality in volume $\left(\mathrm{cm}^{3} / \mathrm{g} \mathrm{STP}\right) ; Q_{0.99}$ is the adsorbed quality in volume at a relative pressure $\left(p / p^{\circ}\right)$ of $0.99\left(\mathrm{~cm}^{3} / \mathrm{g} \mathrm{STP}\right) ; C$ is indicative of the energy of the adsorption process (positive and dimensionless); $Q_{\mathrm{BET}}$ is the monolayer capacity in volume $\left(\mathrm{cm}^{3} / \mathrm{g} \mathrm{STP}\right)$; and $p / p^{\circ}$ is the relative pressure.

Section S2. Additional discussion electrical double layer (EDL)

Based on several researchers (Doğan et al., 2009; Weng et al., 2009; Weng and Wu, 2012), the thickness of the EDL $(1 / \kappa ; \mathrm{nm})$ can be calculated using Equation 6. 


$$
\frac{1}{\kappa}=\sqrt{\frac{2 F^{2} I \times 1000}{\varepsilon \varepsilon_{o} R T}}
$$

where $I$ is the ionic strength $(\mathrm{M}) ; F$ is the Faraday constant $(96500 \mathrm{C} / \mathrm{mol}) ; R$ is the gas constant $(8.314 \mathrm{~J} / \mathrm{mol} \times \mathrm{K}) ; \varepsilon$ is the dielectric constant of water $(78.5) ; \varepsilon_{\mathrm{o}}$ is the vacuum permittivity $(8.854 \times$ $\left.10^{12} \mathrm{C} / \mathrm{V} \times \mathrm{m}\right)$; and $T$ is the absolute temperature in Kelvin $(\mathrm{K})$.

Section S3. Additional discussion on adsorption kinetics

In the batch adsorption study, the amounts of adsorbate adsorbed onto biosorbent in equilibrium $\left(q_{\mathrm{e}} ; \mathrm{mg} / \mathrm{g}\right)$ and at time $\mathrm{t}\left(q_{\mathrm{t}} ; \mathrm{mg} / \mathrm{g}\right)$ are always calculated using the mass balance equations, as follows:

$$
\begin{aligned}
& q_{e}=\frac{\left(C_{o}-C_{e}\right)}{m} V \\
& q_{t}=\frac{\left(C_{o}-C_{t}\right)}{m} V
\end{aligned}
$$

where $C_{\mathrm{o}}(\mathrm{mg} / \mathrm{L}), C_{\mathrm{e}}(\mathrm{mg} / \mathrm{L})$, and $C_{\mathrm{t}}(\mathrm{mg} / \mathrm{L})$ are the adsorbate concentrations in the beginning, in equilibrium, and at time $t$, respectively; $m(\mathrm{~g})$ is the mass of the used biosorbent; and $V(\mathrm{~L})$ is the volume of the adsorbate solution. Therefore, the $m / V$ ratio is defined as solid/liquid ratio.

The pseudo-second-order equation (Blanchard et al., 1984) can be expressed in nonlinear (Equation S9) and linear form (Equation S10):

$$
\begin{aligned}
& q_{t}=\frac{q_{e}^{2} k_{2} t}{1+k_{2} q_{e} t} \\
& \frac{t}{q_{t}}=\left(\frac{1}{q_{e}}\right) t+\frac{1}{k_{2} q_{e}^{2}}
\end{aligned}
$$

where $q_{e}$ and $q_{t}$ are the amounts of adsorbed adsorbate per adsorbent mass (mg/g) in equilibrium and at time $t(\mathrm{~min})$, respectively; and $k_{2}(\mathrm{~g} / \mathrm{mg} \times \min )$ is the rate constant of the pseudo-second-order equation.

The activation energy ( $E$ a) of the adsorption process (in $\mathrm{kJ} / \mathrm{mol}$ ) is defined as the minimum energy that must be overcome by the adsorbate molecules and can be computed through the Arrhenius equation: 
$\ln k_{2}=-\left(\frac{E_{a}}{R}\right) \frac{1}{T}+\ln A$,

where $k_{2}(\mathrm{~g} / \mathrm{mg} \times \mathrm{min})$ is the rate constant of the second-order reactions; $A$ is the pre-exponential factor (frequent factor); $R(8.314 \mathrm{~J} / \mathrm{mol} \times \mathrm{K})$ is the gas constant; and $T(\mathrm{~K})$ is the solution temperature in Kelvin.

Section S4. Additional discussion on adsorption isotherm

The Langmuir model (Langmuir, 1918) can be expressed in nonlinear (Equation S12) and linear (common) forms (Equation S13):

$$
\begin{aligned}
& q_{e}=\frac{Q^{o}{ }_{\max } K_{L} \mathrm{C}_{\mathrm{e}}}{1+K_{L} C_{e}} \\
& \frac{C_{e}}{q_{e}}=\left(\frac{1}{Q_{\max }^{o}}\right) C_{e}+\frac{1}{Q_{\max }^{o} K_{L}},
\end{aligned}
$$

where $C_{\mathrm{e}}$ and $q_{\mathrm{e}}$ are obtained from Equation $\mathrm{S} 7, K_{\mathrm{L}}(\mathrm{L} / \mathrm{mg})$ is the constant related to the affinity between an adsorbent and adsorbate; and $Q^{\circ}{ }_{\max }(\mathrm{mg} / \mathrm{g})$ is the maximum Langmuir adsorption capacity of a certain adsorbent under fixed experimental conditions (i.e., temperature, $\mathrm{pH}$, time, etc.).

Section S5. Additional discussion on adsorption thermodynamics

The thermodynamic parameters for a liquid-phase reaction under non-standard state conditions (concentrations are not all one molar) are calculated using the van't Hoff approach that was described as the following equations:

$\Delta G=-R T \ln K_{C}$

$\Delta H=-R\left[\frac{\partial \ln K_{C}}{\partial(1 / T)}\right]$

$\Delta S=-\frac{(\Delta G-\Delta H)}{T}$

where $K_{\mathrm{C}}$ is the equilibrium constant (dimensionless) of a reaction based on the molar concentrations; $T$ is the absolute temperature (in Kelvin; $K)$; and $R(8.314 \mathrm{~J} / \mathrm{mol} \times \mathrm{K}$ ) is the universal gas constant. 
Equation S15 is the known van't Hoff equation. As shown in Equation S14, the equilibrium constant $K_{\mathrm{c}}$ must be dimensionless for dimension consistency.

The literature survey indicates that there are three ways to obtain the thermodynamic parameters of an adsorption process, depending on the expression of the $K_{\mathrm{C}}$ value in Equations S14 and S15:

(1) The $K_{\mathrm{C}}$ value is directly replaced by the adsorption isotherm constant including the Langmuir, Frumkin, Temkin, Flory-Huggins, Redlich-Peterson, and Henry equations (Chang et al., 2016; Tran et al., 2017b).

(2) The $K_{\mathrm{c}}$ value is substituted by the thermodynamic partition coefficient $\left(K_{p}^{o}\right)$. The changes in the $K_{p}^{o}$ values with temperature were initially studied by Biggar and Cheung (1973) for picloram adsorption on different soils. The thermodynamic partition coefficient is defined as follows:

$$
K_{p}^{o}=\frac{a_{s}}{a_{e}}=\frac{\gamma_{s} C_{s}}{\gamma_{e} C_{e}}
$$

where $a_{\mathrm{s}}$ and $a_{\mathrm{e}}$ are the activities of the adsorbate adsorbed on the adsorbent and in solution at equilibrium, respectively; $\gamma_{\mathrm{s}}$ and $\gamma_{\mathrm{e}}$ are the corresponding activity coefficients; and $C_{\mathrm{s}}$ and $C_{\mathrm{e}}$, both in $\mathrm{mg} / \mathrm{L}$, are the equilibrium concentrations of the adsorbate adsorbed on the adsorbent and in solution, respectively.

When the initial concentration of the adsorbate in solution approaches zero, which results in $C_{\mathrm{s}} \rightarrow 0$ and $C_{\mathrm{e}} \rightarrow 0$, the value of $\gamma_{\mathrm{s}}$ and $\gamma_{\mathrm{e}}$ approaches unity. Equation $\mathrm{S} 17$ can thus be written as:

$$
\lim _{C_{s} \rightarrow 0} K_{p}^{o}=\frac{C_{s}}{C_{e}}
$$

In this case, the $K_{p}^{o}$ value can be obtained by plotting $\ln \left(C_{\mathrm{s}} / C_{\mathrm{e}}\right)$ versus $C_{\mathrm{s}}$ and extrapolating $C_{\mathrm{s}}$ to zero. If a straight line fits the data with a high regression coefficient $\left(R^{2}\right)$ and its intersection with the vertical axis provides the value of $K_{p}^{o}$, the partition coefficient is in unison with the equilibrium constant KC.

(3) The $K_{\mathrm{C}}$ value is expressed by the distribution coefficient $\left(K_{\mathrm{d}}\right)$, which is defined by the following equation (Khan and Singh, 1987):

$$
K_{d}=\frac{q_{e}}{C_{e}}
$$


In this case, the $K_{\mathrm{d}}$ values are obtained by plotting $\ln \left(q_{\mathrm{e}} / C_{\mathrm{e}}\right)$ against $C_{\mathrm{e}}$ and extrapolating to zero

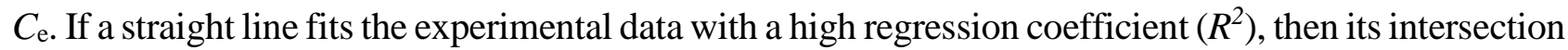
with the vertical axis provides the value of $K_{\mathrm{d}}$. However, the distribution coefficient $K_{\mathrm{d}}$ is dimensional; therefore, it is necessary to convert $K_{\mathrm{d}}$ (dimensional) into $K_{\mathrm{C}}$ (dimensionless) using several appropriate methods (Milonjić, 2009; Tran et al., 2017b). Notably, the distribution and partition coefficients are only appropriate to determine the thermodynamic parameters if the initially used adsorbate concentration is low (infinite dilution). In this situation, the distribution coefficient $K_{\mathrm{d}}$ and partition coefficient $K_{\mathrm{p}}$ will be in unison with the equilibrium constant $K_{\mathrm{c}}$ (Chang et al., 2016).

Section S6. Additional discussion on adsorption dynamics

The Thomas model is commonly applied to estimate the maximum adsorption capacity of the adsorbent under given experimental conditions.

$$
\begin{aligned}
& \frac{C_{t}}{C_{o}}=\frac{1}{1+\exp \left(k_{T H} q_{o} \frac{m_{3}}{Q}-k_{T H} C_{o} t\right)} \\
& \ln \left(\frac{C_{o}}{C_{t}}-1\right)=k_{T H} q_{o} \frac{m_{3}}{Q}-k_{T H} C_{o} t
\end{aligned}
$$

where $k_{T H}(\mathrm{~mL} / \mathrm{min} \times \mathrm{mg})$ is the Thomas adsorption rate constant; $q_{o}(\mathrm{mg} / \mathrm{g})$ is the maximum equilibrium adsorbate uptake per gram of adsorbent in the column; $m_{3}(\mathrm{~g})$ is the mass of the adsorbent used in the column; $C_{\mathrm{o}}(\mathrm{mg} / \mathrm{g})$ is the adsorbate concentration; and $Q(\mathrm{~mL} / \mathrm{min})$ is the volumetric flow rate. Notably, the breakthrough time $\left(\mathrm{t}_{b} ; \min \right)$ and exhaustion (or saturation) time $\left(t_{s} ; \min \right)$ can be obtained when the effluent concentration of the adsorbate reaches approximately $10 \%$ and $95 \%$ of the influent adsorbate concentration, respectively (Ali and Gupta, 2007).

Section S7. Additional discussion on identifying functional groups relevant for the adsorption mechanism

\section{Adsorption of potentially toxic metals, fluoride, uranium, and ammonium}

Meanwhile, Chen et al. (2010a) compared the FTIR spectrum of camphor leaves before and after $\mathrm{Cu}(\mathrm{II})$ adsorption. They concluded that the amino and hydroxyl groups play a pivotal role in 


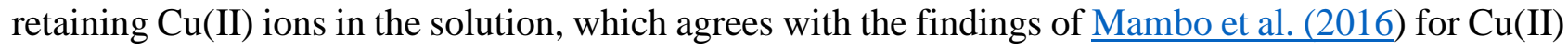
adsorption onto chemically treated potato leaves. In addition, Vilvanathan and Shanthakumar (2016) found that major hydroxyl, carboxyl, and amine functional groups are mainly responsible for capturing $\mathrm{Co}(\mathrm{II})$ and $\mathrm{Ni}(\mathrm{II})$ ions on the biosorbent based onto teak leaves. This agrees with the observations of Kamar Firas et al., 2017 for $\mathrm{Pb}(\mathrm{II}), \mathrm{Cd}(\mathrm{II})$, and $\mathrm{Cu}(\mathrm{II})$, regarding the uptake by cabbage leaves, and of Hossain et al., 2014c, regarding $\mathrm{Cu}(\mathrm{II}), \mathrm{Zn}(\mathrm{II}), \mathrm{Cd}(\mathrm{II})$, and $\mathrm{Pb}(\mathrm{II})$ adsorption onto cabbage leaves.

Moreover, some contributory functional groups (hydroxyl, carboxyl, amino, ether, phe9nolic and phosphate) are 0known as active groups of rubber leaves retaining $\mathrm{Cu}(\mathrm{II})$ ions in solution $\underline{\mathrm{Ngah}}$ and Hanafiah, 2009. For example, Amirnia et al. (2016) stated that active functional groups (hydroxide, phosphorous, and carboxyl) present in maple leaves greatly contribute to $\mathrm{Cu}(\mathrm{II})$ biosorbent interactions. Based on FTIR data, Zahedi et al. (2015) proved that the carboxyl and sulfhydryl groups on the surface of $\mathrm{MgCl}_{2}$-treated white water lily leaves mainly interact with $\mathrm{Ni}(\mathrm{II})$ of $\mathrm{MgCl}_{2}$-treated white water lily leaves. In contrast, Dabbagh et al. (2016) highlighted that sulfonic acid is a dominant functional group accumulating $\mathrm{Co}$ (II) ions onto modified fig leaves. Furthermore, Bose et al. (2016) found that carboxylic, thiol, and sulfahydral groups are primarily responsible for adsorbing $\mathrm{Cd}(\mathrm{II})$ ions onto Urticaceae leaves. The great participation of hydroxyl, carboxylate, phosphate, ether, and amino functional groups in the removal of $\mathrm{Cu}$ (II) ions by $\mathrm{NaOH}$-treated weed leaves has been identified by Hanafiah et al. (2009b).

In addition, Gebrehawaria et al. (2015) proposed that polar functional groups, such as $-\mathrm{OH}$, $-\mathrm{NH}$ and $-\mathrm{C}=\mathrm{O}$ (amide), are mainly related to $\mathrm{Cr}(\mathrm{VI})$ adsorption. However, Mozumder et al. (2008) emphasized that only the amine groups take part in the $\mathrm{Cr}(\mathrm{VI})$ adsorption onto tea-leaf waste. In their study, Zhang et al. (2015) reported the great contribution of the $-\mathrm{COOH},-\mathrm{NH}_{2}$, and $\mathrm{O}-\mathrm{CH}_{3}$ groups of poly(vinyl alcohol)-modified tea waste in removing $\mathrm{Pb}(\mathrm{II}), \mathrm{Hg}(\mathrm{II})$, and $\mathrm{Cu}(\mathrm{II})$. In contrast, the comparison of the FTIR spectra of black tea waste before and after adsorption indicated that the functional groups contributing to $\mathrm{Cu}(\mathrm{II})$ adsorption are the $-\mathrm{OH},-\mathrm{CH}$, and $-\mathrm{C}=\mathrm{C}$ groups (Weng et al., 2014a). Based on XPS and FTIR data, Shi et al. (2016b) concluded that the C-C or C-H, C-O, and $\mathrm{O}-\mathrm{C}=\mathrm{O}$ groups provide the vital sites for the adsorption of $\mathrm{Pb}(\mathrm{II})$ by arborvitae leaves.

Moreover, Xia et al. (2013) proposed that the uranium adsorption onto Banyan leaves mainly involves the $-\mathrm{OH}, \mathrm{C}=\mathrm{O}, \mathrm{P}-\mathrm{O}$, and $\mathrm{Si}=\mathrm{O}$ groups. With respect to fluoride adsorption, the comparison of the FTIR results of neem leaf powder before and after biosorption revealed that the peak intensities at approximately $3468 \mathrm{~cm}^{-1}(-\mathrm{OH}), 2372 \mathrm{~cm}^{-1}(-\mathrm{C} \equiv \mathrm{N})$, and $1640 \mathrm{~cm}^{-1}(\mathrm{C}=\mathrm{O})$ decreased and the peaks slightly shifted to $3456 \mathrm{~cm}^{-1}, 2369 \mathrm{~cm}^{-1}$, and $1608 \mathrm{~cm}^{-1}$, respectively. This demonstrates the vital role such functional groups play in the adsorption (Bharali and Bhattacharyya, 2015). Based on 
FTIR analysis, researchers proposed that the hydroxyl, phenol, and carboxyl groups predominantly contribute to the adsorption of ammonium onto leaf-produced biosorbents including cactus leaves (Wahab et al., 2012), Boston ivy leaves (Liu et al., 2010c), and strawberry leaves (Liu et al., 2010d).

As noted earlier, FTIR can be used to qualitatively identify the integral role of the biosorbent surface functionality in adsorbing potentially toxic metals. Therefore, some authors used the chemical blocking method involving active functional groups to quantitatively analyze the contribution of principal functional groups (i.e., carboxylic and hydroxyl groups). Based on the literature, carboxylic groups on the adsorbent can be individually blocked by acidified methanol $\left(\mathrm{HCl}\right.$ and $\left.\mathrm{CH}_{3} \mathrm{OH}\right)$, while the hydroxyl group is blocked by formaldehyde (HCHO). For example, Muhammad et al. (2009) compared the adsorption capacity of pristine and functional group-blocked biosorbents. They found that the adsorption capacity of the biosorbents remarkably decreased after blocking of carboxyl groups [by $78.6 \%$ for $\mathrm{Ni}$ (II) adsorption and $73.3 \%$ for $\mathrm{Zn}(\mathrm{II})$ adsorption]. Meanwhile, the adsorption capacity of hydroxyl group-blocked biosorbents decreased by $22.6 \%$ for $\mathrm{Ni}$ (II) adsorption and $28.5 \%$ for $\mathrm{Zn}(\mathrm{II})$ adsorption.

Likewise, Iqbal et al. (2009) elaborated that the chemical modification of mango peel waste to block carboxyl and hydroxyl groups demonstrates the larger contribution of the carboxylic group (73\% and $76 \%$ ) to the adsorption of $\mathrm{Cd}(\mathrm{II})$ and $\mathrm{Pb}(\mathrm{II})$ than that of the hydroxyl group (27\% and $24 \%$ ), respectively. The result is consistent with the FTIR analysis; the carboxyl and hydroxyl functional groups are mainly responsible for the adsorption process. Meanwhile, Chojnacka et al. (2005) stated that the $\mathrm{Cr}(\mathrm{III})$ adsorption process is hindered when the carboxyl and phosphate groups on the biosorbent surface are esterified, suggesting their significant role in the biosorption process.

To investigate the contribution of functional groups (i.e., carboxyl, carbonyl, amino, phosphate, hydroxyl, and sulfhydryl) to the biosorption of toxic metals, Ramrakhiani et al. (2017) compared the adsorption ability of pristine and chemically modified biosorbents. They reported that the adsorption capacity of pristine biosorbents decreases after chemical modification of these functional groups by esterification of the carboxylic acids, hydroxyl group, and phosphate group. In addition, methylation of amines and modification of the sulfhydryl and carbonyl groups were observed. 
Table S1. Textural properties of leaf-derived biosorbents

\begin{tabular}{|c|c|c|c|c|c|c|c|}
\hline \multirow[b]{2}{*}{ Leaves } & \multicolumn{2}{|c|}{ Textural property } & \multirow[b]{2}{*}{ Ref. } & \multirow[b]{2}{*}{ Leaves } & \multicolumn{2}{|c|}{ Textural property } & \multirow[b]{2}{*}{ Ref. } \\
\hline & $\begin{array}{c}\mathbf{S}_{\text {BET }} \\
\left(\mathbf{m}^{2} / \mathbf{g}\right)\end{array}$ & $\begin{array}{c}V_{\text {total }} \\
\left(\mathrm{cm}^{3} / \mathrm{g}\right)\end{array}$ & & & $\begin{array}{c}\mathbf{S}_{\mathrm{BET}} \\
\left(\mathrm{m}^{2} / \mathrm{g}\right)\end{array}$ & $\begin{array}{c}V_{\text {total }} \\
\left(\mathrm{cm}^{3} / \mathrm{g}\right)\end{array}$ & \\
\hline Almond & 67.0 & 0.062 & (1) & Pineapple & 5.24 & 0.021 & (31) \\
\hline Jambolan & 53.3 & - & (2) & Bamboo & 3.41 & - & (32) \\
\hline Neptune grass & 38.9 & 0.041 & (3) & Taro & 3.33 & 0.015 & (33) \\
\hline Boston ivy & 31.9 & - & (4) & Oil palm & 2.59 & 0.002 & (34) \\
\hline Arborvitae & 29.5 & - & (5) & Mango & 2.38 & - & (35) \\
\hline Rubber & 29.2 & - & (6) & Strawberry & 2.05 & - & (36) \\
\hline Eggplant & 26.4 & 0.017 & (7) & Mucilaginous & 1.85 & 0.008 & (37) \\
\hline Tiger's claw & 25.3 & - & (8) & Guava & 1.70 & - & (38) \\
\hline Treated cluster fig & 21.2 & 0.066 & (9) & Jackfruit & 1.66 & - & (39) \\
\hline Neem & 21.5 & - & (10) & Southern magnolia & 1.54 & - & (40) \\
\hline Esparto grass & 20.7 & 0.11 & (11) & Used tea & 1.34 & - & $(41)$ \\
\hline Treated Potato & 17.6 & 0.007 & (12) & Cabbage wastes & 1.03 & - & $(42)$ \\
\hline Oriental plane & 15.4 & 0.006 & (13) & Brazilian orchid & 1.27 & - & (43) \\
\hline Roxburgh fig & 15.3 & - & (14) & Modified boxwood & 1.26 & 0.005 & (44) \\
\hline Tea & 13.0 & 0.011 & (15) & Golden shower & 1.09 & 0.002 & (45) \\
\hline Sugar maple & 11.6 & 0.011 & (16) & Cabbage & 1.03 & - & (46) \\
\hline Bamboo & 11.5 & - & (17) & Green honey myrtle & 0.99 & - & (47) \\
\hline Jackfruit & 11.2 & 0.004 & (18) & Teak & 0.96 & - & (48) \\
\hline Tea & 11.0 & 0.009 & (19) & Persimmon & 0.95 & - & (49) \\
\hline Maple & 10.9 & 0.001 & (20) & Cauliflower wastes & 0.89 & - & $(50)$ \\
\hline Tomato & 8.80 & 0.003 & (21) & Tea waste & 0.86 & - & $(51)$ \\
\hline Guava & 8.33 & - & (22) & Tea waste & 0.79 & - & $(52)$ \\
\hline Tea & 8.00 & 0.008 & (23) & Hornbeam & 0.70 & - & (53) \\
\hline Lotus & 7.12 & 0.009 & $(24)$ & Neem & 0.57 & - & $(54)$ \\
\hline Tea & 7.01 & 0.005 & $(25)$ & Rubber & 0.48 & - & $(55)$ \\
\hline Pineapple & 6.86 & - & (26) & Labill & 0.38 & - & $(56)$ \\
\hline Treated persimmon & 6.63 & - & (27) & Strawberry & 0.35 & - & (57) \\
\hline Sacred fig & 6.14 & 0.061 & (28) & Coconut & 0.24 & - & $(58)$ \\
\hline Tea & 6.00 & 0.003 & (29) & Rambai & 0.16 & - & (59) \\
\hline Australian pine & 5.91 & 0.006 & $(30)$ & Phoenix & 0.08 & 一 & $(60)$ \\
\hline
\end{tabular}

Note: Average: $S_{\mathrm{BET}}=9.91 \pm 13.37(n=60)$ and $V_{\mathrm{total}}=0.019 \pm 0.027(n=25)$; Median: $S_{\mathrm{BET}}=5.58$ and $V_{\text {total }}$ $=0.008$.

References: (1) Jain and Gogate, 2017b, (2) Rao et al., 2010c, (3) Dural et al., 2011, (4) Liu et al., 2010a, (5) Shi et al., 2016b, (6) Nag et al., 2016, (7) Yuvaraja et al., 2014, (8) Aditya et al., 2012, (9) Jain and Gogate, 2017c, (10) Sharma and Bhattacharyya, 2008, (11) Lafi et al., 2015, (12) Mambo et al., 2016, (13) Peydayesh and Rahbar-Kelishami, 2015, (14) Rangabhashiyam et al., 2015, (15) Peng et al., 2013, (16) Amirnia et al., 2016, (17) Nag et al., 2017, (18) Saha et al., 2012a, (19) Peng et al., 2013, (20) Hossain et al., 2014b, (21) Gutha et al., 2015, (22) Abdelwahab et al., 2015, (23) Peng et al., 2013, (24) Han et al., 2011, (25) Peng et al., 2013, (26) 27 Ruiyi et al., 2016, (28) Qaiser et al., 2009, (29) Peng et al., 2013 (30), Khan Rao and Khatoon, 2017, (31) Weng et al., 2009, (32) Chen et al., 2011a, (33) Nakkeeran et al., 2016, (34) Setiabudi et al., 2016b, (35) Nag et al., 2017, (36) Liu et al., 2010d, (37) Edokpayi et al., 2015, (385) Gaikwad and Kinldy, 2009, (39) Nag et al., 2017, (40) Liu et al., 2010a, (41) $\underline{\text { Hossain }}$ et al., 2005, (42) Hossain et al., 2014d, (43) Jorgetto et al., 2015, (44) Zolgharnein et al., 2017b, (45) Ahmad et al., 2017b, (46) Hossain et al., 2014c, (47) Kuppusamy et al., 2016, (48) Vilvanathan and Shanthakumar, 2016, (49) Ruiyi et al., 2016, (50) Hossain et al., 2014d, (51) Wan et al., 2014, (52) Amarasinghe and Williams, 2007, (53) Zolgharnein et al., 2013a, (54) Singha and Das, 2012, (55) Hanafiah and Ngah, 2009, (56) Yang and Hong, 2018a, (57) Liu et al., 2010a, (58) Gowda et al., 2012, (59) Sen et al., 2011, (60) Li et al., 2009. 
Table S2. Ultimate analysis (wt.\%) of leaf-based biosorbents

\begin{tabular}{|c|c|c|c|c|c|c|c|c|}
\hline Leaves & $\mathbf{C}$ & $\mathbf{H}$ & $\mathbf{N}$ & $\mathbf{S}$ & $\mathbf{O} *$ & $\mathbf{H} / \mathrm{C}$ & $\mathrm{O} / \mathrm{C}$ & Reference \\
\hline Roxburgh fig & 31.1 & 4.08 & 0.77 & - & 64.1 & 1.57 & 1.55 & $\underline{\text { Rangabhashiyam et al., } 2015}$ \\
\hline Esparto grass & 44.3 & 6.5 & 0.6 & - & 46.5 & 1.76 & 0.79 & $\underline{\text { Lafi et al., } 2015}$ \\
\hline Grey nicker & 59.2 & 7.20 & 2.20 & - & 31.4 & 1.46 & 0.40 & Yuvaraja et al., 2012 \\
\hline Sacred fig & 48.4 & 7.30 & 1.12 & 0.12 & 43.1 & 1.81 & 0.67 & Qaiser et al., 2009 \\
\hline Neptune grass & 38.5 & 5.60 & 0.62 & - & 55.3 & 1.75 & 1.08 & Meseguer et al., 2016 \\
\hline Taro & 37.1 & 3.81 & 2.35 & 0.36 & 56.4 & 1.23 & 1.14 & $\underline{\text { Nakkeeran et al., } 2016}$ \\
\hline Judas & 43.3 & 6.94 & 3.61 & - & 46.2 & 1.92 & 0.80 & Zolgharnein et al., 2013b \\
\hline Hardy catalpa & 43.1 & 5.50 & 2.79 & - & 48.6 & 1.53 & 0.85 & $\underline{\text { Zolgharnein et al., } 2015}$ \\
\hline Southern cattail & 43.5 & 10.1 & 2.49 & 1.21 & 42.9 & 2.79 & 0.74 & $\underline{\text { Abdel-Ghani et al., } 2009}$ \\
\hline Bamboo & 44.0 & 6.20 & 2.57 & - & 47.2 & 1.69 & 0.80 & $\underline{\text { Chen et al., 2011a }}$ \\
\hline Globe artichoke & 42.4 & 6.09 & 1.01 & 0.21 & 50.3 & 1.72 & 0.89 & Benadjemia et al., 2011 \\
\hline Brazilian orchid & 46.7 & 5.57 & 1.68 & 0.31 & 46.1 & 1.43 & 0.74 & $\underline{\text { Jorgetto et al., } 2015}$ \\
\hline Hornbeam & 41.6 & 5.95 & 2.22 & - & 50.2 & 1.81 & 1.81 & $\underline{\text { Zolgharnein et al., 2013a }}$ \\
\hline Almond & 40.4 & 4.44 & 0.34 & - & 63.4 & 1.75 & 1.75 & $\underline{\text { Jain and Gogate, } 2017 \mathrm{~b}}$ \\
\hline Drumstick & 47.2 & 6.79 & 2.47 & 0.59 & 42.9 & 1.73 & 0.68 & $\underline{\text { Reddy et al., } 2010}$ \\
\hline Rubber & 51.1 & 6.89 & 1.09 & - & 40.9 & 1.62 & 0.60 & Ngah and Hanafiah, 2009 \\
\hline $\mathrm{NaOH}$-treated rubber & 50.2 & 6.63 & 1.09 & - & 42.1 & 1.58 & 0.63 & Ngah and Hanafiah, 2008 \\
\hline $\mathrm{NaOH}$-treated almond & 40.4 & 4.44 & 0.34 & - & 54.8 & 1.32 & 1.02 & $\underline{\text { Jain and Gogate, 2017b }}$ \\
\hline Average & 44.0 & 6.11 & 1.63 & 0.47 & 48.5 & 1.69 & 0.94 & - \\
\hline$S D$ & 6.12 & 1.47 & 0.98 & 0.40 & 8.12 & 0.33 & 0.39 & - \\
\hline Minimum & 31.1 & 3.81 & 0.34 & 0.12 & 31.4 & 1.23 & 0.41 & - \\
\hline Maximum & 59.2 & 10.1 & 3.61 & 1.21 & 64.1 & 2.79 & 1.81 & - \\
\hline Median & 43.4 & 6.15 & 1.40 & 0.34 & 46.9 & 1.71 & 0.8 & - \\
\hline
\end{tabular}

Note: Calculated by difference; the $\mathrm{H} / \mathrm{C}$ and $\mathrm{O} / \mathrm{C}$ atomic ratio; $\mathrm{SD}$ means standard deviation 
Table S3. Proximate analysis (wt.\%) of leaf-based biosorbent

\begin{tabular}{|c|c|c|c|c|c|}
\hline Leaves & Moisture & Volatile & $\begin{array}{c}\text { Total } \\
\text { ash }\end{array}$ & $\begin{array}{c}\text { Fixed } \\
\text { carbon }\end{array}$ & Reference \\
\hline Eucalyptus & 4.40 & 57.1 & 4.10 & 34.5 & Mishra et al., 2010 \\
\hline Gulmohar & 4.9 .0 & 85.5 & 7.80 & 1.80 & $\underline{\text { Ponnusami et al., 2009b }}$ \\
\hline Teak & 8.09 & 30.8 & 30.8 & 30.3 & Vilvanathan and Shanthakumar, 2016 \\
\hline Ashoka & 12.4 & 68.5 & 14.8 & 4.41 & Gupta et al., 2012b \\
\hline Roxburgh fig & 4.03 & 62.0 & 24.5 & 9.50 & $\underline{\text { Rangabhashiyam et al., } 2015}$ \\
\hline Jamun & 7.05 & 27.6 & 6.11 & 59.3 & $\underline{\text { Rehman et al., } 2014}$ \\
\hline Guava & 5.81 & 61.5 & 9.58 & 34.1 & $\underline{\text { Kamsonlian et al., 2012b }}$ \\
\hline Drumstick & 8.08 & 36.5 & 12.7 & 42.8 & $\underline{\text { Bello et al., } 2017}$ \\
\hline Carrot & 7.65 & 81.4 & 9.21 & 1.75 & $\underline{\text { Kushwaha et al., 2014b }}$ \\
\hline Potato & 8.19 & 72.1 & 17.6 & 2.15 & $\underline{\text { Gupta et al., 2016b }}$ \\
\hline Tomato & 2.25 & - & 2.32 & - & $\underline{\text { Gutha et al., } 2015}$ \\
\hline Eggplant & 3.46 & & 3.12 & - & $\underline{\text { Yuvaraja et al., } 2014}$ \\
\hline Gum arabic & 8.71 & - & 9.95 & - & Prasad and Thirumalisamy, 2013 \\
\hline Grey nicker & 2.10 & - & 9.12 & - & $\underline{\text { Yuvaraja et al., } 2012}$ \\
\hline Pineapple & 5.01 & - & 6.01 & - & $\underline{\text { Ponou et al., } 2011}$ \\
\hline Neem & 8.33 & - & 13.6 & - & $\underline{\text { Singha and Das, } 2012}$ \\
\hline Jackfruit & 4.88 & - & 16.6 & - & $\underline{\text { Nag et al., } 2017}$ \\
\hline Mango & 5.86 & - & 12.9 & - & $\underline{\text { Nag et al., } 2017}$ \\
\hline Mango & 5.80 & 81.5 & 9.58 & 3.13 & $\underline{\text { Kamsonlian et al., 2012c }}$ \\
\hline Grey nicker & 2.10 & - & 9.12 & - & $\underline{\text { Yuvaraja et al., } 2012}$ \\
\hline Bamboo & 4.10 & - & 12.0 & - & $\underline{\text { Nag et al., } 2017}$ \\
\hline Average & 5.92 & 60.4 & 11.5 & 20.3 & - \\
\hline$S D$ & 2.66 & 20.6 & 6.83 & 20.5 & - \\
\hline Minimum & 2.10 & 27.6 & 2.32 & 1.75 & - \\
\hline Maximum & 4.40 & 57.1 & 4.10 & 34.5 & - \\
\hline Median & 5.81 & 62.0 & 9.58 & 9.50 & - \\
\hline
\end{tabular}

NOTE: SD means standard deviation 
Table S4. pH value and density of leaves-based biosorbent

\begin{tabular}{|c|c|c|c|c|c|}
\hline Leaves & $\mathbf{p H}$ & Ref. & Leaves & $\begin{array}{l}\text { Density } \\
\left(\mathrm{g} / \mathrm{cm}^{3}\right)\end{array}$ & References \\
\hline Roxburgh fig & 8.10 & $\underline{\text { Rangabhashiyam et al., } 2015}$ & Neem & 0.710 & Singha and Das, 2012 \\
\hline Drumstick & 7.08 & Bello et al., 2017 & Mango & 0.367 & $\underline{\text { Nag et al., } 2017}$ \\
\hline Gum arabic & 7.02 & $\begin{array}{l}\text { Prasad and Thirumalisamy, } \\
\underline{\underline{2013}}\end{array}$ & Used black tea & 0.340 & $\underline{\text { Hossain et al., } 2005}$ \\
\hline Phoenix & 6.60 & Li et al., 2009 & Guava & 0.333 & Gaikwad and Kinldy, 2009 \\
\hline Cauliflower & 6.50 & Ansari et al., 2016a & Jackfruit & 0.299 & $\underline{\text { Nag et al., } 2017}$ \\
\hline Leaf tea & 6.48 & $\underline{\text { Jenish and Methodis, } 2011}$ & $\begin{array}{l}\mathrm{H}_{2} \mathrm{SO}_{4} \text {-treated } \\
\text { rubber }\end{array}$ & 0.279 & $\underline{\text { Nag et al., } 2017}$ \\
\hline Castor & 6.28 & Makeswari and Santhi, 2014 & Bamboo & 0.214 & $\underline{\text { Nag et al., } 2017}$ \\
\hline Guava & 6.20 & Gaikwad and Kinldy, 2009 & Coconut & 0.117 & Gowda et al., 2012 \\
\hline Coconut & 6.02 & Gowda et al., 2012 & Gum arabic & 0.272 & $\begin{array}{l}\text { Prasad and Thirumalisamy, } \\
\underline{2013}\end{array}$ \\
\hline $\begin{array}{l}\text { Southern } \\
\text { magnolia }\end{array}$ & 6.01 & $\underline{\text { Liu et al., 2010a }}$ & Kush grass & 0.127 & Pandey et al., 2015b \\
\hline Poplar & 5.60 & Liu et al., 2010a & Bamboo & 0.166 & $\underline{\text { Pandey et al., 2015b }}$ \\
\hline Strawberry & 5.80 & $\underline{\text { Liu et al., 2010a }}$ & & & \\
\hline Boston ivy & 5.50 & Liu et al., 2010a & & & \\
\hline $\mathrm{NaOH}$-treated tea & 5.07 & Weng et al., 2014a & & & \\
\hline Coconut & 4.92 & Ngah and Hanafiah, 2009 & & & \\
\hline Tea & 4.75 & Weng et al., 2014a & & & \\
\hline
\end{tabular}


Table S5. Quantitative information on oxygen-containing functional groups (mmol/g)

\begin{tabular}{lcccccl}
\hline Leaves & Carboxylic & Phenolic & Lactonic & $\begin{array}{c}\text { Total } \\
\text { acid }\end{array}$ & $\begin{array}{c}\text { Total } \\
\text { basic }\end{array}$ & Reference \\
\hline Jamun & 1.99 & 0.003 & 0.001 & 1.99 & - & $\underline{\text { Rehman et al., 2014 }}$ \\
Castor & - & - & - & 4.75 & - & $\underline{\text { Makeswari and Santhi, 2014 }}$ \\
Tea industry waste & 1.03 & 0.98 & 0.46 & 2.47 & - & $\underline{\text { Gundogdu et al., 2013 }}$ \\
Raw lawny & - & - & - & 6.20 & 1.70 & $\underline{\text { Chen et al., 2011b }}$ \\
Esparto grass & 0.58 & 0.96 & 0.030 & 1.57 & 0.40 & $\underline{\text { Lafi et al., 2015 }}$ \\
Tea & 1.03 & 0.98 & 0.46 & 2.47 & - & $\underline{\text { Gundogdu et al., 2013 }}$ \\
Treated-globe artichoke & 3.71 & 3.85 & 2.30 & 9.85 & 2.82 & $\underline{\text { Kahina and Nasser, 2017 }}$ \\
Treated-lawny grass & - & - & - & 0.75 & 2.25 & $\underline{\text { Chen et al., 2011b }}$ \\
Palm & $0.85^{\mathrm{a}}$ & $0.65^{\mathrm{a}}$ & $2.80^{\mathrm{a}}$ & $4.30^{\mathrm{a}}$ & - & $\underline{\text { Abu Al-Rub, 2006 }}$ \\
\hline
\end{tabular}

Note: ${ }^{a}$ (meq $\mathrm{H}^{+} / 100 \mathrm{~g}$ ) 
Table S6. $\mathrm{pH}$ at the point of zero charge (pHpzc) of leaf-based biosorbents

\begin{tabular}{lcclcc}
\hline Leaves & pHrzc & Ref. & Leaves & pHpZc & Ref. \\
\hline Roxburgh fig & 8.00 & $(1)$ & Arborvitae & 5.30 & $(27)$ \\
Sacred fig & 7.59 & $(2)$ & Brazilian orchid & 5.24 & $(28)$ \\
Jambolan & 7.53 & $(3)$ & Castor & 5.06 & $(29)$ \\
Gulmohar & 7.50 & $(4)$ & Hardy catalpa & 4.75 & $(30)$ \\
Modified boxwood & 7.10 & $(5)$ & Grey nicker & 4.51 & $(31)$ \\
Hybrid plane & 7.00 & $(6)$ & Grey nicker & 4.50 & $(32)$ \\
Weeping willow & 6.98 & $(7)$ & Gum arabic & 4.42 & $(33)$ \\
Neem & 6.94 & $(8)$ & Judas & 4.41 & $(34)$ \\
Mango & 6.82 & $(9)$ & Tea waste & 4.20 & $(35)$ \\
Ash & 6.41 & $(10)$ & Boston fern & 4.01 & $(36)$ \\
Chinese ash & 6.40 & $(11)$ & Jackfruit & 3.91 & $(37)$ \\
Esparto grass & 6.30 & $(12)$ & Australian pine & 3.60 & $(38)$ \\
Jackfruit & 6.24 & $(13)$ & Eggplant & 3.52 & $(39)$ \\
Cauliflower & 6.23 & $(14)$ & Tomato & 3.50 & $(40)$ \\
Drago & 6.21 & $(15)$ & Pineapple & 2.81 & $(41)$ \\
Reed & 6.20 & $(16)$ & Maguey & 2.60 & $(42)$ \\
Terap & 6.20 & $(17)$ & Drumstick & 3.72 & $(43)$ \\
Carrot & 6.10 & $(18)$ & NaOH-treated terap & 8.10 & $(44)$ \\
Ashoka & 6.10 & $(19)$ & NaOH-treated weed & 7.34 & $(45)$ \\
Bamboo & 6.00 & $(20)$ & H 2 SO -treated rubber & 7.22 & $(46)$ \\
Camphor & 5.91 & $(21)$ & Ca(OH) -treated maize & 5.51 & $(47)$ \\
Potato & 5.90 & $(22)$ & NaOH-treated Kush grass & 5.50 & $(48)$ \\
Rubber & 5.71 & $(23)$ & NaOH-treated bamboo & 5.00 & $(49)$ \\
Hornbeam & 5.70 & $(24)$ & NaOH-treated persimmon & $3.30^{*}$ & $(50)$ \\
Treated Potato & 5.50 & $(25)$ & Pineapple & $2.30^{*}$ & $(51)$ \\
Treated Labill & 5.30 & $(26)$ & Black tea & $2.40^{*}$ & $(52)$ \\
\hline Nate: & & & &
\end{tabular}

Note: ${ }^{*} \mathrm{pH}_{\mathrm{IEP}}(\mathrm{pH}$ at the isoelectric point $)$.

References: (1) Rangabhashiyam et al., 2015, (2) Rao et al., 2011b, (3) Rao et al., 2010c, (4) Ponnusami et al., 2009b, (5) Zolgharnein et al., 2017b, (6) Kong et al., 2015, (7) Khodabandehloo et al., 2017, (8) Singha and Das, 2012, (9) Nag et al., 2017, (10) Zolgharnein et al., 2016, (11) Javad et al., 2017, (12) Lafi et al., 2015, (13) Nag et al., 2017, (14) Ansari et al., 2016a, (15) Mahmoud et al., 2016, (16) Markou et al., 2016b, (17) Lim et al., 2016b, (18) Kushwaha et al., 2014b, (19) Gupta et al., 2012b, (20) Mondal et al., 2013, (21) Chen et al., 2010a, (22) Gupta et al., 2016b, (23) Hanafiah and Ngah, 2009, (24) Zolgharnein et al., 2013a, (25) Mambo et al., 2016, (26) Yang and Hong, 2018a, (27) Shi et al., 2016b, (28) Jorgetto et al., 2015, (29) Makeswari and Santhi, 2014, (30) Zolgharnein et al., 2015, (31) Yuvaraja et al., 2012, (32) Yuvaraja et al., 2012, (33) Prasad and Thirumalisamy, 2013, (34)

Zolgharnein et al., 2013b, (35) Mozumder et al., 2008, (36) Rao and Khan, 2017, (37) Saha et al., 2012a, (38) Khan Rao and Khatoon, 2017, (39) Yuvaraja et al., 2014, (40) Gutha et al., 2015, (41) Ponou et al., 2011, (42) Hamissa et al., 2010, (43) Reddy et al., 2012, (44) Lim et al., 2016b, (45) Hanafiah et al., 2009b, (46) Nag et al., 2017, (47) Jalil et al., 2012b, (48) Pandey et al., 2015b, (49) Pandey et al., 2015b, (50) Ruiyi et al., 2016, (51) Weng et al., 2009, (52) Weng et al., 2014a. 
Table S7. Zeta potential of leaf-based biosorbent at a given solution $\mathrm{pH}$

\begin{tabular}{lcll}
\hline Leaves & $\zeta$-Potential $(\mathbf{m V})$ & $\mathbf{p H}$ & References \\
\hline Strawberry & -30.0 & 5.8 & $\underline{\underline{\text { Liu et al., 2010a }}}$ \\
Boston ivy & -27.4 & 5.8 & $\underline{\text { Liu et al., 2010a }}$ \\
Southern magnolia & -32.3 & 5.8 & $\underline{\text { Liu et al., 2010a }}$ \\
Poplar & -24.4 & 5.8 & $\underline{\text { Liu et al., 2010a }}$ \\
Green honey myrtle & -6.77 & 7.0 & $\underline{\text { Kuppusamy et al., 2016 }}$ \\
Treated persimmon & -6.12 & 5.0 & $\underline{\text { Ruiyi et al., 2016 }}$ \\
Tobacco leaves & -20.5 & 5.0 & Qi and Aldrich, 2008 \\
\hline
\end{tabular}


Table S8. Comparison of maximum adsorption capacity $\left(Q^{\circ} \max , \mathrm{mg} / \mathrm{g}\right.$ ) of pristine biosorbent calculated from the Langmuir model (single component)

\begin{tabular}{|c|c|c|c|c|c|c|c|}
\hline \multirow{2}{*}{ Leaves } & \multicolumn{5}{|c|}{ Experimental conditions } & \multirow{2}{*}{$\begin{array}{c}\mathbf{Q}^{0} \max \\
(\mathrm{mg} / \mathrm{g})\end{array}$} & \multirow{2}{*}{ References } \\
\hline & $\begin{array}{l}\mathrm{m} / \mathrm{V} \\
(\mathrm{g} / \mathrm{L})\end{array}$ & $\begin{array}{c}\mathrm{t} \\
(\mathrm{h})\end{array}$ & $\begin{array}{c}\mathrm{T} \\
\left({ }^{\circ} \mathrm{C}\right)\end{array}$ & $\mathrm{pH}$ & $\begin{array}{c}\mathrm{C}_{\mathrm{o}} \text { range } \\
(\mathrm{mg} / \mathrm{L})\end{array}$ & & \\
\hline
\end{tabular}

\section{Copper-Cu(II)}

\begin{tabular}{|c|c|c|c|c|c|c|c|}
\hline Castor & 4.0 & 2.0 & - & 5.0 & $50-200$ & 250 & Makeswari and Santhi, 2014 \\
\hline Neem & 1.0 & 2.0 & 60 & $5-6$ & $100-1000$ & 146 & Ang et al., 2013 \\
\hline Paper mulberry & 10 & 2.0 & 30 & 5.0 & $10-500$ & 127 & Nagpal et al., 2011 \\
\hline Sugar maple & 1.0 & 5.0 & RT & 5.0 & $15-150$ & 126 & $\underline{\text { Amirnia et al., } 2016}$ \\
\hline Teak & 3.33 & 3.0 & RT & 5.0 & $20-100$ & 95.4 & $\underline{\text { King et al., } 2006}$ \\
\hline Sunflower & 2.0 & 7.0 & 25 & 5.0 & $20-500$ & 89.4 & Benaïssa and Elouchdi, 2007 \\
\hline Saltbush & 5.0 & 1.0 & 25 & 5.0 & $5-50$ & 67.9 & Sawalha et al., 2007 \\
\hline Grey nicker & 1.4 & 2.0 & 30 & 5.0 & $5-125$ & 58.8 & Yuvaraja et al., 2012 \\
\hline Tea waste & 5.0 & 6.0 & 22 & 5.5 & $25-200$ & 48.0 & Amarasinghe and Williams, 2007 \\
\hline Neem & 0.5 & 2.0 & 30 & 5.5 & $10-50$ & 33.3 & Bhattacharyya et al., 2010 \\
\hline Sugar maple & 4.0 & 1.0 & RT & 5.0 & $15-150$ & 27.8 & $\underline{\text { Amirnia et al., } 2016}$ \\
\hline Neem & 1.5 & 2.0 & 30 & 5.5 & $10-50$ & 25.1 & Bhattacharyya et al., 2010 \\
\hline Papaya & 2.0 & 1.0 & RT & 6.0 & $10-50$ & 24.6 & $\underline{\text { V. and Misra, } 2018}$ \\
\hline Phoenix & 0.5 & 0.84 & RT & 6.0 & $10-50$ & 20.2 & $\underline{\text { Yu et al., } 2015}$ \\
\hline Tea waste & 1.0 & 3.0 & 25 & 5.0 & $5-50$ & 18.5 & Çekim et al., 2015 \\
\hline Tomato & 1.0 & 0.5 & 25 & 4.0 & $10-60$ & 17.2 & Cekim et al., 2015 \\
\hline Camphor & 2.0 & 1.0 & 30 & 4.0 & $5-150$ & 16.8 & Boparai et al., 2011 \\
\hline Mango & 5.0 & 4.0 & RT & 5.0 & $10-80$ & 15.6 & $\underline{\text { Sheen et al., } 2013}$ \\
\hline Teak & 3.3 & 3.0 & RT & 5.0 & $20-100$ & 15.4 & $\underline{\text { Prasanna Kumar et al., } 2006}$ \\
\hline Tehran pine & 10 & 1.0 & RT & 4.0 & $10-1000$ & 15.3 & $\underline{\text { Asgarzadeh et al., } 2016}$ \\
\hline Brazilian orchid & 11 & 0.5 & 25 & 5.0 & $1-480$ & 15.1 & $\underline{\text { Jorgetto et al., } 2015}$ \\
\hline Cabbage waste & 5.0 & 2.0 & RT & 6.0 & $1-500$ & 12.9 & $\underline{\text { Hossain et al., 2014a }}$ \\
\hline Common fig & - & - & - & - & - & 12.9 & $\underline{\text { Batool et al., } 2017}$ \\
\hline Judas & 5.0 & 2.0 & RT & 4.0 & $5-1000$ & 9.35 & $\underline{\text { Salehi et al., } 2008}$ \\
\hline Judas & 10 & 6.0 & RT & 4.0 & $5-1000$ & 9.35 & $\underline{\text { Salehi et al., } 2008}$ \\
\hline Pineapple & 0.2 & 1.0 & 27 & 5.0 & $5-160$ & 9.28 & Weng et al., 2009 \\
\hline
\end{tabular}




\begin{tabular}{llllllll}
\hline Arborvitae & 2.0 & 5.0 & 30 & 5.5 & $5-30$ & 7.94 & Shi et al., 2016a \\
Cabbage & 10 & 2.5 & 25 & 6.0 & $10-100$ & 5.75 & Kamar Firas et al., 2017 \\
Devdaru & 5.0 & 0.66 & 25 & 6.0 & $30-80$ & 1.71 & $\underline{\text { Rehman et al., 2013 }}$ \\
\hline
\end{tabular}

\section{Lead-Pb(II)}

\begin{tabular}{|c|c|c|c|c|c|c|c|}
\hline Maple & 0.05 & 3.0 & 20 & 6.0 & $1-500$ & 126 & $\underline{\text { Hossain et al., 2014b }}$ \\
\hline Bael & 4.0 & 0.5 & 30 & 5.1 & $8.7-180$ & 125 & $\underline{\text { Chakravarty et al., } 2010}$ \\
\hline Hardy catalpa & 18.9 & 1.0 & 25 & 5.0 & $10-1000$ & 120 & $\underline{\text { Zolgharnein et al., } 2015}$ \\
\hline Neem & 0.8 & 3.0 & 25 & 5.0 & $50-150$ & 119 & Bhattacharyya and Sharma, 2004 \\
\hline Paper mulberry & 10.0 & 2.0 & 30 & 5.5 & $10-500$ & 84.7 & Nagpal et al., 2011 \\
\hline Camphor & 1.0 & 2.0 & 30 & 5.0 & $50-400$ & 73.2 & $\underline{\text { Chen et al., 2010b }}$ \\
\hline Phoenix & 5.0 & 24.0 & 30 & 5.0 & 100 & 71.0 & Liang et al., 2016 \\
\hline Maple & 0.5 & 3.0 & 20 & 6.0 & $1-500$ & 66.7 & $\underline{\text { Hossain et al., 2014b }}$ \\
\hline Tea waste & 5.0 & 6.0 & 22 & 5.5 & $25-200$ & 65.1 & Amarasinghe and Williams, 2007 \\
\hline Cabbage waste & 5.0 & 2.0 & RT & 6.0 & $1-500$ & 61.3 & $\underline{\text { Hossain et al., 2014a }}$ \\
\hline Cabbage waste & 5.0 & 3.0 & RT & - & $1-500$ & 60.6 & $\underline{\text { Hossain et al., 2014d }}$ \\
\hline Mistletoe & 2.0 & 2.5 & 30 & 5.5 & $10-210$ & 59.7 & $\underline{\text { Van Suc and Son, } 2016}$ \\
\hline Eggplant & 0.4 & 1.75 & 30 & 5.0 & $30-90$ & 55.6 & $\underline{\text { Yuvaraja et al., } 2014}$ \\
\hline Maple & 1.0 & 3.0 & 20 & 6.0 & $1-500$ & 50.3 & $\underline{\text { Hossain et al., 2014b }}$ \\
\hline $\begin{array}{l}\text { Cauliflower } \\
\text { waste }\end{array}$ & 5.0 & 3.0 & RT & - & $1-500$ & 47.6 & $\underline{\text { Hossain et al., } 2014 \mathrm{~d}}$ \\
\hline Arborvitae & 2.0 & 5.0 & 30 & 5.5 & $5-30$ & 43.7 & $\underline{\text { Shi et al., 2016b }}$ \\
\hline $\begin{array}{l}\text { Diceriocaryum } \\
\text { eriocarpum }\end{array}$ & 1.0 & 0.5 & 25 & 4.0 & $1-50$ & 41.9 & Edokpayi et al., 2015 \\
\hline Tropical-almond & 2.5 & 30.0 & 30 & 2.0 & $20-300$ & 41.8 & $\underline{\text { Ramakul et al., } 2012}$ \\
\hline Maguey & 5.0 & 0.5 & 20 & 5.0 & $20-300$ & 40.0 & $\underline{\text { Hamissa et al., } 2010}$ \\
\hline Secred fig & 5.0 & 1.0 & 25 & 4.0 & $10-1000$ & 37.5 & Qaiser et al., 2009 \\
\hline Arborvitae & 2.0 & 5.0 & 30 & 5.5 & $5-30$ & 35.8 & $\underline{\text { Shi et al., 2016a }}$ \\
\hline Fig & 5.0 & 1.33 & 30 & 6.0 & $5-200$ & 34.4 & $\underline{\text { Farhan et al., 2013b }}$ \\
\hline Fig & 5.0 & 1.33 & 30 & 6.0 & $10-200$ & 34.3 & $\underline{\text { Farhan et al., 2013a }}$ \\
\hline Jambolan & 3.3 & 1.0 & 30 & 6.0 & $20-100$ & 32.5 & $\underline{\text { King et al., } 2007}$ \\
\hline Hairy fig & 3.3 & 1.0 & 30 & 6.0 & $20-100$ & 32.4 & Namdeti and Pulipati, 2014 \\
\hline Tea waste & 1.0 & 3.0 & 25 & 5.0 & $5-50$ & 26.9 & $\underline{\text { Wan et al., } 2014}$ \\
\hline
\end{tabular}




\begin{tabular}{llllllll}
\hline Chickpea & 3.0 & 2.0 & 30 & 6.0 & $50-200$ & 25.6 & $\underline{\text { Nadeem et al., 2006 }}$ \\
Neem & 10.0 & 2.0 & 30 & 5.0 & $5-300$ & 22.3 & $\underline{\text { Singha and Das, 2012 }}$ \\
Palm & 5.0 & 1.5 & 25 & 4.5 & 180 & 20.1 & $\underline{\text { Al-Haidary et al., 2011b }}$ \\
Black tea & 10.0 & 3.0 & RT & 5.0 & $1-50$ & 19.7 & $\underline{\text { Mohammed et al., 2016 }}$ \\
Tehran pine & 10.0 & 1.0 & RT & 4.0 & $10-1000$ & 19.7 & $\underline{\text { Asgarzadeh et al., 2016 }}$ \\
Common fig & - & - & - & - & - & 17.9 & $\underline{\text { Batool et al., 2017 }}$ \\
Neem & 8.3 & 2.0 & 27 & 4.0 & $10-300$ & 13.5 & $\underline{\text { Babarinde, 2016 }}$ \\
Judas & 10.0 & 6.0 & RT & 4.0 & $5-1000$ & 12.5 & $\underline{\text { Salehi et al., 2008 }}$ \\
Judas & 5.0 & 2.0 & RT & 4.0 & $5-1000$ & 12.4 & $\underline{\text { Salehi et al., 2008 }}$ \\
Yerba mate & 5.0 & 16.0 & 25 & 3.0 & $0.5-100$ & 12.3 & $\underline{\text { Copello et al., 2011 }}$ \\
Cashew & 1.5 & 2.0 & 30 & 4.0 & $10-140$ & 11.6 & $\underline{\text { Raju et al., 2013 }}$ \\
Papaya & 1.5 & 1.0 & 30 & 4.0 & $10-140$ & 11.1 & $\underline{\text { Raju et al., 2013 }}$ \\
Star pine & 20.0 & 2.0 & 30 & 5.0 & 30.17 & 7.66 & $\underline{\text { Sarada et al., 2013b }}$ \\
Star pine & 20 & 2.0 & 30 & 5.0 & $11-105$ & 7.65 & $\underline{\text { Sarada et al., 2013a }}$ \\
Cabbage & 10 & 2.5 & 25 & 6.0 & $10-100$ & 3.61 & $\underline{\text { Kamar Firas et al., 2017 }}$ \\
Ashok & 4.0 & 0.5 & 25 & 6.5 & $1-100$ & 3.23 & $\underline{\text { Goyal et al., 2008 }}$ \\
Southern cattail & 10 & 2.0 & 25 & 2.5 & $1-30$ & 0.65 & $\underline{\text { Abdel-Ghani et al., 2009 }}$ \\
\hline
\end{tabular}

Cadmium-Cd(II)

\begin{tabular}{llllllll}
\hline Neptune grass & 1.0 & 1.0 & 20 & 7.0 & $75-200$ & 117 & $\underline{\text { Kaouah et al., 2014 }}$ \\
Fig & 2.0 & 4.0 & 25 & 6.0 & $5-1000$ & 103 & $\underline{\text { Benaïssa, 2006 }}$ \\
Sesame & 3.33 & 0.5 & 25 & 5.5 & $2-1000$ & 84.7 & $\underline{\text { Cheraghi et al., 2015 }}$ \\
Neptune grass & 2.0 & 3.0 & 25 & 6.0 & $25-1000$ & 77.6 & $\underline{\text { Meseguer et al., 2016 }}$ \\
Loquat & 0.4 & 1.0 & 30 & 6.0 & $10-40$ & 48.8 & $\underline{\text { Awwad and Salem, 2014 }}$ \\
Mistletoe & 2.0 & 2.5 & 30 & 5.5 & $10-210$ & 44.8 & $\underline{\text { Van Suc and Son, 2016 }}$ \\
Tropical-almond & 5.0 & 0.5 & 30 & 5.5 & $50-500$ & 35.8 & $\underline{\text { Rao, 2010 }}$ \\
Jambolan & 5.0 & 0.5 & 30 & 5.5 & $50-500$ & 34.5 & $\underline{\text { Rao et al., 2010c }}$ \\
Jambolan & 5.0 & 0.5 & 30 & 5.5 & $50-500$ & 34.5 & $\underline{\text { Rao et al., 2010c }}$ \\
Jambolan & 5.0 & 0.5 & 30 & 5.5 & $50-500$ & 34.5 & $\underline{\text { Rao et al., 2010c }}$ \\
Guava & 5.0 & 0.5 & 30 & 5.5 & $50-500$ & 31.2 & $\underline{\text { Rao et al., 2010a }}$ \\
Fig & 5.0 & 1.33 & 30 & 5.0 & $10-200$ & 30.3 & $\underline{\text { Farhan et al., 2013a }}$ \\
Fig & 5.0 & 1.33 & 30 & 6.0 & $5-60$ & 30.3 & $\underline{\text { Farhan et al., 2013b }}$ \\
\hline
\end{tabular}




\begin{tabular}{|c|c|c|c|c|c|c|c|}
\hline Teak & 20.0 & 0.5 & 30 & 5.5 & $50-1000$ & 29.9 & $\underline{\text { Rao et al., 2010b }}$ \\
\hline Loquat & 4.0 & 1.0 & 30 & 6.0 & $5-60$ & 29.2 & Al-Dujaili et al., 2012 \\
\hline Loquat & 4.0 & 1.0 & 30 & 6.0 & $5-60$ & 29.2 & Al-Dujaili et al., 2012 \\
\hline Jambolan & 50.0 & 1.0 & RT & 5.5 & $50-150$ & 29.1 & $\underline{\text { Rao et al., 2011a }}$ \\
\hline Giant reed & 2.5 & 2.0 & 25 & 5.5 & $5-50$ & 27.9 & Ammari, 2014 \\
\hline Sacred fig & 5.0 & 0.5 & 30 & 5.5 & $50-500$ & 27.1 & $\underline{\text { Rao et al., } 2011 \mathrm{~b}}$ \\
\hline Paper mulberry & 10.0 & 2.0 & 30 & 6.5 & $10-500$ & 26.1 & Nagpal et al., 2011 \\
\hline Cabbage waste & 5.0 & 2.0 & RT & 6.0 & $1-500$ & 22.1 & Hossain et al., 2014a \\
\hline Loquat & 4.0 & 1.0 & 30 & 6.0 & $5-60$ & 21.3 & Al-Dujaili et al., 2012 \\
\hline $\begin{array}{l}\text { Cauliflower } \\
\text { waste }\end{array}$ & 5.0 & 3.0 & RT & - & $1-500$ & 21.3 & $\underline{\text { Hossain et al., } 2014 \mathrm{~d}}$ \\
\hline Cabbage waste & 5.0 & 3.0 & RT & - & $1-500$ & 20.6 & Hossain et al., 2014d \\
\hline Guava & 5.0 & 1.0 & 30 & 6.7 & $20-100$ & 17.2 & $\underline{\text { Abdelwahab et al., } 2015}$ \\
\hline Phoenix & 0.5 & 0.84 & RT & 6.0 & $10-50$ & 16.3 & $\underline{\text { Yu et al., } 2015}$ \\
\hline Urticaceae & 5.0 & 1.17 & 27 & 6.5 & $10-50$ & 13.8 & $\underline{\text { Bose et al., } 2016}$ \\
\hline Common fig & - & - & - & - & - & 12.8 & Batool et al., 2017 \\
\hline Brazilian orchid & 11.0 & 0.5 & 25 & 5.0 & $1-480$ & 12.7 & $\underline{\text { Jorgetto et al., } 2015}$ \\
\hline Maguey & 5.0 & 0.5 & 20 & 5.0 & $20-160$ & 12.5 & $\underline{\text { Hamissa et al., } 2010}$ \\
\hline Cabbage & 10.0 & 2.5 & 25 & 6.0 & $10-100$ & 5.07 & $\underline{\text { Kamar Firas et al., } 2017}$ \\
\hline Yerba mate & 3.0 & - & 28 & 5.8 & $4.5-100$ & 4.48 & Cukierman, 2007 \\
\hline Neem & 8.3 & 2.0 & 27 & 4.0 & $10-300$ & 1.89 & Babarinde, 2016 \\
\hline Cypress & 13.3 & 48 & 22 & 6.5 & $0.5-20$ & 1.43 & Al-Subu, 2002 \\
\hline Pine & 13.3 & 48 & 22 & 6.5 & $0.5-20$ & 0.11 & Al-Subu, 2002 \\
\hline Cinchona & 13.3 & 48 & 22 & 6.5 & $0.5-20$ & 0.10 & Al-Subu, 2002 \\
\hline \multicolumn{8}{|l|}{ Nickel—Ni(II) } \\
\hline Tomato & 0.4 & 3.0 & 30 & 5.5 & $30-90$ & 47.6 & $\underline{\text { Gutha et al., } 2015}$ \\
\hline Golden shower & 1.0 & 4.0 & 30 & 6.0 & $25-800$ & 34.6 & $\underline{\text { Hanif et al., } 2007}$ \\
\hline Teak & 6.0 & 1.0 & 30 & 5.0 & $25-200$ & 17.8 & $\begin{array}{l}\text { Vilvanathan and } \\
\text { Shanthakumar, } 2016\end{array}$ \\
\hline Jackfruit & 2.0 & 3.0 & 30 & 5.6 & $20-100$ & 12.7 & Boruah et al., 2015 \\
\hline Tehran pine & 10.0 & 1.0 & RT & 4.0 & $10-1000$ & 10.5 & $\underline{\text { Asgarzadeh et al., } 2016}$ \\
\hline Common fig & - & - & - & - & - & 10.4 & Batool et al., 2017 \\
\hline
\end{tabular}




\begin{tabular}{llllllll}
\hline Neem & 0.5 & 2.5 & 30 & 5.6 & $10-50$ & 9.10 & Bhattacharyya et al., 2009 \\
Jamun & 16.0 & 2.0 & 30 & 5.0 & $30-80$ & 6.01 & $\underline{\text { Rehman et al., 2014 }}$ \\
Judas & 5.0 & 2.0 & RT & 4.0 & $5-1000$ & 4.68 & $\underline{\text { Salehi et al., 2008 }}$ \\
Deydaru & 5.0 & 0.66 & 25 & 5.0 & $30-80$ & 4.08 & $\underline{\text { Rehman et al., 2013 }}$ \\
Coconut & 4.0 & 4.0 & 27 & 8.0 & $5-27$ & 0.073 & $\underline{\text { Gowda et al., 2012 }}$ \\
\hline
\end{tabular}

Zinc-Zn(II)

\begin{tabular}{llllllll}
\hline Neem & 1.5 & 6.0 & 25 & 4.0 & $25-800$ & 147 & $\underline{\text { Arshad et al., 2008 }}$ \\
Jambolan & 3.3 & 0.5 & RT & 6.0 & $20-100$ & 35.8 & $\underline{\text { King et al., 2008 }}$ \\
Saltbush & 5.0 & 1.0 & 25 & 5.0 & $5-50$ & 32.7 & $\underline{\text { Sawalha et al., 2007 }}$ \\
Teak & 3.3 & 3.0 & 30 & 5.0 & $20-100$ & 16.4 & $\underline{\text { Kumar et al., 2006 }}$ \\
Phoenix & 0.5 & 0.84 & RT & 6.0 & $10-50$ & 15.3 & $\underline{\text { Yu et al., 2015 }}$ \\
Palm & 2.0 & 0.5 & 25 & 5.5 & $20-300$ & 14.6 & $\underline{\text { Abu Al-Rub, 2006 }}$ \\
Indian coral & 20 & 1.0 & 30 & 4.5 & $25-250$ & 12.7 & $\underline{\text { Venkateswarlu et al., 2008 }}$ \\
Cabbage waste & 5.0 & 2.0 & RT & 6.0 & $1-500$ & 10.9 & $\underline{\text { Hossain et al., 2014a }}$ \\
Common fig & - & - & - & - & - & 7.99 & $\underline{\text { Batool et al., 2017 }}$ \\
Bael & 40 & 0.5 & 25 & 5.0 & $10-50$ & 2.08 & $\underline{\text { Kumar et al., 2009 }}$ \\
Southern cattail & 10 & 2.0 & 25 & 2.5 & $5-32$ & 0.2 & $\underline{\text { Abdel-Ghani et al., 2009 }}$ \\
\hline
\end{tabular}

Mercury-Hg(II)

\begin{tabular}{llllllll}
\hline Adulsa & 10.0 & 0.66 & 30 & 6.0 & $25-100$ & 108 & $\underline{\text { Aslam et al., 2013 }}$ \\
Castor & 2.5 & 1.0 & RT & 5.5 & $5-100$ & 37.2 & $\underline{\text { Al Rmalli et al., 2008 }}$ \\
Chinese ash & - & 0.5 & RT & 4.4 & $50-300$ & 29.5 & $\underline{\underline{\text { Zolgharnein and }}}$ \\
Bamboo & 4.0 & 1.0 & 27 & 8.0 & $100-250$ & 27.1 & $\underline{\text { Shahmoradi, 2010 }}$ \\
Rambai & 2.0 & 6.0 & 30 & 6.0 & $5-120$ & 6.48 & $\underline{\text { Sen et al., 2011 }}$ \\
Phragmites karka & 10.0 & 1.0 & 25 & 6.0 & $10-60$ & 1.79 & $\underline{\text { Raza et al., 2015 }}$ \\
\hline
\end{tabular}

Hexavalent chromium-Cr(VI)

\begin{tabular}{llllllll}
\hline Used black tea & 0.1 & 48 & 25 & 1.54 & $50-250$ & 455 & $\underline{\text { Hossain et al., 2005 }}$ \\
Sakura & 0.2 & 48 & 35 & 1.0 & $5-500$ & 362 & Qi et al., 2016 \\
Mango & 0.25 & 2.0 & 30 & 2.0 & $10-300$ & 178 & $\underline{\text { Saha and Saha, 2014 }}$ \\
Sakura & 2.0 & - & RT & 1.0 & $5-500$ & 148 & $\underline{\text { Wenfang et al., 2015 }}$ \\
\hline
\end{tabular}




\begin{tabular}{|c|c|c|c|c|c|c|c|}
\hline Neem & 14.0 & 3.0 & 30 & 5.5 & $7-25$ & 146 & $\begin{array}{l}\text { Sharma and Bhattacharyya, } \\
\underline{2005}\end{array}$ \\
\hline Tobacco & 10.0 & 1.0 & 25 & 1.0 & $50-1000$ & 125 & Chen et al., 2009 \\
\hline Tobacco & 10.0 & 1.0 & 25 & 1.0 & $50-100$ & 113 & $\underline{\text { Chen et al., } 2009}$ \\
\hline Neem & 10.0 & 3.0 & 30 & 5.5 & $7-25$ & 83.6 & Sharma and Bhattacharyya, 2005 \\
\hline Tea waste & 2.5 & 8.0 & 30 & 2.0 & $90-160$ & 73.1 & Mozumder et al., 2008 \\
\hline Gum arabic & 8.0 & 1.5 & RT & 6.0 & $106-176$ & 69.4 & Prasad and Thirumalisamy, 2013 \\
\hline $\begin{array}{l}\text { Green honey } \\
\text { myrtle }\end{array}$ & 5.0 & 3.0 & 24 & 7.0 & $100-500$ & 62.5 & $\underline{\text { Kuppusamy et al., } 2016}$ \\
\hline Mangrove & 4.0 & - & 25 & 2.0 & $50-400$ & 60.2 & $\underline{\text { Sathish et al., } 2015}$ \\
\hline Purple secretia & 10.0 & - & 30 & 2.0 & $50-200$ & 54.0 & $\underline{\text { Sinha et al., 2015a }}$ \\
\hline Purple secretia & 10.0 & 5.0 & 30 & 2.0 & $50-200$ & 53.9 & $\underline{\text { Sinha et al., } 2015 \mathrm{~b}}$ \\
\hline Tamarind & 4.0 & 2.0 & 30 & 6.0 & $200-1000$ & 50.7 & $\underline{\text { Muthulaksmi et al., } 2016}$ \\
\hline Tobacco & 10.0 & 1.0 & 25 & 2.0 & $50-1000$ & 50.5 & $\underline{\text { Chen et al., } 2009}$ \\
\hline Taro & 1.6 & 2.0 & 30 & 2.0 & $20-100$ & 47.6 & $\underline{\text { Nakkeeran et al., } 2016}$ \\
\hline Mould & 4.0 & 24.0 & 25 & 2.0 & $10-1000$ & 43.1 & $\underline{\text { Sharma and Forster, } 1994}$ \\
\hline Neem & 6.0 & 3.0 & 30 & 5.5 & $7-25$ & 38.0 & Sharma and Bhattacharyya, 2005 \\
\hline Mango & 2.0 & 4.0 & 30 & 2.0 & $10-100$ & 35.7 & $\underline{\text { Nag et al., } 2017}$ \\
\hline Green tea & 16.0 & 3.0 & 30 & 2.0 & $5-500$ & 34.6 & $\underline{\text { Jeyaseelan and Gupta, 2016b }}$ \\
\hline Lechuguilla & - & 12.0 & 22 & 2.0 & $5-40$ & 33.2 & $\underline{\underline{\text { Romero-González et al., }}}$ \\
\hline Jackfruit & 2.0 & 4.0 & 30 & 2.0 & $10-100$ & 32.2 & $\underline{\text { Nag et al., } 2017}$ \\
\hline Rubber & 10.0 & 1.0 & 25 & 3.0 & $50-1000$ & 22.9 & $\underline{\text { Nag et al., } 2016}$ \\
\hline Tobacco & 10.0 & 1.0 & 25 & 3.0 & $50-1000$ & 22.8 & $\underline{\text { Chen et al., } 2009}$ \\
\hline Neem & 2.0 & 3.0 & 30 & 5.5 & $7-25$ & 19.5 & $\underline{\text { Sharma and Bhattacharyya, } 2005}$ \\
\hline Tobacco & 10.0 & 1.0 & 25 & 6.0 & $50-1000$ & 14.6 & $\underline{\text { Chen et al., } 2009}$ \\
\hline Neem & 14.0 & 3.0 & 30 & 5.5 & $7-25$ & 14.4 & $\underline{\text { Sharma and Bhattacharyya, } 2005}$ \\
\hline Bamboo & 5.0 & 4.0 & 30 & 2.0 & $10-100$ & 10.8 & $\underline{\text { Nag et al., } 2017}$ \\
\hline Yerba mate & 5.0 & 16.0 & 25 & 2.0 & $0.5-100$ & 8.80 & $\underline{\text { Copello et al., } 2011}$ \\
\hline Roxburgh fig & 5.0 & 2.0 & 25 & 2.0 & $20-100$ & 6.80 & $\underline{\text { Shi et al., 2016a }}$ \\
\hline Dune guarrie & 20.0 & 1.0 & RT & 5.6 & $5-20$ & 3.94 & $\underline{\text { Gebrehawaria et al., } 2015}$ \\
\hline Golden shower & 5.0 & 6.0 & 30 & 2.0 & $30-40$ & 3.84 & $\underline{\text { Ahmad et al., 2017a }}$ \\
\hline Tiger's claw & 50.0 & 3.0 & 30 & 2.85 & $20-180$ & 1.92 & Aditya et al., 2012 \\
\hline
\end{tabular}




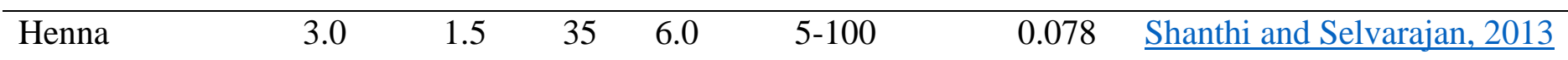

\section{Trivalent chromium-Cr(III)}

\begin{tabular}{llllllll}
\hline Yerba mate & 5.0 & 16.0 & 25 & 3.0 & $0.5-100$ & 11.8 & $\underline{\text { Copello et al., 2011 }}$ \\
Common fig & - & - & - & - & - & 8.35 & $\underline{\text { Batool et al., 2017 }}$ \\
Neem & 8.3 & 2.0 & 27 & 4.0 & $10-300$ & 4.27 & $\underline{\text { Babarinde, 2016 }}$ \\
Jamun & 12.0 & 0.5 & 30 & 4.0 & $30-80$ & 3.82 & $\underline{\text { Rehman et al., 2014 }}$ \\
Ashoka & 40.0 & 0.25 & 30 & 3.0 & $50-300$ & 1.83 & $\underline{\text { Anwar et al., 2011 }}$ \\
\hline
\end{tabular}

\section{Arsenite-As(III)}

\begin{tabular}{llllllll}
\hline Guava & 4.0 & 8.0 & 30 & 8.0 & $50-250$ & 2.59 & Kamsonlian et al., 2012b \\
Rohida & 3.74 & 0.71 & - & 7.56 & $200-600$ & 0.05 & Brahman et al., 2016 \\
\hline
\end{tabular}

Arsenate-As(V)

\begin{tabular}{llllllll}
\hline Chir pine & 20.0 & 0.5 & 25 & 4.0 & $5-30$ & 3.27 & $\underline{\text { Shafique et al., 2012 }}$ \\
Guava & 4.0 & 8.0 & 30 & 4.0 & $50-250$ & 3.25 & $\underline{\text { Kamsonlian et al., 2012b }}$ \\
Rohida & 3.60 & 0.72 & - & 5.48 & $200-600$ & 0.12 & Brahman et al., 2016 \\
\hline
\end{tabular}

\section{Ammonium- $\left(\mathrm{NH}_{4}{ }^{+}\right)$}

\begin{tabular}{llllllll}
\hline Strawberry & 8.0 & 18 & 30 & - & $25-1000$ & 6.71 & $\underline{\text { Liu et al., 2010a }}$ \\
Magnolia & 8.0 & 18 & 30 & - & $25-1000$ & 6.22 & $\underline{\text { Liu et al., 2010a }}$ \\
Boston ivy & 8.0 & 18 & 30 & - & $25-1000$ & 6.07 & $\underline{\text { Liu et al., 2010a }}$ \\
Strawberry & 8.0 & 24 & 25 & - & $25-1000$ & 6.05 & $\underline{\text { Liu et al., 2010d }}$ \\
Boston ivy & 8.0 & 14 & 25 & - & $25-1000$ & 5.28 & $\underline{\text { Liu et al., 2010b }}$ \\
Cactus & 5.0 & 2.0 & 20 & 6.0 & $10-50$ & 2.58 & $\underline{\text { Wahab et al., 2012 }}$ \\
\hline Cobalt-Co(II) & & & & & & & \\
\hline Teak & 6.0 & 1.0 & 30 & 5.0 & $25-200$ & 29.5 & $\underline{\underline{\text { Vilvanathan and }}}$ \\
Common fig & - & - & - & - & - & 11.4 & $\underline{\text { Batool et al., 2017 }}$ \\
Arborvitae & 2.0 & 5.0 & 30 & 5.5 & $5-30$ & 6.78 & $\underline{\text { Shi et al., 2016a }}$ \\
Banyan & 25.0 & 2.0 & RT & 5.0 & $5-150$ & 5.65 & $\underline{\text { Hymavathi and Prabhakar, 2017 }}$ \\
Deydaru & 5.0 & 0.66 & 25 & 6.0 & $30-80$ & 3.99 & $\underline{\text { Rehman et al., 2013 }}$ \\
Tiger's claw & 40.0 & 2.0 & 30 & 7.2 & $25-200$ & 2.71 & $\underline{\text { Vijaya Lakshmi et al., 2008 }}$ \\
\hline
\end{tabular}




\begin{tabular}{llllllll}
\hline Oriental plane & 2.0 & 1.0 & 25 & 4.0 & $25-300$ & 28.7 & $\underline{\text { Sert et al., 2008 }}$ \\
Calabrian pine & 4.0 & 0.5 & 30 & 5.0 & $25-300$ & 22.9 & $\underline{\text { Kütahyali et al., 2010 }}$ \\
\hline
\end{tabular}

\section{Cerium}

\begin{tabular}{llllllll}
\hline Oriental plane & 2.0 & 1.0 & 25 & 4.0 & $25-300$ & 32.1 & Sert et al., 2008 \\
Calabrian pine & 4.0 & 0.25 & 30 & 5.0 & $25-300$ & 17.2 & Kütahyali et al., 2010 \\
\hline
\end{tabular}

\section{Zirconium-Zr(IV)}

\begin{tabular}{lllllll}
\hline Platanaceae & 5.0 & 0.66 & 25 & 3.0 & $2-500$ & 29.5
\end{tabular}

\section{Hafnium-Hf(IV)}

\begin{tabular}{lccccccl}
\hline Platanaceae & 5.0 & 0.66 & 25 & 3.0 & $2-500$ & 14.7 & Boveiri Monji et al., 2008 \\
\hline \multicolumn{2}{l}{ Uranium-U(VI) } & & & & & & \\
\hline Banyan & 5.0 & 1.0 & 30 & 3.0 & $10-400$ & 34.6 & $\underline{\text { Xia et al., 2013 }}$ \\
Neptune grass & 2.5 & 0.5 & 25 & 3.0 & $1-25$ & 9.81 & $\underline{\text { Aydin et al., 2012 }}$ \\
Poplar & 10.0 & 4.0 & 25 & 4.0 & $1-10$ & 2.3 & $\underline{\text { Al-Masri et al., 2010 }}$ \\
\hline
\end{tabular}

\section{Platinum}

\begin{tabular}{llllllll}
\hline Tropical-almond & 2.5 & 30.0 & 30 & 2.0 & $20-300$ & 22.5 & Ramakul et al., 2012
\end{tabular}

\section{Methylene blue dye}

\begin{tabular}{llllllll}
\hline Lotus & 1.0 & 4.0 & 20 & 7.0 & $30-200$ & 222 & $\underline{\text { Han et al., 2011 }}$ \\
Gulmohar & 0.5 & - & - & 7.5 & $50-200$ & 186 & $\underline{\text { Ponnusami et al., 2009a }}$ \\
Cabbage & 1.0 & - & RT & 9.0 & $10-200$ & 149 & $\underline{\text { Ansari et al., 2016b }}$ \\
Pine tree & 0.3 & 4.0 & 30 & 9.2 & $10-80$ & 127 & $\underline{\text { Yagub et al., 2012 }}$ \\
Phoenix & 1.6 & 1.17 & 60 & 12.0 & $20-180$ & 115 & $\underline{\text { Peydayesh and Rahbar- }}$ \\
Lawny grass & 1.0 & 4.0 & - & 5.7 & $40-320$ & 103 & $\underline{\text { Chelishami, 2015 }}$ \\
Bael & 0.6 & 0.33 & 30 & 6.7 & $10-50$ & 100 & $\underline{\text { Baruah et al., 2011c }}$ \\
Plane & 2.5 & 7.0 & 30 & 7.0 & $50-500$ & 99.0 & $\underline{\text { Kong et al., 2015 }}$ \\
Ashoka & 2.0 & 0.5 & 30 & 6.0 & 10 & 90.9 & $\underline{\text { Gupta et al., 2012a }}$ \\
Phoenix tree & 2.0 & 3.0 & 22 & 7.0 & $30-180$ & 80.9 & $\underline{\text { Han et al., 2007 }}$ \\
Acer tree & 5.0 & 0.67 & - & 2.7 & 928 & 69.2 & $\underline{\text { Zolgharnein and Bagtash, }}$ \\
Carrot & 2.0 & 0.5 & 30 & 7.0 & $10-50$ & 66.6 & $\underline{\text { Kushwaha et al., 2014a }}$ \\
\hline
\end{tabular}




\begin{tabular}{llllllll}
\hline Weeping willow & 2.0 & 2.0 & 23 & 7.0 & $20-200$ & 61.0 & $\underline{\text { Khodabandehloo et al., 2017 }}$ \\
Plane & 18.0 & 1.0 & 25 & 6.4 & 1000 & 55.5 & $\underline{\text { Zolgharnein et al., 2010 }}$ \\
Water bamboo & 2.0 & 1.0 & 10 & 6.75 & $50-250$ & 54.2 & $\underline{\text { Zhu et al., 2016 }}$ \\
Potato & 2.0 & 0.42 & 30 & 7.0 & 10 & 52.6 & $\underline{\text { Gupta et al., 2016a }}$ \\
Date palm & 10.0 & 2.67 & 30 & 6.5 & 200 & 43.1 & $\underline{\text { Gouamid et al., 2013 }}$ \\
\hline
\end{tabular}

\section{Malachite green dye}

\begin{tabular}{llllllll}
\hline Lotus & 1.0 & 7.0 & 20 & 4.5 & $30-200$ & 114 & $\underline{\text { Han et al., 2014 }}$ \\
Ashoka & 2.0 & 0.5 & 30 & 6.0 & 10 & 83.3 & Gupta et al., 2012a \\
Plane & 2.5 & 7.5 & 25 & - & $50-500$ & 77.5 & $\underline{\text { Hamdaoui et al., 2008 }}$ \\
Cattail & 2.5 & 4.0 & 25 & 4.0 & $50-500$ & 72.3 & $\underline{\text { Guechi and Hamdaoui, 2013 }}$ \\
Carrot & 2.0 & 0.5 & 30 & 7.0 & 10 & 52.6 & $\underline{\text { Kushwaha et al., 2014a }}$ \\
Potato & 2.0 & 0.42 & 30 & 7.0 & 10 & 33.3 & $\underline{\text { Gupta et al., 2016a }}$ \\
\hline
\end{tabular}

\section{Crystal violet dye}

\begin{tabular}{llllllll}
\hline Pineapple & 1.0 & 3.0 & 30 & 8.0 & 10 & 159 & Neupane et al., 2015 \\
Pineapple & 20.0 & 3.0 & 30 & 8.0 & $20-100$ & 78.2 & Chakraborty et al., 2012 \\
Esparto grass & 2.0 & 2.5 & 25 & 7.0 & $20-100$ & 43.5 & $\underline{\text { Lafi et al., 2015 }}$ \\
Jackfruit & 10.0 & 2.0 & 20 & 7.0 & $20-100$ & 43.4 & $\underline{\text { Saha et al., 2012b }}$ \\
Sodom apple & 10.0 & 1.0 & 20 & - & $10-50$ & 4.14 & Ali and Muhammad, 2008 \\
\hline
\end{tabular}

\section{Amaranth dye}

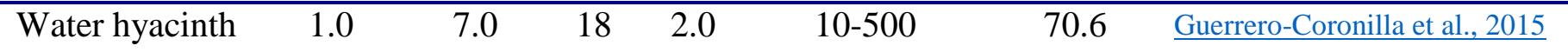

\section{Basic Red 46 dye}

\begin{tabular}{llllllll}
\hline Pine & 1.0 & 1.25 & 45 & 6.0 & $20-100$ & 71.9 & Deniz and Karaman, 2011 \\
Princess & 1.0 & 1.17 & 25 & 8.0 & $20-100$ & 43.1 & Deniz and Saygideger, 2011 \\
\hline
\end{tabular}

\section{Methyl violet dye}

\begin{tabular}{llllllll}
\hline $\begin{array}{l}\text { Platanus } \\
\text { carpinifolia }\end{array}$ & 0.11 & 1.0 & 25 & 3.0 & $500-2500$ & 555 & Zolgharnein et al., 2014 \\
\begin{tabular}{l} 
Neptune grass \\
\hline
\end{tabular} & 3.33 & 1.0 & 25 & 6.0 & $10-300$ & 82.7 & Cengiz and Cavas, 2010 \\
\hline
\end{tabular}

\section{Remazol Brilliant Blue $R$ dye}

\begin{tabular}{lllllll}
\hline Pineapple & 100.0 & 24.0 & RT & - & 500 & $42.2 \quad \underline{\text { Rahmat et al., 2016 }}$
\end{tabular}

\section{Methyl violet 2B dye}




\begin{tabular}{lllllll}
\hline Terap & 2.0 & 4.0 & RT & - & $500-1000$ & $140 \quad$ Lim et al., 2016a
\end{tabular}

Direct Blue-15 dye

\begin{tabular}{llllllll}
\hline Papaya & 0.5 & 0.75 & 30 & 7.0 & 25 & 3.98 & Rehman et al., 2017 \\
\hline
\end{tabular}

\section{Grey BL dye}

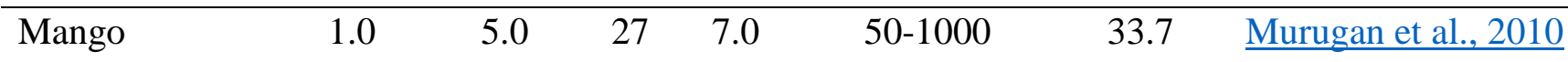

\section{Naphthalene}

\begin{tabular}{llllllll}
\hline Spent tea leave & 20.0 & 2.0 & 45 & 6.0 & $100-400$ & 23.81 & Agarry et al., 2013 \\
\hline
\end{tabular}

\section{Brilliant Green Dye}

\begin{tabular}{llllllll}
\hline Ashoka & 2.0 & 0.5 & 30 & 6.0 & 10 & 125 & Gupta et al., 2012a \\
Jambolan & 60.0 & 0.33 & 50 & 3.0 & $30-80$ & 4.739 & $\underline{\text { Rehman et al., 2012 }}$ \\
Neem & 0.4 & 4.0 & 27 & 6.5 & $10-50$ & - & Bhattacharyya and Sarma, 2003 \\
\hline
\end{tabular}

\section{Ibuprofen}

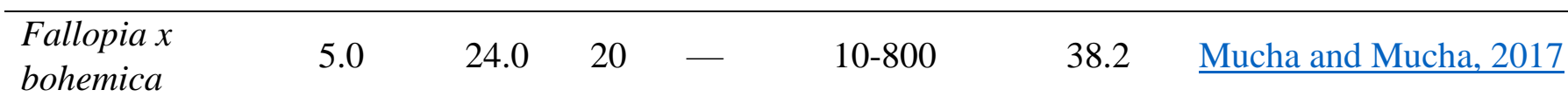

\section{Acetylsalicyic acid}

\begin{tabular}{lllllll}
\hline $\begin{array}{l}\text { Fallopia } x \\
\text { bohemica }\end{array}$ & 5.0 & 24.0 & 20 & - & $10-1000$ & $17.3 \quad$ Mucha and Mucha, 2017 \\
\hline
\end{tabular}

\section{Basic Green 4 dye}

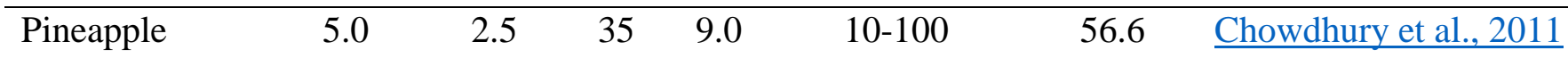

\section{Acid orange 52 dye}

\begin{tabular}{lllllll}
\hline Princess & 0.1 & 3.0 & 25 & 2.0 & $10-100$ & 10.5
\end{tabular}

\section{Auramine dye}

\begin{tabular}{lllllll}
\hline Psium guava & 40.0 & 2.0 & 30 & 9.0 & $50-150$ & $7.76 \quad$ Gaikwad and Kinldy, 2009
\end{tabular}

\section{Direct solophenyl brown AGL dye}

\begin{tabular}{llllllll}
\hline Neptune grass & 20.0 & 24.0 & 30 & 2.0 & $10-100$ & 5.24 & Ncibi et al., 2006 \\
\hline
\end{tabular}

\section{Reactive cibacron red FNR dye}

\begin{tabular}{llllllll}
\hline Neptune grass & 20.0 & 24.0 & 30 & 5.0 & $10-100$ & 9.62 & Ncibi et al., 2006
\end{tabular}

\section{Remazol blue RR dye}

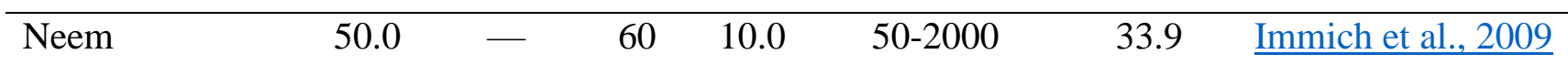


Table S9. Comparison of maximum adsorption capacity ( $Q^{\circ} \max , \mathrm{mg} / \mathrm{g}$ ) of modified/treated biosorbent calculated from the Langmuir model (single component)

\begin{tabular}{|c|c|c|c|c|c|c|c|c|}
\hline \multirow[b]{2}{*}{ Leaves } & \multirow[b]{2}{*}{ Chemicals } & \multicolumn{5}{|c|}{ Experimental conditions } & \multirow[b]{2}{*}{$\begin{array}{l}\mathbf{Q}^{\mathbf{o}} \text { max } \\
(\mathrm{mg} / \mathrm{g})\end{array}$} & \multirow[b]{2}{*}{ References } \\
\hline & & $\begin{array}{l}\mathrm{m} / \mathrm{V} \\
(\mathrm{g} / \mathrm{L})\end{array}$ & $\begin{array}{l}\mathrm{t} \\
\text { (h) }\end{array}$ & $\begin{array}{l}\mathrm{T} \\
\left({ }^{\circ} \mathrm{C}\right)\end{array}$ & $\mathrm{pH}$ & $\begin{array}{l}\text { Co range } \\
(\mathrm{mg} / \mathrm{L})\end{array}$ & & \\
\hline \multicolumn{9}{|c|}{ Copper-Cu(II) } \\
\hline Drumstick & $\mathrm{NaOH}$, citric acid & 0.4 & 2.0 & 30 & 5.0 & $10-1000$ & 151 & $\underline{\text { Reddy et al., } 2012}$ \\
\hline Tea waste & $\mathrm{NaOH}$ & 0.4 & 1.0 & 26 & 4.2 & - & 43.6 & $\underline{\text { Weng et al., 2014a }}$ \\
\hline Phoenix & PMDA & 0.5 & 0.84 & RT & 6.0 & $10-50$ & 31.3 & $\underline{\text { Yu et al., } 2015}$ \\
\hline Lamiaceae & $\mathrm{NaOH}$ & $1-8$ & 1.0 & RT & 5.5 & 50 & 20.3 & Kiliç et al., 2009 \\
\hline Lamiaceae & $\mathrm{NaOH}$ & 2.0 & 1.0 & 30 & 5.5 & $20-200$ & 20.3 & Kılıç and Solak, 2009 \\
\hline Boxwood & $\mathrm{NaOH}$ & 18 & - & - & 5.0 & 50 & 18.8 & Zolgharnein et al., 2017a \\
\hline Sacred fig & $\mathrm{HNO}_{3}$ & 10.0 & 1.0 & 33 & 4.4 & $5-500$ & 18.1 & $\underline{\text { Kazmi et al., } 2015}$ \\
\hline Rubber & $\mathrm{NaOH}$ & 2.0 & 1.0 & 27 & 4.0 & $5-50$ & 14.9 & Ngah and Hanafiah, 2008 \\
\hline Weed & $\mathrm{NaOH}$ & 2.0 & - & 27 & - & $5-20$ & 10.3 & Hanafiah et al., 2009a \\
\hline Rubber & $\mathrm{H}_{2} \mathrm{SO}_{4}, \mathrm{HCHO}$ & 2.0 & 1.5 & 27 & 4.0 & $5-50$ & 8.36 & Ngah and Hanafiah, 2009 \\
\hline Spent tea & $\mathrm{CaOH}_{2}$ & - & - & - & - & - & 7.81 & $\underline{\text { Ghosh et al., } 2015}$ \\
\hline Henna & $\mathrm{H}_{2} \mathrm{SO}_{4}$ & 3.0 & 1.5 & 35 & 6.0 & $5-100$ & 3.65 & $\begin{array}{l}\text { Shanthi and Selvarajan, } \\
\underline{2013}\end{array}$ \\
\hline
\end{tabular}

\section{Lead-Pb(II)}

\begin{tabular}{|c|c|c|c|c|c|c|c|c|}
\hline Drumstick & $\mathrm{NaOH}$, citric & 0.4 & 1.0 & 30 & 5.0 & $10-1000$ & 196 & $\underline{\text { Reddy et al., } 2012}$ \\
\hline Camphor & $\begin{array}{l}\mathrm{NaOH} \text {, alcohol, } \\
\text { succinic anhydride }\end{array}$ & - & 0.5 & RT & 5.0 & $50-1200$ & 186 & Wang et al., 2016 \\
\hline Rubber & Monosodium glutamate & $\begin{array}{l}0.4- \\
2\end{array}$ & 2.0 & 24 & 5.0 & $20-60$ & 110 & $\underline{\text { Fadzil et al., } 2016}$ \\
\hline Rubber & Citric acid & $\begin{array}{l}0.4- \\
2\end{array}$ & 2.0 & 24 & 5.0 & $20-60$ & 97.2 & $\underline{\text { Fadzil et al., } 2016}$ \\
\hline Sacred fig & $\begin{array}{l}\text { Polysulphone, } n, n \text { - } \\
\text { dimethyl-formamide }\end{array}$ & 5.0 & 1.0 & 25 & 5.3 & $10-1000$ & 37.5 & Qaiser et al., 2009 \\
\hline Chinaberry & $\mathrm{NaOH}$ & 3.0 & 1.0 & RT & 7.0 & 25 & 35.1 & Khokhar et al., 2015 \\
\hline Chinaberry & $\mathrm{HCl}$ & 3.0 & 1.0 & RT & 7.0 & 25 & 28.5 & $\underline{\text { Khokhar et al., } 2015}$ \\
\hline Sacred fig & $\mathrm{HNO}_{3}$ & 0.4 & 1.0 & 30 & 5.8 & $10-1000$ & 17.5 & Qaiser et al., 2007 \\
\hline
\end{tabular}

Cadmium-Cd(II)

\begin{tabular}{lllllllll}
\hline Drumstick & $\mathrm{NaOH}$, citric acid & 0.4 & 2.0 & 30 & 5.0 & $10-1000$ & 166 & Reddy et al., 2012 \\
\hline
\end{tabular}




\begin{tabular}{lllllllll}
\hline Phoenix & PMDA & 0.5 & 0.84 & $\mathrm{RT}$ & 6.0 & $10-50$ & 28.3 & $\underline{\text { Yu et al., 2015 }}$ \\
Bamboo & $\mathrm{NaOH}$ & 1.0 & 1.0 & 25 & 6.5 & $10-150$ & 19.7 & $\underline{\text { Pandey et al., 2015a }}$ \\
Kush grass & $\mathrm{NaOH}$ & 1.0 & 1.0 & 25 & 6.5 & $10-150$ & 15.2 & $\underline{\text { Pandey et al., 2015a }}$ \\
\hline Nickel-Ni(II) & & & & & & & & \\
\hline $\begin{array}{l}\text { Drumstick } \\
\text { Tea waste }\end{array}$ & $\mathrm{NaOH}$ citric acid & 0.4 & 2.0 & 30 & 5.0 & $10-1000$ & 149 & $\underline{\text { Reddy et al., 2012 }}$ \\
$\begin{array}{l}\text { White nenuphar } \\
\text { Tea waste }\end{array}$ & $\mathrm{MgCl}_{2}$ & 2.6 & 1.5 & $\mathrm{RT}$ & 7.0 & $0.01-15$ & 121 & $\underline{\text { Shah et al., 2015b }}$ \\
Boxwood & $\mathrm{Fe}_{3} \mathrm{O}_{4}$ nanoparticle & 5.0 & 3.0 & 30 & 4.0 & $50-100$ & 38.3 & $\underline{\underline{\text { Panneerselvam et al., }}}$ \\
\hline
\end{tabular}

\section{Zinc-Zn(II)}

\begin{tabular}{llccccccl}
\hline Phoenix & PMDA & 0.5 & 0.84 & RT & 6.0 & $10-50$ & 27.3 & $\underline{\text { Yu et al., 2015 }}$ \\
\hline Sacred fig & $\mathrm{HNO}_{3}$ & 10.0 & 1.0 & 33 & 5.2 & $5-500$ & 24.9 & $\underline{\text { Kazmi et al., 2015 }}$ \\
\hline Boxwood & $\mathrm{NaOH}$ & 18 & - & - & 5.0 & 50 & 21.2 & $\underline{\text { Zolgharnein et al., 2017a }}$ \\
\hline
\end{tabular}

\section{Mercury-Hg(II)}

\begin{tabular}{lllllllll}
\hline Bastard teak & $\mathrm{NaOH}, \mathrm{CaCl}_{2}$ & 4.0 & 3.0 & RT & 6.0 & 150 & 95.4 & Devani et al., 2015 \\
Bastard teak & $\mathrm{NaOH}, \mathrm{CaCl}_{2}$ & 4.0 & 3.0 & RT & 6.0 & 100 & 88.7 & Devani et al., 2015 \\
\hline
\end{tabular}

\section{Hexavalent chromium-Cr(VI)}

\begin{tabular}{|c|c|c|c|c|c|c|c|c|}
\hline London plane & $\mathrm{HNO}_{3}$ & 2.0 & 72 & 30 & 3.0 & $53-316$ & 75.8 & Aoyama, 2003c \\
\hline London plane & $\mathrm{HNO}_{3}$ & 2.0 & 72 & 30 & 3.0 & $\begin{array}{l}52.82- \\
315.58\end{array}$ & 75.7 & Aoyama, 2003b \\
\hline Black locust & $\mathrm{HNO}_{3}$ & 2.0 & 48 & 30 & 3.0 & $5-300$ & 51.6 & Aoyama et al., 2000a \\
\hline Neem & $\mathrm{HCl}$ & 10.0 & 72 & 30 & 2.0 & $20-700$ & 62.9 & Babu and Gupta, 2008 \\
\hline Rubber & $\mathrm{H}_{2} \mathrm{SO}_{4}$ & 5.0 & 4.0 & 30 & 2.0 & $10-100$ & 29.8 & $\underline{\text { Nag et al., } 2017}$ \\
\hline Sacred fig & $\mathrm{HNO}_{3}$ & 10.0 & 1.0 & 30 & 5.2 & $10-1000$ & 26.3 & Qaiser et al., 2007 \\
\hline Ficus nitida & $\mathrm{H}_{2} \mathrm{SO}_{4}$ & 8.0 & 0.42 & 25 & 4.0 & $50-200$ & 21.0 & $\underline{\text { Ali and Alrafai, } 2016}$ \\
\hline Japanese red pine & $\mathrm{HNO}_{3}$ & 2.0 & 24 & 30 & 3.0 & $1-100$ & 14.5 & $\underline{\text { Aoyama et al., 1999a }}$ \\
\hline Lettuce & $\mathrm{NaOH}$ & 10.0 & 5.0 & 40 & 7.0 & $10-90$ & 7.15 & $\underline{\text { Li et al., } 2014}$ \\
\hline Mangrove & $\mathrm{H}_{2} \mathrm{SO}_{4}, \mathrm{NaOH}$ & 10.0 & 6.0 & 30 & 7.0 & $10-150$ & 5.72 & Elangovan et al., 2008 \\
\hline \multicolumn{9}{|c|}{ Trivalent chromium $-\mathrm{Cr}(\mathrm{III})$} \\
\hline Mangrove & $\mathrm{H}_{2} \mathrm{SO}_{4}, \mathrm{NaOH}$ & 10.0 & 6.0 & 30 & 5.0 & $10-150$ & 6.54 & Elangovan et al., 2008 \\
\hline \multicolumn{9}{|c|}{ Arsenic-As(III) } \\
\hline Devdaru & $\mathrm{HCl}$ & 1.0 & 2.0 & 30 & 7.5 & $1-5$ & 1.51 & Choudhary, 2015 \\
\hline
\end{tabular}




\section{Cerium}

Calabrian pine

Citric acid

$\begin{array}{lllll}0.5 & 0.75 & 40 & 4.0 & 10-90\end{array}$

62.1

Kütahyal1 et al., 2012

\section{Uranium-U(VI)}

\begin{tabular}{lllllllll}
\hline Sotetsu & DETA & 0.4 & 2.0 & 25 & 8.2 & $5-30$ & 0.91 & Xiao et al., 2016 \\
\hline
\end{tabular}

\section{Vanadium}

Neptune grass

$\mathrm{HCl}$

$\begin{array}{lllllll}10.0 & 0.5 & \text { RT } & 3.0 & 20-40 & 16.0 & \text { Pennesi et al., 2013 }\end{array}$

\section{Molybdenum}

Neptune grass

$\mathrm{HCl}$

$\begin{array}{lllll}10.0 & 0.5 & \text { RT } & 3.0 & 20-40\end{array}$

18.0

$\underline{\text { Pennesi et al., } 2013}$

\section{Methylene blue dye}

\begin{tabular}{|c|c|c|c|c|c|c|c|c|}
\hline Lawny grass & Citric acid & 1.0 & 4.0 & - & 5.7 & $40-320$ & 301 & Chen et al., 2011c \\
\hline Fig & $\mathrm{Fe}_{3} \mathrm{O}_{4}$ nanoparticle & 3.5 & 0.5 & - & - & 4 & 61.7 & Alizadeh et al., 2017 \\
\hline Pineapple & $\begin{array}{l}\text { Hexadecyltrimethylam } \\
\text { monium bromide }\end{array}$ & - & 2.0 & RT & - & $5-1000$ & 52.6 & $\underline{\text { Kamaru et al., } 2016}$ \\
\hline Azolla & $\mathrm{Fe}_{3} \mathrm{O}_{4}$ & 3.5 & 0.5 & RT & - & 4 & 25.1 & Alizadeh et al., 2017 \\
\hline \multicolumn{9}{|c|}{ Malachite green dye } \\
\hline Labil & Ammonia, lauric acid & - & - & 30 & 10.0 & $100-500$ & 370 & Yang and Hong, 2018b \\
\hline Maize & $\mathrm{CaOH}_{2}$ & 2.5 & 0.5 & 50 & 6.0 & $10-200$ & 81.5 & Jalil et al., 2012a \\
\hline
\end{tabular}

\section{Crystal violet dye}

\begin{tabular}{lllllllll}
\hline Phoenix trees & $\mathrm{NaOH}$ & 1.0 & 11.0 & 30 & 8.0 & $100-1000$ & 662 & Ren et al., 2015 \\
Fig & $\mathrm{Fe}_{3} \mathrm{O}_{4}$ nanoparticle & 2.5 & 1.0 & - & - & 4 & 53.5 & Alizadeh et al., 2017 \\
Azolla & $\mathrm{Fe}_{3} \mathrm{O}_{4}$ nanoparticle & 1.5 & 1.0 & - & - & 4 & 30.2 & Alizadeh et al., 2017
\end{tabular}

Acid violet 17 dye

\begin{tabular}{lllllllll} 
Cluster fig & $\mathrm{NaOH}, \mathrm{H}_{2} \mathrm{SO}_{4}$ & 3.0 & 4.0 & 30 & 2.0 & $50-200$ & 111 & Jain and Gogate, $2017 \mathrm{~d}$ \\
\hline
\end{tabular}

\section{Methyl orange dye}

$\begin{array}{lllllllll}\text { Pineapple } & \begin{array}{l}\text { Hexadecyltrimethylam } \\ \text { monium bromide }\end{array} & - & 2.0 & \text { RT } & - & 5-1000 & 47.6 \quad \text { Kamaru et al., } 2016\end{array}$

\section{Methyl violet 2B dye}

\begin{tabular}{lllllllll}
\hline Terap & $\mathrm{NaOH}$ & 2.0 & 4.0 & $\mathrm{RT}$ & - & $500-1000$ & 1004 & $\underline{\text { Lim et al., 2016a }}$ \\
\hline
\end{tabular}

Direct Blue-15 dye

\begin{tabular}{lllllllll}
\hline Tea & Acetone & 1.0 & 0.67 & 40 & 3.0 & 25 & 90.9 & Rehman et al., 2017 \\
\hline
\end{tabular}

\section{Acid Blue 25 dye}

Cluster fig

$\mathrm{NaOH}$

$\begin{array}{lllll}4.0 & 3.0 & 50 & 2.0 & 50-400\end{array}$

$83.3 \quad$ Jain and Gogate, 2017a 


\section{Pyrocatechol violet dye}

\begin{tabular}{lllllllll}
\hline Black locust & $\mathrm{NaCl}$ & - & 0.83 & 22 & 1.82 & 38.28 & 82.6 & Khorshidi and Niazi, 2016 \\
\hline
\end{tabular}

\section{Brilliant green dye}

\begin{tabular}{lllllllll}
\hline Jambolan & $\mathrm{NaOH}$ & 60.0 & 0.33 & 50 & 3.0 & $30-80$ & 5.13 & Rehman et al., 2012 \\
Jambolan & $\mathrm{HCl}$ & 60.0 & 0.33 & 50 & 3.0 & $30-80$ & 0.17 & Rehman et al., 2012 \\
\hline
\end{tabular}

Acid blue 113 dye

\begin{tabular}{lllllllll}
\hline Almond & Surfactant CTAB & 10.0 & 2.5 & 20 & 6.5 & $50-200$ & 97.1 & $\underline{\text { Jain and Gogate, 2017b }}$ \\
& $\mathrm{C}_{19} \mathrm{H}_{42} \mathrm{BrN}$ & 10.0 & 2.5 & 20 & 6.5 & $50-200$ & 25.5 & $\underline{\text { Jain and Gogate, 2017b }}$ \\
Almond & $\mathrm{NaOH}$ & & & & & &
\end{tabular}

\section{Congo red dye}

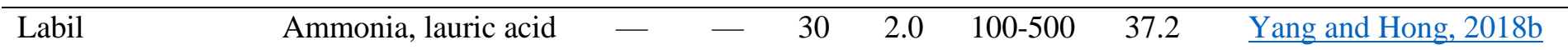

\section{Orthophosphate}

\begin{tabular}{lllllllll}
\hline Kush grass & $\mathrm{CaOH}_{2}$ & 4.0 & 24 & 25 & 7.0 & $12.5-200$ & 12.3 & Markou et al., 2016b \\
Kush grass & $\mathrm{CaOH}_{2}$ & 4.0 & 24 & 25 & 7.0 & $50-200$ & 12.2 & Markou et al., 2016a \\
\hline
\end{tabular}

Acid green 25 dye

\begin{tabular}{lllllllll}
\hline Almond & $\mathrm{NaOH}$ & 6.0 & 5.5 & 30 & 2.0 & $50-200$ & 46.6 & Jain and Gogate, 2018 \\
\hline
\end{tabular}


Table S10. Some common inorganic salt used for the effect study of ionic strength

\begin{tabular}{|c|c|c|}
\hline Inorganic salt & Adsorbate & Reference \\
\hline $\mathrm{NaCl}$ & Acid blue 113 & $\underline{\text { Jain and Gogate, } 2017 \mathrm{~b}}$ \\
\hline $\mathrm{NaCl}$ & Methylene blue, malachite green & $\underline{\text { Sangi et al., } 2008}$ \\
\hline $\mathrm{NaCl}$ & Methylene blue & $\underline{\text { Ansari et al., 2016a }} ; \underline{\text { Han et al., 2007 }}$; Han et al., \\
\hline $\mathrm{NaCl}$ & Acid blue 45 and acid black 1 & Maleki et al., 2017 \\
\hline $\mathrm{NaCl}$ & Heavy metal & $\underline{\text { Rao et al., 2011b }}$; $\underline{\text { Ruiyi }, 2010}$ et al., 2016; Srinivasa Rao et \\
\hline $\mathrm{NaCl}$ & Heavy metal & Ngah and Hanafiah, 2008 \\
\hline $\mathrm{NaCl}$ & Heavy metal & Zhang et al., 2015 \\
\hline $\mathrm{NaCl}$ & Malachite green & $\underline{\text { Hamdaoui et al., } 2008}$ \\
\hline $\mathrm{NaCl}$ & Basic red 46 & Deniz and Karaman, 2011 \\
\hline $\mathrm{NaCl}$ & Toluidine blue and crystal violet & $\underline{\text { Lafi et al., } 2015}$ \\
\hline $\mathrm{NaNO}_{3}$ & Heavy metal & $\underline{\text { Sangi et al., } 2008}$ \\
\hline $\mathrm{NaNO}_{3}$ & Methylene blue & Weng et al., 2009 \\
\hline $\mathrm{Ca}_{2} \mathrm{NO}_{3}$ & Heavy metal & $\underline{\text { Sangi et al., } 2008}$ \\
\hline $\mathrm{NaClO}_{4}$ & Heavy metal & $\underline{\text { Weng and } \mathrm{Wu}, 2012}$ \\
\hline $\mathrm{CaCl}_{2}$ & Methylene blue & 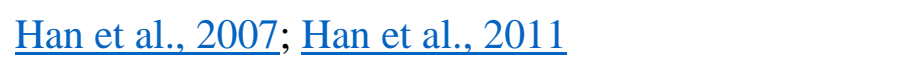 \\
\hline $\mathrm{Na}_{2} \mathrm{SO}_{4}$ & Heavy metal & $\underline{\text { Rao et al., 2011b; }} \underline{\text { Srinivasa Rao et al., } 2010}$ \\
\hline $\mathrm{KNO}_{3}$ & Cationic methyl violet $2 \mathrm{~B}$ dye & $\underline{\text { Lim et al., } 2016 \mathrm{~b}}$ \\
\hline $\mathrm{NH}_{42} \mathrm{SO}_{4}$ & Acid blue 45 and acid black 1 & Maleki et al., 2017 \\
\hline $\mathrm{NaHCO}_{3}$ & Acid blue 45 and acid black 1 & Maleki et al., 2017 \\
\hline
\end{tabular}


Table S11. Thermodynamic parameters for the biosorption of toxic metal ions onto pristine leaves

\begin{tabular}{|c|c|c|c|c|c|c|}
\hline \multirow[b]{2}{*}{ Leaves } & \multirow[b]{2}{*}{$\begin{array}{c}\mathbf{T} \\
(\mathbf{K})\end{array}$} & \multirow{2}{*}{$\begin{array}{c}\text { Derivation of } \\
\mathbf{K}_{\mathbf{C}} \\
\text { (unit) }\end{array}$} & \multicolumn{3}{|c|}{ Thermodynamic parameters } & \multirow[b]{2}{*}{ References } \\
\hline & & & $\begin{array}{c}\Delta \mathbf{G}^{\circ} \\
(\mathrm{kJ} / \mathrm{mol})\end{array}$ & $\begin{array}{c}\Delta \mathbf{H}^{\circ} \\
(\mathrm{kJ} / \mathrm{mol})\end{array}$ & $\begin{array}{c}\Delta \mathbf{S}^{\circ} \\
(\mathrm{kJ} / \mathrm{mol} \times \\
\mathrm{K})\end{array}$ & \\
\hline \multicolumn{7}{|c|}{ Lead $\left(\mathrm{Pb}^{2+}\right)$} \\
\hline Camphor & $\begin{array}{l}303 \\
313 \\
323 \\
333\end{array}$ & $\begin{array}{c}\mathrm{K}_{\mathrm{L}} \\
\mathrm{L} / \mathrm{mol}\end{array}$ & $\begin{array}{l}-23.9 \\
-25.3 \\
-26.7 \\
-27.8\end{array}$ & 15.1 & 0.129 & Chen et al., 2010b \\
\hline Potato & $\begin{array}{l}303 \\
313 \\
323 \\
\end{array}$ & $\begin{array}{c}\mathrm{K}_{\mathrm{L}} \\
\mathrm{L} / \mathrm{mg}\end{array}$ & $\begin{array}{l}-8.75 \\
-8.51 \\
-7.98\end{array}$ & 3.69 & 0.039 & Yuvaraja et al., 2014 \\
\hline Sacred fig & $\begin{array}{l}303 \\
313 \\
323 \\
\end{array}$ & $\begin{array}{l}\mathrm{K}_{\mathrm{d}} \\
\mathrm{L} / \mathrm{g}\end{array}$ & $\begin{array}{l}-2.95 \\
-0.12 \\
4.94 \\
\end{array}$ & -105 & -0.350 & Qaiser et al., 2009 \\
\hline Tea waste & $\begin{array}{l}288 \\
298 \\
308 \\
318 \\
328\end{array}$ & $\begin{array}{c}\mathrm{K}_{\mathrm{d}} \\
\mathrm{mL} / \mathrm{g}\end{array}$ & $\begin{array}{l}-14.8 \\
-14.6 \\
-12.8 \\
-12.6 \\
-11.3\end{array}$ & 25.1 & 0.138 & Wan et al., 2014 \\
\hline Neem & $\begin{array}{l}308 \\
313 \\
318\end{array}$ & $\begin{array}{c}\mathrm{K}_{\mathrm{d}} \\
\mathrm{mL} / \mathrm{g}\end{array}$ & $\begin{array}{l}-4.69 \\
-4.26 \\
-3.96\end{array}$ & 10.9 & -0.029 & $\begin{array}{l}\text { Bhattacharyya and Sharma, } \\
\underline{2004}\end{array}$ \\
\hline Palm & $\begin{array}{l}283 \\
298 \\
308 \\
323\end{array}$ & $\begin{array}{c}\mathrm{K}_{\mathrm{L}} \\
\mathrm{L} / \mathrm{mg}\end{array}$ & $\begin{array}{l}-8.23 \\
-8.19 \\
-7.43 \\
-7.16\end{array}$ & -16.7 & -0.029 & Al-Haidary et al., 2011a \\
\hline Cadmium & $2+)$ & & & & & \\
\hline Jambolan & $\begin{array}{l}303 \\
313 \\
323 \\
\end{array}$ & $\begin{array}{l}\mathrm{K}_{\mathrm{p}} \\
\text { No }\end{array}$ & $\begin{array}{l}-1.40 \\
-1.58 \\
-1.74 \\
\end{array}$ & 3.70 & 0.017 & $\underline{\text { Rao et al., 2010c }}$ \\
\hline Loquat & $\begin{array}{l}293 \\
303 \\
313 \\
\end{array}$ & $\begin{array}{l}\mathrm{K}_{\mathrm{p}} \\
\mathrm{No}\end{array}$ & $\begin{array}{l}-7.02 \\
-8.21 \\
-9.55\end{array}$ & 29.7 & 0.125 & Awwad and Salem, 2014 \\
\hline Hornbeam & $\begin{array}{l}298 \\
308 \\
318 \\
328\end{array}$ & $\begin{array}{l}\mathrm{K}_{\mathrm{p}} \\
\mathrm{No}\end{array}$ & $\begin{array}{l}-4.29 \\
-4.04 \\
-3.65 \\
-3.44\end{array}$ & -13.1 & -0.029 & Zolgharnein et al., 2013a \\
\hline Date Tree & $\begin{array}{l}298 \\
308 \\
313 \\
333 \\
\end{array}$ & $\begin{array}{l}\mathrm{K}_{\mathrm{p}} \\
\mathrm{No}\end{array}$ & $\begin{array}{l}-7.37 \\
-7.52 \\
-7.92 \\
-10.8 \\
\end{array}$ & 21.6 & 0.095 & Boudrahem et al., 2011 \\
\hline Tea waste & $\begin{array}{l}288 \\
298 \\
308 \\
318 \\
328\end{array}$ & $\begin{array}{c}\mathrm{K}_{\mathrm{d}} \\
\mathrm{mL} / \mathrm{g}\end{array}$ & $\begin{array}{l}-12.5 \\
-12.4 \\
-12.2 \\
-12.1 \\
-11.8\end{array}$ & 10.5 & 0.079 & Wan et al., 2014 \\
\hline Loquat & $\begin{array}{l}293 \\
303\end{array}$ & $\begin{array}{l}\mathrm{K}_{\mathrm{p}} \\
\mathrm{No}\end{array}$ & $\begin{array}{l}-6.33 \\
-6.98\end{array}$ & 12.3 & 0.064 & Al-Dujaili et al., 2012 \\
\hline
\end{tabular}




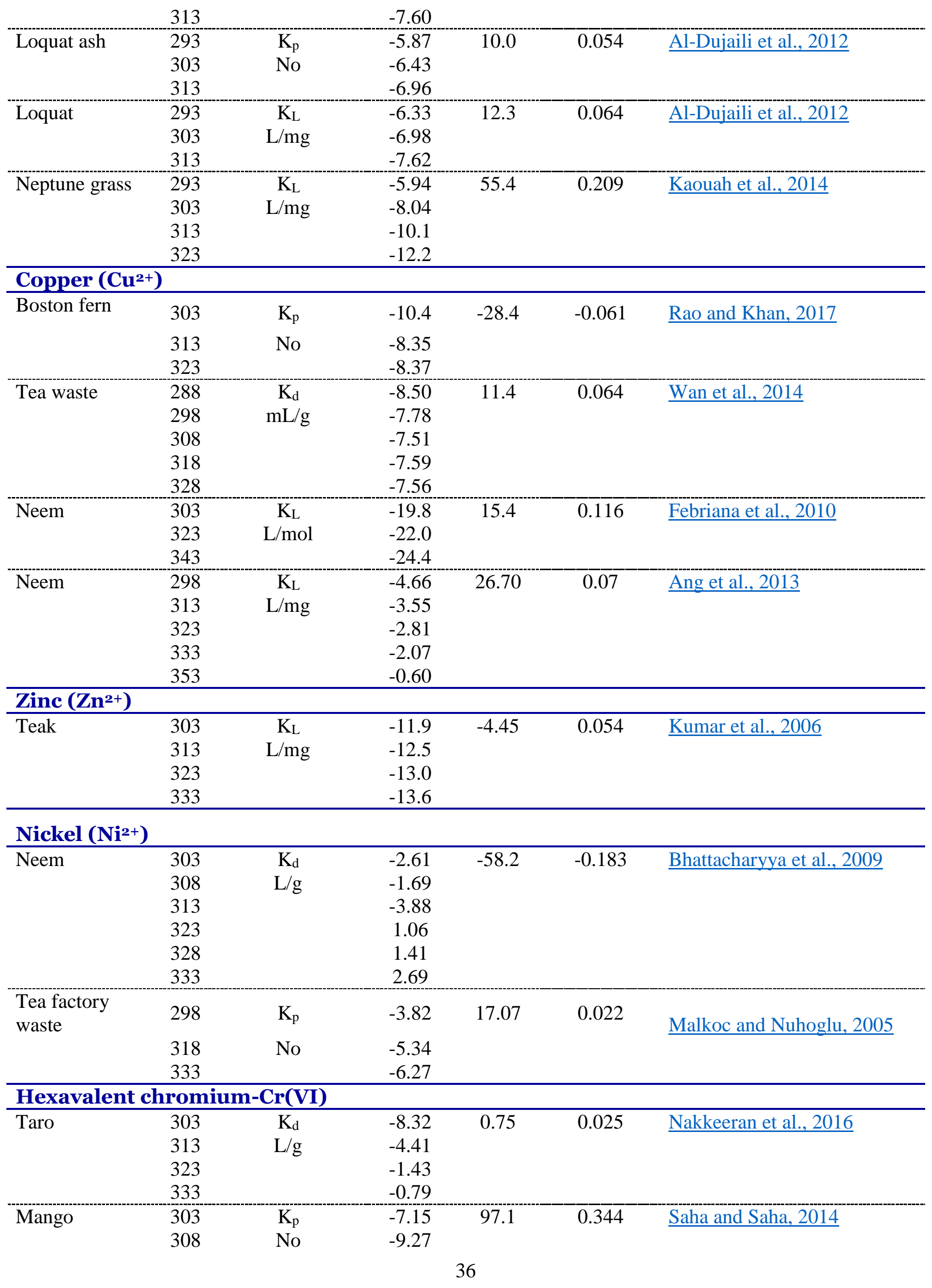




\begin{tabular}{|c|c|c|c|c|c|c|}
\hline & 313 & & -10.7 & & & \\
\hline \multirow[t]{3}{*}{ Green tea } & 298 & $\mathrm{~K}_{\mathrm{L}}$ & -3.96 & -41.0 & 0.125 & Jeyaseelan and Gupta, 2016a \\
\hline & 313 & $\mathrm{~L} / \mathrm{mg}$ & -1.37 & & & \\
\hline & 323 & & -0.62 & & & \\
\hline \multirow[t]{4}{*}{ Purple secretia } & 303 & $\mathrm{~K}_{\mathrm{L}}$ & -1.85 & 11.35 & 0.391 & $\underline{\text { Sinha et al., } 2015 \mathrm{a}}$ \\
\hline & 308 & $\mathrm{~L} / \mathrm{mg}$ & -3.09 & & & \\
\hline & 313 & & -4.22 & & & \\
\hline & 323 & & -5.28 & & & \\
\hline \multirow[t]{3}{*}{ Golden shower } & 293 & $\mathrm{~K}_{\mathrm{L}}$ & 4.44 & & & \\
\hline & 303 & $\mathrm{~L} / \mathrm{mg}$ & 3.20 & 41.55 & 0.1267 & $\underline{\text { Ahmad et al., 2017a }}$ \\
\hline & 313 & & 1.91 & & & \\
\hline \multicolumn{7}{|c|}{ Mercury (Hg2+) } \\
\hline \multirow[t]{3}{*}{ Bamboo } & 293 & $\mathrm{~K}_{\mathrm{d}}$ & -0.87 & 10.3 & 0.023 & Mondal et al., 2013 \\
\hline & 300 & $\mathrm{~L} / \mathrm{g}$ & -1.25 & & & \\
\hline & 307 & & -2.03 & & & \\
\hline \multicolumn{7}{|l|}{ Arsenic (III) } \\
\hline \multirow[t]{4}{*}{ Mango } & 283 & $\mathrm{~K}_{\mathrm{d}}$ & -17.9 & 23.9 & 0.144 & Kamsonlian et al., 2012c \\
\hline & 293 & $\mathrm{~L} / \mathrm{g}$ & -18.1 & & & \\
\hline & 303 & & -20.0 & & & \\
\hline & 318 & & -20.2 & & & \\
\hline \multicolumn{7}{|c|}{ Cadmium (Cd2+) } \\
\hline \multirow[t]{3}{*}{ Java plum } & 303 & $\mathrm{~K}_{\mathrm{L}}$ & -1.40 & 3.7 & 0.017 & Rao et al., 2010c \\
\hline & 313 & $\mathrm{~L} / \mathrm{mg}$ & -1.58 & & & \\
\hline & 323 & & -1.74 & & & \\
\hline
\end{tabular}

NOTE: $K_{\mathrm{L}}$ (the Langmuir constant related to the affinity between an adsorbent and adsorbate that has been defined in Equation 12); $K_{\mathrm{p}}$ (thermodynamic partition coefficient that has been defined in Equation 18 ); $K_{\mathrm{d}}$ (distribution coefficient that has been defined in Equation 19) 
Table S12. Thermodynamic parameters for the biosorption of toxic metal ions onto modified/treated leaves

\begin{tabular}{|c|c|c|c|c|c|c|c|}
\hline \multirow[b]{2}{*}{ Leaves } & \multirow[b]{2}{*}{ Chemical } & \multirow[b]{2}{*}{$\begin{array}{l}\mathbf{T} \\
\mathbf{K}\end{array}$} & \multirow[b]{2}{*}{$\begin{array}{c}\text { Derivation of } \\
\mathbf{K}_{\mathbf{C}} \\
\text { (unit) }\end{array}$} & \multicolumn{3}{|c|}{ Thermodynamic parameters } & \multirow[b]{2}{*}{ Ref. } \\
\hline & & & & $\begin{array}{c}\Delta \mathbf{G}^{\circ} \\
\mathrm{kJ} / \mathrm{mol}\end{array}$ & $\begin{array}{c}\Delta \mathbf{H}^{\circ} \\
(\mathrm{kJ} / \mathrm{mol})\end{array}$ & $\begin{array}{c}\Delta \mathbf{S}^{\circ} \\
(\mathrm{kJ} / \mathrm{mol} \times \\
\mathrm{K})\end{array}$ & \\
\hline \multicolumn{8}{|c|}{ Lead $\left(\mathrm{Pb}^{2+}\right)$} \\
\hline Drumstick & $\begin{array}{l}\mathrm{HNO}_{3}, \\
\mathrm{NaOH}\end{array}$ & $\begin{array}{l}293 \\
303 \\
313\end{array}$ & $\begin{array}{l}\mathrm{K}_{\mathrm{L}} \\
\mathrm{L} / \mathrm{g}\end{array}$ & $\begin{array}{l}-3.94 \\
-4.92 \\
-5.39\end{array}$ & 17.5 & 0.074 & $\underline{\text { Reddy et al., } 2010}$ \\
\hline Rubber & $\begin{array}{l}\mathrm{NaOH}, \\
\mathrm{CD}\end{array}$ & $\begin{array}{l}303 \\
313 \\
\end{array}$ & $\begin{array}{c}\mathrm{K}_{\mathrm{d}} \\
\mathrm{mL} / \mathrm{g}\end{array}$ & $\begin{array}{l}-5.48 \\
-4.95\end{array}$ & 21.4 & 0.052 & Khalir et al., 2012 \\
\hline $\begin{array}{l}\text { Australian } \\
\text { pine }\end{array}$ & $\mathrm{NaAlO}_{2}$ & $\begin{array}{l}303 \\
313 \\
323 \\
\end{array}$ & $\begin{array}{c}\mathrm{K}_{\mathrm{p}} \\
\text { no unit }\end{array}$ & $\begin{array}{l}-7.24 \\
-8.87 \\
-9.88 \\
\end{array}$ & 33.8 & 0.135 & $\begin{array}{l}\text { Khan Rao and } \\
\text { Khatoon, } 2017\end{array}$ \\
\hline \multicolumn{8}{|c|}{ Cadmium (Cd2+) } \\
\hline Kush grass & $\mathrm{NaOH}$ & $\begin{array}{l}298 \\
308 \\
318 \\
\end{array}$ & $\begin{array}{l}K_{L} \\
L / g\end{array}$ & $\begin{array}{l}-0.39 \\
-1.51 \\
-1.11 \\
\end{array}$ & 5.50 & 0.002 & $\underline{\text { Pandey et al., 2015b }}$ \\
\hline Bamboo & $\mathrm{NaOH}$ & $\begin{array}{l}298 \\
308 \\
318\end{array}$ & $\begin{array}{l}\mathrm{K}_{\mathrm{L}} \\
\mathrm{L} / \mathrm{g}\end{array}$ & $\begin{array}{l}-0.66 \\
-1.73 \\
-2.05\end{array}$ & 9.28 & 0.003 & $\underline{\text { Pandey et al., 2015b }}$ \\
\hline Drumstick & $\begin{array}{l}\mathrm{HNO}_{3} \\
\mathrm{NaOH}\end{array}$ & $\begin{array}{l}293 \\
303 \\
313 \\
323 \\
\end{array}$ & $\begin{array}{l}\mathrm{K}_{\mathrm{L}} \\
\mathrm{L} / \mathrm{g}\end{array}$ & $\begin{array}{l}-3.68 \\
-4.50 \\
-4.95 \\
-5.42 \\
\end{array}$ & 15.3 & 0.063 & $\underline{\text { Reddy et al., } 2012}$ \\
\hline \multicolumn{8}{|c|}{ Copper $\left(\mathrm{Cu}^{2+}\right)$} \\
\hline Rubber & $\begin{array}{l}\mathrm{H}_{2} \mathrm{SO}_{4} \\
\mathrm{HCHO}\end{array}$ & $\begin{array}{l}300 \\
310 \\
320\end{array}$ & $\begin{array}{c}\mathrm{K}_{\mathrm{L}} \\
\mathrm{L} / \mathrm{mol}\end{array}$ & $\begin{array}{l}-23.5 \\
-24.4 \\
-25.3\end{array}$ & 3.20 & 0.089 & $\begin{array}{l}\text { Ngah and Hanafiah, } \\
\underline{2009}\end{array}$ \\
\hline Drumstick & $\begin{array}{l}\mathrm{HNO}_{3} \\
\mathrm{NaOH}\end{array}$ & $\begin{array}{l}293 \\
303 \\
313\end{array}$ & $\begin{array}{l}\mathrm{K}_{\mathrm{L}} \\
\mathrm{L} / \mathrm{g}\end{array}$ & $\begin{array}{l}-3.17 \\
-3.75 \\
-4.25\end{array}$ & 12.8 & 0.053 & Reddy et al., 2012 \\
\hline $\begin{array}{l}\text { Australian } \\
\text { pine }\end{array}$ & $\mathrm{NaAlO}_{2}$ & $\begin{array}{l}303 \\
313 \\
323 \\
\end{array}$ & $\begin{array}{c}\mathrm{K}_{\mathrm{p}} \\
\text { no unit }\end{array}$ & $\begin{array}{l}-7.85 \\
-9.19 \\
-10.7\end{array}$ & 36.2 & 0.145 & 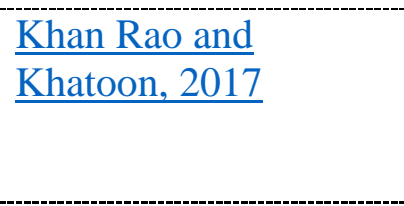 \\
\hline $\begin{array}{l}\text { Black tea } \\
\text { waste }\end{array}$ & $\mathrm{NaOH}$ & $\begin{array}{l}289 \\
299 \\
311 \\
\end{array}$ & $\begin{array}{c}\mathrm{K}_{\mathrm{L}} \\
\mathrm{L} / \mathrm{mol}\end{array}$ & $\begin{array}{r}-19.0 \\
-19.9 \\
-20.7 \\
-21.7\end{array}$ & 2.89 & 0.079 & $\underline{\text { Weng et al., 2014b }}$ \\
\hline Lamiaceae & $\mathrm{NaOH}$ & $\begin{array}{l}283 \\
293 \\
303 \\
313 \\
318\end{array}$ & $\begin{array}{c}\mathrm{K}_{\mathrm{L}} \\
\mathrm{L} / \mathrm{mg}\end{array}$ & $\begin{array}{l}6.51 \\
6.31 \\
5.32 \\
4.06 \\
2.57\end{array}$ & 37.2 & 0.377 & $\underline{\text { Kiliç and Solak, } 2009}$ \\
\hline \multicolumn{8}{|c|}{ Mercury $\left(\mathrm{Hg}^{2+}\right)$} \\
\hline Bamboo & TX-100 & 293 & $\mathrm{~K}_{\mathrm{d}}$ & $\begin{array}{l}-1.07 \\
38\end{array}$ & 15.9 & 0.098 & Mondal et al., 2013 \\
\hline
\end{tabular}




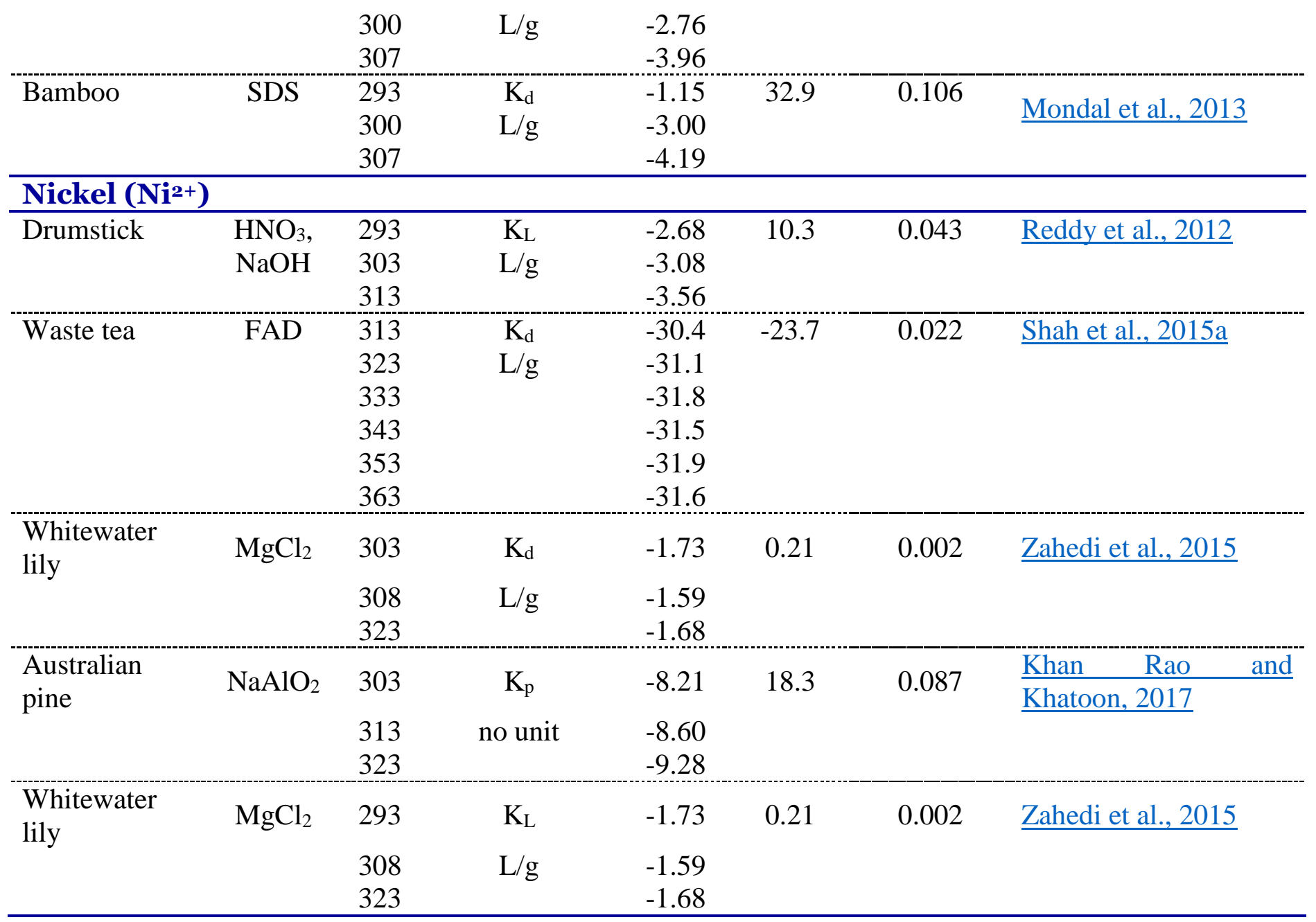

Note: SDS (sodium dodecyl sulfate), FAD (formaldehyde), CD (carbon disulfide);

$K_{\mathrm{L}}$ (the Langmuir constant related to the affinity between an adsorbent and adsorbate that has been defined in Equation 12); $K_{\mathrm{p}}$ (thermodynamic partition coefficient that has been defined in Equation 18 ); $K_{\mathrm{d}}$ (distribution coefficient that has been defined in Equation 19) 
Table S13. Thermodynamic parameters for the biosorption of organic dyes onto pristine leaves

\begin{tabular}{|c|c|c|c|c|c|c|}
\hline \multirow[b]{2}{*}{ Leaves } & \multirow{2}{*}{$\begin{array}{l}\mathbf{T} \\
(\mathrm{K})\end{array}$} & \multirow{2}{*}{$\begin{array}{c}\text { Derivation } \\
\text { of } \mathbf{K}_{\mathbf{C}} \\
\text { (Unit) }\end{array}$} & \multicolumn{3}{|c|}{ Thermodynamic parameters } & \multirow[b]{2}{*}{ References } \\
\hline & & & $\begin{array}{c}\Delta \mathbf{G}^{\circ} \\
(\mathrm{kJ} / \mathrm{mol})\end{array}$ & $\begin{array}{c}\Delta \mathbf{H}^{\circ} \\
(\mathrm{kJ} / \mathrm{mol})\end{array}$ & $\begin{array}{c}\Delta \mathbf{S}^{\circ} \\
(\mathrm{kJ} / \mathrm{mol} \times \\
\mathrm{K}) \\
\end{array}$ & \\
\hline \multicolumn{7}{|c|}{ Methylene blue dye } \\
\hline Carrot & $\begin{array}{l}303 \\
313 \\
323\end{array}$ & $\begin{array}{c}\mathrm{K}_{\mathrm{L}} \\
\mathrm{L} / \mathrm{mg}\end{array}$ & $\begin{array}{l}-4.79 \\
-4.53 \\
-4.27\end{array}$ & -12.7 & -0.026 & $\underline{\text { Kushwaha et al., 2014a }}$ \\
\hline Weeping willow & $\begin{array}{l}293 \\
333\end{array}$ & $\begin{array}{c}\mathrm{K}_{\mathrm{L}} \\
\mathrm{L} / \mathrm{mg}\end{array}$ & $\begin{array}{l}-21.1 \\
-20.0\end{array}$ & -28.1 & -0.024 & Khodabandehloo et al., 2017 \\
\hline Phoenix tree & $\begin{array}{l}295 \\
309 \\
323 \\
\end{array}$ & $\begin{array}{c}\mathrm{K}_{\mathrm{L}} \\
\mathrm{L} / \mathrm{mg}\end{array}$ & $\begin{array}{l}-3.89 \\
-4.62 \\
-5.01\end{array}$ & 7.77 & -0.040 & Han et al., 2007 \\
\hline Potato & $\begin{array}{l}303 \\
313 \\
323 \\
\end{array}$ & $\begin{array}{c}\mathrm{K}_{\mathrm{L}} \\
\mathrm{L} / \mathrm{mg}\end{array}$ & $\begin{array}{l}-4.38 \\
-4.27 \\
-4.17 \\
\end{array}$ & -7.49 & -0.010 & Gupta et al., 2016a \\
\hline $\begin{array}{l}\text { Brassica } \\
\text { oleracea }\end{array}$ & $\begin{array}{l}303 \\
313 \\
323 \\
\end{array}$ & $\begin{array}{c}\mathrm{K}_{\mathrm{d}} \\
\text { no unit }\end{array}$ & $\begin{array}{l}-5.53 \\
-5.12 \\
-4.71 \\
\end{array}$ & -18.1 & -0.041 & $\underline{\text { Ansari et al., 2016b }}$ \\
\hline Hybrid plane & $\begin{array}{l}293 \\
303 \\
313 \\
323 \\
\end{array}$ & $\begin{array}{c}\mathrm{K}_{\mathrm{L}} \\
\mathrm{L} / \mathrm{mg}\end{array}$ & $\begin{array}{l}-4.93 \\
-5.38 \\
-7.45 \\
-7.76 \\
\end{array}$ & 28.3 & 0.113 & $\underline{\text { Kong et al., } 2015}$ \\
\hline Oriental plane & $\begin{array}{l}298 \\
313 \\
323 \\
333 \\
\end{array}$ & $\begin{array}{c}\mathrm{K}_{\mathrm{L}} \\
\mathrm{L} / \mathrm{mg}\end{array}$ & $\begin{array}{l}-0.17 \\
-0.70 \\
-0.99 \\
-1.37\end{array}$ & 9.94 & 0.034 & $\begin{array}{l}\text { Peydayesh and Rahbar-Kelishami, } \\
\underline{2015}\end{array}$ \\
\hline Oil palm & $\begin{array}{l}303 \\
308 \\
313 \\
318 \\
323 \\
328 \\
\end{array}$ & $\begin{array}{c}\mathrm{K}_{\mathrm{L}} \\
\mathrm{L} / \mathrm{mg}\end{array}$ & $\begin{array}{l}-1.41 \\
-1.78 \\
-2.16 \\
-2.54 \\
-2.92 \\
-3.29\end{array}$ & 21.5 & 0.076 & $\underline{\text { Setiabudi et al., 2016a }}$ \\
\hline Pineapple & $\begin{array}{l}308 \\
313 \\
333\end{array}$ & $\begin{array}{c}\mathrm{K}_{\mathrm{L}} \\
\mathrm{L} / \mathrm{mg}\end{array}$ & $\begin{array}{l}-4.32 \\
-4.33 \\
-4.44\end{array}$ & -2.79 & 0.004 & $\underline{\text { Kamaru et al., } 2016}$ \\
\hline Pine & $\begin{array}{l}303 \\
313 \\
323 \\
333 \\
\end{array}$ & $\begin{array}{l}\mathrm{K}_{\mathrm{d}} \\
\mathrm{L} / \mathrm{g}\end{array}$ & $\begin{array}{l}-10.4 \\
-11.3 \\
-12.1 \\
-12.9\end{array}$ & 15.3 & 0.085 & $\underline{\text { Yagub et al., } 2012}$ \\
\hline Water bamboo & $\begin{array}{l}283 \\
293 \\
303 \\
313 \\
323\end{array}$ & $\mathrm{~K}_{\mathrm{d}}$ & $\begin{array}{l}-2.39 \\
-2.18 \\
-1.63 \\
-0.92 \\
-0.57\end{array}$ & -16.3 & -0.049 & Zhu et al., 2016 \\
\hline Date palm & $\begin{array}{l}303 \\
318 \\
333\end{array}$ & $\begin{array}{c}\mathrm{K}_{\mathrm{p}} \\
\text { no unit }\end{array}$ & $\begin{array}{l}4.13 \\
4.04 \\
3.73\end{array}$ & 8.09 & 0.013 & Gouamid et al., 2013 \\
\hline
\end{tabular}




\begin{tabular}{|c|c|c|c|c|c|c|}
\hline Ashoka & $\begin{array}{l}303 \\
313 \\
323\end{array}$ & $\begin{array}{c}\mathrm{K}_{\mathrm{L}} \\
\mathrm{L} / \mathrm{mg}\end{array}$ & $\begin{array}{l}-6.56 \\
-6.38 \\
-6.21\end{array}$ & -11.8 & -0.017 & Gupta et al., 2012a \\
\hline Lotus & $\begin{array}{l}293 \\
303 \\
313\end{array}$ & $\begin{array}{c}\mathrm{K}_{\mathrm{L}} \\
\mathrm{L} / \mathrm{mg}\end{array}$ & $\begin{array}{l}-25.7 \\
-26.6 \\
-27.7\end{array}$ & 4.70 & 0.103 & Han et al., 2011 \\
\hline \multicolumn{7}{|c|}{ Malachite green dye } \\
\hline Carrot & $\begin{array}{l}303 \\
313 \\
323\end{array}$ & $\begin{array}{c}\mathrm{K}_{\mathrm{L}} \\
\mathrm{L} / \mathrm{mg}\end{array}$ & $\begin{array}{l}-2.78 \\
-2.60 \\
-2.42\end{array}$ & -8.21 & -0.018 & Kushwaha et al., 2014a \\
\hline Potato & $\begin{array}{l}303 \\
313 \\
323\end{array}$ & $\begin{array}{c}\mathrm{K}_{\mathrm{L}} \\
\mathrm{L} / \mathrm{mg}\end{array}$ & $\begin{array}{l}-3.06 \\
-2.96 \\
-2.85\end{array}$ & -6.30 & -0.0107 & Gupta et al., 2016a \\
\hline Lotus & $\begin{array}{l}296 \\
306 \\
316 \\
\end{array}$ & $\begin{array}{c}\mathrm{K}_{\mathrm{L}} \\
\mathrm{L} / \mathrm{mg}\end{array}$ & $\begin{array}{l}-10.7 \\
-12.4 \\
-13.9\end{array}$ & 35.9 & 0.157 & Han et al., 2014 \\
\hline Ashoka & $\begin{array}{l}303 \\
313 \\
323\end{array}$ & $\begin{array}{c}\mathrm{K}_{\mathrm{L}} \\
\mathrm{L} / \mathrm{mg}\end{array}$ & $\begin{array}{l}-4.19 \\
-4.11 \\
-4.03\end{array}$ & -6.67 & -0.008 & Gupta et al., 2012a \\
\hline \multicolumn{7}{|c|}{ Crystal violet dye } \\
\hline Pineapple & $\begin{array}{l}293 \\
303 \\
313\end{array}$ & $\begin{array}{c}\mathrm{K}_{\mathrm{L}} \\
\mathrm{L} / \mathrm{mg}\end{array}$ & $\begin{array}{l}-18.3 \\
-16.6 \\
-14.8\end{array}$ & -68.5 & -0.171 & $\underline{\text { Chakraborty et al., } 2012}$ \\
\hline Esparto grass & $\begin{array}{l}298 \\
308 \\
318 \\
328\end{array}$ & $\begin{array}{c}\mathrm{K}_{\mathrm{L}} \\
\mathrm{L} / \mathrm{mg}\end{array}$ & $\begin{array}{l}2.68 \\
3.74 \\
4.79 \\
5.85\end{array}$ & 28.9 & 0.101 & $\underline{\text { Lafi et al., } 2015}$ \\
\hline \multicolumn{7}{|c|}{ Amaranth dye } \\
\hline Water hyacinth & $\begin{array}{l}291 \\
301 \\
313 \\
323 \\
\end{array}$ & $\mathrm{~K}_{\mathrm{L}} \mathrm{L} / \mathrm{mg}$ & $\begin{array}{l}58.6 \\
59.9 \\
61.7 \\
63.1 \\
\end{array}$ & 17.3 & -0.142 & Guerrero-Coronilla et al., 2015 \\
\hline \multicolumn{7}{|c|}{ Basic Red 46 dye } \\
\hline Turkish pine & $\begin{array}{l}298 \\
308 \\
318\end{array}$ & $\mathrm{~K}_{\mathrm{L}} \mathrm{L} / \mathrm{mg}$ & $\begin{array}{l}-4.71 \\
-7.11 \\
-8.13\end{array}$ & 46.4 & 0.170 & Deniz and Karaman, 2011 \\
\hline Princess & $\begin{array}{l}298 \\
308 \\
318 \\
\end{array}$ & $\mathrm{~K}_{\mathrm{L}} \mathrm{L} / \mathrm{mg}$ & $\begin{array}{l}-4.29 \\
-3.17 \\
-1.64\end{array}$ & -43.8 & -0.130 & Deniz and Saygideger, 2011 \\
\hline \multicolumn{7}{|c|}{ Methyl violet dye } \\
\hline Neptune grass & $\begin{array}{l}293 \\
308 \\
318 \\
\end{array}$ & $\mathrm{~K}_{\mathrm{L}} \mathrm{L} / \mathrm{mg}$ & $\begin{array}{l}-7.37 \\
-8.73 \\
-9.65\end{array}$ & 17.2 & 0.084 & $\underline{\text { Cengiz and Cavas, } 2010}$ \\
\hline $\begin{array}{l}\text { Platanus } \\
\text { carpinifolia }\end{array}$ & $\begin{array}{l}298 \\
308 \\
318 \\
328 \\
\end{array}$ & $\mathrm{~K}_{\mathrm{L}} \mathrm{L} / \mathrm{mg}$ & $\begin{array}{l}-1.96 \\
-3.63 \\
-4.95 \\
-6.27\end{array}$ & 37.3 & 0.132 & Zolgharnein et al., 2014 \\
\hline Basic Green & dye & & & & & \\
\hline Pineapple & $\begin{array}{l}298 \\
308 \\
318\end{array}$ & $\mathrm{~K}_{\mathrm{L}} \mathrm{L} / \mathrm{mg}$ & $\begin{array}{l}-17.9 \\
-14.8 \\
-12.3\end{array}$ & -101.40 & -0.280 & Chowdhury et al., 2011 \\
\hline
\end{tabular}


Acid orange 52

dye

$\begin{array}{lllllll}\text { Princess } & 298 & \mathrm{~K}_{\mathrm{L}} \mathrm{L} / \mathrm{mg} & 6.42 & -5.63 & -0.040 & \text { Deniz and Saygideger, 2010 } \\ & 308 & & 6.81 & & & \end{array}$

Direct solophenyl brown AGL dye

\begin{tabular}{|c|c|c|c|c|c|c|}
\hline Neptune grass & $\begin{array}{l}288 \\
303 \\
318 \\
333\end{array}$ & $\mathrm{~K}_{\mathrm{L}} \mathrm{L} / \mathrm{mg}$ & $\begin{array}{l}-6.73 \\
-6.37 \\
-5.82 \\
-5.68\end{array}$ & 57.8 & -0.104 & Ncibi et al., 2006 \\
\hline \multicolumn{7}{|c|}{ Reactive cibacron red FNR } \\
\hline Neptune grass & $\begin{array}{l}288 \\
303 \\
318 \\
333\end{array}$ & $\mathrm{~K}_{\mathrm{L}} \mathrm{L} / \mathrm{mg}$ & $\begin{array}{l}-5.00 \\
-3.22 \\
-2.83 \\
-2.51\end{array}$ & 84.1 & -0.226 & Ncibi et al., 2006 \\
\hline \multicolumn{7}{|c|}{ Remazol blue R dye } \\
\hline Neem & $\begin{array}{l}298 \\
313 \\
333\end{array}$ & $\begin{array}{c}\mathrm{K}_{\mathrm{L}} \\
\mathrm{L} / \mathrm{mg}\end{array}$ & $\begin{array}{l}5.52 \\
6.62 \\
7.98\end{array}$ & -14.6 & 0.030 & Immich et al., 2009 \\
\hline \multicolumn{7}{|c|}{ Brilliant Green dye } \\
\hline Neem & $\begin{array}{l}300 \\
303 \\
313 \\
323\end{array}$ & $\mathrm{~K}_{\mathrm{d}}$ & $\begin{array}{l}7.15 \\
7.28 \\
7.70 \\
8.13 \\
\end{array}$ & 5.66 & 0.043 & Bhattacharyya and Sarma, 2003 \\
\hline Ashoka & $\begin{array}{l}303 \\
313 \\
323\end{array}$ & $\mathrm{~K}_{\mathrm{L}} \mathrm{L} / \mathrm{mg}$ & $\begin{array}{l}-7.98 \\
-7.43 \\
-6.88\end{array}$ & -24.7 & -0.055 & Gupta et al., 2012a \\
\hline \multicolumn{7}{|c|}{ Rhodamine B } \\
\hline Ashoka & $\begin{array}{l}303 \\
313 \\
323\end{array}$ & $\mathrm{~K}_{\mathrm{L}} \mathrm{L} / \mathrm{mg}$ & $\begin{array}{l}-1.78 \\
-1.65 \\
-1.51 \\
\end{array}$ & -5.94 & -0.014 & Gupta et al., 2012a \\
\hline \multicolumn{7}{|c|}{ Toluidine blue dye } \\
\hline Esparto grass & $\begin{array}{l}298 \\
308 \\
318 \\
328\end{array}$ & $\mathrm{~K}_{\mathrm{L}} \mathrm{L} / \mathrm{mg}$ & $\begin{array}{l}2.31 \\
2.99 \\
3.66 \\
4.34\end{array}$ & 17.9 & 0.061 & Lafi et al., 2015 \\
\hline
\end{tabular}


Table S14. Thermodynamic parameters for the biosorption of organic dyes onto modified/treated leaves

\begin{tabular}{|c|c|c|c|c|c|c|c|}
\hline \multirow[b]{2}{*}{ Leaves } & \multirow[b]{2}{*}{ Chemical } & \multirow[b]{2}{*}{$\begin{array}{l}\mathbf{T} \\
\mathbf{K}\end{array}$} & \multirow{2}{*}{$\begin{array}{c}\text { Derivation } \\
\text { of } \mathbf{K}_{\mathbf{C}} \\
\text { (unit) }\end{array}$} & \multicolumn{3}{|c|}{ Thermodynamic parameters } & \multirow[b]{2}{*}{ Ref. } \\
\hline & & & & $\begin{array}{c}\Delta \mathbf{G}^{\circ} \\
(\mathrm{kJ} / \mathrm{mol})\end{array}$ & $\begin{array}{c}\Delta \mathbf{H}^{\circ} \\
(\mathrm{kJ} / \mathrm{mol})\end{array}$ & $\begin{array}{c}\Delta \mathbf{S}^{\circ} \\
(\mathrm{kJ} / \mathrm{mol} \times \\
\mathrm{K})\end{array}$ & \\
\hline \multicolumn{8}{|c|}{ Malachite green dye } \\
\hline Maize & $\mathrm{CaOH}_{2}$ & $\begin{array}{l}303 \\
313 \\
323\end{array}$ & $\begin{array}{c}\mathrm{K}_{\mathrm{p}} \\
\text { No unit }\end{array}$ & $\begin{array}{l}-5.93 \\
-7.19 \\
-8.46\end{array}$ & 32.4 & 0.127 & $\underline{\text { Jalil et al., } 2012 \mathrm{a}}$ \\
\hline Labill & $\begin{array}{l}\text { Ammoni, } \\
\text { lauric } \\
\text { acid }\end{array}$ & $\begin{array}{l}293 \\
303 \\
313 \\
323 \\
\end{array}$ & $\begin{array}{r}\mathrm{K}_{\mathrm{d}} \\
\mathrm{L} / \mathrm{g}\end{array}$ & $\begin{array}{l}-6.88 \\
-7.85 \\
-8.12 \\
-9.72 \\
\end{array}$ & 11.5 & 0.063 & Yang and Hong, 2018b \\
\hline \multicolumn{8}{|c|}{ Crystal violet dye } \\
\hline $\begin{array}{l}\text { Phoenix } \\
\text { tree }\end{array}$ & $\mathrm{NaOH}$ & $\begin{array}{l}293 \\
303 \\
313 \\
\end{array}$ & $\begin{array}{c}\mathrm{K}_{\mathrm{p}} \\
\text { No unit }\end{array}$ & $\begin{array}{l}-5.79 \\
-6.61 \\
-7.21 \\
\end{array}$ & 14.9 & 0.071 & $\underline{\text { Ren et al., } 2015}$ \\
\hline \multicolumn{8}{|c|}{ Acid violet 17 dye } \\
\hline Cluster fig & $\begin{array}{l}\mathrm{NaOH} \\
\mathrm{H}_{2} \mathrm{SO}_{4}\end{array}$ & $\begin{array}{l}293 \\
303 \\
313 \\
323 \\
\end{array}$ & $\begin{array}{c}\mathrm{K}_{\mathrm{L}} \\
\mathrm{L} / \mathrm{mg}\end{array}$ & $\begin{array}{l}-26.6 \\
-27.8 \\
-29.1 \\
-30.5\end{array}$ & 10.9 & 0.130 & Jain and Gogate, $2017 \mathrm{~d}$ \\
\hline \multicolumn{8}{|c|}{ Pyrocatechol violet } \\
\hline Black locust & $\mathrm{NaCl}$ & $\begin{array}{l}296 \\
298 \\
303 \\
308 \\
313\end{array}$ & $\begin{array}{c}\mathrm{K}_{\mathrm{p}} \\
\text { No unit }\end{array}$ & $\begin{array}{l}-2.43 \\
-2.42 \\
-2.27 \\
-2.18 \\
-2.01\end{array}$ & -9.67 & 0.024 & $\underline{\underline{2016}}$ \\
\hline \multicolumn{8}{|c|}{ Acid blue 113 dye } \\
\hline Almond & $\begin{array}{l}\mathrm{NaOH} \\
\mathrm{CTAB}\end{array}$ & $\begin{array}{l}293 \\
303 \\
313 \\
323\end{array}$ & NA & $\begin{array}{l}-29.4 \\
-29.2 \\
-29.1 \\
-29.2\end{array}$ & -31.3 & -0.007 & Jain and Gogate, $2017 \mathrm{~b}$ \\
\hline \multicolumn{8}{|c|}{ Acid blue 25 dye } \\
\hline Cluster fig & $\mathrm{NaOH}$ & $\begin{array}{l}293 \\
303 \\
313 \\
323 \\
\end{array}$ & $\begin{array}{c}\mathrm{K}_{\mathrm{L}} \\
\mathrm{L} / \mathrm{mg}\end{array}$ & $\begin{array}{l}-26.6 \\
-28.3 \\
-30.3 \\
-32.4\end{array}$ & 29.9 & 0.192 & Jain and Gogate, 2017a \\
\hline Cluster fig & $\mathrm{NaOH}$ & $\begin{array}{l}293 \\
303 \\
313 \\
323 \\
\end{array}$ & $\begin{array}{l}\text { Temkin } \\
\mathrm{L} / \mathrm{mg}\end{array}$ & $\begin{array}{l}-34.3 \\
-36.8 \\
-39.7 \\
-42.8\end{array}$ & 48.7 & 0.283 & Jain and Gogate, $2017 \mathrm{a}$ \\
\hline \multicolumn{8}{|c|}{ Methyl orange dye } \\
\hline Pineapple & HDTMA & $\begin{array}{l}308 \\
313 \\
333\end{array}$ & $\begin{array}{c}\mathrm{K}_{\mathrm{p}} \\
\text { No unit }\end{array}$ & $\begin{array}{l}-3.75 \\
-3.69 \\
-3.35\end{array}$ & -8.75 & -0.016 & $\underline{\text { Kamaru et al., } 2016}$ \\
\hline
\end{tabular}


Acid green 25 dye

\begin{tabular}{|c|c|c|c|c|c|c|c|}
\hline Almond & $\mathrm{NaOH}$ & $\begin{array}{l}293 \\
303 \\
313 \\
323\end{array}$ & $\begin{array}{c}\mathrm{K}_{\mathrm{L}} \\
\mathrm{L} / \mathrm{mg}\end{array}$ & $\begin{array}{l}-34.7 \\
-36.0 \\
-37.4 \\
-38.9\end{array}$ & 6.99 & 0.142 & Jain and Gogate, 2018 \\
\hline Almond & $\mathrm{NaOH}$ & $\begin{array}{l}293 \\
303 \\
313 \\
323 \\
\end{array}$ & $\begin{array}{c}\text { Temkin } \\
\text { L/mg }\end{array}$ & $\begin{array}{l}-43.7 \\
-45.7 \\
-47.9 \\
-50.4\end{array}$ & 21.9 & 0.224 & Jain and Gogate, 2018 \\
\hline \multicolumn{8}{|c|}{ Congo red dye } \\
\hline \multirow[t]{3}{*}{ Labill } & \multirow{3}{*}{$\begin{array}{l}\text { Ammoni, } \\
\text { lauric } \\
\text { acid }\end{array}$} & 293 & $\mathrm{~K}_{\mathrm{d}}$ & -1.47 & \multirow[t]{3}{*}{0.004} & \multirow[t]{3}{*}{0.006} & \multirow[t]{3}{*}{ Yang and Hong, $2018 \mathrm{~b}$} \\
\hline & & 303 & $\mathrm{~L} / \mathrm{g}$ & -2.05 & & & \\
\hline & & $\begin{array}{l}313 \\
323 \\
\end{array}$ & & $\begin{array}{l}-2.14 \\
-2.19\end{array}$ & & & \\
\hline
\end{tabular}

NOTE: CTAB (cetyltrimethylammonium bromide; hexadecyltrimethylammonium bromide), HDTMA (Hexadecyltrimethylammonium bromide); NA (not clearly mentioned in the original paper) 
Table S15. Thermodynamic parameters for the biosorption of other contaminants onto pristine and treated/modified leaves

\begin{tabular}{|c|c|c|c|c|c|c|c|}
\hline \multirow[b]{2}{*}{ Leaves } & \multirow[b]{2}{*}{ Chemical } & \multirow[b]{2}{*}{$\begin{array}{c}\mathbf{T} \\
(\mathbf{K})\end{array}$} & \multirow[b]{2}{*}{$\begin{array}{c}\text { Derivation of } \\
\mathbf{K}_{\mathbf{C}} \\
\text { (unit) }\end{array}$} & \multicolumn{3}{|c|}{ Thermodynamic parameters } & \multirow[b]{2}{*}{ Ref. } \\
\hline & & & & $\begin{array}{c}\Delta \mathbf{G}^{\circ} \\
(\mathrm{kJ} / \mathrm{mol})\end{array}$ & $\begin{array}{c}\Delta \mathbf{H}^{\circ} \\
(\mathrm{kJ} / \mathrm{mol})\end{array}$ & $\begin{array}{c}\Delta \mathbf{S}^{\circ} \\
(\mathrm{kJ} / \mathrm{mol} \times \\
\mathrm{K})\end{array}$ & \\
\hline \multicolumn{8}{|c|}{ Naphthalene } \\
\hline \multirow{2}{*}{\multicolumn{2}{|c|}{$\begin{array}{l}\text { Spent tea } \\
\text { leaves }\end{array}$}} & 303 & $\mathrm{~K}_{\mathrm{d}}$ & -0.54 & 217 & 0.718 & Agarry et al., 2013 \\
\hline & & $\begin{array}{l}308 \\
313 \\
318 \\
\end{array}$ & $(\mathrm{~L} / \mathrm{g})$ & $\begin{array}{l}-2.29 \\
-6.32 \\
-11.2 \\
\end{array}$ & & & \\
\hline \multicolumn{8}{|c|}{ Fluoride } \\
\hline \multirow{2}{*}{\multicolumn{2}{|c|}{ Neem }} & 298 & $\begin{array}{c}\mathrm{K}_{\mathrm{L}} \\
(\mathrm{L} / \mathrm{g})\end{array}$ & -0.83 & -29.9 & -0.001 & $\begin{array}{l}\text { Bharali and } \\
\text { Bhattacharyya, } 2015\end{array}$ \\
\hline & & $\begin{array}{l}303 \\
308 \\
313 \\
318\end{array}$ & & $\begin{array}{l}-0.34 \\
0.15 \\
0.54 \\
1.12\end{array}$ & & & \\
\hline \multicolumn{8}{|c|}{ Orthophosphate } \\
\hline Reed & $\mathrm{Ca}(\mathrm{OH})_{2}$ & $\begin{array}{l}298 \\
308 \\
318\end{array}$ & $\begin{array}{c}\mathrm{K}_{\mathrm{p}} \\
\text { (No unit) }\end{array}$ & $\begin{array}{l}-15.6 \\
-20.1 \\
-22.2\end{array}$ & 85.0 & 0.339 & Markou et al., 2016a \\
\hline
\end{tabular}


Table S16. The $Q^{\circ}{ }_{\max }(\mathrm{mmol} / \mathrm{kg})$, CEC (mmol $\left./ \mathrm{kg}\right)$, ECEC (mmol $\left./ \mathrm{kg}\right), \alpha$ or $\beta$ ratio of bisorbent and zeolite to some cationic and oxyanionic metal ions

\begin{tabular}{|c|c|c|c|c|c|c|c|c|c|c|c|}
\hline Adsorbent & Adsorbate & $\mathbf{Q}^{\mathbf{o}}$ max & $\begin{array}{c}\text { CEC/ } \\
\text { ECEC }\end{array}$ & $\boldsymbol{\alpha} / \boldsymbol{\beta}$ & Ref. & Adsorbent & Adsorbate & $\mathbf{Q}^{\mathbf{o}}$ max & $\begin{array}{l}\text { CEC/ } \\
\text { ECEC }\end{array}$ & $\alpha / \beta$ & Ref. \\
\hline \multicolumn{6}{|c|}{ Pristine biosorbent } & \multicolumn{6}{|c|}{ Modified biosorbent } \\
\hline CAN & Cd(II) & 30.4 & 66.5 & 0.81 & $\frac{\frac{\text { Tran and }}{\text { Chao, }}}{\underline{2018}}$ & CAN & Cd(II) & 45.4 & 113 & 0.71 & $\frac{\frac{\text { Tran and }}{\text { Chao, }}}{\underline{2018}}$ \\
\hline $\mathrm{PC}$ & $\mathrm{Cd}(\mathrm{II})$ & 17.3 & 43.5 & 0.71 & $\frac{\text { Tran and }}{\frac{\text { Chao, }}{\underline{2018}}}$ & $\mathrm{PC}$ & $\mathrm{Cd}(\mathrm{II})$ & 30.9 & 81.3 & 0.68 & $\frac{\frac{\text { Tran and }}{\text { Chao, }}}{\underline{2018}}$ \\
\hline LP & $\mathrm{Cd}(\mathrm{II})$ & 11.5 & 38.3 & 0.54 & $\frac{\text { Tran and }}{\frac{\text { Chao, }}{\underline{2018}}}$ & LP & $\mathrm{Cd}(\mathrm{II})$ & 27.2 & 76.5 & 0.63 & $\frac{\frac{\text { Tran and }}{\text { Chao, }}}{\underline{\underline{2018}}}$ \\
\hline AS & $\mathrm{Cd}(\mathrm{II})$ & 7.40 & 22.6 & 0.58 & $\frac{\text { Tran and }}{\frac{\text { Chao, }}{\underline{2018}}}$ & AS & $\mathrm{Cd}(\mathrm{II})$ & 18.9 & 46.1 & 0.73 & $\frac{\frac{\text { Tran and }}{\text { Chao, }}}{\underline{\underline{2018}}}$ \\
\hline SB & $\mathrm{Cd}(\mathrm{II})$ & 6.13 & 11.8 & 0.92 & $\frac{\text { Tran and }}{\frac{\text { Chao, }}{\underline{2018}}}$ & SB & $\mathrm{Cd}(\mathrm{II})$ & 14.3 & 21.1 & 0.50 & $\frac{\frac{\text { Tran and }}{\text { Chao, }}}{\underline{\underline{2018}}}$ \\
\hline BS & $\mathrm{Cd}(\mathrm{II})$ & 7.03 & 19.6 & 0.64 & $\frac{\text { Tran and }}{\frac{\text { Chao, }}{\underline{2018}}}$ & BS & $\mathrm{Cd}(\mathrm{II})$ & 9.16 & 32.6 & 1.03 & $\frac{\frac{\text { Tran and }}{\text { Chao, }}}{\underline{\underline{2018}}}$ \\
\hline CAN & $\mathbf{C u}(\mathrm{II})$ & 23.5 & 66.5 & 1.11 & $\frac{\text { Tran and }}{\frac{\text { Chao, }}{\underline{2018}}}$ & CAN & $\mathrm{Cu}(\mathrm{II})$ & 33.1 & 113 & 2.67 & $\frac{\frac{\text { Tran and }}{\text { Chao, }}}{\underline{\underline{2018}}}$ \\
\hline $\mathrm{PC}$ & $\mathrm{Cu}(\mathrm{II})$ & 14.0 & 43.5 & 1.01 & $\frac{\text { Tran and }}{\frac{\text { Chao, }}{\underline{2018}}}$ & $\mathrm{PC}$ & $\mathrm{Cu}(\mathrm{II})$ & 25.4 & 81.3 & 5.88 & $\frac{\frac{\text { Tran and }}{\text { Chao, }}}{\underline{\underline{2018}}}$ \\
\hline LP & $\mathrm{Cu}(\mathrm{II})$ & 8.61 & 38.3 & 0.70 & $\frac{\text { Tran and }}{\frac{\text { Chao, }}{\underline{2018}}}$ & LP & $\mathrm{Cu}(\mathrm{II})$ & 22.4 & 76.5 & 3.58 & $\frac{\frac{\text { Tran and }}{\text { Chao, }}}{\underline{\underline{2018}}}$ \\
\hline AS & $\mathrm{Cu}(\mathrm{II})$ & 6.14 & 22.6 & 0.85 & $\frac{\text { Tran and }}{\frac{\text { Chao, }}{\underline{2018}}}$ & AS & $\mathrm{Cu}(\mathrm{II})$ & 14.9 & 46.1 & 2.82 & $\begin{array}{c}\frac{\text { Tran and }}{\text { Chao, }} \\
\underline{\underline{2018}}\end{array}$ \\
\hline SB & $\mathrm{Cu}(\mathrm{II})$ & 6.54 & 11.8 & 1.75 & $\frac{\frac{\text { Tran and }}{\underline{\text { Chao, }}}}{\underline{\underline{2018}}}$ & SB & $\mathrm{Cu}(\mathrm{II})$ & 13.9 & 21.1 & 2.55 & $\frac{\frac{\text { Tran and }}{\text { Chao, }}}{\underline{\underline{2018}}}$ \\
\hline BS & $\mathrm{Cu}(\mathrm{II})$ & 5.51 & 19.6 & 0.88 & $\frac{\text { Tran and }}{\frac{\text { Chao, }}{\underline{2018}}}$ & $\mathrm{BS}$ & $\mathrm{Cu}(\mathrm{II})$ & 8.99 & 32.6 & 3.05 & $\frac{\frac{\text { Tran and }}{\text { Chao, }}}{\underline{\underline{2018}}}$ \\
\hline CAN & $\mathbf{P b}(\mathrm{II})$ & 81.1 & 66.5 & 1.18 & $\frac{\text { Tran and }}{\frac{\text { Chao, }}{\underline{2018}}}$ & CAN & $\mathbf{P b}(\mathrm{II})$ & 143 & 113 & 1.22 & $\frac{\frac{\text { Tran and }}{\text { Chao, }}}{\underline{\underline{2018}}}$ \\
\hline $\mathrm{PC}$ & $\mathrm{Pb}(\mathrm{II})$ & 49.1 & 43.5 & 1.09 & $\frac{\frac{\text { Tran and }}{\text { Chao, }}}{\underline{\underline{2018}}}$ & $\mathrm{PC}$ & $\mathrm{Pb}(\mathrm{II})$ & 78.2 & 81.3 & 0.93 & $\frac{\frac{\text { Tran and }}{\text { Chao, }}}{\underline{2018}}$ \\
\hline
\end{tabular}




\begin{tabular}{|c|c|c|c|c|c|c|c|c|c|c|c|}
\hline LP & $\mathrm{Pb}(\mathrm{II})$ & 34.5 & 38.3 & 0.87 & $\frac{\frac{\text { Tran and }}{\underline{\text { Chao, }}}}{\underline{\underline{2018}}}$ & LP & $\mathrm{Pb}(\mathrm{II})$ & 68.0 & 76.5 & 0.86 & $\frac{\frac{\text { Tran and }}{\underline{\text { Chao, }}}}{\underline{2018}}$ \\
\hline AS & $\mathrm{Pb}(\mathrm{II})$ & 23.9 & 22.6 & 1.02 & $\frac{\text { Tran and }}{\underline{\text { Chao, }}}$ & AS & $\mathrm{Pb}(\mathrm{II})$ & 52.9 & 46.1 & 1.11 & $\frac{\text { Tran and }}{\underline{\text { Chao, }}}$ \\
\hline SB & $\mathrm{Pb}(\mathrm{II})$ & 8.82 & 11.8 & 0.72 & $\frac{\text { Tran and }}{\underline{\text { Chao, }}}$ & SB & $\mathrm{Pb}(\mathrm{II})$ & 33.7 & 21.1 & 1.32 & $\frac{\text { Tran and }}{\underline{\text { Chao, }}}$ \\
\hline BS & $\mathrm{Pb}(\mathrm{II})$ & 25.4 & 19.6 & 1.25 & $\frac{\frac{\text { Tran and }}{\text { Chao, }}}{\underline{2018}}$ & BS & $\mathrm{Pb}(\mathrm{II})$ & 29.7 & 32.6 & 0.88 & $\frac{\frac{\text { Tran and }}{\text { Chao, }}}{\underline{2018}}$ \\
\hline Y zeolite & & \multicolumn{10}{|c|}{ HDTMA-modified NaY zeolite } \\
\hline & $\mathrm{Cu}(\mathrm{II})$ & 371 & 3120 & 0.24 & $\frac{\frac{\text { Chao and }}{\text { Chen, }}}{\underline{2012}}$ & & $\mathrm{Cu}(\mathrm{II})$ & 388 & 2880 & 0.27 & $\frac{\frac{\text { Chao and }}{\underline{\text { Chen }}}}{\underline{2012}}$ \\
\hline & $\mathrm{Zn}(\mathrm{II})$ & 354 & 3120 & 0.23 & $\frac{\frac{\text { Chao and }}{\text { Chen, }}}{\underline{2012}}$ & & $\mathrm{Zn}(\mathrm{II})$ & 318 & 2880 & 0.22 & $\frac{\frac{\text { Chao and }}{\underline{\text { Chen }}}}{\underline{2012}}$ \\
\hline & $\mathrm{Ni}(\mathrm{II})$ & 331 & 3120 & 0.21 & $\frac{\frac{\text { Chao and }}{\text { Chen, }}}{\underline{2012}}$ & & $\mathrm{Ni}(\mathrm{II})$ & 315 & 2880 & 0.22 & $\frac{\text { Chao and }}{\underline{\underline{\text { Chen, }}}}$ \\
\hline & $\mathrm{Pb}(\mathrm{II})$ & 671 & 3120 & 0.25 & $\frac{\text { Chao and }}{\underline{\text { Chen, }}}$ & & $\mathrm{Pb}(\mathrm{II})$ & 653 & 2880 & 0.45 & $\frac{\text { Chao and }}{\underline{\text { Chen, }}}$ \\
\hline & $\mathrm{Cd}(\mathrm{II})$ & 390 & 3120 & 0.43 & $\frac{\frac{\text { Chao and }}{\text { Chen, }}}{\underline{2012}}$ & & $\mathrm{Cd}(\mathrm{II})$ & 351 & 2880 & 0.24 & $\frac{\text { Chao and }}{\underline{\text { Chen, }}}$ \\
\hline & - & - & - & - & - & & ${ }^{\mathrm{a}} \mathrm{Cr}_{2} \mathrm{O}_{7}{ }^{2-}$ & 184 & 260 & 1.42 & $\frac{\text { Chao and }}{\underline{\text { Chen }}}$ \\
\hline & - & - & - & - & - & & ${ }^{\mathrm{b}} \mathrm{MnO}_{4}{ }^{-}$ & 412 & 260 & 2.58 & $\frac{\frac{\text { Chao and }}{\text { Chen, }}}{\underline{2012}}$ \\
\hline
\end{tabular}

Note: CAN (cantaloupe peel), PC (pine cone), LP (litchi fruit peel), AS (annona squamosal), SB (sugarcane bagasse), BS (bamboo shoot); $\alpha=2 Q^{\mathrm{o}}{ }_{\max } / \mathrm{CEC},{ }^{\mathrm{a}} \beta=2 Q^{\mathrm{o}}{ }_{\max } / \mathrm{ECEC},{ }^{\mathrm{b}} \beta=Q^{\mathrm{o}}{ }_{\max } / \mathrm{ECEC}$. 
Table S17. Removal percentage of Cr(VI) from dichromate solutions by various biosorbents Aoyama, $\underline{2003 a}$

\begin{tabular}{ccccccccc}
\hline \multirow{2}{*}{$\mathbf{p H}$} & \multicolumn{2}{c}{ Black locust leaves $^{\mathbf{a}}$} & & \multicolumn{2}{c}{ Coniferous leaves $^{\mathbf{b}}$} & & \multicolumn{2}{c}{ Larch bark $^{\mathbf{c}}$} \\
\cline { 2 - 3 } & $\mathbf{C r}(\mathbf{V I})$ & Total Cr & & $\mathbf{C r}(\mathbf{V I})$ & Total Cr & & Cr(VI) & Total Cr \\
\hline 2 & 100 & 63.1 & & 100 & 67.5 & & 99.9 & 83.1 \\
3 & 100 & 99.5 & & 92.5 & 90.9 & & 95.3 & 95.3 \\
4 & 82.7 & 82.4 & & 76.8 & 76.5 & & 57.9 & 57.9 \\
5 & 77.9 & 77.3 & & 41.7 & 41.6 & & 51.4 & 51.4 \\
\hline
\end{tabular}

Note: ${ }^{\mathrm{a} A o y a m a}$ et al., 2000b, ${ }^{\mathrm{b}}$ Aoyama et al., 1999b, and ${ }^{\mathrm{c}}$ Aoyama and Tsuda, 2001 


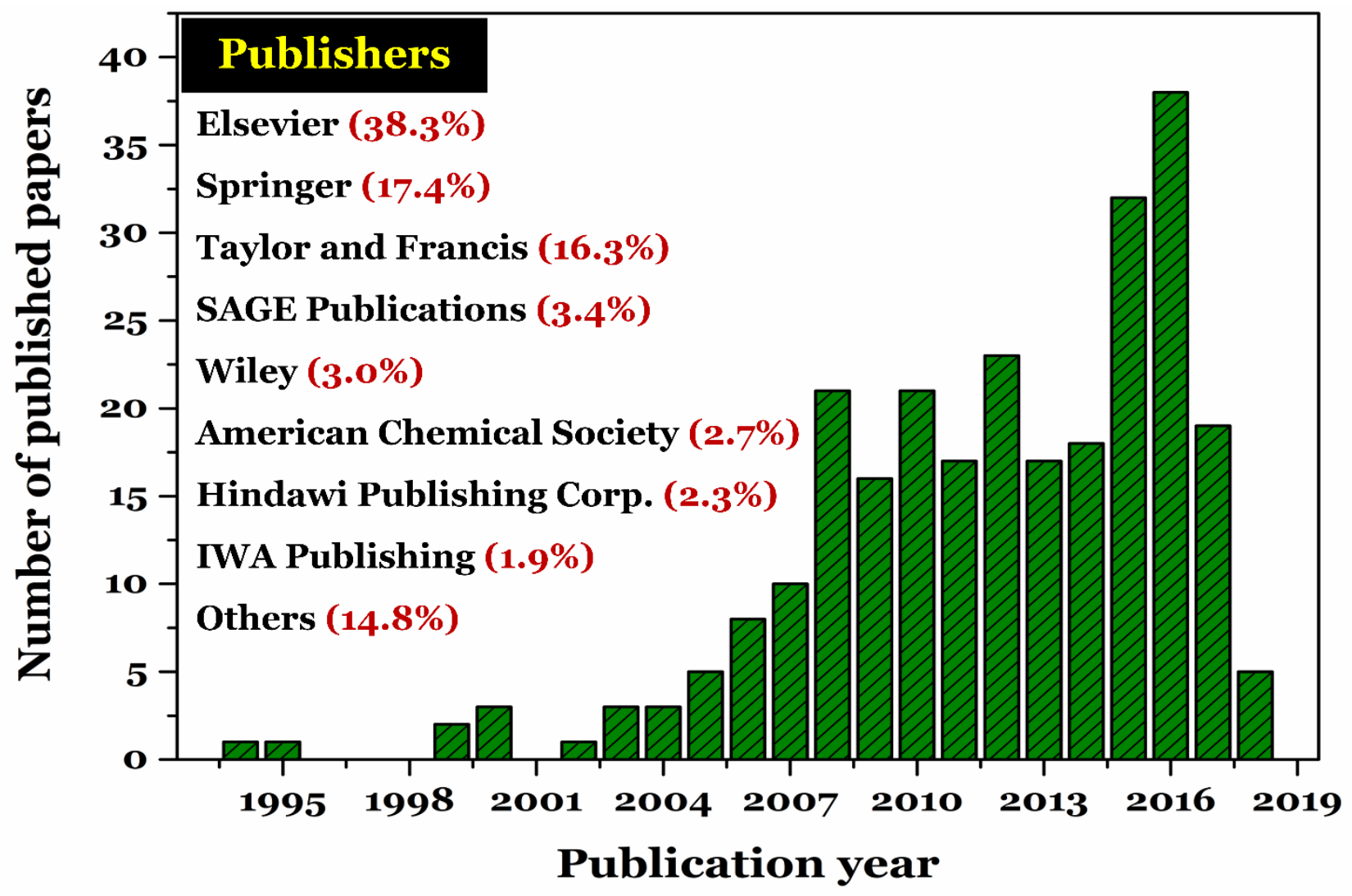

Figure S1. Number of articles published applying leaf-based biosorbent for removal of toxic pollutants from water bodies per year (only for the published original papers) and distribution of publisher relevant to the topic 


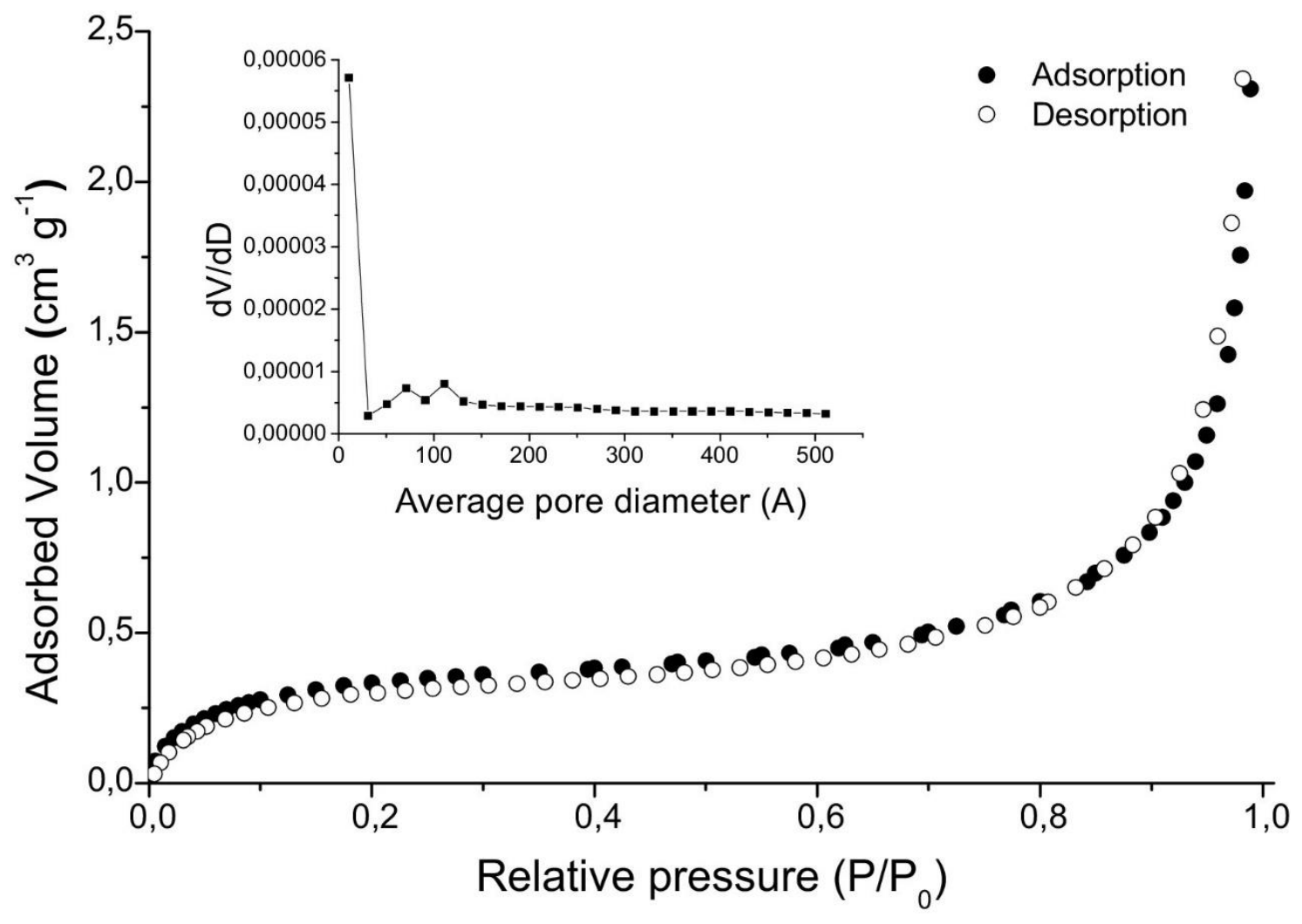

Figure S2. Typical adsorption/desorption isotherm of biosorbent derived from Brazilian orchid tree (pata-de-vaca) leaves and its pore size distribution (Jorgetto et al., 2015) 

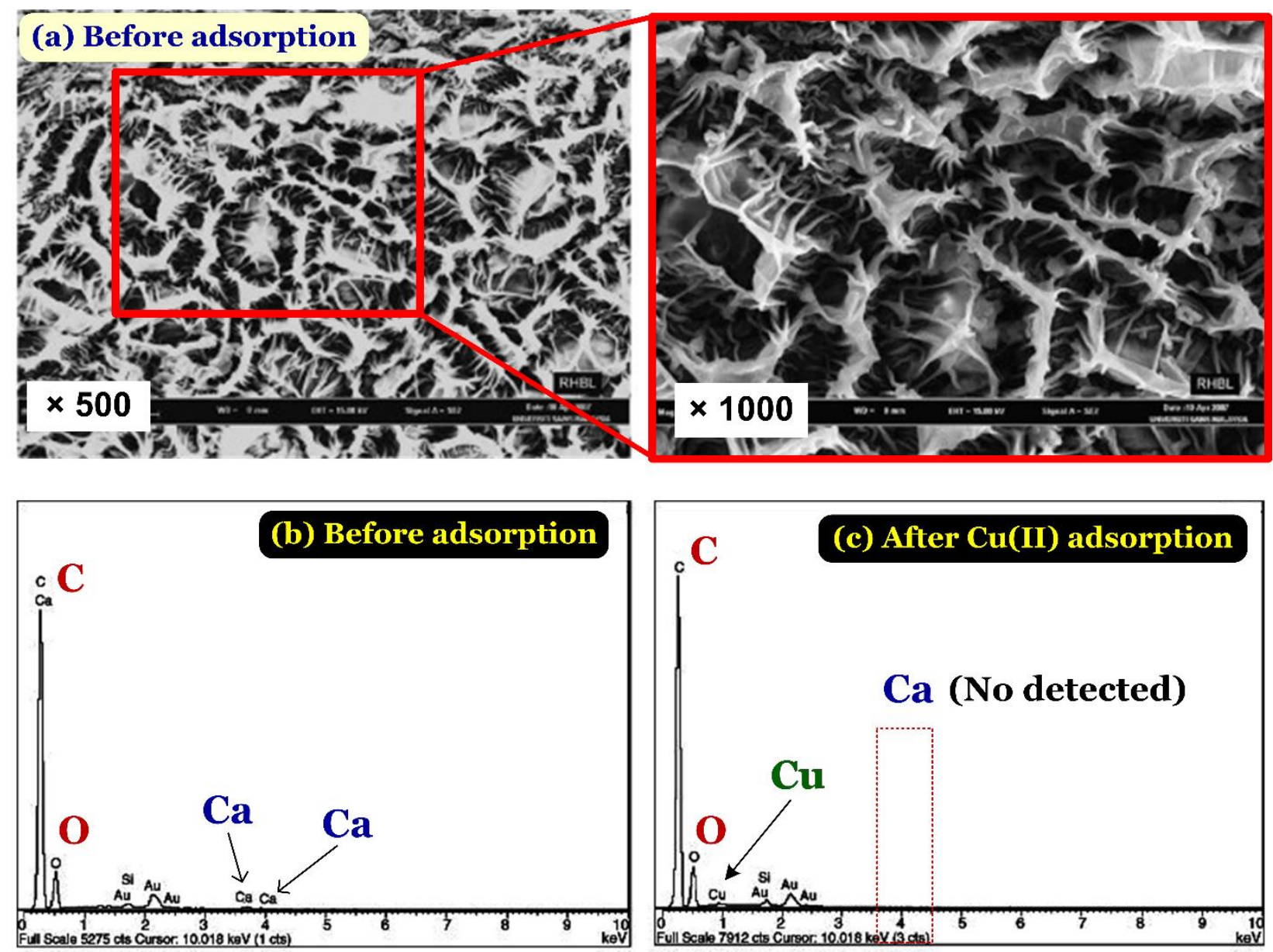

\section{(d) Cation exchange mechanism}

(1) Biosorbent + copper solution ("Released")

(2)Biosorbent + deionized water ("Dissolved")

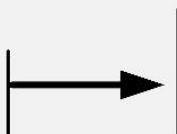

Analysis $\mathrm{pH}$ and the amount of alkaline earth and alkali metals

(3) The amount of ion exchange: (1) "Released" - (2) "Dissolved"

The ratio of cations bound $\left(\mathrm{Cu}^{2+}\right.$ and $\left.1 / 2 \mathrm{H}^{+}\right)$to biosorbent surface and
released $\left(\mathrm{Mg}^{2+}+\mathrm{Ca}^{2+}+1 / 2 \mathrm{Na}^{+}\right)$is $\mathbf{0 . 8 5}$, suggesting that ion-
exchange is the primary adsorption mechanism

Figure S3. (a) SEM image of rubber (Hevea brasiliensis) leaf powders, (b)-(c) EDS spectra, and (d) confirmation of the ion exchange mechanism (Wan Ngah and Hanafiah, 2008) 

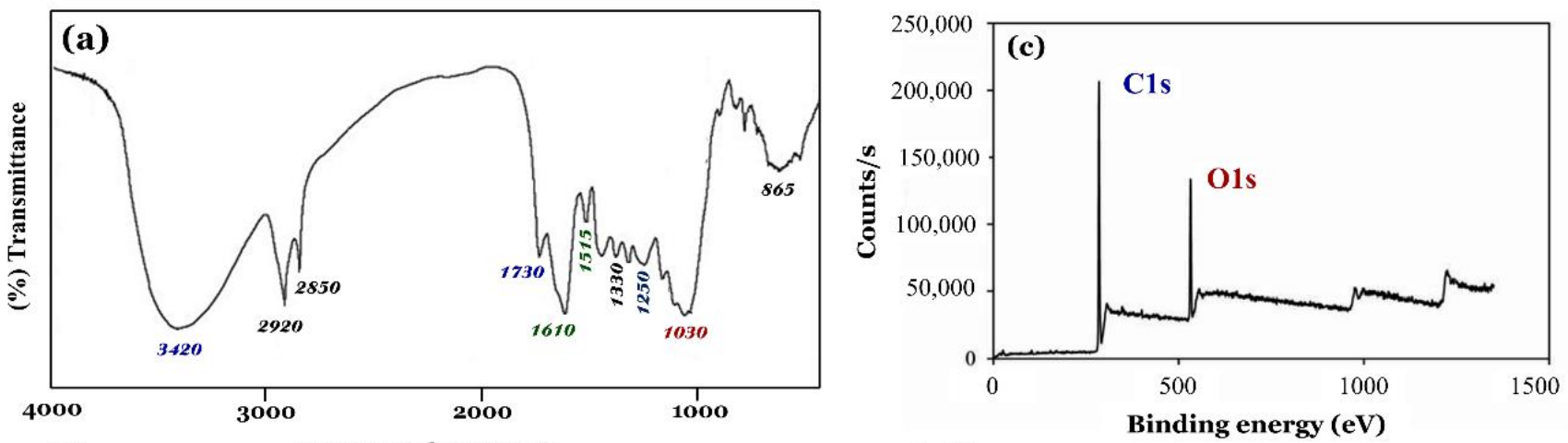

(b)

Wavenumber $\left(\mathrm{cm}^{-1}\right)$

\begin{tabular}{cl}
\hline IR Peaks $\left(\mathbf{c m}^{-1}\right)$ & \multicolumn{1}{c}{ Functional groups } \\
\hline 3420 & The $(\mathrm{OH})$ stretching vibration of hydroxyl group \\
2920 and 2850 & The $\mathrm{C}-\mathrm{H}$ stretching vibration of methyl $\left(-\mathrm{CH}_{3}-\right)$ \\
& \\
1735 & The carbonylene $(\mathrm{C}=\mathrm{O})$ groups \\
1610 and 1515 & The skeletal $\mathrm{C}=\mathrm{C}$ vibrations in aromatic rings \\
1440 & The ionic carboxylic $\left(-\mathrm{COO}^{-}\right)$group \\
1330 & The $(\mathrm{C}=\mathrm{O})$ vibration in carboxylate group \\
1250 & The $\mathrm{C}-\mathrm{O}-\mathrm{C}$ stretching of aryl-alkyl ether linkages in lignin \\
1030 & The $\mathrm{C}-\mathrm{O}$ stretching vibrations of cellulose backbone \\
865 & The aromatic $\mathrm{C}-\mathrm{H}$ out-of-plane bending mode \\
\hline
\end{tabular}

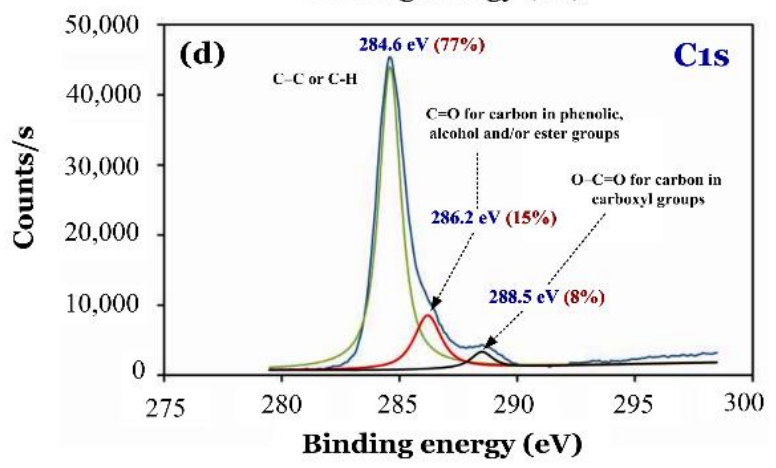

Figure S4. (a) FTIR spectra of pristine biosorbent derived from fallen Cinnamomum camphora leaves (Chen et al., 2010b) and (b) the spectroscopic assignment; and (c) XPS spectra of arborvitae leaves and (b) C 1s XPS spectra of arborvitae leaves (Shi et al., 2016b) 

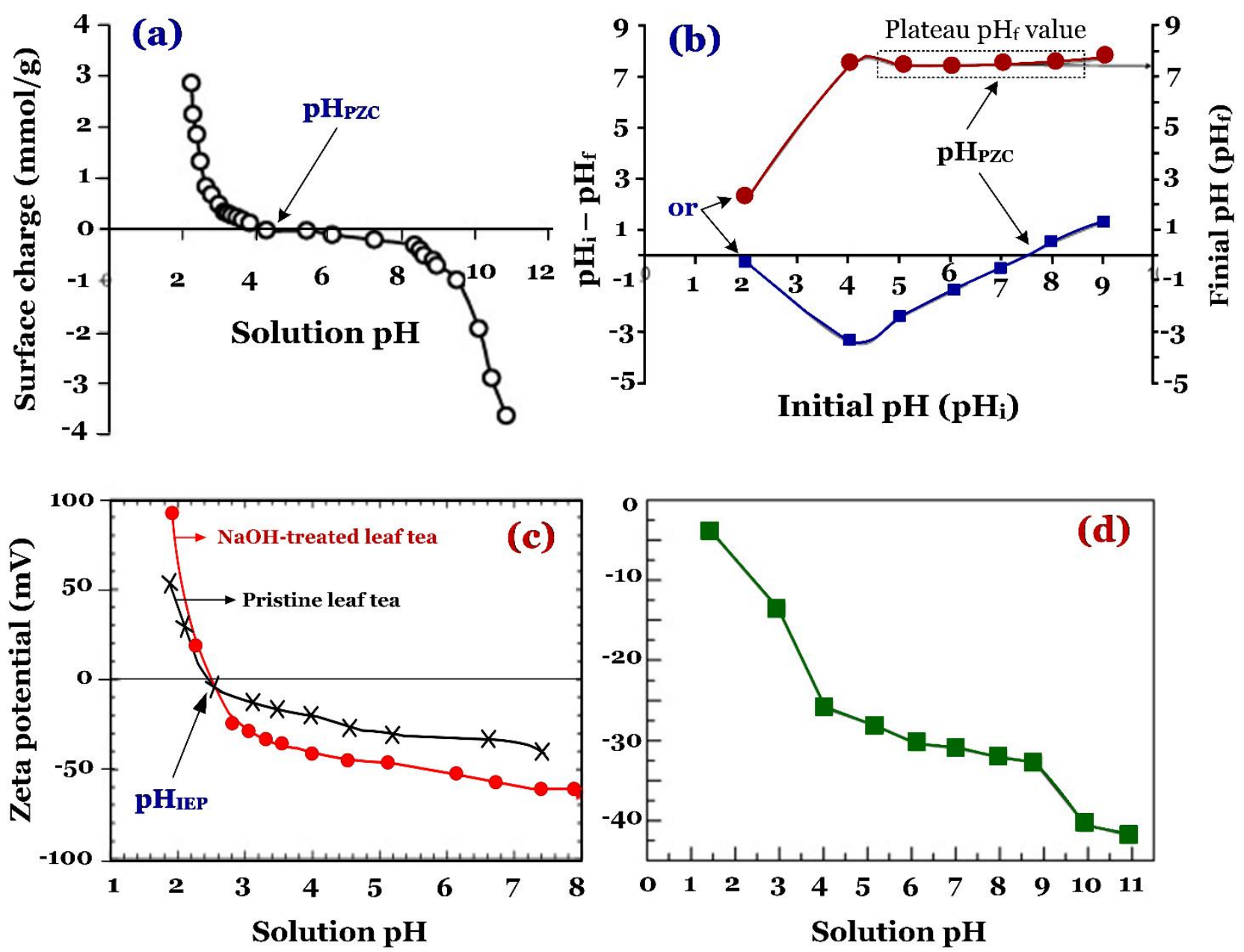

Figure S5. Point of zero charge (PZC) of (a) tea waste leaves determined by the acid-base titration method Uddin et al., 2009 [License number: 4435871145286] and (b) gulmohar leaves determined by the "drift method" Ponnusami et al., 2009b [License number: 4435871247208]; and isoelectric point (IEP) of (c) treated black tea waste leaves determined by a zeta meter Weng et al., 2014a [License number: 4435871464044] and (d) strawberry leaves determined by an electrokinetic analyzer Liu et al., 2010d [License Number: 4435880051225] 

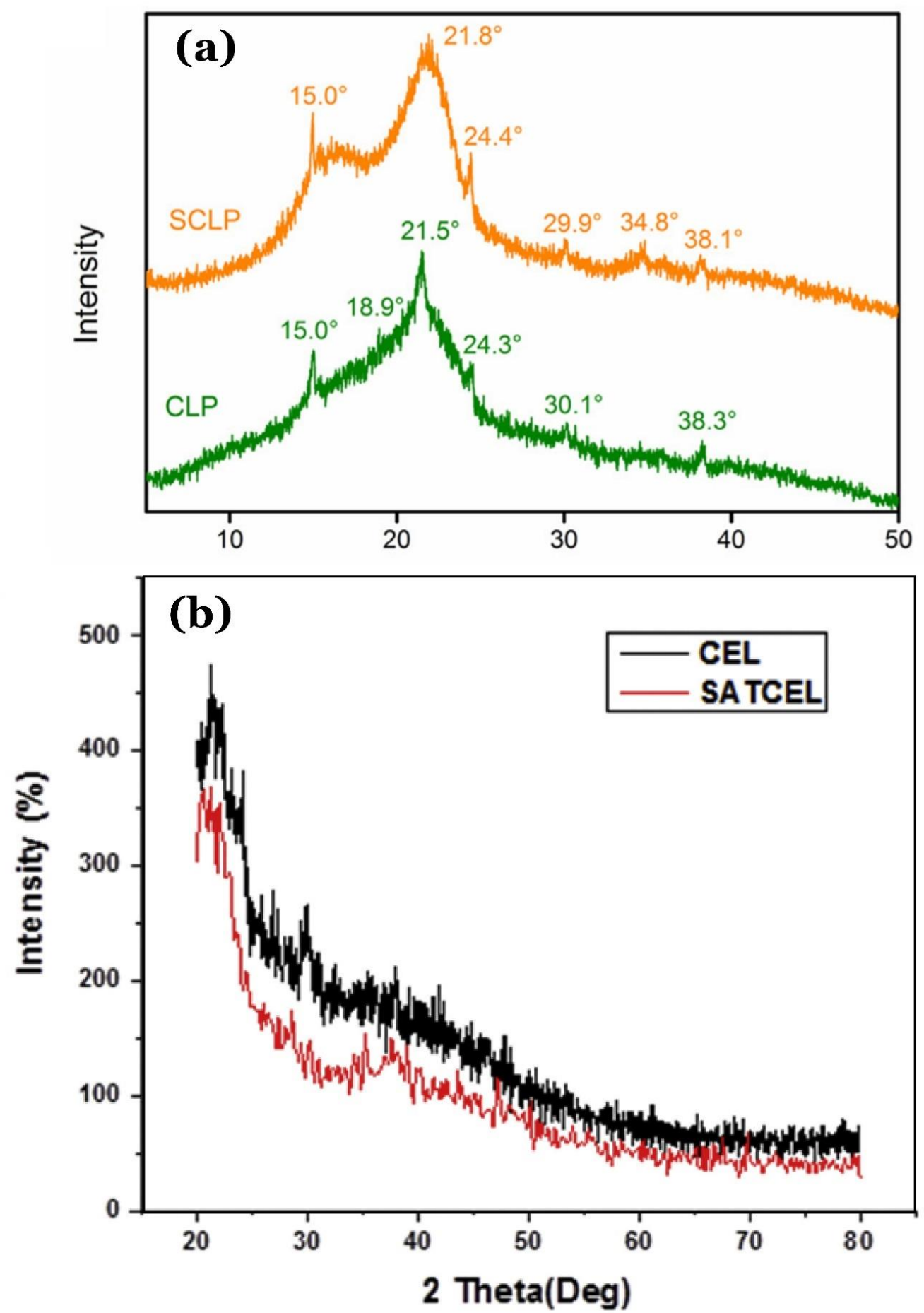

Figure S6. XRD spectra of (a) pristine (CLP) and succinic anhydridemodified camphor (SCLP) leaves (Wang et al., 2016), and (b) pristine (CEL) and aluminate-treated Casuarina equisetifolia (SATCEL) leaves (Khan Rao and Khatoon, 2017) 

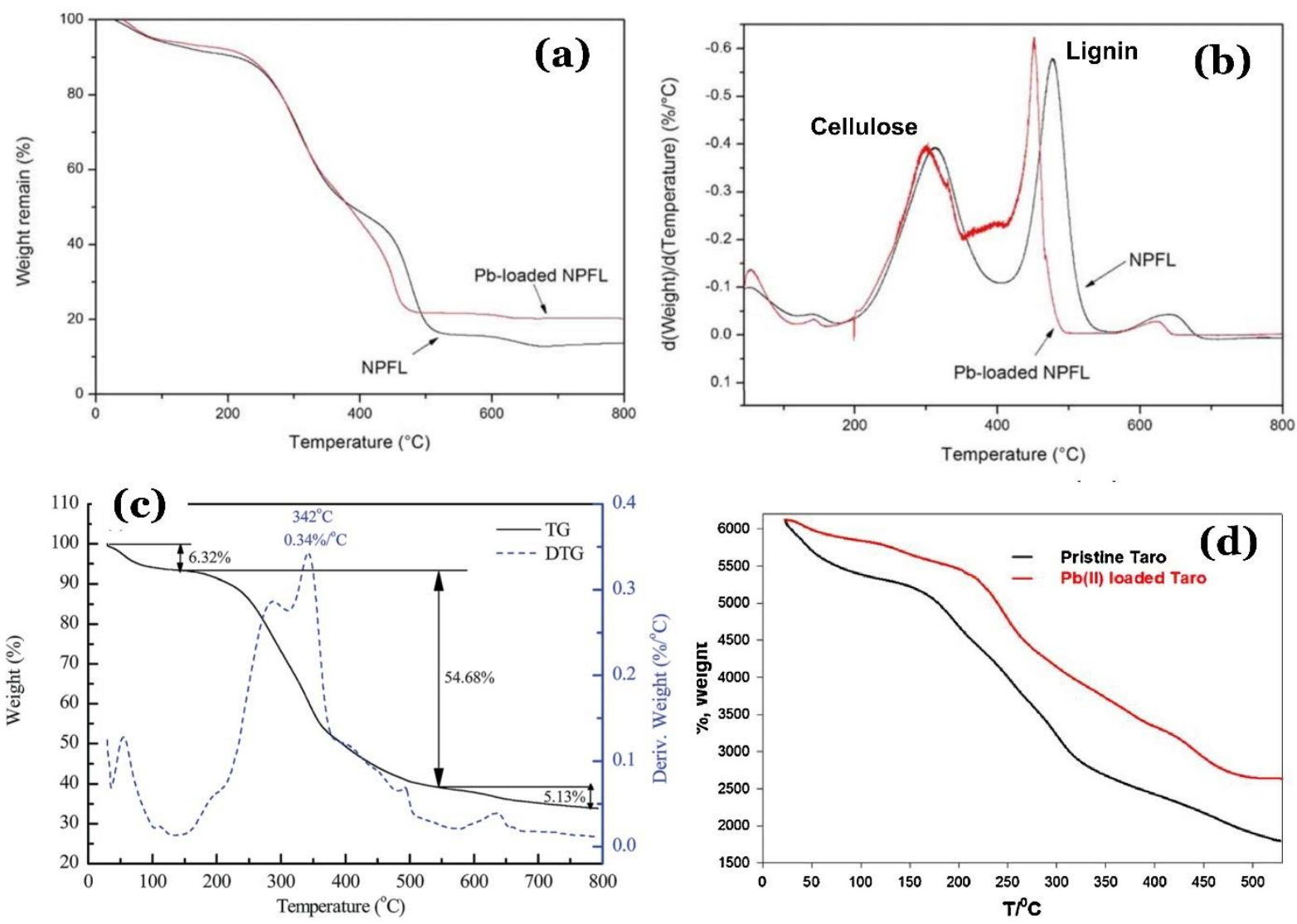

Figure S7. (a) TG and (b) DTG curves of alkali-treated persimmon fallen leaves (NPFL) (Ruiyi et al., 2016), (c) TG-DTG curves of raw phoenix tree leaves (Liang et al., 2016), and (d) TGA of pristine and Pb-loaded Taro leaves (Saha et al., 2017) 

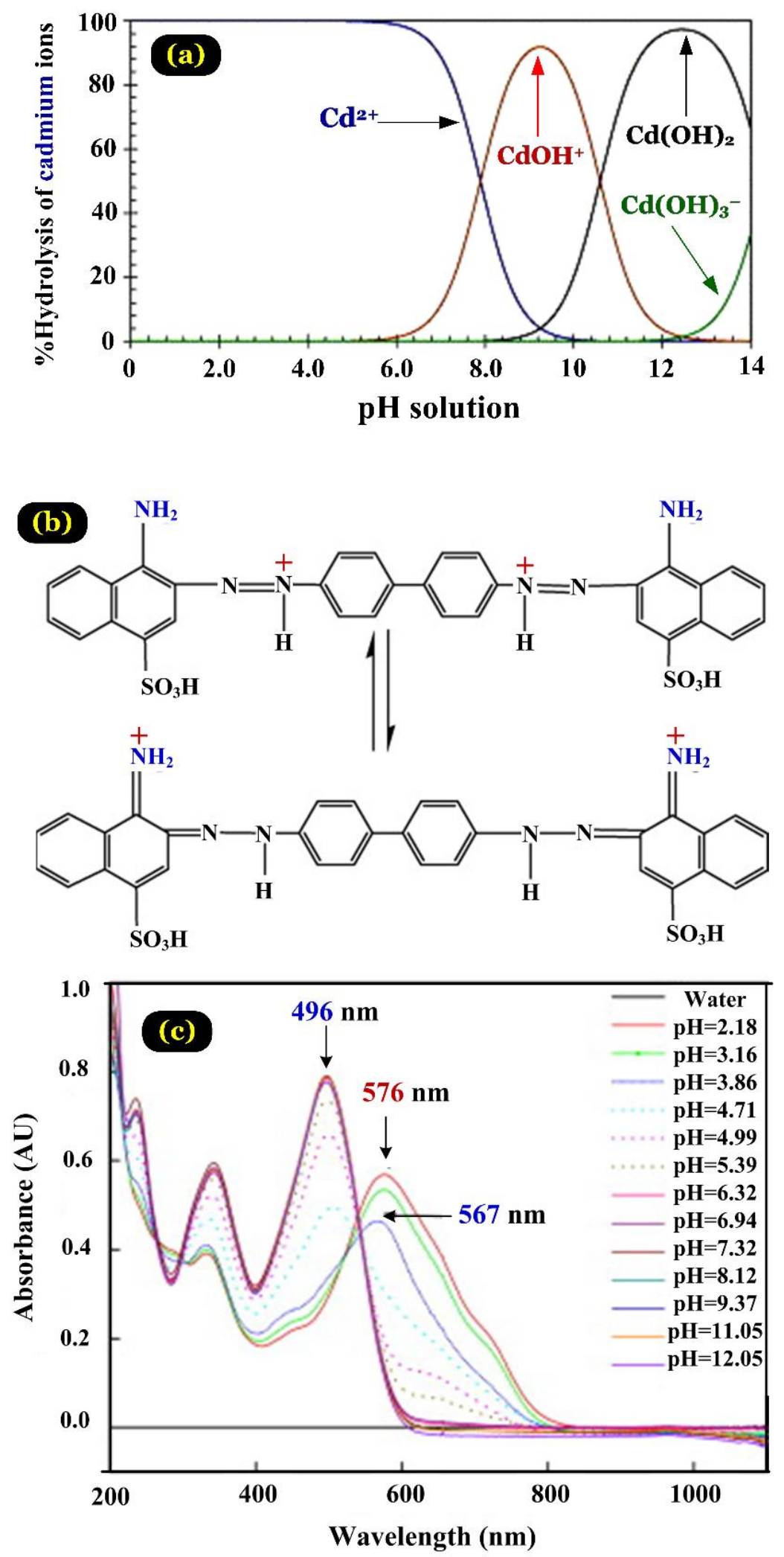

Figure S8. (a) Distribution of various cadmium species as a function of the $\mathrm{pH}$ (Srivastava et al., 2006); (b) chemical structure of Congo Red dye and (c) UV-Vis spectra of Congo Red solutions at different solution $\mathrm{pH}$ values (Zhou et al., 2011) 

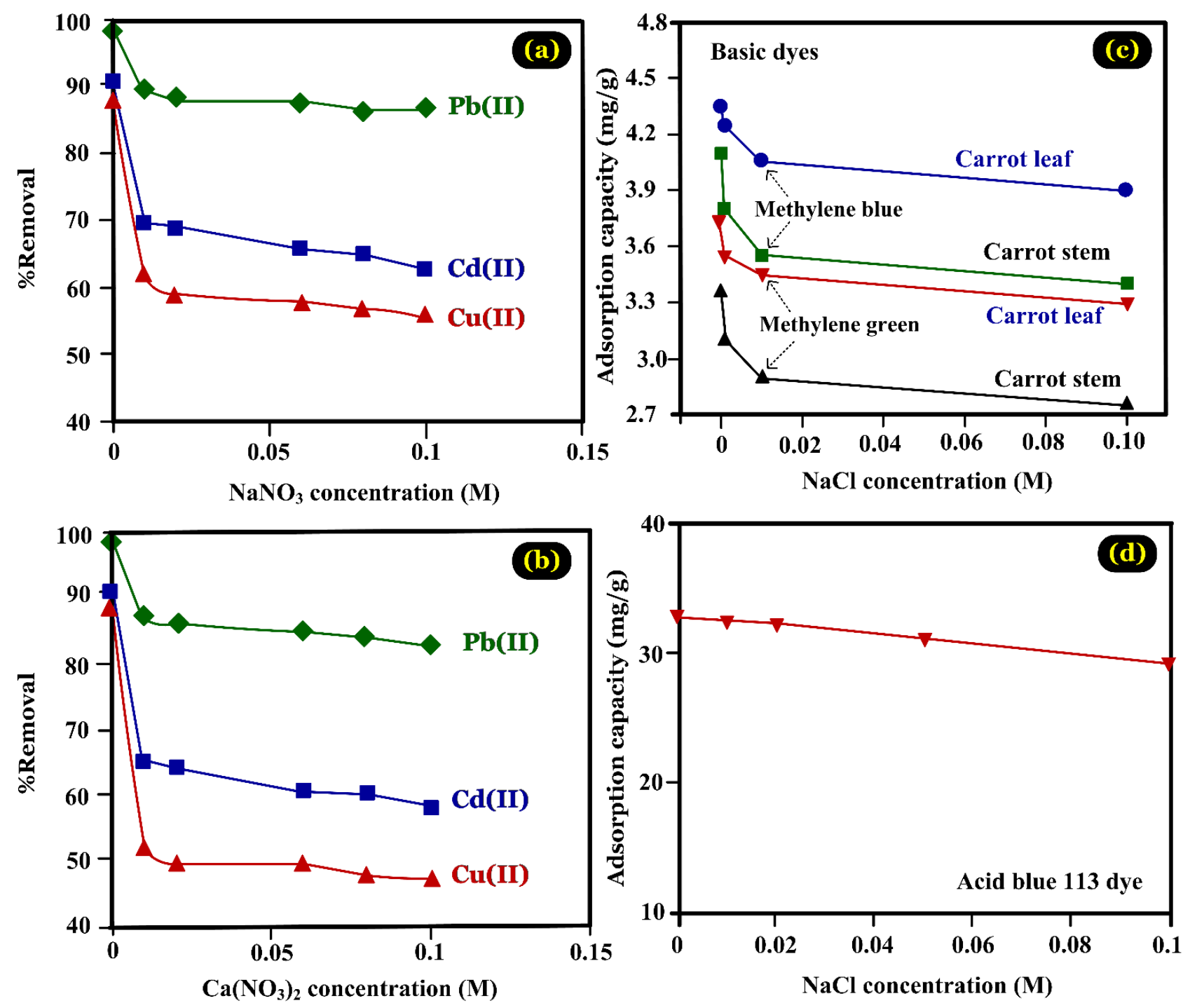

Figure S9. Effect of the ionic strength on the adsorption process of (a-b) potentially toxic metals onto Ulmus carpinifolia tree leaves (Sangi et al., 2008), (c) cationic dyes onto Daucus carota stems and leaves (Kushwaha et al., 2014b), and (d) anionic dye onto surfactant-modified Prunus Dulcis leaves (Jain and Gogate, 2017b) 


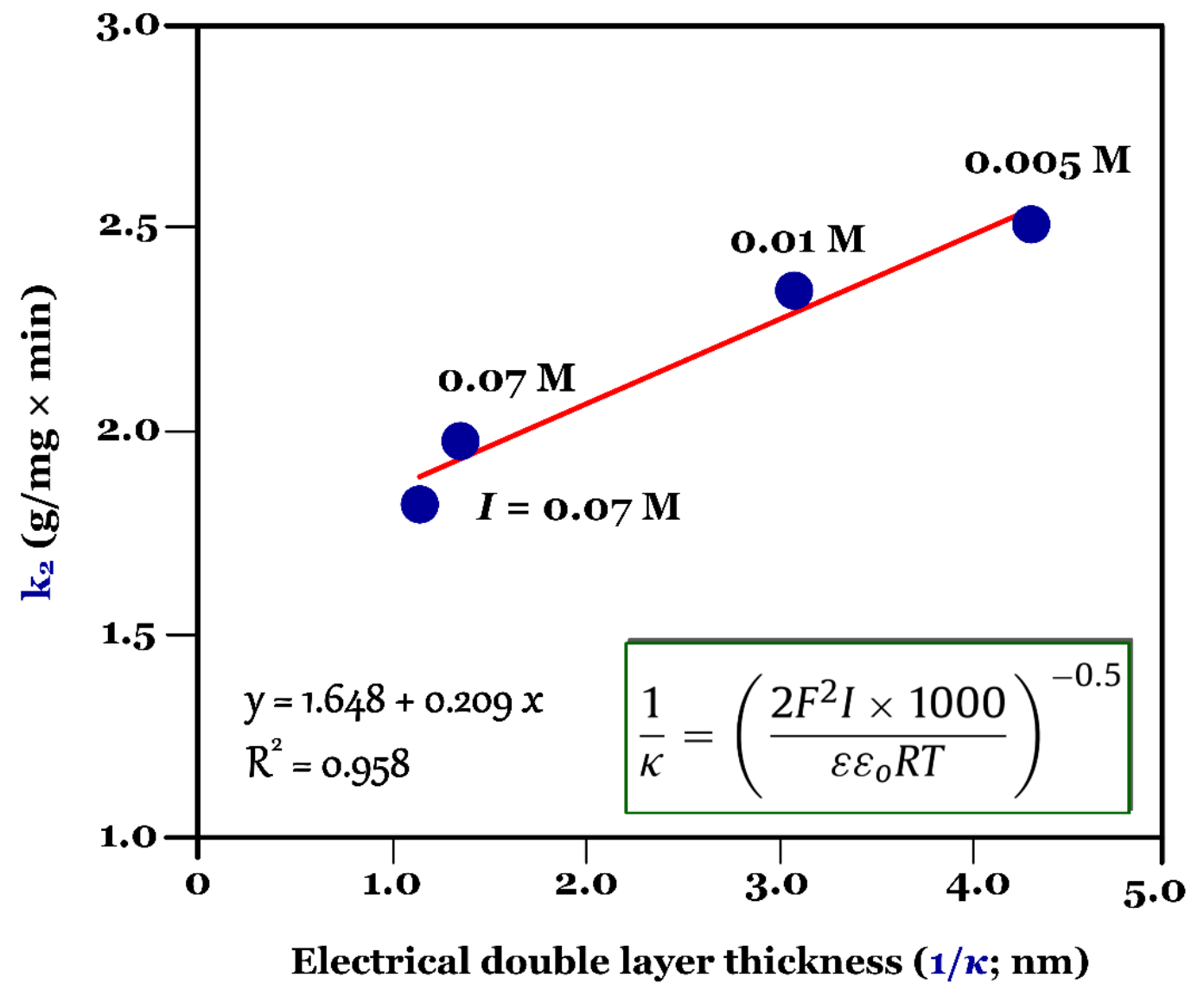

Figure S10. Linear relationship between the rate constant $k_{2}$ of pseudo-secondorder model and the thickness of the electrical double layer Weng et al., 2009 

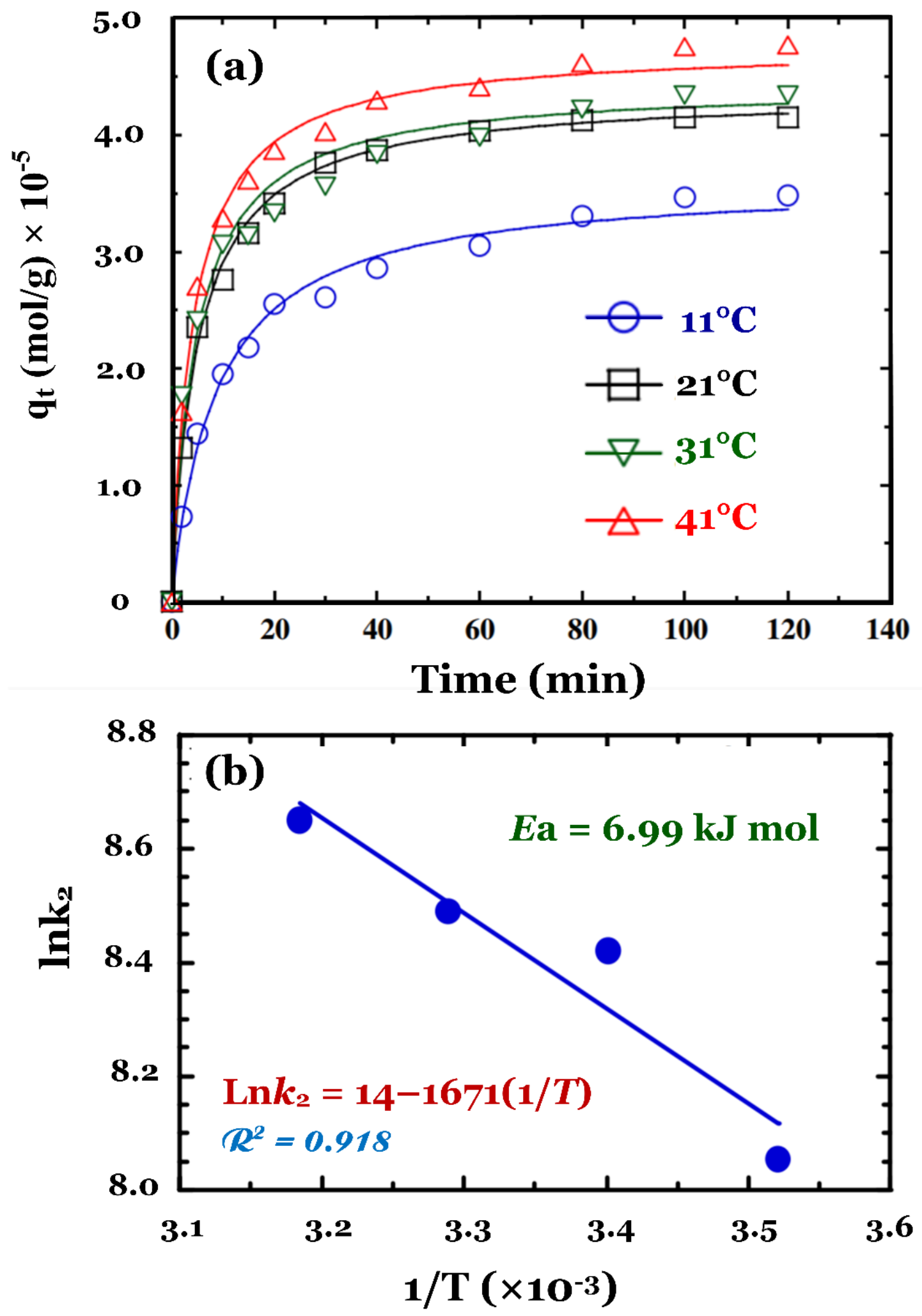

Figure S11. (a) Effect of the contact time on the $\mathrm{Cu}(\mathrm{II})$ adsorption process onto pineapple leaf powders at different operation temperatures, and (b) plot of the Arrhenius equation (Weng and Wu, 2012) 

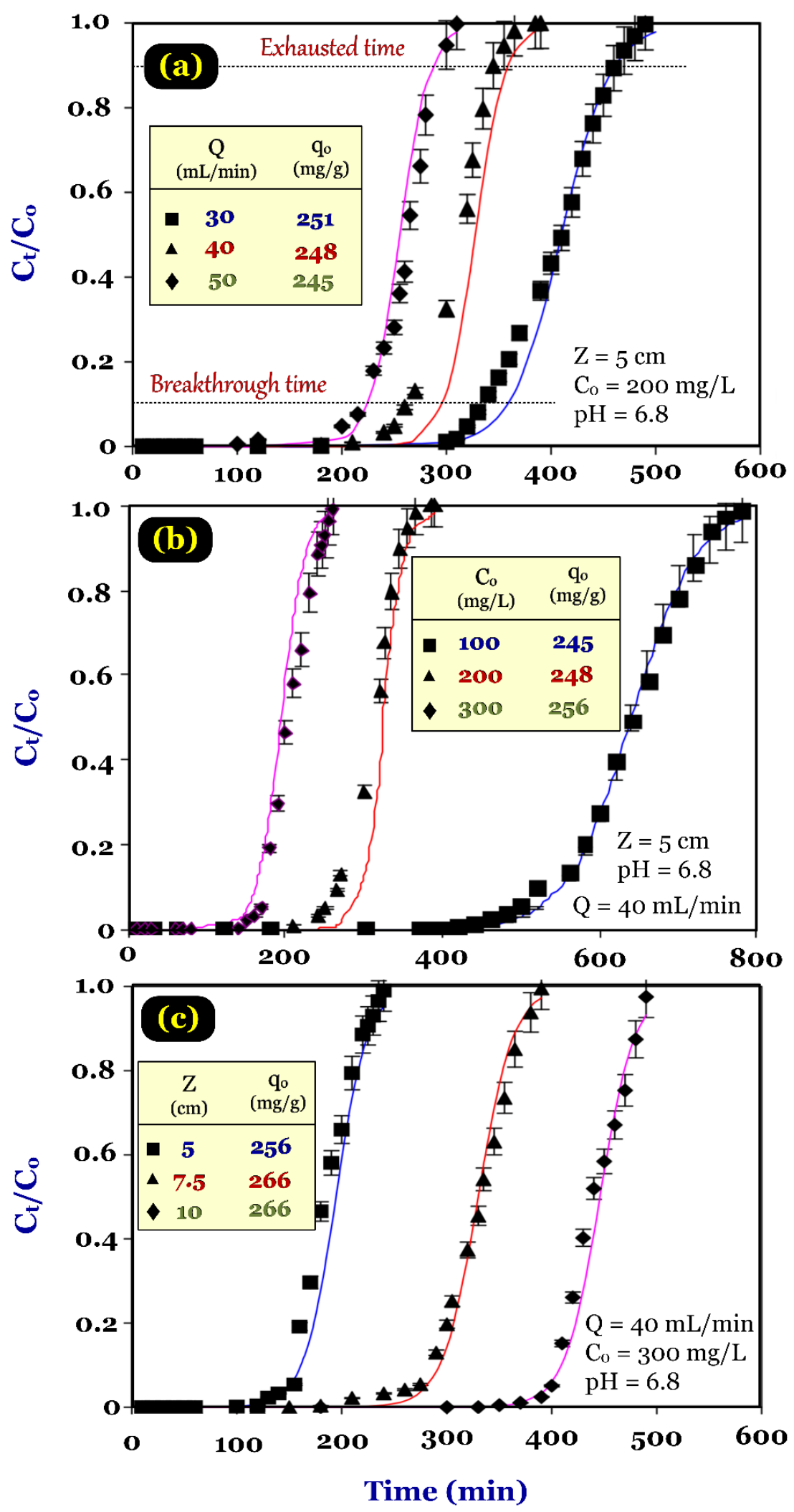

Figure S12. Typical breakthrough curve for methylene blue adsorption onto jackfruit leaves at different (a) flow rates, (b) feed concentrations, and (c) bed heights (Tamez Uddin et al., 2009) 

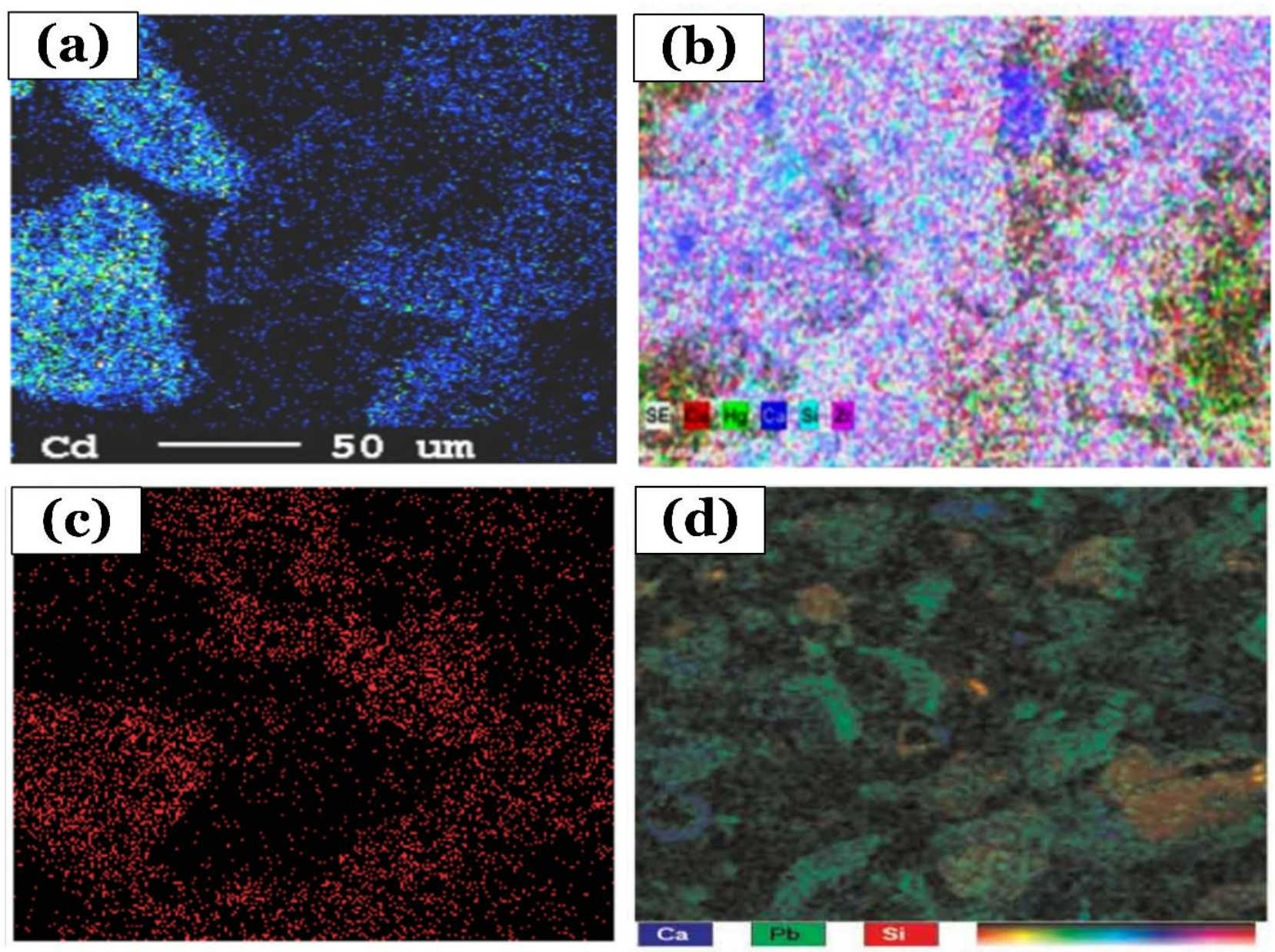

Figure S13. (a) Scanning Electron Micrographs of Syzygium cumini L. leaves after Cd(II) adsorption (Rao et al., 2010c), (b) Element distributions of EDX analysis region of tobacco leaves after $\mathrm{Cu}$ (II) biosorption (Çekim et al., 2015), (c) Cr mapping of Sakura leaves after Cr (VI) adsorption (Wenfang et al., 2015), and (d) X-ray mapping of maple leaves after $\mathrm{Pb}$ (II) adsorption (Hossain et al., 2014b) 


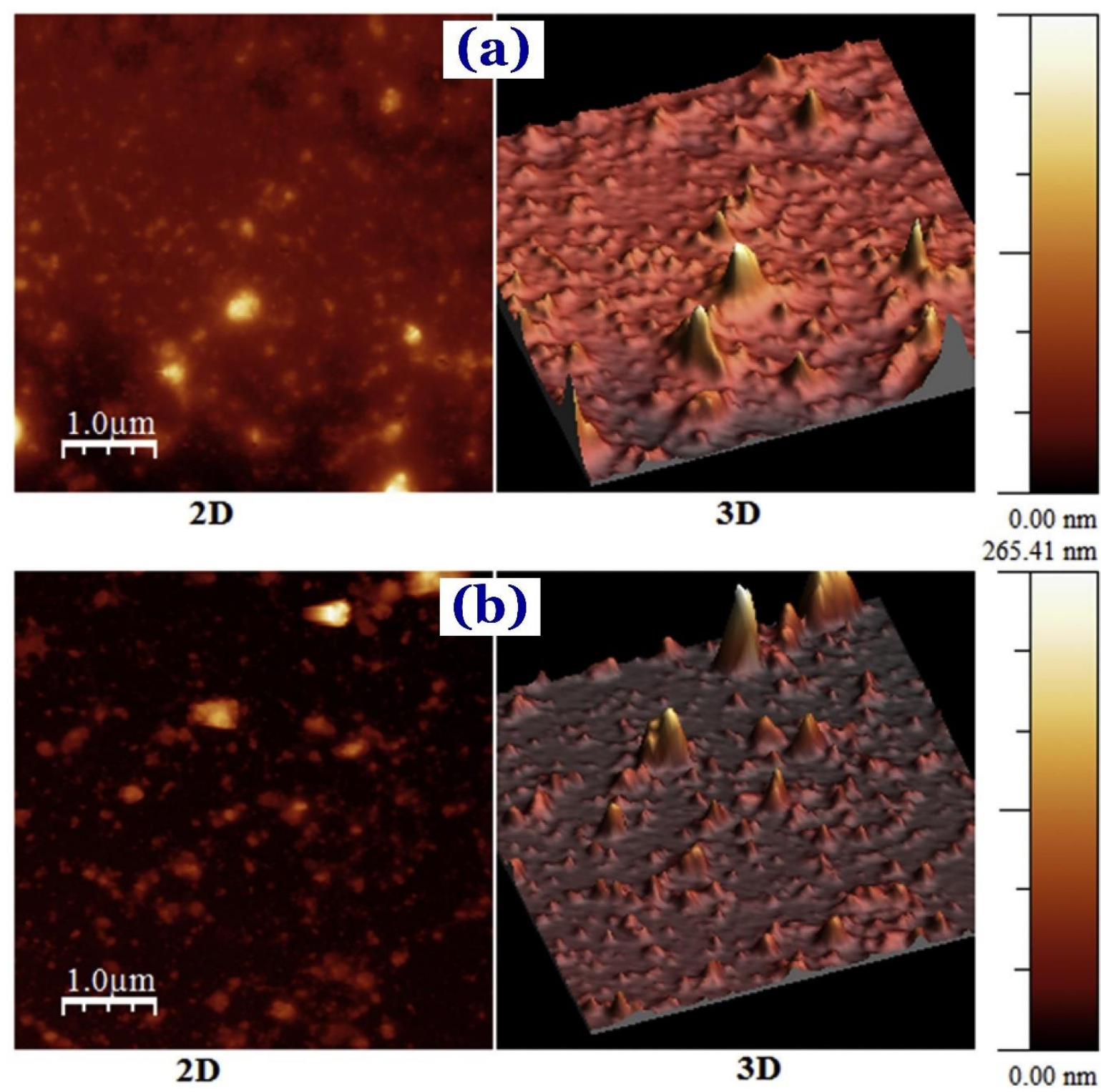

Figure S14. Atomic force microscopy (AFM) image of sodium aluminate-treated Casuarina equisetifolia leaves (a) before and (b) after Cu(II) biosorption (Khan Rao and Khatoon, 2017) 


\section{(a)}

\begin{tabular}{|c|c|c|c|}
\hline $\begin{array}{l}\text { Binding } \\
\text { group }\end{array}$ & $\begin{array}{l}\text { Structural } \\
\text { formula }\end{array}$ & pKa & $\begin{array}{l}\text { Ligand } \\
\text { atom }\end{array}$ \\
\hline Hydroxyl & $\equiv \mathrm{C}-\mathrm{OH}$ & $9.5^{-13}$ & $\mathbf{0}$ \\
\hline Carboxyl & $\begin{array}{c}-\mathbf{C}=\mathbf{0} \\
! \\
0 \\
0\end{array}$ & $1.7-4.7$ & $\mathbf{0}$ \\
\hline $\begin{array}{c}\text { Sulfhydryl } \\
\text { (thiol) }\end{array}$ & $-\mathbf{S H}$ & $8.3-10.8$ & $\mathbf{S}$ \\
\hline Sulfonate & $\begin{array}{c}0 \\
\stackrel{0}{\|} \\
-\underset{I}{S}=\mathbf{0} \\
0\end{array}$ & 1.3 & $\mathbf{S}$ \\
\hline Amine & $-\mathbf{N H}_{2}$ & $8-11$ & $\mathbf{N}$ \\
\hline
\end{tabular}

\section{(b)}<smiles>[M]OC(=O)C(C)(C)C(C)(C)C</smiles>

Chelation between carboxyl and phenolic hydroxyl<smiles>CC(C)(C)C(=O)OC(=O)C(C)(C)C</smiles>

Chelation between two carboxyl groups<smiles>[Y16]OC(=O)C(C)(C)C</smiles>

Complexation with a carboxyl group

Figure S15. (a) Some major binding functional groups for adsorption (Volesky, 2007), and (b) binding of a metal ion $\left(\mathrm{M}^{2+}\right)$ by oxygencontaining functional groups (Manahan, 2000). 


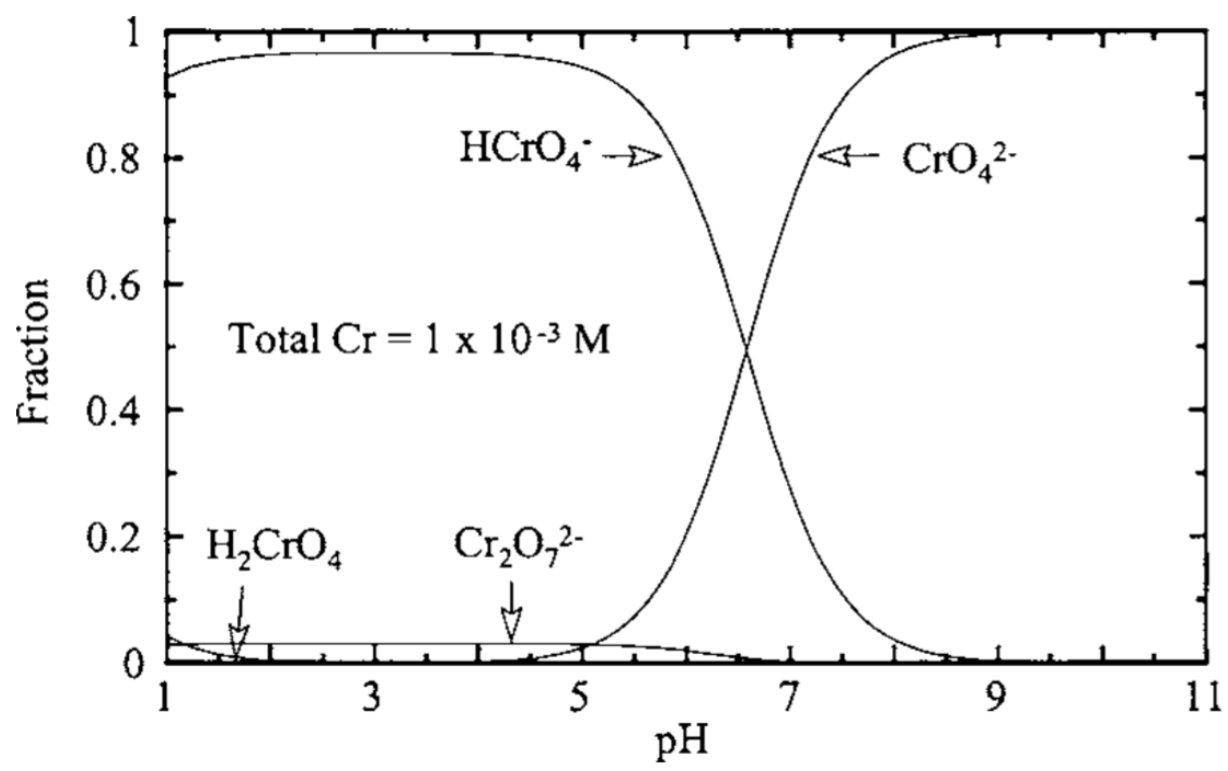

Figure S16. $\mathrm{Cr}$ (VI) speciation diagram as function of $\mathrm{pH}$ (Weng et al., 2006) 


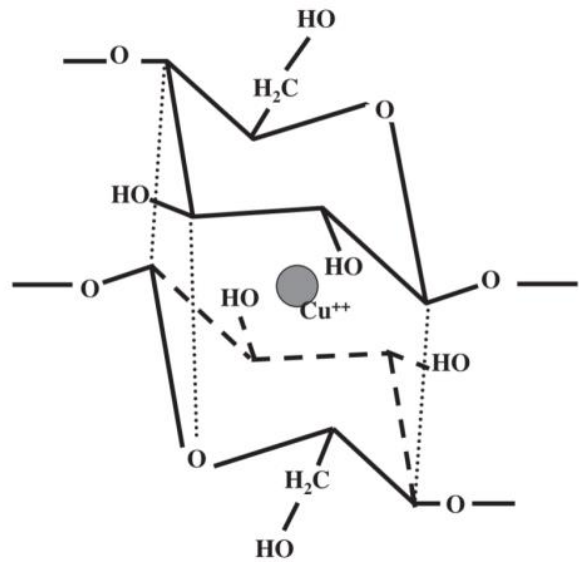

Figure S17. Model for the possible sorption site of a copper ion between two adjacent fibers of the biomass derived from Maitenus truncata leaves Carvalho et al., 2003 


\section{Licenses}

Figure 3. Effect of the $\mathrm{pH}$ solution on the adsorption process on (a) potentially toxic metal cations onto Fraxinus excelsior tree leaf-biosorbent [Adapted from Sangi et al. Sangi et al., 2008. Copyright (2008), with permission from Elsevier. License Number: 4435910682650], (b) fluoride onto Azadirachta indica tree leaf-biosorbent [Adapted from Bharali and Bhattacharyya Bharali and Bhattacharyya, 2015. Copyright (2015), with permission from Elsevier. License Number: 4440010650238], (c) ammonium onto Parthenocissus tricuspidata tree leafbiosorbent [Adapted from Liu et al. Liu et al., 2010c. Copyright (2010), with permission from Elsevier. License Number: 4435910810287], (d) cationic dyes onto Saraca asoca tree leaf-biosorbent [Adapted from Gupta et al. Gupta et al., 2012b. Copyright (2012), with permission from Elsevier. License Number: 4435910987708], (e) hexavalent chromium onto Melaleuca diosmifolia tree leaf-biosorbent [Adapted from Kuppusamy et al. Kuppusamy et al., 2016. Copyright (2016), with permission from Elsevier. License Number: 4435911095229], (f) acid violet 17 dye onto activated Ficus racemosa tree leaf-adsorbent [Adapted from Jain and Gogate Jain and Gogate, 2017c. Copyright (2017), with permission from Elsevier. License Number: 4435911196015], (g) arsenic onto Psidium guajava leaf tree leaf-biosorbent [Adapted from Kamsonlian et al. Kamsonlian et al., $2012 a$. Copyright (2012), with permission from Taylor \& Francis. License Number: 4435940299690], and (h) mercury onto pristine and modified bamboo leaf tree leaf-biosorbents [Adapted from Mondal et al. Mondal et al., 2013. Copyright (2013), with permission from Taylor \& Francis. License Number: 4435920032442].

Figure 5. Typical adsorption isotherm determined by two different methods, that is by changing (a) solid/liquid ratio [Adapted from Kılıç et al. Kılıç et al., 2009. Copyright (2009), with permission from Elsevier. License Number: 501431317], and (b) initial adsorbate concentrations [Adapted from Chen et al. Chen et al., 2010a. Copyright (2010) with permission from Elsevier. License Number: 4435921407628$].$

Figure 8. (a) Effect of solution pH on the adsorption of two anionic dyes [Sumfixe Supra red (SSR) and Alpacelle Lumiere brown (ALB)] onto Agave americana leaves, and (b) effect of $\mathrm{pH}$ on the dye desorption Hamissa et al., 2007 [Creative Commons CC-BY by SAGE]; (c) Effect of different eluents on copper desorption from treated rubber leaves [Adapted from Ngah, et al. Ngah and Hanafiah, 2008; Copyright (2008) with permission from Elsevier. License Number:4443540449114]; (d) Desorption kinetics of anionic Amaranth dye from water hyacinth leaves [Adapted from Guerrero-Coronilla et al. Guerrero-Coronilla et al., 2015. Copyright (2015) with permission from Elsevier. License Number: 4435930384912]; (e) Five cycles of Pb(II) adsorption-desorption with $0.4 \mathrm{M} \mathrm{HCl}$ [Adapted from Reddy et al. Reddy et al., 2010. Copyright (2010) with permission from Elsevier. License Number: 4435930464723]; (f) Biosorption-desorption cycles for regenerating SATCEL with 0.1 N $\mathrm{HCl}$ [Adapted from Khan Rao and Khatoon Khan Rao and Khatoon, 2017. Copyright (2017) with permission from Elsevier. License Number: 4435930646149]. 
Figure 9. (a) Mechanisms proposed for $\mathrm{Cr}(\mathrm{VI})$ biosorption by nonliving biomass [Adapted from Park et al. $\underline{\text { Park }}$ et al., 2005. Copyright (2005) with permission from Elsevier. License Number: 4440510789887]; and (b) highresolution spectra collected from the $\mathrm{Cr} 2 \mathrm{p}$ core regions of the $\mathrm{Cr}$-laden biosorbent derived from Korean red pine tree leaves as well as standard $\mathrm{Cr}(\mathrm{III})$ and $\mathrm{Cr}(\mathrm{VI})$ chemicals [Adapted from Park et al. Park et al., 2011. Copyright (2011) with permission from Elsevier. License Number: 4435931207985].

Figure 10. The potential adsorption mechanisms between toxic metals and biosorbents [Adapted from Tran and Chao, 2018a. Copyright (2018) with permission from Springer. License Number: 4525340872276]

Figure 11. Typical interactions contributing to the adsorption of cationic methylene green 5 dye onto biosorbent [Adapted from Tran et al. Tran et al., 2017c. Copyright (2017) with permission from Taylor \& Francis. License Number: 4435940108341$]$. 


\section{References}

Abdel-Ghani, N.T., Hegazy, A.K. and El-Chaghaby, G.A., 2009. Typha domingensis leaf powder for decontamination of aluminium, iron, zinc and lead: Biosorption kinetics and equilibrium modeling. International Journal of Environmental Science \& Technology, 6, 243-248.

Abdelwahab, O., Fouad, Y.O., Amin, N.K. and Mandor, H., 2015. Kinetic and thermodynamic aspects of cadmium adsorption onto raw and activated guava (Psidium guajava) leaves. Environmental Progress \& Sustainable Energy, 34, 351-358.

Abu Al-Rub, F.A., 2006. Biosorption of Zinc on Palm Tree Leaves: Equilibrium, Kinetics, and Thermodynamics Studies. Separation Science and Technology, 41, 3499-3515.

Aditya, G.V.V., Pujitha, B.P., Babu, N.C. and Venkateswarlu, P., 2012. Biosorption of chromium onto Erythrina Variegata Orientalis leaf powder. Korean Journal of Chemical Engineering, 29, 64-71.

Agarry, S., Ogunleye, O. and Aworanti, O., 2013. Biosorption equilibrium, kinetic and thermodynamic modelling of naphthalene removal from aqueous solution onto modified spent tea leaves. Environmental technology, 34, 825-839.

Ahmad, A., Ghazi, Z.A., Saeed, M., Ilyas, M., Ahmad, R., Khattak, A.M. and Iqbal, A., 2017a. A comparative study of the removal of $\mathrm{Cr}$ (vi) from synthetic solution using natural biosorbents. New Journal of Chemistry, 41, 10799-10807.

Ahmad, A., Ghazi, Z.A., Saeed, M., Ilyas, M., Ahmad, R., Muqsit Khattak, A. and Iqbal, A., 2017b. A comparative study of the removal of $\mathrm{Cr}(\mathrm{VI})$ from synthetic solution using natural biosorbents. New Journal of Chemistry, 41, 10799-10807.

Al-Dujaili, A.H., Awwad, A.M. and Salem, N.M., 2012. Biosorption of cadmium (II) onto loquat leaves (Eriobotrya japonica) and their ash from aqueous solution, equilibrium, kinetics, and thermodynamic studies. International Journal of Industrial Chemistry, 3, 22.

Al-Haidary, A.M.A., Zanganah, F.H., Al-Azawi, S.R., Khalili, F.I. and Al-Dujaili, A.H., 2011a. A study on using date palm fibers and leaf base of palm as adsorbents for $\mathrm{Pb}$ (II) ions from its aqueous solution. Water, Air, and Soil Pollution, 214, 73-82.

Al-Haidary, A.M.A., Zanganah, F.H.H., Al-Azawi, S.R.F., Khalili, F.I. and Al-Dujaili, A.H., 2011b. A study on using date palmfibers and leaf base of palm as adsorbents for $\mathrm{Pb}(\mathrm{II})$ ions from its aqueous solution. Water, Air, \& Soil Pollution, 214, 73-82.

Al-Masri, M., Amin, Y., Al-Akel, B. and Al-Naama, T., 2010. Biosorption of cadmium, lead, and uranium by powder of poplar leaves and branches. Applied Biochemistry and Biotechnology, 160, 976-987. 
Al-Subu, M.M., 2002. The interaction effects of cypress (Cupressus sempervirens), cinchona (Eucalyptus longifolia) and pine (Pinus halepensis) leaves on their efficiencies for lead removal from aqueous solutions. Advances in Environmental Research, 6, 569-576.

Al Rmalli, S.W., Dahmani, A.A., Abuein, M.M. and Gleza, A.A., 2008. Biosorption of mercury from aqueous solutions by powdered leaves of castor tree (Ricinus communis L.). Journal of Hazardous Materials, 152, 955-959.

Ali, H. and Muhammad, S.K., 2008. Biosorption of crystal violet from water on leaf biomass of Calotropis procera. Journal of Environmental Science and Technology, 1, 143-150.

Ali, I. and Gupta, V.K., 2007. Advances in water treatment by adsorption technology. Nature protocols, 1, 2661.

Ali, I.H. and Alrafai, H., 2016. Kinetic, isotherm and thermodynamic studies on biosorption of chromium (VI) by using activated carbon from leaves of Ficus nitida. Chemistry Central Journal, 10, 36.

Alizadeh, N., Shariati, S. and Besharati, N., 2017. Adsorption of Crystal Violet and Methylene Blue on Azolla and Fig Leaves Modified with Magnetite Iron Oxide Nanoparticles. International Journal of Environmental Research, 1-10.

Amarasinghe, B.M.W.P.K. and Williams, R.A., 2007. Tea waste as a low cost adsorbent for the removal of Cu and $\mathrm{Pb}$ from wastewater. Chemical Engineering Journal, 132, 299-309.

Amirnia, S., Ray, M.B. and Margaritis, A., 2016. Copper ion removal by Acer saccharum leaves in a regenerable continuous-flow column. Chemical Engineering Journal, 287, 755-764.

Ammari, T.G., 2014. Utilization of a natural ecosystem bio-waste; leaves of Arundo donax reed, as a raw material of low-cost eco-biosorbent for cadmium removal from aqueous phase. Ecological Engineering, 71, 466-473.

Ansari, S.A., Khan, F. and Ahmad, A., 2016a. Cauliflower leave, an agricultural waste biomass adsorbent, and its application for the removal of MB dye from aqueous solution: Equilibrium, kinetics, and thermodynamic studies. International Journal of Analytical Chemistry, 2016, 10.

Ansari, S.A., Khan, F. and Ahmad, A., 2016b. Cauliflower Leave, an Agricultural Waste Biomass Adsorbent, and Its Application for the Removal of MB Dye from Aqueous Solution: Equilibrium, Kinetics, and Thermodynamic Studies. International journal of analytical chemistry, 2016.

Anwar, J., Shafique, U., Waheed uz, Z., un Nisa, Z., Munawar, M.A., Jamil, N., Salman, M., Dar, A., Rehman, R., Saif, J., Gul, H. and Iqbal, T., 2011. Removal of chromium on Polyalthia longifolia leaves biomass. International Journal of Phytoremediation, 13, 410-420. 
Ang, X., Sethu, V., Andresen, J. and Sivakumar, M., 2013. Copper (II) ion removal from aqueous solutions using biosorption technology: thermodynamic and SEM-EDX studies. Clean Technologies and Environmental Policy, 15, 401-407.

Aoyama, M., 2003a. Comment on "Biosorption of chromium(VI) from aqueous solution by cone biomass of Pinus sylvestris”. Bioresource Technology, 89, 317-318.

Aoyama, M., 2003b. Removal of Cr (VI) from aqueous solution by London plane leaves. Journal of Chemical Technology and Biotechnology, 78, 601-604.

Aoyama, M., 2003c. Removal of Cr(VI) from aqueous solution by London plane leaves. Journal of Chemical Technology \& Biotechnology, 78, 601-604.

Aoyama, M., Sugiyama, T., Doi, S., Cho, N.-S. and Kim, H.-E., 1999a. Removal of hexavalent chromium from dilute aqueous solution by coniferous leaves. Holzforschung, 53, 365-368.

Aoyama, M., Sugiyama, T., Doi, S., Cho, N.S. and Kim, H.E., 1999b. Removal of hexavalent chromium from dilute aqueous solution by coniferous leaves, 365$)$. Holzforschung.

Aoyama, M. and Tsuda, M., 2001. Removal of Cr(VI) from aqueous solutions by larch bark. Wood Science and Technology, 35, 425-434.

Aoyama, M., Tsuda, M., Seki, K., Doi, S., Kurimoto, Y. and Tamura, Y., 2000a. Adsorption of Cr (VI) from dichromate solutions onto black locust leaves. Holzforschung, 54, 340-342.

Aoyama, M., Tsuda, M., Seki, K., Doi, S., Kurimoto, Y. and Tamura, Y., 2000b. Adsorption of Cr(VI) from Dichromate Solutions onto Black Locust Leaves Holzforschung, 340).

Arshad, M., Zafar, M.N., Younis, S. and Nadeem, R., 2008. The use of Neem biomass for the biosorption of zinc from aqueous solutions. Journal of Hazardous Materials, 157, 534-540.

Asgarzadeh, S., Rostamian, R., Faez, E., Maleki, A. and Daraei, H., 2016. Biosorption of Pb(II), Cu(II), and $\mathrm{Ni}(\mathrm{II})$ ions onto novel lowcost P. eldarica leaves-based biosorbent: isotherm, kinetics, and operational parameters investigation. Desalination and Water Treatment, 57, 14544-14551.

Aslam, M., Rais, S., Alam, M. and Pugazhendi, A., 2013. Adsorption of Hg(II) from Aqueous Solution Using Adulsa (Justicia adhatoda) Leaves Powder: Kinetic and Equilibrium Studies. Journal of Chemistry, 2013, 11.

Awwad, A.M. and Salem, N.M., 2014. Kinetics and thermodynamics of Cd(II) biosorption onto loquat (Eriobotrya japonica) leaves. Journal of Saudi Chemical Society, 18, 486-493.

Aydin, M., Cavas, L. and Merdivan, M., 2012. An alternative evaluation method for accumulated dead leaves of Posidonia oceanica (L.) Delile on the beaches: removal of uranium from aqueous solutions. Journal of Radioanalytical and Nuclear Chemistry, 293, 489-496. 
Babarinde, N., 2016. Kinetic, equilibrium and thermodynamic studies of the biosorption of $\mathrm{Pb}$ (II), Cd (II) and $\mathrm{Cr}$ (III) by neem leaf. Journal of Innovative Research in Engineering and Sciences, 2.

Babu, B.V. and Gupta, S., 2008. Adsorption of Cr(VI) using activated neem leaves: kinetic studies. Adsorption, 14, 85-92.

Baruah, S., Devi, A., Bhattacharyya, K. and Sarma, A., 2017. Developing a biosorbent from Aegle Marmelos leaves for removal of methylene blue from water. International Journal of Environmental Science and Technology, 14, 341-352.

Batool, F., Iqbal, S. and Akbar, J., 2017. Impact of metal ionic characteristics on adsorption potential of Ficus carica leaves using QSPR modeling. Journal of Environmental Science and Health, Part B, 1-6.

Bello, O.S., Adegoke, K.A. and Akinyunni, O.O., 2017. Preparation and characterization of a novel adsorbent from Moringa oleifera leaf. Applied Water Science, 7, 1295-1305.

Benadjemia, M., Millière, L., Reinert, L., Benderdouche, N. and Duclaux, L., 2011. Preparation, characterization and Methylene Blue adsorption of phosphoric acid activated carbons from globe artichoke leaves. Fuel Processing Technology, 92, 1203-1212.

Benaïssa, H., 2006. Screening of new sorbent materials for cadmium removal from aqueous solutions. Journal of Hazardous Materials, 132, 189-195.

Benaïssa, H. and Elouchdi, M.A., 2007. Removal of copper ions from aqueous solutions by dried sunflower leaves. Chemical Engineering and Processing: Process Intensification, 46, 614-622.

Bharali, R.K. and Bhattacharyya, K.G., 2015. Biosorption of fluoride on Neem (Azadirachta indica) leaf powder. Journal of Environmental Chemical Engineering, 3, 662-669.

Bhattacharyya, K.G. and Sarma, A., 2003. Adsorption characteristics of the dye, Brilliant Green, on Neem leaf powder. Dyes and pigments, 57, 211-222.

Bhattacharyya, K.G., Sarma, A. and Sarma, J., 2010. Adsorption of Cu(II) ions onto a cellulosic biosorbent, Azadirachta Indica leaf powder: Application in water treatment. Adsorption Science \& Technology, 28, 869-883.

Bhattacharyya, K.G., Sarma, J. and Sarma, A., 2009. Azadirachta indica leaf powder as a biosorbent for Ni(II) in aqueous medium. Journal of Hazardous Materials, 165, 271-278.

Bhattacharyya, K.G. and Sharma, A., 2004. Adsorption of Pb(II) from aqueous solution by Azadirachta indica (Neem) leaf powder. Journal of Hazardous Materials, 113, 97-109.

Biggar, J.W. and Cheung, M.W., 1973. Adsorption of Picloram (4-Amino-3,5,6-Trichloropicolinic Acid) on Panoche, Ephrata, and Palouse Soils: A Thermodynamic Approach to the Adsorption Mechanism1. Soil Science Society of America Journal, 37, 863-868. 
Blanchard, G., Maunaye, M. and Martin, G., 1984. Removal of heavy metals from waters by means of natural zeolites. Water Research, 18, 1501-1507.

Boparai, H.K., Joseph, M. and O'Carroll, D.M., 2011. Kinetics and thermodynamics of cadmium ion removal by adsorption onto nano zerovalent iron particles. Journal of Hazardous Materials, 186, 458-465.

Boruah, P., Sarma, A. and Bhattacharyya, K.G., 2015. Removal of Ni (II) ions from aqueous solution by using low cost biosorbent prepared from jackfruit (Artocarpus heterophyllus) leaf powder.

Bose, R.S., Bora, P.P., Deka, R.C. and Sarma, K.P., 2016. Removal of Cd(II) ion from aqueous solution by powdered leaf biomass of Boehmeria listeri: equilibrium and kinetic studies. Desalination and Water Treatment, 57, 20877-20888.

Boudrahem, F., Aissani-Benissad, F. and Soualah, A., 2011. Adsorption of Lead(II) from Aqueous Solution by Using Leaves of Date Trees As an Adsorbent. Journal of Chemical \& Engineering Data, 56, 18041812.

Boveiri Monji, A., Javad Ahmadi, S. and Zolfonoun, E., 2008. Selective Biosorption of Zirconium and Hafnium from Acidic Aqueous Solutions by Rice Bran, Wheat Bran and Platanus Orientalis Tree Leaves. Separation Science and Technology, 43, 597-608.

Brahman, K.D., Kazi, T.G., Afridi, H.I., Baig, J.A., Abro, M.I., Arain, S.S., Ali, J. and Khan, S., 2016. Simultaneously removal of inorganic arsenic species from stored rainwater in arsenic endemic area by leaves of Tecomella undulata: A multivariate study. Environmental Science and Pollution Research, $23,15149-15163$.

Carvalho, d.R.P., Freitas, J.R., de Sousa, A.M.G., Moreira, R.L., Pinheiro, M.V.B. and Krambrock, K., 2003. Biosorption of copper ions by dried leaves: chemical bonds and site symmetry. Hydrometallurgy, 71, 277-283.

Çekim, M., Yildiz, S. and Dere, T., 2015. Biosorption of copper from synthetic waters by using tobacco leaf: Equilibrium, inetic and thermodynamic tests. Journal of Environmental Engineering and Landscape Management, 23, 172-182.

Cengiz, S. and Cavas, L., 2010. A promising evaluation method for dead leaves of Posidonia oceanica (L.) in the adsorption of methyl violet. Marine Biotechnology, 12, 728-736.

Copello, G.J., Garibotti, R.E., Varela, F., Tuttolomondo, M.V. and Diaz, L.E., 2011. Exhausted yerba mate leaves (Ilex Paraguariensis) as biosorbent for the removal of metals from aqueous solutions. Journal of the Brazilian Chemical Society, 22, 790-795.

Cukierman, A.L., 2007. Metal Ion Biosorption Potential of Lignocellulosic Biomasses and Marine Algae for Wastewater Treatment. Adsorption Science \& Technology, 25, 227-244. 
Chakraborty, S., Chowdhury, S. and Saha, P.D., 2012. Insight into biosorption equilibrium, kinetics and thermodynamics of crystal violet onto Ananas comosus (pineapple) leaf powder. Applied Water Science, 2, 135-141.

Chakravarty, S., Mohanty, A., Sudha, T.N., Upadhyay, A.K., Konar, J., Sircar, J.K., Madhukar, A. and Gupta, K.K., 2010. Removal of $\mathrm{Pb}(\mathrm{II})$ ions from aqueous solution by adsorption using bael leaves (Aegle marmelos). Journal of Hazardous Materials, 173, 502-509.

Chang, Y., Lai, J.-Y. and Lee, D.-J., 2016. Thermodynamic parameters for adsorption equilibrium of heavy metals and dyes from wastewaters: Research updated. Bioresource Technology, 222, 513-516.

Chao, H.-P. and Chen, S.-H., 2012. Adsorption characteristics of both cationic and oxyanionic metal ions on hexadecyltrimethylammonium bromide-modified $\mathrm{NaY}$ zeolite. Chemical Engineering Journal, 193194, 283-289.

Chen, B., Yuan, M. and Liu, H., 2011a. Removal of polycyclic aromatic hydrocarbons from aqueous solution using plant residue materials as a biosorbent. Journal of Hazardous Materials, 188, 436-442.

Chen, H., Dai, G., Zhao, J., Zhong, A., Wu, J. and Yan, H., 2010a. Removal of copper(II) ions by a biosorbent-Cinnamomum camphora leaves powder. Journal of Hazardous Materials, 177, 228-236.

Chen, H., Zhao, J., Dai, G., Wu, J. and Yan, H., 2010b. Adsorption characteristics of Pb(II) from aqueous solution onto a natural biosorbent, fallen Cinnamomum camphora leaves. Desalination, 262, 174-182.

Chen, L., Ramadan, A., Lü, L., Shao, W., Luo, F. and Chen, J., 2011b. Biosorption of methylene blue from aqueous solution using lawny grass modified with citric acid. Journal of Chemical \& Engineering Data, 56, 3392-3399.

Chen, L., Ramadan, A., Lü, L., Shao, W., Luo, F. and Chen, J., 2011c. Biosorption of methylene blue from aqueous solution using lawny grass modified with citric acid. Journal of Chemical \& Engineering Data, 56, 3392-3399.

Chen, Y., Tang, G., Yu, Q.J., Zhang, T., Chen, Y. and Gu, T., 2009. Biosorption properties of hexavalent chromium on to biomass of tobacco-leaf residues. Environmental Technology, 30, 1003-1010.

Cheraghi, E., Ameri, E. and Moheb, A., 2015. Adsorption of cadmium ions from aqueous solutions using sesame as a low-cost biosorbent: kinetics and equilibrium studies. International Journal of Environmental Science and Technology, 12, 2579-2592.

Chojnacka, K., Chojnacki, A. and Górecka, H., 2005. Biosorption of Cr3+, Cd2+ and Cu2+ ions by blue-green algae Spirulina sp.: kinetics, equilibrium and the mechanism of the process. Chemosphere, 59, 75-84.

Choudhary, M., 2015. Aqueous removal of arsenic (III) using acid treated Devdaru (Polyalthia longifolia) leaf powder. Journal of Applied and Fundamental Sciences, 1, 98. 
Chowdhury, S., Chakraborty, S. and Saha, P., 2011. Biosorption of Basic Green 4 from aqueous solution by Ananas comosus (pineapple) leaf powder. Colloids and Surfaces B: Biointerfaces, 84, 520-527.

Dabbagh, R., Ashtiani Moghaddam, Z. and Ghafourian, H., 2016. Removal of cobalt(II) ion from water by adsorption using intact and modified Ficus carica leaves as low-cost natural sorbent. Desalination and Water Treatment, 57, 19890-19902.

Deniz, F. and Karaman, S., 2011. Removal of Basic Red 46 dye from aqueous solution by pine tree leaves. Chemical Engineering Journal, 170, 67-74.

Deniz, F. and Saygideger, S.D., 2010. Equilibrium, kinetic and thermodynamic studies of Acid Orange 52 dye biosorption by Paulownia tomentosa Steud. leaf powder as a low-cost natural biosorbent. Bioresource Technology, 101, 5137-5143.

Deniz, F. and Saygideger, S.D., 2011. Removal of a hazardous azo dye (Basic Red 46) from aqueous solution by princess tree leaf. Desalination, 268, 6-11.

Devani, M.A., Munshi, B. and Oubagaranadin, J.U.K., 2015. Characterization and use of chemically activated Butea monosperma leaf dust for mercury (II) removal from solutions. Journal of Environmental Chemical Engineering, 3, 2212-2218.

Doğan, M., Türkyilmaz, A., Alkan, M. and Demirbaş, Ö., 2009. Adsorption of copper (II) ions onto sepiolite and electrokinetic properties. Desalination, 238, 257-270.

Dural, M.U., Cavas, L., Papageorgiou, S.K. and Katsaros, F.K., 2011. Methylene blue adsorption on activated carbon prepared from Posidonia oceanica (L.) dead leaves: Kinetics and equilibrium studies. Chemical Engineering Journal, 168, 77-85.

Edokpayi, J.N., Odiyo, J.O., Msagati, T.A. and Popoola, E.O., 2015. A Novel Approach for the removal of lead (II) ion from wastewater using mucilaginous leaves of diceriocaryum eriocarpum plant. Sustainability, 7, 14026-14041.

Elangovan, R., Philip, L. and Chandraraj, K., 2008. Biosorption of chromium species by aquatic weeds: Kinetics and mechanism studies. Journal of Hazardous Materials, 152, 100-112.

Fadzil, F., Ibrahim, S. and Hanafiah, M.A.K.M., 2016. Adsorption of lead (II) onto organic acid modified rubber leaf powder: Batch and column studies. Process Safety and Environmental Protection, 100, 1-8.

Farhan, A.M., Al-Dujaili, A.H. and Awwad, A.M., 2013a. Equilibrium and kinetic studies of cadmium (II) and lead (II) ions biosorption onto Ficus carcia leaves. International Journal of Industrial Chemistry, 4, 24.

Farhan, A.M., Al-Dujaili, A.H. and Awwad, A.M., 2013b. Equilibrium and kinetic studies of cadmium(II) and lead(II) ions biosorption onto Ficus carcia leaves. International Journal of Industrial Chemistry, 4, 24. 
Febriana, N., Lesmana, S.O., Soetaredjo, F.E., Sunarso, J. and Ismadji, S., 2010. Neem leaf utilization for copper ions removal from aqueous solution. Journal of the Taiwan Institute of Chemical Engineers, $41,111-114$.

Gaikwad, R.W. and Kinldy, S.A.M., 2009. Studies on auramine dye adsorption on psidium guava leaves. Korean Journal of Chemical Engineering, 26, 102-107.

Gebrehawaria, G., Hussen, A. and Rao, V.M., 2015. Removal of hexavalent chromium from aqueous solutions using barks of Acacia albida and leaves of Euclea schimperi. International Journal of Environmental Science and Technology, 12, 1569-1580.

Ghosh, A., Das, P. and Sinha, K., 2015. Modeling of biosorption of Cu(II) by alkali-modified spent tea leaves using response surface methodology (RSM) and artificial neural network (ANN). Applied Water Science, 5, 191-199.

Gouamid, M., Ouahrani, M. and Bensaci, M., 2013. Adsorption equilibrium, kinetics and thermodynamics of methylene blue from aqueous solutions using date palm leaves. Energy Procedia, 36, 898-907.

Gowda, R., Nataraj, A. and Rao, N.M., 2012. Coconut leaves as a low cost adsorbent for the removal of nickel from electroplating effluents. Int J Sci Eng Res, 2, 1-5.

Goyal, P., Sharma, P., Srivastava, S. and Srivastava, M.M., 2008. Saraca indica leaf powder for decontamination of $\mathrm{Pb}$ : removal, recovery, adsorbent characterization and equilibrium modeling. International Journal of Environmental Science \& Technology, 5, 27-34.

Guechi, E.-K. and Hamdaoui, O., 2013. Cattail leaves as a novel biosorbent for the removal of malachite green from liquid phase: data analysis by non-linear technique. DESALINATION AND WATER TREATMENT, 51, 3371-3380.

Guerrero-Coronilla, I., Morales-Barrera, L. and Cristiani-Urbina, E., 2015. Kinetic, isotherm and thermodynamic studies of amaranth dye biosorption from aqueous solution onto water hyacinth leaves. Journal of Environmental Management, 152, 99-108.

Gundogdu, A., Duran, C., Senturk, H.B., Soylak, M., Imamoglu, M. and Onal, Y., 2013. Physicochemical characteristics of a novel activated carbon produced from tea industry waste. Journal of Analytical and Applied Pyrolysis, 104, 249-259.

Gupta, N., Kushwaha, A.K. and Chattopadhyaya, M., 2012a. Adsorption studies of cationic dyes onto Ashoka (Saraca asoca) leaf powder. Journal of the Taiwan Institute of Chemical Engineers, 43, 604-613.

Gupta, N., Kushwaha, A.K. and Chattopadhyaya, M., 2016a. Application of potato (Solanum tuberosum) plant wastes for the removal of methylene blue and malachite green dye from aqueous solution. Arabian Journal of Chemistry, 9, S707-S716. 
Gupta, N., Kushwaha, A.K. and Chattopadhyaya, M.C., 2012b. Adsorption studies of cationic dyes onto Ashoka (Saraca asoca) leaf powder. Journal of the Taiwan Institute of Chemical Engineers, 43, 604613.

Gupta, N., Kushwaha, A.K. and Chattopadhyaya, M.C., 2016b. Application of potato (Solanum tuberosum) plant wastes for the removal of methylene blue and malachite green dye from aqueous solution. Arabian Journal of Chemistry, 9, S707-S716.

Gutha, Y., Munagapati, V.S., Naushad, M. and Abburi, K., 2015. Removal of Ni(II) from aqueous solution by Lycopersicum esculentum (Tomato) leaf powder as a low-cost biosorbent. Desalination and Water Treatment, 54, 200-208.

Hamdaoui, O., Saoudi, F., Chiha, M. and Naffrechoux, E., 2008. Sorption of malachite green by a novel sorbent, dead leaves of plane tree: Equilibrium and kinetic modeling. Chemical Engineering Journal, $143,73-84$.

Hamissa, A.M.B., Brouers, F., Mahjoub, B. and Seffen, M., 2007. Adsorption of textile dyes using Agave americana (L.) fibres: Equilibrium and kinetics modelling. Adsorption Science \& Technology, 25, 311325.

Hamissa, A.M.B., Lodi, A., Seffen, M., Finocchio, E., Botter, R. and Converti, A., 2010. Sorption of Cd(II) and $\mathrm{Pb}(\mathrm{II})$ from aqueous solutions onto Agave americana fibers. Chemical Engineering Journal, 159, 6774.

Han, R., Zou, W., Yu, W., Cheng, S., Wang, Y. and Shi, J., 2007. Biosorption of methylene blue from aqueous solution by fallen phoenix tree's leaves. Journal of Hazardous Materials, 141, 156-162.

Han, X., Wang, W. and Ma, X., 2011. Adsorption characteristics of methylene blue onto low cost biomass material lotus leaf. Chemical Engineering Journal, 171, 1-8.

Han, X., Yuan, J. and Ma, X., 2014. Adsorption of malachite green from aqueous solutions onto lotus leaf: Equilibrium, kinetic, and thermodynamic studies. Desalination and Water Treatment, 52, 5563-5574.

Hanafiah, M., Zakaria, H. and Ngah, W.W., 2009a. Preparation, characterization, and adsorption behavior of $\mathrm{Cu}$ (II) ions onto alkali-treated weed (Imperata cylindrica) leaf powder. Water, Air, and Soil Pollution, $201,43-53$.

Hanafiah, M.A.K.M. and Ngah, W.S.W., 2009. Preparation, characterization and adsorption mechanism of $\mathrm{Cu}$ (II) onto protonated rubber leaf powder. CLEAN - Soil, Air, Water, 37, 696-703.

Hanafiah, M.A.K.M., Zakaria, H. and Wan Ngah, W.S., 2009b. Preparation, characterization, and adsorption behavior of $\mathrm{Cu}(\mathrm{II})$ Ions onto alkali-treated weed (Imperata cylindrica) leaf powder. Water, Air, and Soil Pollution, 201, 43-53. 
Hanif, M.A., Nadeem, R., Bhatti, H.N., Ahmad, N.R. and Ansari, T.M., 2007. Ni(II) biosorption by Cassia fistula (Golden Shower) biomass. Journal of Hazardous Materials, 139, 345-355.

Hossain, M., Ngo, H., Guo, W., Nghiem, L., Hai, F., Vigneswaran, S. and Nguyen, T., 2014a. Competitive adsorption of metals on cabbage waste from multi-metal solutions. Bioresource technology, 160, 7988.

Hossain, M.A., Kumita, M., Michigami, Y. and Mori, S., 2005. Optimization of parameters for Cr (VI) adsorption on used black tea leaves. Adsorption, 11, 561-568.

Hossain, M.A., Ngo, H.H., Guo, W., Zhang, J. and Liang, S., 2014b. A laboratory study using maple leaves as a biosorbent for lead removal from aqueous solutions. Water Quality Research Journal of Canada, 49, 195-209.

Hossain, M.A., Ngo, H.H., Guo, W.S., Nghiem, L.D., Hai, F.I., Vigneswaran, S. and Nguyen, T.V., 2014c. Competitive adsorption of metals on cabbage waste from multi-metal solutions. Bioresource Technology, 160, 79-88.

Hossain, M.A., Ngo, H.H., Guo, W.S., Nguyen, T.V. and Vigneswaran, S., 2014d. Performance of cabbage and cauliflower wastes for heavy metals removal. Desalination and Water Treatment, 52, 844-860.

Hymavathi, D. and Prabhakar, G., 2017. Studies on the Removal of Cobalt (II) from Aqueous solutions by Adsorption with Ficus benghalensis Leaf powder through Response Surface Methodology. Chemical Engineering Communications, 204, 1401-1411.

Immich, A.P.S., de Souza, A.A.U. and de Arruda Guelli Ulson de Souza, S.M., 2009. Adsorption of remazol blue RR from textile effluents using Azadirachta indica leaf powder as an alternative adsorbent. Adsorption Science \& Technology, 27, 461-478.

Iqbal, M., Saeed, A. and Zafar, S.I., 2009. FTIR spectrophotometry, kinetics and adsorption isotherms modeling, ion exchange, and EDX analysis for understanding the mechanism of $\mathrm{Cd} 2+$ and $\mathrm{Pb} 2+$ removal by mango peel waste. Journal of Hazardous Materials, 164, 161-171.

Jain, S. and Gogate, P., 2017a. NaOH-treated dead leaves of Ficus racemosa as an efficient biosorbent for Acid Blue 25 removal. International Journal of Environmental Science and Technology, 14, 531-542.

Jain, S.N. and Gogate, P.R., 2017b. Acid Blue 113 removal from aqueous solution using novel biosorbent based on $\mathrm{NaOH}$ treated and surfactant modified fallen leaves of Prunus Dulcis. Journal of Environmental Chemical Engineering, 5, 3384-3394.

Jain, S.N. and Gogate, P.R., 2017c. Adsorptive removal of acid violet 17 dye from wastewater using biosorbent obtained from $\mathrm{NaOH}$ and $\mathrm{H} 2 \mathrm{SO} 4$ activation of fallen leaves of Ficus racemosa. Journal of Molecular Liquids, 243, 132-143. 
Jain, S.N. and Gogate, P.R., 2017d. Adsorptive removal of acid violet 17 dye from wastewater using biosorbent obtained from $\mathrm{NaOH}$ and $\mathrm{H} 2 \mathrm{SO} 4$ activation of fallen leaves of Ficus racemosa. Journal of Molecular Liquids, 243, 132-143.

Jain, S.N. and Gogate, P.R., 2018. Efficient removal of Acid Green 25 dye from wastewater using activated Prunus Dulcis as biosorbent: Batch and column studies. Journal of environmental management, 210, 226-238.

Jalil, A., Triwahyono, S., Yaakob, M., Azmi, Z., Sapawe, N., Kamarudin, N., Setiabudi, H., Jaafar, N., Sidik, S. and Adam, S., 2012a. Utilization of bivalve shell-treated Zea mays L.(maize) husk leaf as a low-cost biosorbent for enhanced adsorption of malachite green. Bioresource Technology, 120, 218-224.

Jalil, A.A., Triwahyono, S., Yaakob, M.R., Azmi, Z.Z.A., Sapawe, N., Kamarudin, N.H.N., Setiabudi, H.D., Jaafar, N.F., Sidik, S.M., Adam, S.H. and Hameed, B.H., 2012b. Utilization of bivalve shell-treated Zea mays L. (maize) husk leaf as a low-cost biosorbent for enhanced adsorption of malachite green. Bioresource Technology, 120, 218-224.

Javad, Z., Ali, S., Maryam, B., Dermanaki, F.S. and Peyman, Z., 2017. Chemometrics optimization for simultaneous adsorptive removal of ternary mixture of $\mathrm{Cu}(\mathrm{II}), \mathrm{Cd}(\mathrm{II})$, and $\mathrm{Pb}(\mathrm{II})$ by Fraxinus tree leaves. Journal of Chemometrics, 31, e2935.

Jenish, S. and Methodis, P.A., 2011. Fluoride removal from drinking water using used tea leaves as adsorbent. Asian Journal of Chemistry, 23, 2889.

Jeyaseelan, C. and Gupta, A., 2016a. Green Tea Leaves as a Natural Adsorbent for the Removal of Cr (VI) From Aqueous Solutions. Air, Soil and Water Research, 9, ASWR. S35227.

Jeyaseelan, C. and Gupta, A., 2016b. Green Tea Leaves as a Natural Adsorbent for the Removal of Cr(VI) from Aqueous Solutions. Air, Soil and Water Research, 9, ASWR.S35227.

Jorgetto, A.d.O., da Silva, A.C.P., Wondracek, M.H.P., Silva, R.I.V., Velini, E.D., Saeki, M.J., Pedrosa, V.A. and Castro, G.R., 2015. Multilayer adsorption of $\mathrm{Cu}(\mathrm{II})$ and $\mathrm{Cd}(\mathrm{II})$ over Brazilian Orchid Tree (Patade-vaca) and its adsorptive properties. Applied Surface Science, 345, 81-89.

Kahina, L. and Nasser, S.M., 2017. Adsorption of Auramine-O using activated Globe artichoke leaves: Kinetic and isotherm studies. Asian Journal of Chemistry, 29.

Kamar Firas, H., Nechifor Aurelia, C., Nechifor, G., Al-Musawi Tariq, J. and Mohammed Asem, H., 2017. Aqueous phase biosorption of $\mathrm{Pb}(\mathrm{II}), \mathrm{Cu}(\mathrm{II})$, and $\mathrm{Cd}(\mathrm{II})$ onto cabbage leaves powder International Journal of Chemical Reactor Engineering. 
Kamaru, A.A., Sani, N.S. and Malek, N.A.N.N., 2016. Raw and surfactant-modified pineapple leaf as adsorbent for removal of methylene blue and methyl orange from aqueous solution. Desalination and Water Treatment, 57, 18836-18850.

Kamsonlian, S., Suresh, S., Majumder, C.B. and Chand, S., 2012a. Biosorption of Arsenic from Contaminated Water onto Solid Psidium guajava Leaf Surface: Equilibrium, Kinetics, Thermodynamics, and Desorption Study. Bioremediation Journal, 16, 97-112.

Kamsonlian, S., Suresh, S., Majumder, C.B. and Chand, S., 2012b. Biosorption of arsenic from contaminated water onto solid Psidium guajava leaf surface: Equilibrium, kinLetics, thermodynamics, and desorption study. Bioremediation Journal, 16, 97-112.

Kamsonlian, S., Suresh, S., Ramanaiah, V., Majumder, C.B., Chand, S. and Kumar, A., 2012c. Biosorptive behaviour of mango leaf powder and rice husk for arsenic(III) from aqueous solutions. International Journal of Environmental Science and Technology, 9, 565-578.

Kaouah, F., Berrama, T., Brahmi, L., Boumaza, S. and Bendjama, Z., 2014. Removal of cadmium from aqueous solution by Posidonia oceanica (L.) leaf sheaths fibres using discontinuous stirring tank reactor. Desalination and Water Treatment, 52, 2272-2281.

Kazmi, M., Ramzan, N., Feroze, N., Almas, Q., Zafar, M. and Saeed, Z., 2015. Removal of zinc and copper from contaminated water using Ficus religiosa leaves: kinetic, equilibrium and mechanistic studies. Pak. J. Agri. Sci, 52, 619-625.

K1lıç, M. and Solak, M., 2009. A comprehensive study on removal and recovery of copper (II) from aqueous solutions by $\mathrm{NaOH}$-pretreated Marrubium globosum ssp. globosum leaves powder: Potential for utilizing the copper (II) condensed desorption solutions in agricultural applications. Bioresource technology, 100, 2130-2137.

Kılıç, M., Yazıcı, H. and Solak, M., 2009. A comprehensive study on removal and recovery of copper(II) from aqueous solutions by $\mathrm{NaOH}$-pretreated Marrubium globosum ssp. globosum leaves powder: Potential for utilizing the copper(II) condensed desorption solutions in agricultural applications. Bioresource Technology, 100, 2130-2137.

King, P., Rakesh, N., Beenalahari, S., Prasanna Kumar, Y. and Prasad, V.S.R.K., 2007. Removal of lead from aqueous solution using Syzygium cumini L.: Equilibrium and kinetic studies. Journal of Hazardous Materials, 142, 340-347.

King, P., Rakesh, N., Lahari, S.B., Kumar, Y.P. and Prasad, V.S.R.K., 2008. Biosorption of zinc onto Syzygium cumini L.: Equilibrium and kinetic studies. Chemical Engineering Journal, 144, 181-187. 
King, P., Srinivas, P., Kumar, Y.P. and Prasad, V.S.R.K., 2006. Sorption of copper(II) ion from aqueous solution by Tectona grandis 1.f. (teak leaves powder). Journal of Hazardous Materials, 136, 560-566.

Kong, L., Gong, L. and Wang, J., 2015. Removal of methylene blue from wastewater using fallen leaves as an adsorbent. DESALINATION AND WATER TREATMENT, 53, 2489-2500.

Kumar, P.S., Kirthika, K. and Kumar, K.S., 2009. Bael Tree Leaves as a Natural Adsorbent for the Removal of Zinc(II) Ions from Industrial Effluents. Adsorption Science \& Technology, 27, 503-512.

Kumar, Y.P., King, P. and Prasad, V.S.R.K., 2006. Zinc biosorption on Tectona grandis L.f. leaves biomass: Equilibrium and kinetic studies. Chemical Engineering Journal, 124, 63-70.

Kuppusamy, S., Thavamani, P., Megharaj, M., Venkateswarlu, K., Lee, Y.B. and Naidu, R., 2016. Potential of Melaleuca diosmifolia leaf as a low-cost adsorbent for hexavalent chromium removal from contaminated water bodies. Process Safety and Environmental Protection, 100, 173-182.

Kushwaha, A.K., Gupta, N. and Chattopadhyaya, M., 2014a. Removal of cationic methylene blue and malachite green dyes from aqueous solution by waste materials of Daucus carota. Journal of Saudi Chemical Society, 18, 200-207.

Kushwaha, A.K., Gupta, N. and Chattopadhyaya, M.C., 2014b. Removal of cationic methylene blue and malachite green dyes from aqueous solution by waste materials of Daucus carota. Journal of Saudi Chemical Society, 18, 200-207.

Kütahyali, C., Sert, Ş., Çetinkaya, B., Inan, S. and Eral, M., 2010. Factors Affecting Lanthanum and Cerium Biosorption on Pinus brutia Leaf Powder. Separation Science and Technology, 45, 1456-1462.

Kütahyalı, C., Sert, Ş., Çetinkaya, B., Yalçıntaş, E. and Bahadır Acar, M., 2012. Biosorption of Ce(III) onto modified Pinus brutia leaf powder using central composite design. Wood Science and Technology, 46, 721-736.

Khalir, W.M., Azira, W.K., Hanafiah, M., Kamal, M.A., So'ad, M., Zaiton, S., Ngah, W., Saime, W., Majid, A. and Azran, Z., 2012. Batch, column and thermodynamic of $\mathrm{Pb}$ (II) adsorption on xanthated rubber (Hevea brasiliensis) leaf powder. Journal of Applied Sciences, 12, 1142-1147.

Khan, A.A. and Singh, R.P., 1987. Adsorption thermodynamics of carbofuran on Sn (IV) arsenosilicate in H+, $\mathrm{Na}+$ and $\mathrm{Ca} 2+$ forms. Colloids and Surfaces, 24, 33-42.

Khan Rao, R.A. and Khatoon, A., 2017. Aluminate treated Casuarina equisetifolia leaves as potential adsorbent for sequestering $\mathrm{Cu}(\mathrm{II}), \mathrm{Pb}(\mathrm{II})$ and $\mathrm{Ni}(\mathrm{II})$ from aqueous solution. Journal of Cleaner Production, 165, 1280-1295. 
Khodabandehloo, A., Rahbar-Kelishami, A. and Shayesteh, H., 2017. Methylene blue removal using Salix babylonica (Weeping willow) leaves powder as a low-cost biosorbent in batch mode: Kinetic, equilibrium, and thermodynamic studies. Journal of Molecular Liquids, 244, 540-548.

Khokhar, A., Siddique, Z. and Misbah, 2015. Removal of heavy metal ions by chemically treated Melia azedarach L. leaves. Journal of Environmental Chemical Engineering, 3, 944-952.

Khorshidi, N. and Niazi, A., 2016. Optimization of pyrocatechol violet biosorption by Robinia pseudoacacia leaf powder using response surface methodology: kinetic, isotherm and thermodynamic studies. Journal of Water Reuse and Desalination, 6, 333-344.

Lafi, R., Hamdi, N. and Hafiane, A., 2015. Study of the performance of Esparto grass fibers as adsorbent of dyes from aqueous solutions. Desalination and Water Treatment, 56, 722-735.

Langmuir, I., 1918. The adsorption of gases on plane surfaces of glass, mica and platinum. Journal of the American Chemical Society, 40, 1361-1403.

Li, C., Fen-xia, Y., Shuai, Y., Shu-li, C. and Pei-qin, M., 2014. Removal of chromium from aqueous solutions using modified lettuce leaves. Water Science and Technology, 69, 2497-2503.

Li, Z., Tang, X., Chen, Y., Wei, L. and Wang, Y., 2009. Activation of Firmiana Simplex leaf and the enhanced $\mathrm{Pb}(\mathrm{II})$ adsorption performance: Equilibrium and kinetic studies. Journal of Hazardous Materials, 169, 386-394.

Liang, S., Ye, N., Hu, Y., Shi, Y., Zhang, W., Yu, W., Wu, X. and Yang, J., 2016. Lead adsorption from aqueous solutions by a granular adsorbent prepared from phoenix tree leaves. RSC Advances, 6 , 25393-25400.

Lim, L., Priyantha, N. and Zaidi, N.M., 2016a. A superb modified new adsorbent, Artocarpus odoratissimus leaves, for removal of cationic methyl violet 2B dye. Environmental Earth Sciences, 75, 1179.

Lim, L.B.L., Priyantha, N. and Mohamad Zaidi, N.A.H., 2016b. A superb modified new adsorbent, Artocarpus odoratissimus leaves, for removal of cationic methyl violet 2B dye. Environmental Earth Sciences, 75, 1179 .

Liu, H., Dong, Y., Liu, Y. and Wang, H., 2010a. Screening of novel low-cost adsorbents from agricultural residues to remove ammonia nitrogen from aqueous solution. Journal of Hazardous Materials, 178, 1132-1136.

Liu, H., Dong, Y., Wang, H. and Liu, Y., 2010b. Adsorption behavior of ammonium by a bioadsorbent-Boston ivy leaf powder. Journal of Environmental Sciences, 22, 1513-1518.

Liu, H., Dong, Y., Wang, H. and Liu, Y., 2010c. Adsorption behavior of ammonium by a bioadsorbent Boston ivy leaf powder. Journal of Environmental Sciences, 22, 1513-1518. 
Liu, H., Dong, Y., Wang, H. and Liu, Y., 2010d. Ammonium adsorption from aqueous solutions by strawberry leaf powder: Equilibrium, kinetics and effects of coexisting ions. Desalination, 263, 70-75.

Mahmoud, A.E.D., Fawzy, m. and Radwan, A., 2016. Optimization of Cadmium (CD2+) removal from aqueous solutions by novel biosorbent. International Journal of Phytoremediation, 18, 619-625.

Makeswari, M. and Santhi, T., 2014. Use of Ricinus communis leaves as a low-cost adsorbent for removal of $\mathrm{Cu}(\mathrm{II})$ ions from aqueous solution. Research on Chemical Intermediates, 40, 1157-1177.

Maleki, A., Hamesadeghi, U., Daraei, H., Hayati, B., Najafi, F., McKay, G. and Rezaee, R., 2017. Amine functionalized multi-walled carbon nanotubes: Single and binary systems for high capacity dye removal. Chemical Engineering Journal, 313, 826-835.

Malkoc, E. and Nuhoglu, Y., 2005. Investigations of nickel(II) removal from aqueous solutions using tea factory waste. Journal of Hazardous Materials, 127, 120-128.

Mambo, M., Admire, C. and Tichaona, N., 2016. Removal of Copper from Aqueous Solution Using Chemically Treated Potato (Solanum tuberosum) Leaf Powder. CLEAN - Soil, Air, Water, 44, 488-495.

Manahan, S., 2000. Chapter 3. Fundamentals of Aquatic Chemistry. Environmental chemistry: CRC press.

Markou, G., Mitrogiannis, D., Muylaert, K., Çelekli, A. and Bozkurt, H., 2016a. Biosorption and retention of orthophosphate onto $\mathrm{Ca}(\mathrm{OH})$ 2-pretreated biomass of Phragmites sp. Journal of Environmental Sciences, 45, 49-59.

Markou, G., Mitrogiannis, D., Muylaert, K., Çelekli, A. and Bozkurt, H., 2016b. Biosorption and retention of orthophosphate onto $\mathrm{Ca}(\mathrm{OH}) 2$-pretreated biomass of Phragmites sp. Journal of Environmental Sciences, 45, 49-59.

Meseguer, V.F., Ortuño, J.F., Aguilar, M.I., Pinzón-Bedoya, M.L., Lloréns, M., Sáez, J. and Pérez-Marín, A.B., 2016. Biosorption of cadmium (II) from aqueous solutions by natural and modified non-living leaves of Posidonia oceanica. Environmental Science and Pollution Research, 23, 24032-24046.

Milonjić, S.K., 2009. Comments on "removal of uranium (VI) from aqueous solution by adsorption of hematite”, by X. Shuibo, Z. Chun, Z. Xinghuo, Y. Jing, Z. Xiaojian, W. Jingsong. Journal of Environmental Radioactivity, 100, 921-922.

Mishra, V., Balomajumder, C. and Agarwal, V.K., 2010. Zn(II) Ion Biosorption onto Surface of Eucalyptus Leaf Biomass: Isotherm, Kinetic, and Mechanistic Modeling. CLEAN - Soil, Air, Water, 38, 10621073.

Mohammed, A.A., Abed, F.I. and Al-Musawi, T.J., 2016. Biosorption of $\mathrm{Pb}(\mathrm{II})$ from aqueous solution by spent black tea leaves and separation by flotation. Desalination and Water Treatment, 57, 2028-2039. 
Mondal, D.K., Nandi, B.K. and Purkait, M.K., 2013. Removal of mercury (II) from aqueous solution using bamboo leaf powder: Equilibrium, thermodynamic and kinetic studies. Journal of Environmental Chemical Engineering, 1, 891-898.

Mozumder, M.S.I., Khan, M.M.R. and Islam, M.A., 2008. Kinetics and mechanism of Cr(VI) adsorption onto tea-leaves waste. Asia-Pacific Journal of Chemical Engineering, 3, 452-458.

Mucha, M. and Mucha, M., 2017. Ibuprofen and acetylsalicylic acid biosorption on the leaves of the knotweed Fallopia x bohemica. New Journal of Chemistry, 41, 7953-7959.

Muhammad, I., Silke, S. and Randall, C., 2009. Mechanistic elucidation and evaluation of biosorption of metal ions by grapefruit peel using FTIR spectroscopy, kinetics and isotherms modeling, cations displacement and EDX analysis. Journal of Chemical Technology \& Biotechnology, 84, 1516-1526.

Murugan, T., Ganapathi, A. and Valliappan, R., 2010. Removal of dyes from aqueous solution by adsorption on biomass of mango (Mangifera indica) leaves. Journal of Chemistry, 7, 669-676.

Muthulaksmi, A., Baskaran, R. and Karthick, N.A., 2016. Removal of high concentrations of chromium from aqueous solutions using leaves of Tamarindus indica: Kinetics and equilibrium studies. Journal of Environmental Biology, 37, 1443.

Nadeem, M., Tan, I.B., Haq, M.R.U., Shahid, S.A., Shah, S.S. and McKay, G., 2006. Sorption of Lead Ions from Aqueous Solution by Chickpea Leaves, Stems and Fruit Peelings. Adsorption Science \& Technology, 24, 269-282.

Nag, S., Mondal, A., Bar, N. and Das, S.K., 2017. Biosorption of chromium (VI) from aqueous solutions and ANN modelling. Environmental Science and Pollution Research, 24, 18817-18835.

Nag, S., Mondal, A., Mishra, U., Bar, N. and Das, S.K., 2016. Removal of chromium(VI) from aqueous solutions using rubber leaf powder: Batch and column studies. Desalination and Water Treatment, 57, 16927-16942.

Nagpal, U.M.K., Bankar, A.V., Pawar, N.J., Kapadnis, B.P. and Zinjarde, S.S., 2011. Equilibrium and Kinetic Studies on Biosorption of Heavy Metals by Leaf Powder of Paper Mulberry (Broussonetia papyrifera). Water, Air, \& Soil Pollution, 215, 177-188.

Nakkeeran, E., Saranya, N., Giri Nandagopal, M.S., Santhiagu, A. and Selvaraju, N., 2016. Hexavalent chromium removal from aqueous solutions by a novel powder prepared from Colocasia esculenta leaves. International Journal of Phytoremediation, 18, 812-821.

Namdeti, R. and Pulipati, K., 2014. Lead removal from aqueous solution using Ficus Hispida leaves powder. Desalination and Water Treatment, 52, 339-349. 
Ncibi, M.C., Mahjoub, B. and Seffen, M., 2006. Studies on the biosorption of textile dyes from aqueous solutions using Posidonia oceanica (L.) leaf sheath fibres. Adsorption Science \& Technology, 24, 461474.

Neupane, S., Ramesh, S., Gandhimathi, R. and Nidheesh, P., 2015. Pineapple leaf (Ananas comosus) powder as a biosorbent for the removal of crystal violet from aqueous solution. DESALINATION AND WATER TREATMENT, 54, 2041-2054.

Ngah, W.S.W. and Hanafiah, M.A.K.M., 2008. Biosorption of copper ions from dilute aqueous solutions on base treatedrubber (Hevea brasiliensis) leaves powder: Kinetics, isotherm, and biosorption mechanisms. Journal of Environmental Sciences, 20, 1168-1176.

Ngah, W.S.W. and Hanafiah, M.A.K.M., 2009. Surface modification of rubber (Hevea brasiliensis) leaves for the adsorption of copper ions: kinetic, thermodynamic and binding mechanisms. Journal of Chemical Technology \& Biotechnology, 84, 192-201.

Pandey, R., Prasad, R.L., Ansari, N.G. and Murthy, R.C., 2015a. Utilization of NaOH modified Desmostachya bipinnata (Kush grass) leaves and Bambusa arundinacea (bamboo) leaves for Cd (II) removal from aqueous solution. Journal of Environmental Chemical Engineering, 3, 593-602.

Pandey, R., Prasad, R.L., Ansari, N.G. and Murthy, R.C., 2015b. Utilization of NaOH modified Desmostachya bipinnata (Kush grass) leaves and Bambusa arundinacea (bamboo) leaves for Cd(II) removal from aqueous solution. Journal of Environmental Chemical Engineering, 3, 593-602.

Panneerselvam, P., Morad, N. and Tan, K.A., 2011. Magnetic nanoparticle (Fe3O4) impregnated onto tea waste for the removal of nickel (II) from aqueous solution. Journal of Hazardous Materials, 186, 160-168.

Park, D., Yun, Y.-S., Lee, D.S. and Park, J.M., 2011. Optimum condition for the removal of Cr(VI) or total Cr using dried leaves of Pinus densiflora. Desalination, 271, 309-314.

Park, D., Yun, Y.-S. and Park, J.M., 2005. Studies on hexavalent chromium biosorption by chemically-treated biomass of Ecklonia sp. Chemosphere, 60, 1356-1364.

Pennesi, C., Totti, C. and Beolchini, F., 2013. Removal of vanadium (III) and molybdenum (V) from wastewater using Posidonia oceanica (Tracheophyta) biomass. PloS One, 8, e76870.

Peng, C., Yan, X.-b., Wang, R.-t., Lang, J.-w., Ou, Y.-j. and Xue, Q.-j., 2013. Promising activated carbons derived from waste tea-leaves and their application in high performance supercapacitors electrodes. Electrochimica Acta, 87, 401-408.

Peydayesh, M. and Rahbar-Kelishami, A., 2015. Adsorption of methylene blue onto Platanus orientalis leaf powder: Kinetic, equilibrium and thermodynamic studies. Journal of Industrial and Engineering Chemistry, 21, 1014-1019. 
Ponnusami, V., Gunasekar, V. and Srivastava, S., 2009a. Kinetics of methylene blue removal from aqueous solution using gulmohar (Delonix regia) plant leaf powder: multivariate regression analysis. Journal of Hazardous Materials, 169, 119-127.

Ponnusami, V., Gunasekar, V. and Srivastava, S.N., 2009b. Kinetics of methylene blue removal from aqueous solution using gulmohar (Delonix regia) plant leaf powder: Multivariate regression analysis. Journal of Hazardous Materials, 169, 119-127.

Ponou, J., Kim, J., Wang, L.P., Dodbiba, G. and Fujita, T., 2011. Sorption of Cr(VI) anions in aqueous solution using carbonized or dried pineapple leaves. Chemical Engineering Journal, 172, 906-913.

Prasad, A.L. and Thirumalisamy, S., 2013. Evaluation of the use of acacia nilotica leaf as an ecofriendly adsorbent for $\mathrm{Cr}(\mathrm{VI})$ and its suitability in real waste water: Study of residual errors. Journal of Chemistry, 2013, 7.

Prasanna Kumar, Y., King, P. and Prasad, V.S.R.K., 2006. Equilibrium and kinetic studies for the biosorption system of copper(II) ion from aqueous solution using Tectona grandis L.f. leaves powder. Journal of Hazardous Materials, 137, 1211-1217.

Purai, A. and Rattan, V., 2012. Biosorption of Leather Dye (Acid Blue 193) from Aqueous Solution using Ash Prepared from Cow Dung, Mango Stone, Parthenium Leaves and Activated Carbon. Indian Chemical Engineer, 54, 190-209.

Qaiser, S., Saleemi, A.R. and Mahmood Ahmad, M., 2007. Heavy metal uptake by agro based waste materials. Electronic Journal of Biotechnology, 10, 409-416.

Qaiser, S., Saleemi, A.R. and Umar, M., 2009. Biosorption of lead from aqueous solution by Ficus religiosa leaves: Batch and column study. Journal of Hazardous Materials, 166, 998-1005.

Qi, B.C. and Aldrich, C., 2008. Biosorption of heavy metals from aqueous solutions with tobacco dust. Bioresource Technology, 99, 5595-5601.

Qi, W., Zhao, Y., Zheng, X., Ji, M. and Zhang, Z., 2016. Adsorption behavior and mechanism of Cr(VI) using Sakura waste from aqueous solution. Applied Surface Science, 360, 470-476.

Rahmat, N.A., Ali, A.A., Hussain, N., Muhamad, M.S., Kristanti, R.A. and Hadibarata, T., 2016. Removal of Remazol Brilliant Blue R from Aqueous Solution by Adsorption Using Pineapple Leaf Powder and Lime Peel Powder. Water, Air, and Soil Pollution, 227, 105.

Raju, D., Kiran, G.R. and Rao, D.V., 2013. Comparison studies on biosorption of lead (II) from an aqueous solution using anacardium occidentale and carica papaya leaves powder. J. Emerging Trends In Engineering and Development, 3, 273-283. 
Ramakul, P., Yanachawakul, Y., Leepipatpiboon, N. and Sunsandee, N., 2012. Biosorption of palladium (II) and platinum (IV) from aqueous solution using tannin from Indian almond (Terminalia catappa L.) leaf biomass: Kinetic and equilibrium studies. Chemical engineering journal, 193, 102-111.

Ramrakhiani, L., Halder, A., Majumder, A., Mandal, A.K., Majumdar, S. and Ghosh, S., 2017. Industrial waste derived biosorbent for toxic metal remediation: Mechanism studies and spent biosorbent management. Chemical Engineering Journal, 308, 1048-1064.

Rangabhashiyam, S., Nakkeeran, E., Anu, N. and Selvaraju, N., 2015. Biosorption potential of a novel powder, prepared from Ficus auriculata leaves, for sequestration of hexavalent chromium from aqueous solutions. Research on Chemical Intermediates, 41, 8405-8424.

Rao, K., 2010. Equilibrium and kinetic studies for Cd (II) adsorption from aqueous solution on Terminalia catappa Linn leaf powder biosorbent.

Rao, K., Anand, S. and Venkateswarlu, P., 2011a. Modeling the kinetics of Cd (II) adsorption on Syzygium cumini L leaf powder in a fixed bed mini column. Journal of Industrial and Engineering Chemistry, $17,174-181$.

Rao, K., Anand, S. and Venkateswarlu, P., 2010a. Psidium guvajava L leaf powder-a potential low-cost biosorbent for the removal of cadmium(II) Ions from wastewater. Adsorption Science \& Technology, $28,163-178$.

Rao, K.S., Anand, S. and Venkateswarlu, P., 2010b. Adsorption of cadmium (II) ions from aqueous solution by Tectona grandis LF (teak leaves powder). BioResources, 5, 438-454.

Rao, K.S., Anand, S. and Venkateswarlu, P., 2011b. Adsorption of cadmium from aqueous solution by Ficus religiosa leaf powder and characterization of loaded biosorbent. CLEAN - Soil, Air, Water, 39, 384391.

Rao, K.S., Anand, S. and Venkateswarlu, P., 2010c. Cadmium removal from aqueous solutions using biosorbent Syzygium cumini leaf powder: Kinetic and equilibrium studies. Korean Journal of Chemical Engineering, 27, 1547-1554.

Rao, R.A.K. and Khan, U., 2017. Adsorption studies of Cu(II) on Boston fern (Nephrolepis exaltata Schott cv. Bostoniensis) leaves. Applied Water Science, 7, 2051-2061.

Raza, M.H., Sadiq, A., Farooq, U., Athar, M., Hussain, T., Mujahid, A. and Salman, M., 2015. Phragmites karka as a Biosorbent for the Removal of Mercury Metal Ions from Aqueous Solution: Effect of Modification. Journal of Chemistry, 2015, 12. 
Reddy, D.H.K., Harinath, Y., Seshaiah, K. and Reddy, A.V.R., 2010. Biosorption of Pb(II) from aqueous solutions using chemically modified Moringa oleifera tree leaves. Chemical Engineering Journal, 162, 626-634.

Reddy, D.H.K., Seshaiah, K., Reddy, A.V.R. and Lee, S.M., 2012. Optimization of Cd(II), Cu(II) and Ni(II) biosorption by chemically modified Moringa oleifera leaves powder. Carbohydrate Polymers, 88 , 1077-1086.

Rehman, R., Anwar, J. and Mahmud, T., 2014. Adsorptive Elimination of Chromium (III) and Nickel (II) from Water by Spent Eugenia jambolana Leaves: Isothermal and Thermodynamical Studies. Asian Journal of Chemistry, 26, 644.

Rehman, R., Mahmud, T., Anwar, J. and Salman, M., 2012. Isothermal modeling of batch biosorption of Brilliant Green dye from water by chemically modified Eugenia jambolana leaves. J Chem Soc Pak, $34,136-143$.

Rehman, R., Mahmud, T., Ejaz, R., Rauf, A. and Mitu, L., 2017. Sorptive removal of Direct Blue-15 dye from water using Camellia sinensis and Carica papaya leaves. BULGARIAN CHEMICAL COMMUNICATIONS, 49, 20-25.

Rehman, R., Shafique, U., Anwar, J. and Ghafoor, S., 2013. Kinetic and isothermal biosorption studies of Co (II), $\mathrm{Cu}$ (II) and Ni (II) using Polyalthia longifolia leaf powder. Asian Journal of Chemistry, 25, 8285.

Ren, X., Xiao, W., Zhang, R., Shang, Y. and Han, R., 2015. Adsorption of crystal violet from aqueous solution by chemically modified phoenix tree leaves in batch mode. DESALINATION AND WATER TREATMENT, 53, 1324-1334.

Romero-González, J., Peralta-Videa, J.R., Rodríguez, E., Ramirez, S.L. and Gardea-Torresdey, J.L., 2005. Determination of thermodynamic parameters of $\mathrm{Cr}(\mathrm{VI})$ adsorption from aqueous solution onto Agave lechuguilla biomass. The Journal of Chemical Thermodynamics, 37, 343-347.

Rostami, B. and Niazi, A., 2013. Biosorption of a textile dye (Eosin) by eucalyptus tree leaves biomass: estimation of equilibrium, thermodynamic and kinetic parameters. Advanced Science Focus, 1, 50-56.

Ruiyi, F., Qingping, Y., Yucong, X., Feng, X., Qinglin, Z. and Zhengrong, L., 2016. Enhanced adsorption and recovery of $\mathrm{Pb}(\mathrm{II})$ from aqueous solution by alkali-treated persimmon fallen leaves. Journal of Applied Polymer Science, 133.

Saha, G.C., Hoque, M.I.U., Miah, M.A.M., Holze, R., Chowdhury, D.A., Khandaker, S. and Chowdhury, S., 2017. Biosorptive removal of lead from aqueous solutions onto Taro (Colocasiaesculenta(L.) Schott) as a low cost bioadsorbent: Characterization, equilibria, kinetics and biosorption-mechanism studies. Journal of Environmental Chemical Engineering, 5, 2151-2162. 
Saha, P.D., Chakraborty, S. and Chowdhury, S., 2012a. Batch and continuous (fixed-bed column) biosorption of crystal violet by Artocarpus heterophyllus (jackfruit) leaf powder. Colloids and Surfaces B: Biointerfaces, 92, 262-270.

Saha, P.D., Chakraborty, S. and Chowdhury, S., 2012b. Batch and continuous (fixed-bed column) biosorption of crystal violet by Artocarpus heterophyllus (jackfruit) leaf powder. Colloids and surfaces B: Biointerfaces, 92, 262-270.

Saha, R. and Saha, B., 2014. Removal of hexavalent chromium from contaminated water by adsorption using mango leaves (Mangifera indica). Desalination and Water Treatment, 52, 1928-1936.

Salehi, P., Asghari, B. and Mohammadi, F., 2008. Removal of heavy metals from aqueous solutions by Cercis siliquastrum L. Journal of the Iranian Chemical Society, 5, S80-S86.

Sangi, M.R., Shahmoradi, A., Zolgharnein, J., Azimi, G.H. and Ghorbandoost, M., 2008. Removal and recovery of heavy metals from aqueous solution using Ulmus carpinifolia and Fraxinus excelsior tree leaves. Journal of Hazardous Materials, 155, 513-522.

Sarada, B., Prasad, M.K., Kumar, K.K. and Murthy, C., 2013a. POTENTIAL USE OF LEAF BIOMASS, ARAUCARIA HETEROPHYLLA FOR REMOVAL OF Pb+2. International Journal of Phytoremediation, 15, 756-773.

Sarada, B., Prasad, M.K., Kumar, K.K. and Murthy, C., 2013b. Potential use of leaf biomass, Araucaria heterophylla for removal $\mathrm{OF} \mathrm{Pb}+2$. International journal of phytoremediation, 15, 756-773.

Sathish, T., Vinithkumar, N.V., Dharani, G. and Kirubagaran, R., 2015. Efficacy of mangrove leaf powder for bioremediation of chromium (VI) from aqueous solutions: kinetic and thermodynamic evaluation. Applied Water Science, 5, 153-160.

Sawalha, M.F., Peralta-Videa, J.R., Romero-González, J., Duarte-Gardea, M. and Gardea-Torresdey, J.L., 2007. Thermodynamic and isotherm studies of the biosorption of $\mathrm{Cu}(\mathrm{II}), \mathrm{Pb}(\mathrm{II})$, and $\mathrm{Zn}$ (II) by leaves of saltbush (Atriplex canescens). The Journal of Chemical Thermodynamics, 39, 488-492.

Sen, T.K., Azman, A.F.B., Maitra, S. and Dutta, B.K., 2011. Removal of mercury (II) from aqueous solutions using the leaves of the rambai tree (Baccaurea motleyana). Water Environment Research, 83, 834-842.

Sert, Ş., Kütahyali, C., İnan, S., Talip, Z., Çetinkaya, B. and Eral, M., 2008. Biosorption of lanthanum and cerium from aqueous solutions by Platanus orientalis leaf powder. Hydrometallurgy, 90, 13-18.

Setiabudi, H., Jusoh, R., Suhaimi, S. and Masrur, S., 2016a. Adsorption of methylene blue onto oil palm (Elaeis guineensis) leaves: process optimization, isotherm, kinetics and thermodynamic studies. Journal of the Taiwan Institute of Chemical Engineers, 63, 363-370. 
Setiabudi, H.D., Jusoh, R., Suhaimi, S.F.R.M. and Masrur, S.F., 2016b. Adsorption of methylene blue onto oil palm (Elaeis guineensis) leaves: Process optimization, isotherm, kinetics and thermodynamic studies. Journal of the Taiwan Institute of Chemical Engineers, 63, 363-370.

Shafique, U., Ijaz, A., Salman, M., Zaman, W.u., Jamil, N., Rehman, R. and Javaid, A., 2012. Removal of arsenic from water using pine leaves. Journal of the Taiwan Institute of Chemical Engineers, 43, 256263.

Shah, J., Jan, M.R., Haq, A.u. and Zeeshan, M., 2015a. Equilibrium, kinetic and thermodynamic studies for sorption of Ni (II) from aqueous solution using formaldehyde treated waste tea leaves. Journal of Saudi Chemical Society, 19, 301-310.

Shah, J., Jan, M.R., ul Haq, A. and Zeeshan, M., 2015b. Equilibrium, kinetic and thermodynamic studies for sorption of Ni (II) from aqueous solution using formaldehyde treated waste tea leaves. Journal of Saudi Chemical Society, 19, 301-310.

Shanthi, T. and Selvarajan, V.M., 2013. Removal of Cr(VI) and Cu(II) Ions from Aqueous Solution by Carbon Prepared from Henna Leaves. Journal of Chemistry, 2013, 6.

Sharma, A. and Bhattacharyya, K.G., 2005. Adsorption of Chromium (VI) on Azadirachta Indica (Neem) Leaf Powder. Adsorption, 10, 327-338.

Sharma, A. and Bhattacharyya, K.G., 2008. Interactions of Pb (II), Cd (II) and Cr (VI) with Neem (Azadirachta indica) leaf powder: kinetics and thermodynamics. International Journal of Environment and Pollution, 34, 374-399.

Sharma, D.C. and Forster, C.F., 1994. The treatment of chromium wastewaters using the sorptive potential of leaf mould. Bioresource Technology, 49, 31-40.

Sheen, O.P., Ong, S.T. and Hung, Y.T., 2013. Utilization of Mango Leaf as A Low-Cost Adsorbent for The Removal of Cu (II) Ions from Aqueous Solution. Asian Journal of Chemistry, 25, 6141.

Shi, J., Fang, Z., Zhao, Z., Sun, T. and Liang, Z., 2016a. Comparative study on Pb(II), Cu(II), and Co(II) ions adsorption from aqueous solutions by arborvitae leaves. Desalination and Water Treatment, 57, 47324739.

Shi, J., Zhao, Z., Liang, Z. and Sun, T., 2016b. Adsorption characteristics of $\mathrm{Pb}(\mathrm{II})$ from aqueous solutions onto a natural biosorbent, fallen arborvitae leaves. Water Science and Technology, 73, 2422-2429.

Singha, B. and Das, S.K., 2012. Removal of $\mathrm{Pb}(\mathrm{II})$ ions from aqueous solution and industrial effluent using natural biosorbents. Environmental Science and Pollution Research, 19, 2212-2226. 
Sinha, V., Pakshirajan, K. and Chaturvedi, R., 2015a. Evaluation of Cr (VI) Exposed and Unexposed Plant Parts of Tradescantia pallida (Rose) DR Hunt. for Cr Removal from Wastewater by Biosorption. International journal of phytoremediation, 17, 1204-1211.

Sinha, V., Pakshirajan, K. and Chaturvedi, R., 2015b. Evaluation of Cr(VI) Exposed and Unexposed Plant Parts of Tradescantia pallida (Rose) D. R. Hunt. for Cr Removal from Wastewater by Biosorption. International Journal of Phytoremediation, 17, 1204-1211.

Srinivasa Rao, K., Anand, S. and Venkateswarlu, P., 2010. Adsorption of cadmium (II) ions from aqueous solution by Tectona grandis LF (teak leaves powder). BioResources.

Srivastava, V.C., Mall, I.D. and Mishra, I.M., 2006. Equilibrium modelling of single and binary adsorption of cadmium and nickel onto bagasse fly ash. Chemical Engineering Journal, 117, 79-91.

Tamez Uddin, M., Rukanuzzaman, M., Maksudur Rahman Khan, M. and Akhtarul Islam, M., 2009. Adsorption of methylene blue from aqueous solution by jackfruit (Artocarpus heteropyllus) leaf powder: A fixedbed column study. Journal of Environmental Management, 90, 3443-3450.

Tran, H.N. and Chao, H.-P., 2018. Adsorption and desorption of potentially toxic metals on modified biosorbents through new green grafting process. Environmental Science and Pollution Research.

Tran, H.N., Lee, C.-K., Nguyen, T.V. and Chao, H.-P., 2017a. Saccharide-derived microporous spherical biochar prepared from hydrothermal carbonization and different pyrolysis temperatures: synthesis, characterization, and application in water treatment. Environmental Technology, 1-14.

Tran, H.N., You, S.-J., Hosseini-Bandegharaei, A. and Chao, H.-P., 2017b. Mistakes and inconsistencies regarding adsorption of contaminants from aqueous solutions: A critical review. Water Research, 120, 88-116.

Tran, H.N., You, S.-J., Nguyen, T.V. and Chao, H.-P., 2017c. Insight into the adsorption mechanism of cationic dye onto biosorbents derived from agricultural wastes. Chemical Engineering Communications, 204, 1020-1036.

Uddin, M.T., Islam, M.A., Mahmud, S. and Rukanuzzaman, M., 2009. Adsorptive removal of methylene blue by tea waste. Journal of Hazardous Materials, 164, 53-60.

V., G.V. and Misra, A.K., 2018. Copper contaminated wastewater - An evaluation of bioremedial options. Indoor and Built Environment, 27, 84-95.

Van Suc, N. and Son, L.N., 2016. Mistletoe leaves as a biosorbent for removal of $\mathrm{Pb}(\mathrm{II})$ and $\mathrm{Cd}(\mathrm{II})$ from aqueous solution. Desalination and Water Treatment, 57, 3606-3618. 
Venkateswarlu, P., Durga, G.V., Babu, N.C. and Rao, M.V., 2008. Biosorption of Zn (II) from an aqueous solution by Erythrina variegata orientalis leaf powder. International Journal of Physical Sciences, 3, 197-204.

Vijaya Lakshmi, G., Chitti Babu, N., Ravi Kumar, P.V., Subba Rao, D. and Venkateswarlu, P., 2008. POTENTIAL OF ERYTHRINA VARIEGATA ORIENTALIS LEAF POWDER FOR THE REMOVAL OF COBALT(II). Chemical Engineering Communications, 196, 463-480.

Vilvanathan, S. and Shanthakumar, S., 2016. Removal of Ni(II) and Co(II) ions from aqueous solution using teak (Tectona grandis) leaves powder: adsorption kinetics, equilibrium and thermodynamics study. Desalination and Water Treatment, 57, 3995-4007.

Volesky, B., 2007. Biosorption and me. Water Research, 41, 4017-4029.

Wahab, M.A., Boubakri, H., Jellali, S. and Jedidi, N., 2012. Characterization of ammonium retention processes onto Cactus leaves fibers using FTIR, EDX and SEM analysis. Journal of Hazardous Materials, 241 242, 101-109.

Wan Ngah, W.S. and Hanafiah, M.A.K.M., 2008. Adsorption of copper on rubber (Hevea brasiliensis) leaf powder: Kinetic, equilibrium and thermodynamic studies. Biochemical Engineering Journal, 39, 521530.

Wan, S., Ma, Z., Xue, Y., Ma, M., Xu, S., Qian, L. and Zhang, Q., 2014. Sorption of Lead(II), Cadmium(II), and Copper(II) Ions from Aqueous Solutions Using Tea Waste. Industrial \& Engineering Chemistry Research, 53, 3629-3635.

Wang, C., Wang, H. and Liu, Y., 2016. Purification of Pb (II) ions from aqueous solution by camphor leaf modified with succinic anhydride. Colloids and Surfaces A: Physicochemical and Engineering Aspects, 509, 80-85.

Wenfang, Q., Yue, W., Min, J., Yingxin, Z. and Zhenya, Z., 2015. Highly efficient adsorption of Cr (VI) by Sakura leaves from aqueous solution. Chemistry Letters, 44, 697-699.

Weng, C.-H., Lin, T.Y., Chu, S.-H. and Yuan, C., 2006. Laboratory-scale evaluation of Cr (VI) removal from clay by electrokinetics incorporated with $\mathrm{Fe}(\mathrm{O})$ barrier. Practice Periodical of Hazardous, Toxic, and Radioactive Waste Management, 10, 171-178.

Weng, C.-H., Lin, Y.-T., Hong, D.-Y., Sharma, Y.C., Chen, S.-C. and Tripathi, K., 2014a. Effective removal of copper ions from aqueous solution using base treated black tea waste. Ecological Engineering, 67, 127-133. 
Weng, C.-H., Lin, Y.-T., Hong, D.-Y., Sharma, Y.C., Chen, S.-C. and Tripathi, K., 2014b. Effective removal of copper ions from aqueous solution using base treated black tea waste. Ecological engineering, 67, 127133.

Weng, C.-H., Lin, Y.-T. and Tzeng, T.-W., 2009. Removal of methylene blue from aqueous solution by adsorption onto pineapple leaf powder. Journal of Hazardous Materials, 170, 417-424.

Weng, C.-H. and Wu, Y.-C., 2012. Potential low-cost biosorbent for copper removal: Pineapple leaf powder. Journal of Environmental Engineering, 138, 286-292.

Xia, L., Tan, K., Wang, X., Zheng, W., Liu, W. and Deng, C., 2013. Uranium Removal from Aqueous Solution by Banyan Leaves: Equilibrium, Thermodynamic, Kinetic, and Mechanism Studies. Journal of Environmental Engineering, 139, 887-895.

Xiao, X., Xue, J., Ding, D., He, B., He, D., Tan, L. and Liao, L., 2016. Adsorption of low concentration of uranium(VI) from aqueous solution by diethylenetriamine functionalized Cycas revoluta leaves. Journal of Radioanalytical and Nuclear Chemistry, 308, 1027-1037.

Yagub, M.T., Sen, T.K. and Ang, H., 2012. Equilibrium, kinetics, and thermodynamics of methylene blue adsorption by pine tree leaves. Water, Air, and Soil Pollution, 223, 5267-5282.

Yang, J.-X. and Hong, G.-B., 2018a. Adsorption behavior of modified Glossogyne tenuifolia leaves as a potential biosorbent for the removal of dyes. Journal of Molecular Liquids, 252, 289-295.

Yang, J.-X. and Hong, G.-B., 2018b. Adsorption behavior of modified Glossogyne tenuifolia leaves as a potential biosorbent for the removal of dyes. Journal of Molecular Liquids.

Yu, J.-x., Feng, L.-y., Cai, X.-1., Wang, L.-y. and Chi, R.-a., 2015. Adsorption of Cu2+, Cd2+ and Zn2+ in a modified leaf fixed-bed column: competition and kinetics. Environmental Earth Sciences, 73, 17891798.

Yuvaraja, G., Krishnaiah, N., Subbaiah, M.V. and Krishnaiah, A., 2014. Biosorption of Pb(II) from aqueous solution by Solanum melongena leaf powder as a low-cost biosorbent prepared from agricultural waste. Colloids and Surfaces B: Biointerfaces, 114, 75-81.

Yuvaraja, G., Subbaiah, M.V. and Krishnaiah, A., 2012. Caesalpinia bonducella leaf powder as biosorbent for $\mathrm{Cu}(\mathrm{II})$ removal from aqueous environment: Kinetics and isotherms. Industrial \& Engineering Chemistry Research, 51, 11218-11225.

Zahedi, R., Dabbagh, R., Ghafourian, H. and Behbahanini, A., 2015. Nickel removal by Nymphaea alba leaves and effect of leaves treatment on the sorption capacity: A kinetic and thermodynamic study. Water Resources, 42, 690-698. 
Zhang, Y., Li, X. and Li, Y., 2015. Influence of solution chemistry on heavy metals removal by bioadsorbent tea waste modified by poly (vinyl alcohol). Desalination and Water Treatment, 53, 2134-2143.

Zhou, Q., Xie, C., Gong, W., Xu, N. and Zhou, W., 2011. Comments on the method of using maximum absorption wavelength to calculate Congo Red solution concentration published in J. Hazard. Mater. Journal of Hazardous Materials, 198, 381-382.

Zhu, L., Wang, Y., He, T., You, L. and Shen, X., 2016. Assessment of potential capability of water bamboo leaves on the adsorption removal efficiency of cationic dye from aqueous solutions. Journal of Polymers and the Environment, 24, 148-158.

Zolgharnein, J., Adhami, Z., Shahmoradi, A. and Mousavi, S.N., 2010. Optimization of removal of methylene blue by Platanus tree leaves using response surface methodology. Analytical Sciences, 26, 111-116.

Zolgharnein, J., Asanjarani, N. and Shariatmanesh, T., 2013a. Taguchi L16 orthogonal array optimization for Cd (II) removal using Carpinus betulus tree leaves: Adsorption characterization. International Biodeterioration \& Biodegradation, 85, 66-77.

Zolgharnein, J. and Bagtash, M., 2015. Hybrid central composite design optimization for removal of Methylene blue by Acer tree leaves: characterization of adsorption. DESALINATION AND WATER TREATMENT, 54, 2601-2610.

Zolgharnein, J., Bagtash, M., Feshki, S., Zolgharnein, P. and Hammond, D., 2017a. Crossed mixture process design optimization and adsorption characterization of multi-metal (Cu (II), $\mathrm{Zn}$ (II) and $\mathrm{Ni}$ (II)) removal by modified Buxus sempervirens tree leaves. Journal of the Taiwan Institute of Chemical Engineers, 78, 104-117.

Zolgharnein, J., Bagtash, M., Feshki, S., Zolgharnein, P. and Hammond, D., 2017b. Crossed mixture process design optimization and adsorption characterization of multi-metal $(\mathrm{Cu}(\mathrm{II}), \mathrm{Zn}(\mathrm{II})$ and $\mathrm{Ni}(\mathrm{II}))$ removal by modified Buxus sempervirens tree leaves. Journal of the Taiwan Institute of Chemical Engineers, 78, 104-117.

Zolgharnein, J., Gholami, F., Asanjarani, N., Zolgharnein, P. and Azimi, G., 2014. Removal of Methyl Violet Dye from Aqueous Solution by sf Platanus Carpinifolia Tree Leaves as Highly Efficient Sorbent: Multivariate Optimization, Isotherm Modeling, and Kinetic Studies. Separation Science and Technology, 49, 752-762.

Zolgharnein, J. and Shahmoradi, A., 2010. Characterization of Sorption Isotherms, Kinetic Models, and Multivariate Approach for Optimization of $\mathrm{Hg}$ (II) Adsorption onto Fraxinus Tree Leaves. Journal of Chemical \& Engineering Data, 55, 5040-5049. 
Zolgharnein, J., Shahmoradi, A., Zolgharnein, P. and Amani, S., 2016. Multivariate Optimization and Adsorption Characterization of As(III) by Using Fraxinus Tree Leaves. Chemical Engineering Communications, 203, 210-223.

Zolgharnein, J., Shariatmanesh, T. and Asanjarani, N., 2013b. Cercis siliquastrum tree leaves as an efficient adsorbent for removal of $\operatorname{Ag}(\mathrm{I})$ : Response surface optimization and characterization of biosorption. CLEAN-Soil, Air, Water, 41, 1183-1195.

Zolgharnein, J., Shariatmanesh, T., Asanjarani, N. and Zolanvari, A., 2015. Doehlert design as optimization approach for the removal of $\mathrm{Pb}(\mathrm{II})$ from aqueous solution by Catalpa Speciosa tree leaves: adsorption characterization. Desalination and Water Treatment, 53, 430-445. 